University of Louisville

ThinkIR: The University of Louisville's Institutional Repository

Electronic Theses and Dissertations

$12-2005$

\title{
Indentation response of polymer films and aircraft wiring with polymer insulation.
}

Kaushik Bindiganavile Nagendran 1979-

University of Louisville

Follow this and additional works at: https://ir.library.louisville.edu/etd

\section{Recommended Citation}

Nagendran, Kaushik Bindiganavile 1979-, "Indentation response of polymer films and aircraft wiring with polymer insulation." (2005). Electronic Theses and Dissertations. Paper 1036.

https://doi.org/10.18297/etd/1036

This Master's Thesis is brought to you for free and open access by ThinkIR: The University of Louisville's Institutional Repository. It has been accepted for inclusion in Electronic Theses and Dissertations by an authorized administrator of ThinkIR: The University of Louisville's Institutional Repository. This title appears here courtesy of the author, who has retained all other copyrights. For more information, please contact thinkir@louisville.edu. 


\author{
By
}

Kaushik Bindiganavile Nagendran

B.E., Bangalore University, India, 2001

\begin{abstract}
A Thesis
Submitted to the Faculty of the Graduate School of the University of Louisville

In Partial Fulfillment of the Requirements
\end{abstract}

For the Degree of

Master of Science

Department of Mechanical Engineering

University of Louisville

Louisville, Kentucky

December 2005 
INDENTATION REPSONSE OF POLYMER FILMS AND AIRCRAFT WIRING

WITH POLYMER INSULATION

By

Kaushik Bindiganavile Nagendran

B.E., Bangalore University, India, 2001

A Thesis Approved on

November 22, 2005

by the following Thesis Committee:

Dr. Roger D. Bradshaw, Thesis Director, Department of Mechanical Engineering

$\overline{\text { Dr. Julius P. Wong, Department of Mechanical Engineering }}$

Dr. Jafar P. Mohsen, Department of Civil and Environmental Engineering 


\section{DEDICATION}

I would like to dedicate this thesis to my grand uncle, Prof. B. S. Rajagopala Iyengar, who is an embodiment of knowledge and perseverance; parents, B. V. Nagendran and Padma Nagendran, my perpetual motivators; sister, Dr. Kokila B. Nagendran for her relentless support; grandparents Rama Sampath and Late B. N. Sampath, Late B. V. Neelamma and B. S. Doreswamy Iyengar, whose affection and guidance through the years have made me what I am today. 


\section{ACKNOWLEDGEMENT}

My sincere and heartfelt thanks to Dr. Roger D. Bradshaw for his untiring enthusiasm and support in every stage of my work. Without his guidance and help, this thesis would not have taken shape. I am indeed grateful to Dr. Catherine L. Brinson, Department of Mechanical Engineering, Northwestern University, for her support. The work in this thesis was supported by the Aircraft Airworthiness Assurance Center of Excellence (AACE) Program of the Federal Aviation Administration (FAA). I am grateful to the $\mathrm{AACE}$ and the FAA for providing me an opportunity to be a part of the program. A great deal of experimentation was conducted using the RSA III Dynamic Mechanical Analyzer (DMA). Required indentation tools were made by Mr. John C Jones of the Mechanical Engineering Department. I would like to thank him for his help throughout the project. 


\section{ABSTRACT \\ INDENTATION RESPONSE OF POLYMER FILMS AND AIRCRAFT WIRING WITH POLYMER INSULATION \\ Kaushik Bindiganavile Nagendran \\ $22^{\text {nd }}$ November, 2005}

The airline regulatory communities are interested in methods that can assess degradation in the polymer insulation of aging aircraft wiring. This study investigates the response of bulk polymer films and aircraft wiring under indentation; changes in the behavior of the material may provide an indication of degradation. For this study, indentation tests are performed using a dynamic mechanical analyzer (DMA), which provides excellent force and displacement sensitivity and can test materials at a wide range of temperatures. Each indentation test consists of two test phases: loading and relaxation. During loading, the indenter is displaced into the material at a constant rate. During relaxation, the indenter is maintained at the final position of the loading phase for a period of time. The force is monitored throughout the test, increasing during the loading phase and decreasing during the relaxation phase. Pristine and aged specimens were considered to assess the changes occurring in the force response of the material in question. Tests were performed on bulk polymer films and a limited number of wire samples. The findings were as expected, with the wires and the polymer film specimens stiffening with aging. The findings from the study will be used to assist in the ongoing development of methods to assess wire degradation in a field environment. 


\section{TABLE OF CONTENTS}

ACKNOWLEDGEMENT ............................................................................... iv

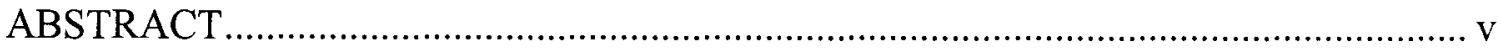

LIST OF TABLES ............................................................................................... vii

LIST OF FIGURES

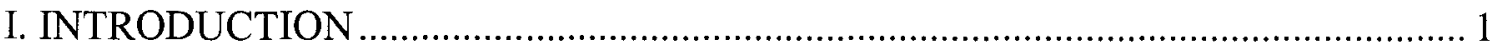

Background Information ................................................................................ 1

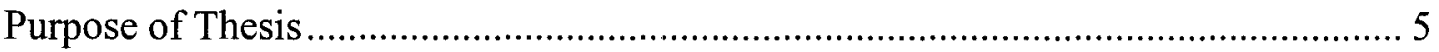

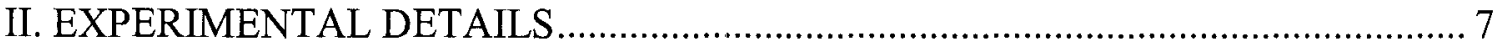

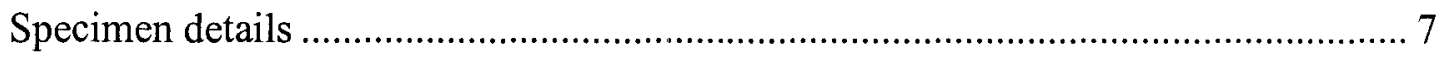

Indenter and support fixtures ...................................................................... 9

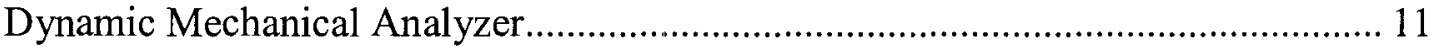

Multiple Extension Mode ................................................................................. 13

Specimen Placement ................................................................................... 14

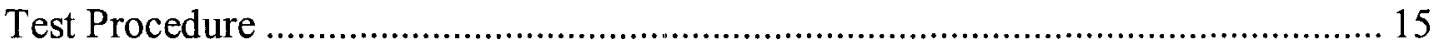

III. ANALYSIS ............................................................................................... 18

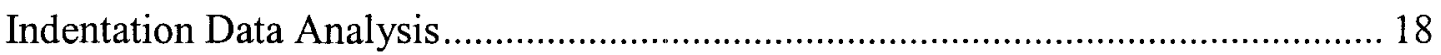

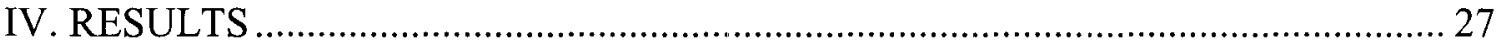

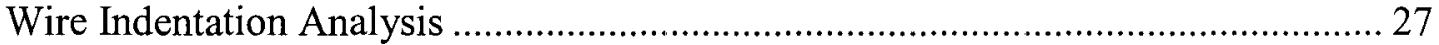

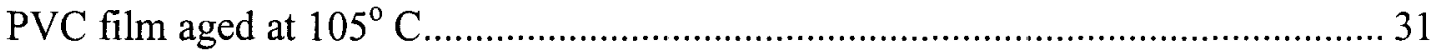

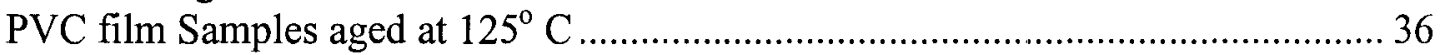

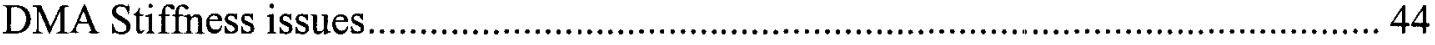

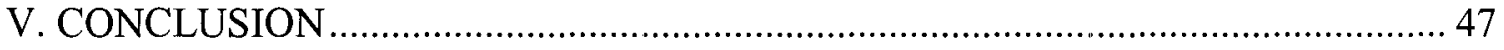

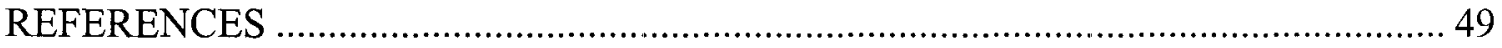

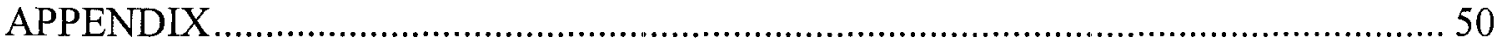

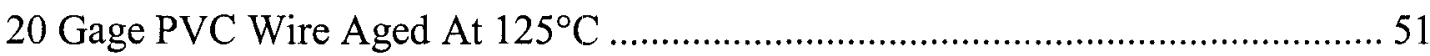

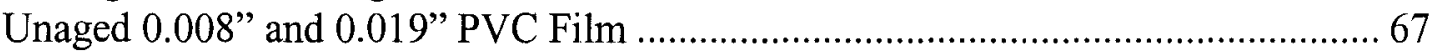

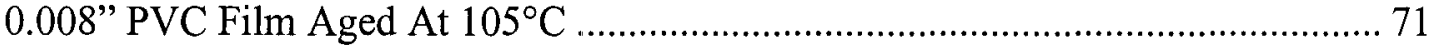

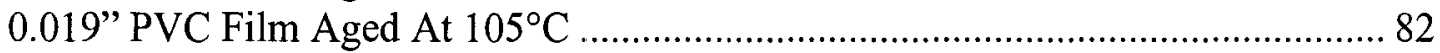

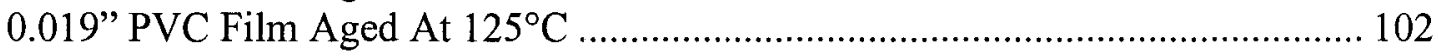

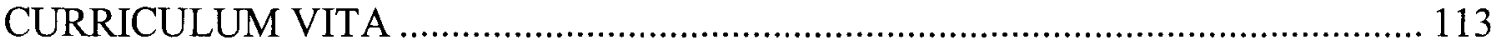




\section{LIST OF TABLES}

Table 1. Fit coefficients for unaged PVC wire ............................................................ 24

Table 2. Fit parameters for 5 tests on unaged PVC wire.............................................. 26

Table 3. Fit parameters for 20 gage $\mathrm{PVC}$ wire aged at $125^{\circ} \mathrm{C}$ for the period indicated

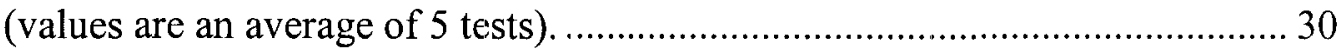

Table 4. Fit parameters for $0.008^{\prime \prime} \mathrm{PVC}$ film aged at $105^{\circ} \mathrm{C}$ for the period indicated (values are an average of 5 tests).

Table 5. Fit parameters for $0.019^{\prime \prime} \mathrm{PVC}$ film aged at $105^{\circ} \mathrm{C}$ for the period indicated (values are an average of 5 tests). 36

Table 6. Fit parameters for $0.008^{\prime \prime} \mathrm{PVC}$ film aged at $125^{\circ} \mathrm{C}$ for the period indicated (values are an average of 5 tests; gray values lead to poor fits of test data.

Table 7. Fit parameters for $0.019^{\prime \prime} \mathrm{PVC}$ film aged at $125^{\circ} \mathrm{C}$ for the period indicated (values are an average of 5 tests; gray values lead to poor fits of test data) ...... 43

Table 8. Data fit coefficients for unaged 20 gage PVC wire ................................................ 65

Table 9. Data fit coefficients for 20 gage PVC wire aged for 2 weeks at $125^{\circ} \mathrm{C}$............. 65

Table 10. Data fit coefficients for 20 gage PVC wire aged for 4 weeks at $125^{\circ} \mathrm{C}$........... 66

Table 11. Data fit coefficients for 20 gage PVC wire aged for 6 weeks at $125^{\circ} \mathrm{C}$........... 66

Table 12. Data fit coefficients for 20 gage PVC wire aged for 8 weeks at $125^{\circ} \mathrm{C}$........... 66

Table 13. Data fit coefficients for 20 gage PVC wire aged for 10 weeks at $125^{\circ} \mathrm{C} \ldots \ldots \ldots . .66$

Table 14. Data fit coefficients for 20 gage PVC wire aged for 12 weeks at $125^{\circ} \mathrm{C}$.........6 67

Table 15. Data fit coefficients for 20 gage PVC wire aged for 14 weeks at $125^{\circ} \mathrm{C}$..........67 67

Table 16. Data fit coefficients for 20 gage PVC wire aged for 16 weeks at $125^{\circ} \mathrm{C} \ldots \ldots . . .67$

Table 17. Data fit coefficients for unaged 0.008" PVC film............................................. 69

Table 18. Data fit coefficients for unaged 0.019" PVC film.......................................... 71

Table 19. Data fit coefficients for $0.008^{\prime \prime} \mathrm{PVC}$ film aged for 2 days at $105^{\circ} \mathrm{C}$............... 73

Table 20. Data fit coefficients for $0.008^{\prime \prime}$ PVC film aged for 5 days at $105^{\circ} \mathrm{C} \ldots \ldots \ldots \ldots \ldots . . .75$

Table 21. Data fit coefficients for $0.008^{\prime \prime} \mathrm{PVC}$ film aged for 1 week at $105^{\circ} \mathrm{C}$............... 77

Table 22. Data fit coefficients for $0.008^{\prime \prime} \mathrm{PVC}$ film aged for 2 weeks at $105^{\circ} \mathrm{C}$............ 79

Table 23. Data fit coefficients for $0.008^{\prime \prime} \mathrm{PVC}$ film aged for 3 weeks at $105^{\circ} \mathrm{C} \ldots \ldots \ldots \ldots . . .81$

Table 24. Data fit coefficients for 0.019 " PVC film aged for 2 days at $105^{\circ} \mathrm{C} \ldots \ldots \ldots \ldots \ldots . . . . .83$

Table 25. Data fit coefficients for 0.019 " PVC film aged for 5 days at $105^{\circ} \mathrm{C}$............... 85

Table 26. Data fit coefficients for 0.019" PVC film aged for 1 week at $105^{\circ} \mathrm{C}$.............. 87

Table 27. Data fit coefficients for 0.019" PVC film aged for 2 weeks at $105^{\circ} \mathrm{C}$............. 89

Table 28. Data fit coefficients for 0.019 " PVC film aged for 3 weeks at $105^{\circ} \mathrm{C}$............ 91 
Table 29. Data fit coefficients for $0.008^{\prime \prime} \mathrm{PVC}$ film aged for 2 days at $125^{\circ} \mathrm{C}$ 93

Table 30. Data fit coefficients for $0.008^{\prime \prime} \mathrm{PVC}$ film aged for 5 days at $125^{\circ} \mathrm{C}$ 95

Table 31. Data fit coefficients for $0.008^{\prime \prime} \mathrm{PVC}$ film aged for 1 week at $125^{\circ} \mathrm{C}$ .97

Table 32. Data fit coefficients for $0.008^{\prime \prime} \mathrm{PVC}$ film aged for 2 weeks at $125^{\circ} \mathrm{C}$ 100

Table 33. Data fit coefficients for $0.008^{\prime \prime} \mathrm{PVC}$ film aged for 3 weeks at $125^{\circ} \mathrm{C}$ 102

Table 34. Data fit coefficients for 0.019 " PVC film aged for 2 days at $125^{\circ} \mathrm{C}$ 104

Table 35. Data fit coefficients for 0.019 " PVC film aged for 5 days at $125^{\circ} \mathrm{C} \ldots \ldots \ldots \ldots . .106$

Table 36. Data fit coefficients for 0.019 " PVC film aged for 1 week at $125^{\circ} \mathrm{C}$............. 108

Table 37. Data fit coefficients for $0.019 " \mathrm{PVC}$ film aged for 2 weeks at $125^{\circ} \mathrm{C} \ldots \ldots \ldots . .110$

Table 38. Data fit coefficients for 0.019 " PVC film aged for 3 weeks at $125^{\circ} \mathrm{C}$ 112 


\section{LIST OF FIGURES}

Figure 1. Operating environment of wires inside the air craft (Brinson, Bradshaw et al. 2004).

Figure 2. Optical microscopy images of the aged wire .................................................. 8

Figure 3. PVC film specimens of two thicknesses aged at $105^{\circ} \mathrm{C}$................................ 8

Figure 4. PVC film specimens of two thicknesses aged at $125^{\circ} \mathrm{C}$.............................. 9

Figure 5. Film indentation using spherical indenter. ................................................ 10

Figure 6. Wire indentation configurations using spherical indenter (left), using cylindrical indenter (right) ................... 10

Figure 7. RSA III Dynamic Mechanical Analyzer. ........................................................ 12

Figure 8. Multiple extension mode input dialog box on Orchestrator 7.0 ..................... 14

Figure 9. Schematic of a typical load-hold indentation test with the load (blue) and indenter displacement (red) shown vs. time (displacement values vary for

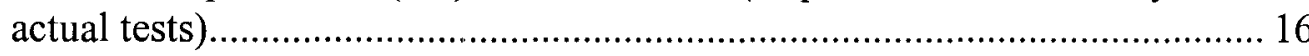

Figure 10. Input values for the typical test using Multiple extension mode.................... 17

Figure 11. Screen capture of Orchestrator 7.0 window after test. ................................. 19

Figure 12. Load versus deformation data and fit for unaged PVC wire ......................... 20

Figure 13. Load versus deformation data and fit for unaged PVC wire ......................... 21

Figure 14. Parabolic curve fits of the load portion data for 5 tests on for unaged 20 gage PVC wire.

Figure 15. Relaxation data fits fro 5 tests on an unaged 20 gage PVC wire. ................. 25

Figure 16. Curve fits of the load portion data for the indentation of 20 gage PVC wire aged at $125^{\circ} \mathrm{C}$ for the period of time indicated.

Figure 17. Curve fits of the load portion data for the indentation of 20 gage PVC wire aged at $125^{\circ} \mathrm{C}$ for the period of time indicated (a subset of aging time data shown).

Figure 18. Stiffness $K$ obtained from the indentation of 20 gage PVC wire aged at $125^{\circ} \mathrm{C}$ for the period of time indicated (each result represents an average of 5 tests) 29

Figure 19. Cubic curve fits of the norrnalized hold (relaxation) data for the indentation of 20 gage $\mathrm{PVC}$ wire aged at $125^{\circ} \mathrm{C}$ for the period of time indicated (subset of

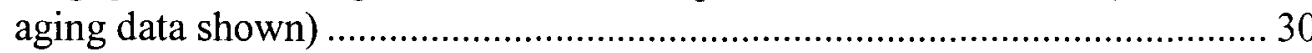

Figure 20. Parabolic curve fits of the load portion data for the indentation of $0.008^{\prime}$ PVC film aged at $105^{\circ} \mathrm{C}$ for the period of time indicated

Figure 21. Parabolic curve fits of the load portion data for the indentation of 0.019 " PVC film aged at $105^{\circ} \mathrm{C}$ for the period of time indicated.

Figure 22. Stiffness $K$ obtained from the indentation of $0.008^{\prime \prime} \mathrm{PVC}$ film aged at $105^{\circ} \mathrm{C}$ for the period of time indicated (average of 5 tests, error bars shown), ......... 33

Figure 23. Stiffness $K$ obtained from the indentation of 0.019 " PVC film aged at $105^{\circ} \mathrm{C}$ for the period of time indicated (average of 5 tests, error bars shown). ......... 34 
Figure 24. Cubic curve fits of the normalized hold (relaxation) data for the indentation of $0.008^{\prime \prime} \mathrm{PVC}$ film aged at $105^{\circ} \mathrm{C}$ for the period of time indicated. 35

Figure 25. Cubic curve fits of the normalized hold (relaxation) data for the indentation of $0.019^{\prime \prime} \mathrm{PVC}$ film aged at $105^{\circ} \mathrm{C}$ for the period of time indicated.................. 35

Figure 26. Parabolic curve fits of the load portion data for the indentation of $0.008^{\prime \prime}$ PVC film aged at $125^{\circ} \mathrm{C}$ for the period of time indicated. ................................... 37

Figure 27. Parabolic curve fits of the load portion data for the indentation of 0.019 " PVC film aged at $125^{\circ} \mathrm{C}$ for the period of time indicated. ..................................... 37

Figure 28. Load portion data for 1 indentation test on $0.008^{\prime \prime} \mathrm{PVC}$ film aged at $125^{\circ} \mathrm{C}$ for

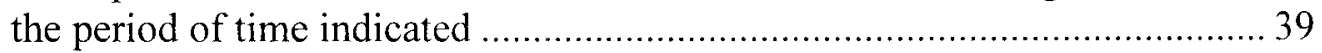

Figure 29. Load portion data for 1 indentation test on 0.019 " PVC film aged at $125^{\circ} \mathrm{C}$ for the period of time indicated...................................................................... 39

Figure 30. Stiffness $K$ obtained from the indentation of $0.008^{\prime \prime} \mathrm{PVC}$ film aged at $125^{\circ} \mathrm{C}$ for the period of time indicated (average of 5 tests, error bars shown). ........ 41

Figure 31. Stiffness $K$ obtained from the indentation of 0.019 " PVC film aged at $125^{\circ} \mathrm{C}$ for the period of time indicated (average of 5 tests, error bars shown)......... 41

Figure 32. Cubic curve fits of the normalized hold (relaxation) data for the indentation of $0.008^{\prime \prime} \mathrm{PVC}$ film aged at $125^{\circ} \mathrm{C}$ for the period of time indicated. 42

Figure 33. Cubic curve fits of the normalized hold (relaxation) data for the indentation of 0.019 " PVC film aged at $125^{\circ} \mathrm{C}$ for the period of time indicated. 43

Figure 34. Force versus displacement for a steel shim in 3 point bending using two test approaches (with firmware, without firmware) compared to theoretical prediction. 46

Figure 36. Load-displacement data for unaged 20 gage PVC wire ................................ 51

Figure 37. Load-displacement fits for unaged 20 gage PVC wire.................................. 52

Figure 38. Load-displacement data for 20 gage PVC wire aged for 2 weeks at $125^{\circ} \mathrm{C} \ldots 52$ Figure 39. Load-displacement fits for 20 gage PVC wire aged for 2 weeks at $125^{\circ} \mathrm{C} \ldots . .53$ Figure 40. Load-displacement data for 20 gage PVC wire aged for 4 weeks at $125^{\circ} \mathrm{C} \ldots 53$ Figure 41. Load-displacement fits for 20 gage PVC wire aged for 4 weeks at $125^{\circ} \mathrm{C}$..... 54 Figure 42. Load-displacement data for 20 gage PVC wire aged for 6 weeks at $125^{\circ} \mathrm{C} \ldots 54$ Figure 43. Load-displacement fits for 20 gage PVC wire aged for 6 weeks at $125^{\circ} \mathrm{C} \ldots . .55$ Figure 44. Load-displacement data for 20 gage PVC wire aged for 8 weeks at $125^{\circ} \mathrm{C} \ldots 55$ Figure 45. Load-displacement fits for 20 gage PVC wire aged for 8 weeks at $125^{\circ} \mathrm{C}$.... 56 Figure 46. Load-displacement data for 20 gage PVC wire aged for 10 weeks at $125^{\circ} \mathrm{C} .56$ Figure 47. Load-displacement fits for 20 gage PVC wire aged for 10 weeks at $125^{\circ} \mathrm{C} \ldots 57$ Figure 48. Load-displacement data for 20 gage PVC wire aged for 12 weeks at $125^{\circ} \mathrm{C} .57$ Figure 49. Load-displacement fits for 20 gage PVC wire aged for 12 weeks at $125^{\circ} \mathrm{C} \ldots 58$ Figure 50. Load-displacement data for 20 gage PVC wire aged for 14 weeks at $125^{\circ} \mathrm{C} .58$ Figure 51. Load-displacement fits for 20 gage PVC wire aged for 14 weeks at $125^{\circ} \mathrm{C} \ldots 59$ Figure 52. Load-displacement data for 20 gage PVC wire aged for 16 weeks at $125^{\circ} \mathrm{C} .59$ Figure 53. Load-displacement fits for 20 gage $\mathrm{PVC}$ wire aged for 16 weeks at $125^{\circ} \mathrm{C} \ldots 60$ Figure 54. Normalized relaxation fits for unaged 20 gage PVC wire.............................. 61 Figure 55. Normalized relaxation fits for 20 gage PVC wire aged for 2 weeks at $125^{\circ} \mathrm{C} 61$ Figure 56. Normalized relaxation fits for 20 gage PVC wire aged for 4 weeks at $125^{\circ} \mathrm{C} 62$ Figure 57. Normalized relaxation fits for 20 gage PVC wire aged for 6 weeks at $125^{\circ} \mathrm{C} 62$ Figure 58. Normalized relaxation fits for 20 gage PVC wire aged for 8 weeks at $125^{\circ} \mathrm{C} 63$ 
Figure 59. Normalized relaxation fits for 20 gage PVC wire aged for 10 weeks at $125^{\circ} \mathrm{C}$

Figure 60. Normalized relaxation fits for 20 gage PVC wire aged for 12 weeks at $125^{\circ} \mathrm{C}$

Figure 61. Normalized relaxation fits for 20 gage $\mathrm{PVC}$ wire aged for 14 weeks at $125^{\circ} \mathrm{C}$

Figure 62. Normalized relaxation fits for 20 gage PVC wire aged for 16 weeks at $125^{\circ} \mathrm{C}$

Figure 63. Load-displacement data for unaged 0.008" PVC film ................................6 68

Figure 64. Load-displacement fits for unaged 0.008" PVC film ...................................6 68

Figure 65. Normalized relaxation fits for unaged 0.008 " PVC film ............................. 69

Figure 66. Load-displacement data for unaged 0.019" PVC film. .............................. 70

Figure 67. Load-displacement fits for unaged 0.019" PVC film .................................. 70

Figure 68. Normalized relaxation fits for 0.019 " PVC film unaged ............................ 71

Figure 69. Load-displacement data for $0.008^{\prime \prime} \mathrm{PVC}$ film aged for 2 days at $105^{\circ} \mathrm{C} \ldots \ldots .72$

Figure 70. Load-displacement fits for $0.008^{\prime \prime} \mathrm{PVC}$ film aged for 2 days at $105^{\circ} \mathrm{C} \ldots \ldots . .72$

Figure 71. Normalized relaxation fits for $0.008^{\prime \prime} \mathrm{PVC}$ film aged for 2 days at $105^{\circ} \mathrm{C} \ldots .73$

Figure 72. Load-displacement fits for $0.008^{\prime \prime}$ PVC film aged for 5 days at $105^{\circ} \mathrm{C} \ldots \ldots . .74$

Figure 73. Load-displacement data for $0.008^{\prime \prime}$ PVC film aged for 5 days at $105^{\circ} \mathrm{C} \ldots \ldots .74$

Figure 74. Normalized relaxation fits for $0.008^{\prime \prime}$ PVC film aged for 5 days at $105^{\circ} \mathrm{C} \ldots 75$

Figure 75. Load-displacement fits for $0.008^{\prime}$ " PVC film aged for 1 week at $105^{\circ} \mathrm{C} \ldots \ldots .76$

Figure 76. Load-displacement fits for $0.008^{\prime}$ " PVC film aged for 1 week at $105^{\circ} \mathrm{C} \ldots \ldots .76$

Figure 77. Normalized relaxation fits for $0.008^{\prime \prime}$ PVC film aged for 1 week at $105^{\circ} \mathrm{C} .77$

Figure 78. Load-displacement fits for $0.008^{\prime \prime}$ PVC film aged for 2 weeks at $105^{\circ} \mathrm{C} \ldots . .78$

Figure 79. Load-displacement fits for $0.008^{\prime \prime}$ PVC film aged for 2 weeks at $105^{\circ} \mathrm{C} \ldots . .78$

Figure 80. Normalized relaxation fits for $0.008^{\prime \prime}$ PVC film aged for 2 weeks at $105^{\circ} \mathrm{C} .79$

Figure 81. Load-displacement fits for $0.008^{\prime}$ " PVC film aged for 3 weeks at $105^{\circ} \mathrm{C} \ldots . .80$

Figure 82. Load-displacement fits for $0.008^{\prime \prime} \mathrm{PVC}$ film aged for 3 weeks at $105^{\circ} \mathrm{C} \ldots . .80$

Figure 83. Normalized relaxation fits for $0.008^{\prime \prime} \mathrm{PVC}$ film aged for 3 weeks at $105^{\circ} \mathrm{C} .81$

Figure 84. Load-displacement data for $0.019^{\prime \prime} \mathrm{PVC}$ film aged for 2 days at $105^{\circ} \mathrm{C} \ldots \ldots 82$

Figure 85. Load-displacement fits for $0.019^{\prime \prime} \mathrm{PVC}$ film aged for 2 days at $105^{\circ} \mathrm{C} \ldots \ldots . .82$

Figure 86. Normalized relaxation fits for 0.019 " PVC film aged for 2 days at $105^{\circ} \mathrm{C} \ldots .83$

Figure 87. Load-displacement fits for $0.019^{\prime \prime} \mathrm{PVC}$ film aged for 5 days at $1.05^{\circ} \mathrm{C} \ldots \ldots . .84$

Figure 88. Load-displacement fits for 0.019 " $\mathrm{PVC}$ film aged for 5 days at $105^{\circ} \mathrm{C} \ldots \ldots . .84$

Figure 89. Normalized relaxation fits for $0.019^{\prime \prime}$ PVC film aged for 5 days at $105^{\circ} \mathrm{C} \ldots 85$

Figure 90. Load-displacement fits for $0.019^{\prime}$ PVC film aged for 1 week at $105^{\circ} \mathrm{C} \ldots \ldots .86$

Figure 91. Load-displacement fits for $0.019^{\prime \prime} \mathrm{PVC}$ film aged for 1 week at $105^{\circ} \mathrm{C} \ldots \ldots .86$

Figure 92. Normalized relaxation fits for $0.019^{\prime \prime} \mathrm{PVC}$ film aged for 1 week at $105^{\circ} \mathrm{C} .87$

Figure 93. Load-displacement fits for $0.019^{\prime \prime} \mathrm{PVC}$ film aged for 2 weeks at $105^{\circ} \mathrm{C} \ldots . .88$

Figure 94. Load-displacement fits for $0.019^{\prime \prime}$ PVC film aged for 2 weeks at $105^{\circ} \mathrm{C} \ldots . .88$

Figure 95. Normalized relaxation fits for $0.019^{\prime \prime} \mathrm{PVC}$ film aged for 2 weeks at $105^{\circ} \mathrm{C} .89$

Figure 96. Load-displacement data for $0.019^{\prime}$ " PVC film aged for 3 weeks at $105^{\circ} \mathrm{C} \ldots . .90$

Figure 97. Load-displacement data for $0.019^{\prime}$ ' PVC film aged for 3 weeks at $105^{\circ} \mathrm{C} \ldots . .90$

Figure 98. Normalized relaxation fits for $0.019^{\prime \prime} \mathrm{PVC}$ film aged for 3 weeks at $105^{\circ} \mathrm{C} .91$

Figure 99. Load-displacement data for $0.008^{\prime \prime}$ PVC film aged for 2 days at $125^{\circ} \mathrm{C} \mathrm{\ldots ....} 92$

Figure 100. Load-displacement data for 0.008 " PVC film aged for 2 days at $125^{\circ} \mathrm{C} \ldots . .92$ 
Figure 101. Normalized relaxation fits for $0.206 \mathrm{~mm}$ PVC film aged for 2 days at $125^{\circ} \mathrm{C}$.

Figure 102. Load-displacement fits for $0.008^{\prime \prime} \mathrm{PVC}$ film aged for 5 days at $125^{\circ} \mathrm{C}$....... 94

Figure 103. Load-displacement fits for $0.008^{\prime \prime}$ PVC film aged for 5 days at $125^{\circ} \mathrm{C} \ldots \ldots . .94$

Figure 104. Normalized relaxation fits for $0.206 \mathrm{~mm}$ PVC film aged for 5 days at $125^{\circ} \mathrm{C}$

Figure 105. Load-displacement fits for 0.008 " PVC film aged for 1 week at $125^{\circ} \mathrm{C}$..... 96

Figure 106. Load-displacement fits for $0.008^{\prime \prime}$ PVC film aged for 1 week at $125^{\circ} \mathrm{C}$..... 96

Figure 107. Normalized relaxation fits for $0.008^{\prime \prime} \mathrm{PVC}$ film aged for 1 week at $125^{\circ} \mathrm{C} 97$

Figure 108. Load-displacement fits for $0.008^{\prime \prime}$ PVC film aged for 2 weeks at $125^{\circ} \mathrm{C} \ldots .98$

Figure 109. Load-displacement fits for $0.008^{\prime \prime}$ PVC film aged for 2 weeks at $125^{\circ} \mathrm{C}$... 99

Figure 110. Normalized relaxation fits for $0.008^{\prime \prime} \mathrm{PVC}$ film aged for 2 weeks at $125^{\circ} \mathrm{C} 99$

Figure 111. Load-displacement fits for $0.008^{\prime \prime}$ PVC film aged for 3 weeks at $125^{\circ} \mathrm{C} . .100$

Figure 112. Load-displacement fits for $0.008^{\prime \prime}$ PVC film aged for 3 weeks at $125^{\circ} \mathrm{C} . .101$

Figure 113. Normalized relaxation fits for $0.008^{\prime \prime} \mathrm{PVC}$ film aged for 3 weeks at $125^{\circ} \mathrm{C}$

Figure 114. Load-displacement data for 0.019" PVC film aged for 2 days at $125^{\circ} \mathrm{C} \ldots 102$

Figure 115. Load-displacement data for 0.019 " PVC film aged for 2 days at $125^{\circ} \mathrm{C} \ldots 103$

Figure 116. Normalized relaxation fits for 0.019 " PVC film aged for 2 days at $125^{\circ} \mathrm{C} 103$ Figure 117. Load-displacement data for $0.019^{\prime \prime} \mathrm{PVC}$ film aged for 5 days at $125^{\circ} \mathrm{C} \ldots 104$ Figure 118. Load-displacement data for 0.019 " PVC film aged for 5 days at $125^{\circ} \mathrm{C} \ldots 105$ Figure 119. Normalized relaxation fits for 0.019 " PVC film aged for 5 days at $125^{\circ} \mathrm{C} 105$ Figure 120. Load-displacement data for $0.019^{\prime \prime}$ PVC film aged for 1 week at $125^{\circ} \mathrm{C} . .106$ Figure 121. Load-displacement data for 0.019" PVC film aged for 1 week at $125^{\circ} \mathrm{C}$. . 107 Figure 122. Normalized relaxation fits for 0.019 " PVC film aged for 1 week at $125^{\circ} \mathrm{C}$.

Figure 123. Load-displacement data for 0.019 " PVC film aged for 2 weeks at $125^{\circ} \mathrm{C} .108$ Figure 124. Load-displacement data for $0.019^{\prime \prime} \mathrm{PVC}$ film aged for 2 weeks at $125^{\circ} \mathrm{C} .109$ Figure 125. Normalized relaxation fits for 0.019 " PVC film aged for 2 weeks at $125^{\circ} \mathrm{C}$

Figure 126. Load-displacement data for 0.019 " PVC film aged for 3 weeks at $125^{\circ} \mathrm{C} .110$ Figure 127. Load-displacement data for 0.019 " PVC film aged for 3 weeks at $125^{\circ} \mathrm{C} .111$ Figure 128. Normalized relaxation fits for 0.019 " PVC film aged for 3 weeks at $125^{\circ} \mathrm{C}$ 


\section{INTRODUCTION}

\section{Background Information}

An important mandate for the Federal Aviation Administration (FAA) is to ensure the safety of electrical systems in aging aircraft. One particular area of concern is the integrity of aircraft wiring. Electrical systems are critical to the safe operation of transport category airplanes, and wiring is used to distribute power and communication signals throughout the systems. Many transport category airplanes contain over 100 miles of wiring. Electrical wire consists of a conductor usually copper or coated copper that is encased in a protective layer of insulation. Each wire is routed throughout an airplane in a series of bundles with clamps and connectors. Safe routing practices include measures to prevent wires from wear, abrasion, contamination and contact with other components; to gently bend and turn wires during installation to prevent cracking of the insulation; and physically separate wires from systems whose signals may interfere with one another. When the protective layer of insulation on a wire is compromised, the potential exists for a hazardous electrical system malfunction caused by a short circuit or an arc. The failure of aircraft wiring in this manner has been identified as a causal factor in several aircraft accidents. As the average aircraft has aged, aging wire has increased the potential for this type of activity to occur.(Leob 1999)

The operating environment for miles of aircraft wiring running in an aircraft is not very congenial, as the wires can undergo degradation due to temperature, moisture, 
chemicals, abrasion and cuts. The operating environments of aircraft wiring for two sample aircraft locations are shown in Figure 1. A report by the FAA states that on site inspections of aircraft have noted deterioration of wiring components (insulation cracking) as well as contamination of wire bundles with metal shavings, excessive dust, and various fluids. Given the critical nature of the wiring in aircraft, it is important to be able to reliably assess when specific wires have degraded to the point where replacement is necessary. (FAA 1998)
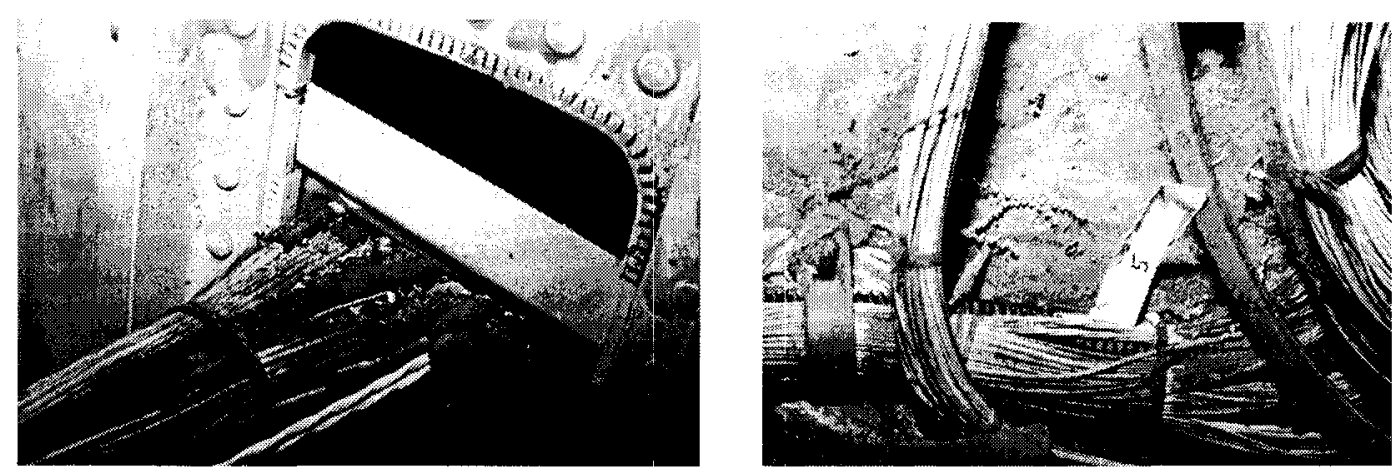

Figure 1. Operating environment of wires inside the air craft (Brinson, Bradshaw et al.

$$
\text { 2004). }
$$

Non-destructive test equipment exists that can be used to assess aircraft wiring with various types of insulation and shielding. For example, one type of instrument called an ultrasonic detector can identify a fault (discontinuity in the insulation) location within several centimeters and compare the examined wire performance to new wiring specifications. The information gained from this test can then be compared to a database of other aircraft as part of the management of the health of the wiring circuits, assessing risk due to wiring faults and planning for various maintenance and management decisions. The equipment can also identify certain cost centers (the points in an aircraft 
which add to the maintenance costs), providing one aspect in the measure of Total Ownership Cost for the aircraft.(Teal and Saterlee 2000)

The commercial air fleet continues to get older, with the average age of commercial air fleet now exceeding 12 years. Furthermore, 2500 aircraft have exceeded their design service objective (DSO), with some exceeding 35 years of age. Forecasts indicate that both average age and the number of years beyond DSO will continue to increase over the next several decades (Teal and Saterlee 2000). One problem for aging aircraft is that current inspections methods for examining the condition of aircraft wiring are typically only $25 \%$ effective (generally successful in regions where the wire can be easily examined). This has placed special emphasis on wire testing, improved testing methods and new wire system designs to ensure cost effective maintenance and improved safety. These facts have resulted in the FAA beginning to issue guidance for electrical systems as part of their aging aircraft program. In the past, extending the safe and useful life of the aircraft has focused only on aircraft structure (Teal and Saterlee 2000).

Other methods of monitoring aging wire focus on applying electrical sensing techniques that are, sensitive to the condition of the conductor, but not very sensitive to the condition of the insulation. Some methods are electrical reflectometry, measuring electrical signal intensity between points.

As such, the development of techniques to quantify and monitor aging wire insulation is highly warranted. The ultrasonic probe method has certain limitations. The probe is not small. The geometry of the probe and the space limitations in the wire testing process limit the use of the probe. One approach currently in development measures wire insulation stiffness by ultrasonic guided waves. Initial laboratory tests were performed on 
a simple model consisting of a solid cylinder and a solid cylinder with a polymer coating. Experimental measurements demonstrate that the lowest order extensional mode could be sensitive to stiffness changes in the wire insulation (Anastasi and Madaras 2005). To test this theory, conventional 12, 16 and 20 gage wire samples (typically found in aircraft) were heat damaged in an oven. The heat damage introduced material changes in the wire insulation that made the originally flexible insulation brittle and darker in color Extensional mode phase velocity increased for the samples that were exposed to heat for a longer duration. Although the heat damage conditions may be more extreme than those encountered in environmental aging, indications are that this technique has the potential to detect and quantify degradation in wire insulation (Anastasi and Madaras 2005).

Another approach, considered in previous and ongoing research work at Northwestern University, has been to employ impedance spectroscopy techniques to examine electrical properties of wiring insulation. In this technique, the impedance analyzer inputs low alternating voltage to the system (aqueous cell with the wire or film specimens) under study and measures the resulting alternating current. For films, this is much like a traditional capacitor arrangement and the resulting real and imaginary impedance provides information about its dielectric response in frequency space. Wires were also tested using this method. While impedance spectroscopy is a promising method for such assessment, implementation in the field remains problematic and would require further development and device design. Another approach is to use changes in the mechanical behavior of the polymer insulation as a measure of degradation. One such technique is to assess changes in the elongation at break (EAB) when compared to the baseline (pristine) material. In this test, a piece of insulation material is cut from a wire 
and loaded in tension until failure. The elongation at failure (EAB) of the specimen is noted. A reduction in this value with aging (likely due to several damage mechanisms including temperature exposure, chemical exposure, mechanical effects, etc.) is presumed to indicate an analogous reduction in the quality of the insulating material. Unfortunately, such a test is clearly destructive to the wire considered and would necessitate a wire repair in regions where employed (Denny 2004)

Another approach is to use measurements obtained from a non-destructive indentation test to assess the mechanical behavior of the polymer insulation of the wire. In previous research work, Analog Interfaces (AI) has developed the Indenter Polymer Aging Monitor (IPAM3) for this purpose. A piece of wire is inserted into the device and a probe is used to indent the insulation. The force is increased linearly until the maximum force is reached (typically 2 pounds); at that point, the penetration depth is maintained and the observed load decreases in the fashion of a classic relaxation curve. A plot of load versus penetration depth provides a stiffness measurement while the constant penetration depth data provides data describing relaxation behavior (presumably due to viscoelastic effects). Analog Interfaces has demonstrated a good correlation between the modulus measurements and elongation at break for a number of materials (Denny 2004).

\section{Purpose of Thesis}

The purpose of this thesis is to study the relationship between insulation degradation and indentation. The indentation studies used a dynamic mechanical analyzer (DMA) to obtain precise load-displacement data during indentation of PVC films and wires with PVC insulation under indentation. Both pristine and aged films and wires are tested. The change in the response of aged films and wires is compared to that of pristine 
films and wires; it is demonstrated that the change in stiffness is related to degradation in the polymer material. 


\section{EXPERIMENTAL. DETAILS}

In this section, experimental details are presented. This includes the material of the wire and film specimens. This section also provides the details of the indenters and the experimental set up used during testing.

\section{$\underline{\text { Specimen details }}$}

The PVC films are 0.008" $(0.20 \mathrm{~mm})$ and $0.019^{\prime \prime}(0.48 \mathrm{~mm})$ thick and were obtained from McMaster-Carr ${ }^{* *}$. PVC film samples were thermally aged at $105^{\circ} \mathrm{C}$ and $125^{\circ} \mathrm{C}$ (lab air environment) in two separate constant temperature ovens at Northwestern University. Samples were removed at aging times of 2 days, 5 days, 1 week, 2 weeks and 3 weeks and subsequently tested. The 20 gage PVC wires used for the tests were thermally aged at 125 degrees for $2,4,6,8,12,14$ and 16 weeks; these were provided in the aged condition by Analog interfaces. The PVC wire specification was given as MIL-DTL-16878/1C. (Denny 2004) Optical microscopic images of the wires showed a change in color of the insulation with aging times; these are shown in Figure 2 for the wire and Figure 3 and Figure 4 for the films.

\footnotetext{
"* Both films described as "Clear PVC, Type 1." The 0.008" and 0.019" films have McMaster-Carr item numbers $8562 \mathrm{~K} 9$ and $87875 \mathrm{~K} 17$, respectively.
} 


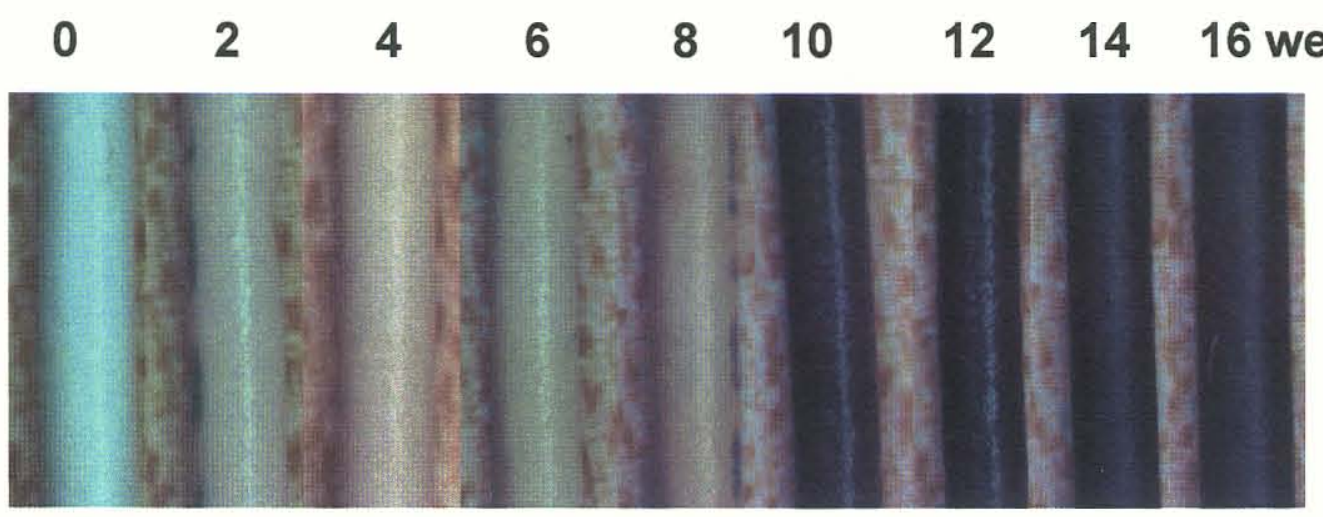

Figure 2. Optical microscopy images of the aged wire.

2

5

$0.019 "$

$0.008 ”$
7
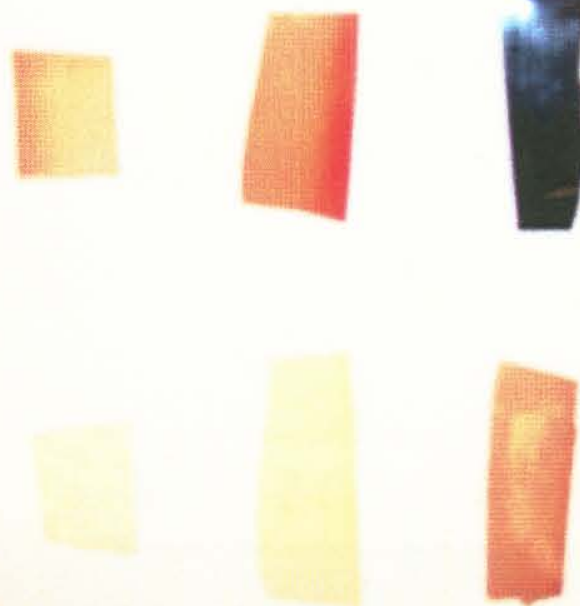

14
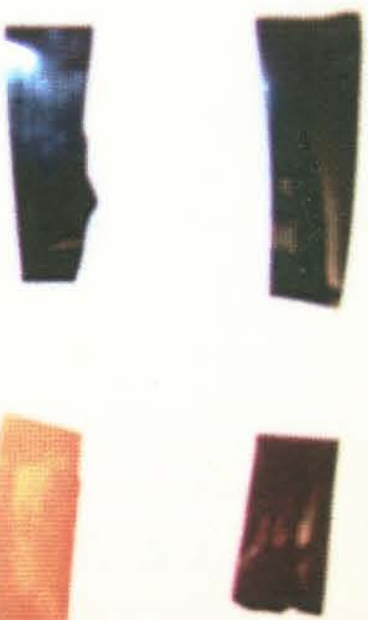

Figure 3. PVC film specimens of two thicknesses aged at $105^{\circ} \mathrm{C}$ 
2 5 7

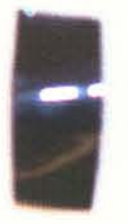

$0.019 "$

$0.008 ”$
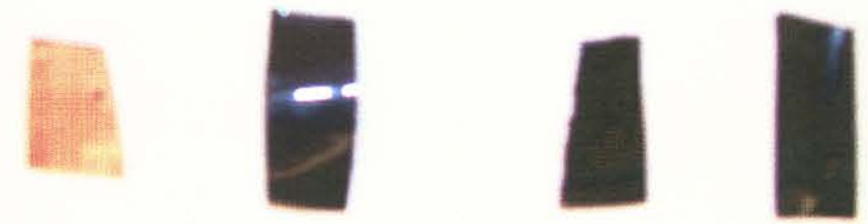

Figure 4. PVC film specimens of two thicknesses aged at $125^{\circ} \mathrm{C}$

\section{Indenter and support fixtures}

In order to use the DMA for wire and film indentation, indentation fixtures for the DMA were fabricated. One fixture is a spherical indenter made at the University of Louisville. This fixture begins with a $1 / 2$ "diameter precision ground stainless steel rod, machined to match the profile of the fixtures provided by TA instruments in the location where they attach to the DMA. A hole is made in the end of the rod using a drill that is 0.373 "diameter. A precision stainless steel ball ( 0.375 " diameter) is press fit into the hole leaving approximately $40-50 \%$ of the ball exposed. Another indenter fixture has a spherical tip identical to that used for the IPAM 3. This tip was provided by Analog Interfaces; a custom mounting rod was made at the University of Louisville that matched the profile of the fixtures provided by TA instruments. This fixture can be used to test polymer films and sheets by resting them on the standard flat faced DMA fixture as 
shown in Figure 5. A $1 / 2$ " rod with a $\mathrm{V}$ groove was also made to mount in the lower DMA attachment point to support wire specimens. This can be used to test wire using the spherical indenter as shown in Figure 6.

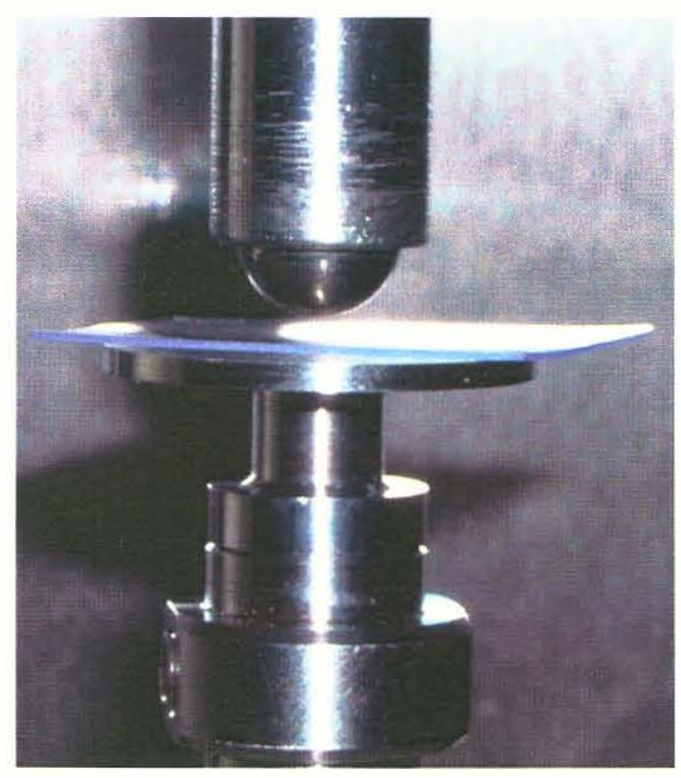

Figure 5. Film indentation using spherical indenter.
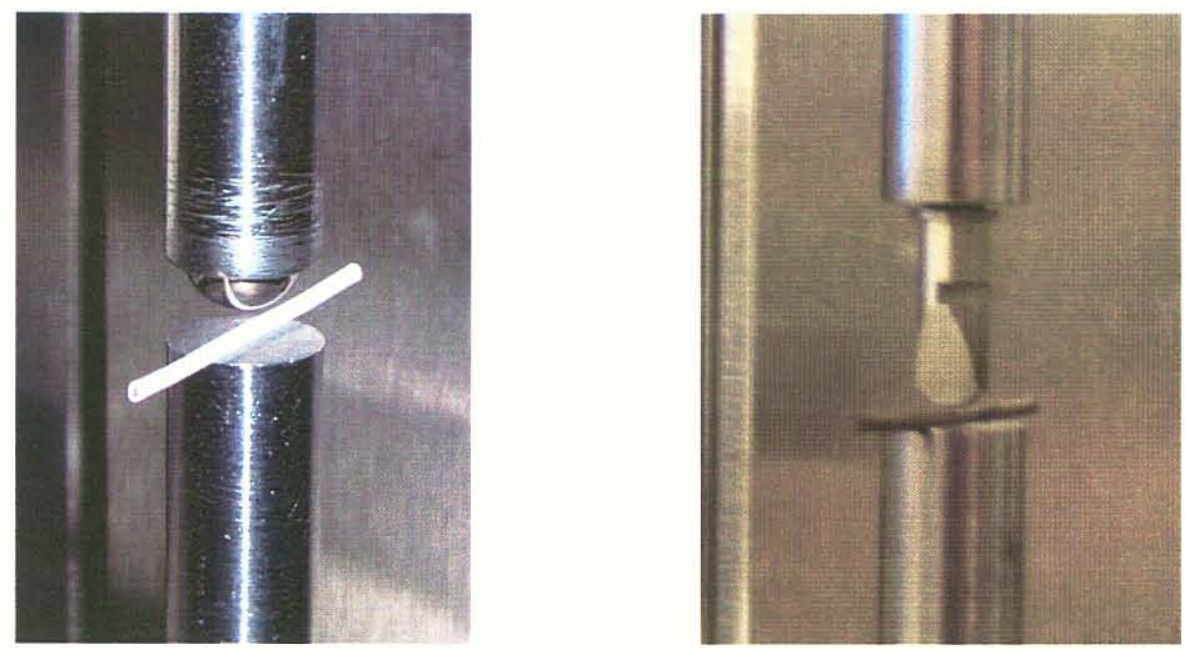

Figure 6. Wire indentation configurations using spherical indenter (left), using cylindrical indenter (right) 


\section{Dynamic Mechanical Analyzer}

Dynamic mechanical testing involves the application of an oscillatory strain to a sample. This can be related as:

$$
\varepsilon(t)=\varepsilon_{o} \sin \omega t
$$

The resulting sinusoidal stress is measured and correlated against the input strain; which will have the following form.

$$
\sigma(t)=\sigma_{o} \sin (\omega t-\delta)
$$

where $\delta$ is the phase angle between stress and strain. If the sample behaves as an ideal elastic solid, then the resulting stress is proportional to the strain amplitude (Hooke's law) and the stress and strain signals are in phase $(\delta=0)$. If the sample behaves as an ideal fluid, then the stress is proportional to the strain rate (Newton's law). In this case, the stress signal is out of phase with the strain, leading it by $90^{\circ}\left(\delta=90^{\circ}\right)$. For viscoelastic materials, the phase angle $\delta$ between stress and strain occurs between the elastic and the viscous extremes $\left(0<\delta<90^{\circ}\right)$. In this case, stress signal generated by a viscoelastic material can be separated into two components: an elastic stress (in phase with strain) and a viscous stress $\left(90^{\circ}\right.$ out of phase with strain). The elastic stress is a measure of the degree to which the material behaves as an elastic solid. The viscous stress is a measure of the degree to which the material behaves as an ideal (Newtonian) fluid. By separating the stress into these components, both the viscous and elastic properties of the sample are simultaneously measured.

The RSA III, shown in Figure 7, tests the dynamic mechanical properties by using a servo drive linear actuator to mechanically impose an oscillatory deformation, (strain) upon the material. The sample is coupled between the actuator and the transducer, which 
measures the resultant force generated by sample deformation. Strain displacement amplitudes are set and the actual sample deformation is determined by the measured actuator and transducer displacement (TA Instruments 2003). The RSA III also comes with the Orchestrator 7.0 software package to control the system via the control computer. The software is used to run the tests, control the test conditions and collect output data.

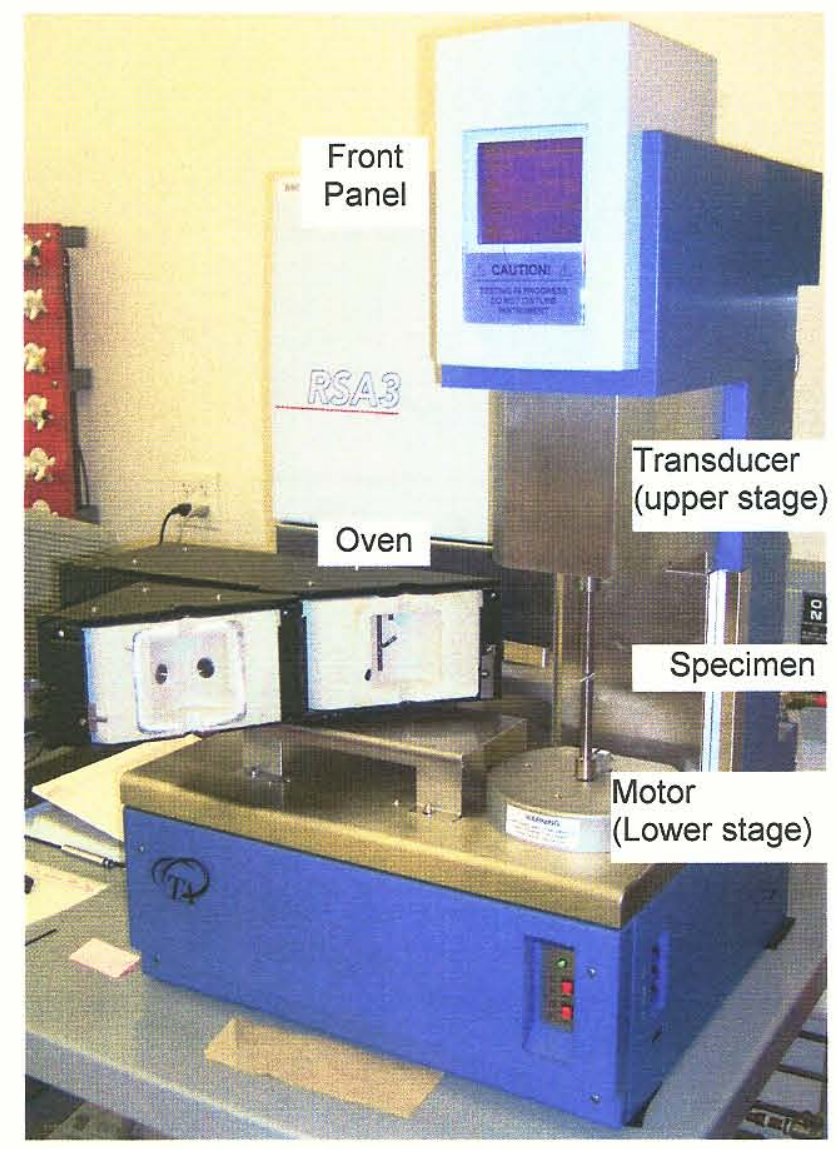

Figure 7. RSA III Dynamic Mechanical Analyzer.

The RSA III can also subject the sample to a specified thermal environment. In this case, a forced air convection oven is used to enclose the sample. Two resistive heater guns are used to control the sample test temperature. An optional liquid nitrogen controller (not installed at University of Louisville) also allows low temperature sample 
testing; by injecting cold $\mathrm{N}_{2}$ gas into the oven. To monitor actual oven temperature, three platinum resistance thermometers (PRT) are installed in the oven. Two PRTs are associated with each heater gun while a third measures the sample temperature. The direction of the third sample PRT can be changed to monitor the temperature at different points in the work space. The temperature loops (which use two of the three PRTs) which measure the actual temperature can be independently selected. The temperature controller monitors PRT resistance to determine the actual internal oven temperature. This is compared to the commanded temperature, resulting in adjustment to heater guns until the desired value is reached. Although tests can be performed at elevated temperatures, all tests reported in this thesis are at room temperature. As such, testing in this thesis was always conducted with the oven removed as in Figure 7.

\section{Multiple Extension Mode}

Multiple extension mode offers four zones in which a variety of separate extensional test types can be performed. The extension modes can be based on the displacement rate, Hencky strain (related to the specimen geometry), imposed creep force or a compressive rim shear (squeeze flow). Positive and negative entries to any of these inputs move the grips in the tensile and compressive directions respectively. Each test can consist of 4 separate control regions (zones).

Each zone can have its own extension mode and zone time. The zone time determines the duration of occurrence of the test type in each zone while the extension value specifies the appropriate deformation value. The "End Test" mode halts the series of extensional mode testing. In this example, the extension mode is set to Rate $(\mathrm{mm} / \mathrm{s})$ 
(Figure 8). In this case, the specimen length will be increased at the rate of $0.01 \mathrm{~mm} / \mathrm{s}$ for $10 \mathrm{~s}$ (total change in length of $0.1 \mathrm{~mm}$ ). All tests in this thesis were accomplished vis. rate loading.

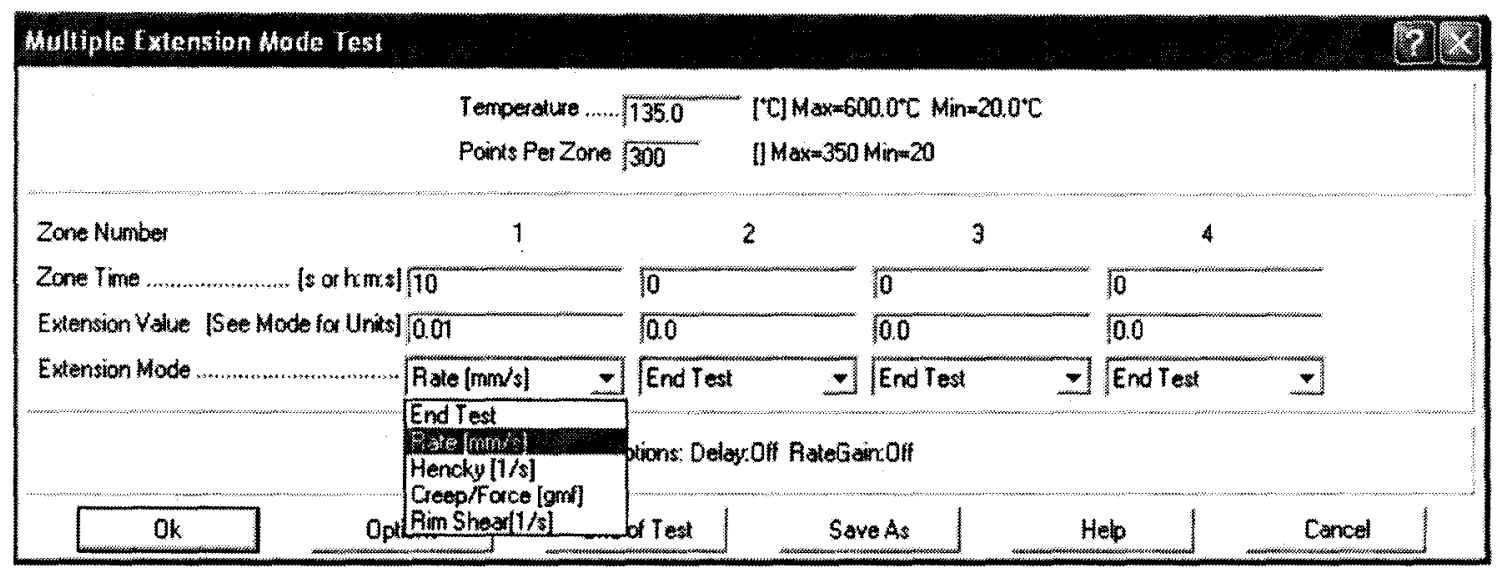

Figure 8. Multiple extension mode input dialog box on Orchestrator 7.0.

\section{$\underline{\text { Specimen Placement }}$}

Both film and wire specimens are tested in this thesis. For wire specimens, the support fixture with the $\mathrm{V}$ groove is mounted on the lower stage and the chosen (spherical or cylindrical) indenter is mounted on the upper stage. The upper indenter is lowered until it barely makes contact with the $\mathrm{V}$ groove fixture. This is the zero position. The transducer stage is then moved up and the wire specimen is placed in the $\mathrm{V}$ groove. The indenter is then moved close to the wire such that it makes contact with a very small load as shown in Figure 6. The specimen is then ready for testing.

For film testing, the flat-faced $25 \mathrm{~mm}$ diameter support fixture is mounted on the lower stage. The spherical indenter is mounted to the upper stage. The upper fixture is then lowered to make contact with the lower fixture to establish the zero position. The upper indenter is then moved up and the film sample is placed on the lower fixture. The 
upper indenter is moved to make contact with the film with a very small load as shown in Figure 5.

If the wire or film is not initially flat, it will exhibit an initial soft stiffness until full contact is achieved. On application of a small initial load the upper indenter makes solid contact with the specimen and the lower fixture. This eliminates the initial contact problems and helps resolve any issues of specimens in a non-flat condition.

\section{Test Procedure}

The wire and the film specimens are tested using load/time values similar to those used by Analog Interfaces with the IPAM 3. A typical test begins with a load segment, during which the indenter is displaced into the specimen at a constant rate while force is measured. The load segment ends after 2 seconds. The indenter position is then maintained constant for the remainder of the test. This is called the relaxation segment; during which the force on the indenter decreases (presumably as the insulation of the wire deforms in a viscoelastic / viscoplastic manner) as shown in Figure 9. 


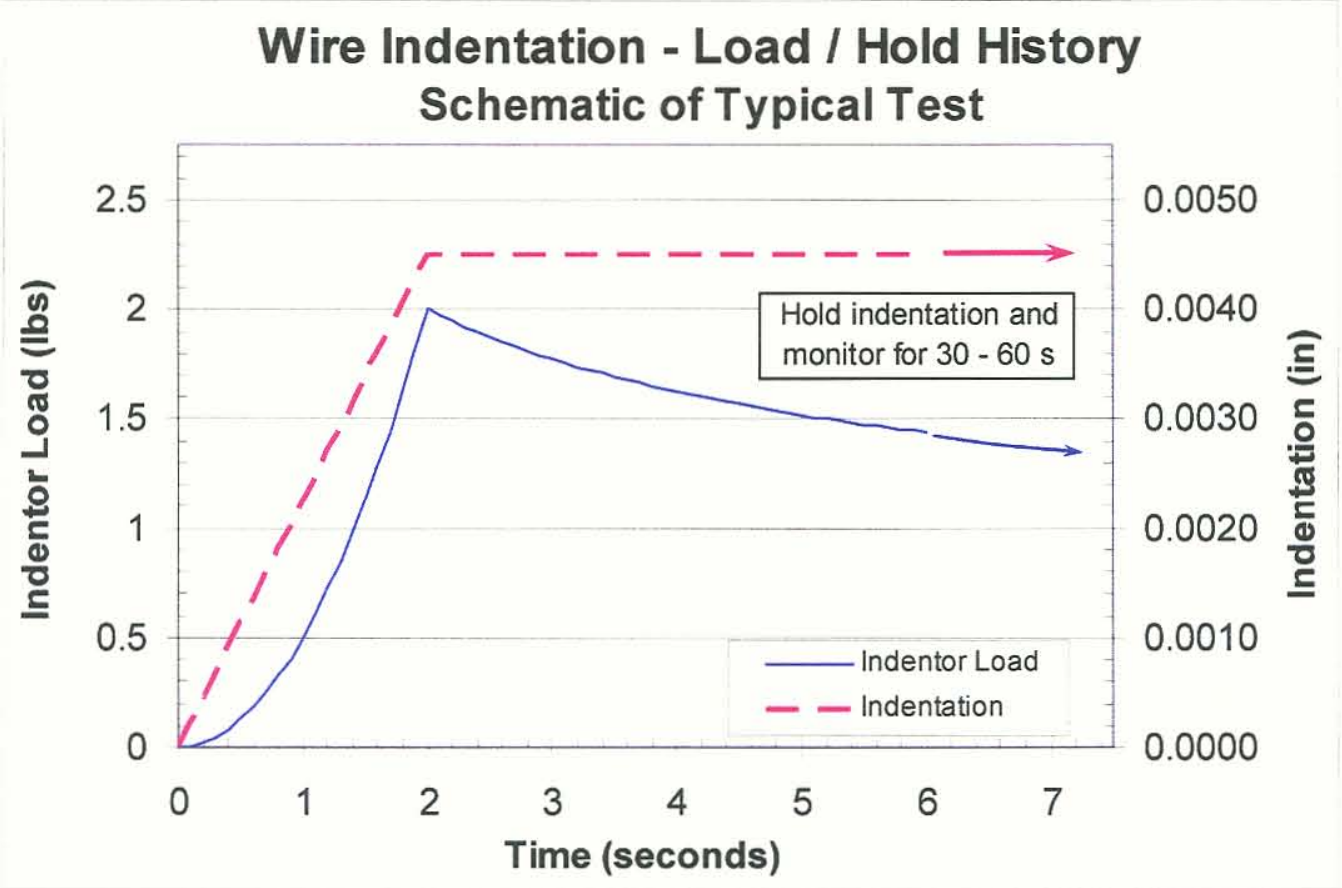

Figure 9. Schematic of a typical load-hold indentation test with the load (blue) and indenter displacement (red) shown vs. time (displacement values vary for actual tests)

The goal of the test is to achieve a load of $2 \mathrm{lbs}$ at the end of the load segment. However the tests cannot be performed in this manner, as the DMA operates in either force control (desired for the load segment) or displacement control (desired for the relaxation segment) but not both ${ }^{\dagger \dagger}$. To overcome this constraint, trial tests are done to find the displacement value which corresponds to a force of $2 \mathrm{lbs}$. This displacement value is then used in the load segment (adjusted to an appropriate rate/zone time).

The tests are then conducted on the wire/film specimens. The loading phase has only one zone lasting for 2 seconds. Data is collected at 300 points in each zone. The relaxation phase has 3 zones, the $1^{\text {st }}$ zone lasting for one second, the $2^{\text {nd }}$ zone lasting for

\footnotetext{
"H In the future, this issue could be resolved by programming the DMA to run a series of tests. The first test for the loading phase using force control and the following tests for the relaxation using displacement control.
} 
10 seconds, the $3^{\text {rd }}$ lasting for 49 seconds (total of 60 seconds relaxation). The $1^{\text {st }}$ zone corresponds to the initial phase of relaxation in which a great deal of change occurs over a short period; as such sampling rate is high. The sampling rate is reduced in the $2^{\text {nd }}$ and $3^{\text {rd }}$ zones as the relaxation change with time is less dramatic. Five trials are conducted on the same specimen at 5 different locations to test the repeatability of the test.

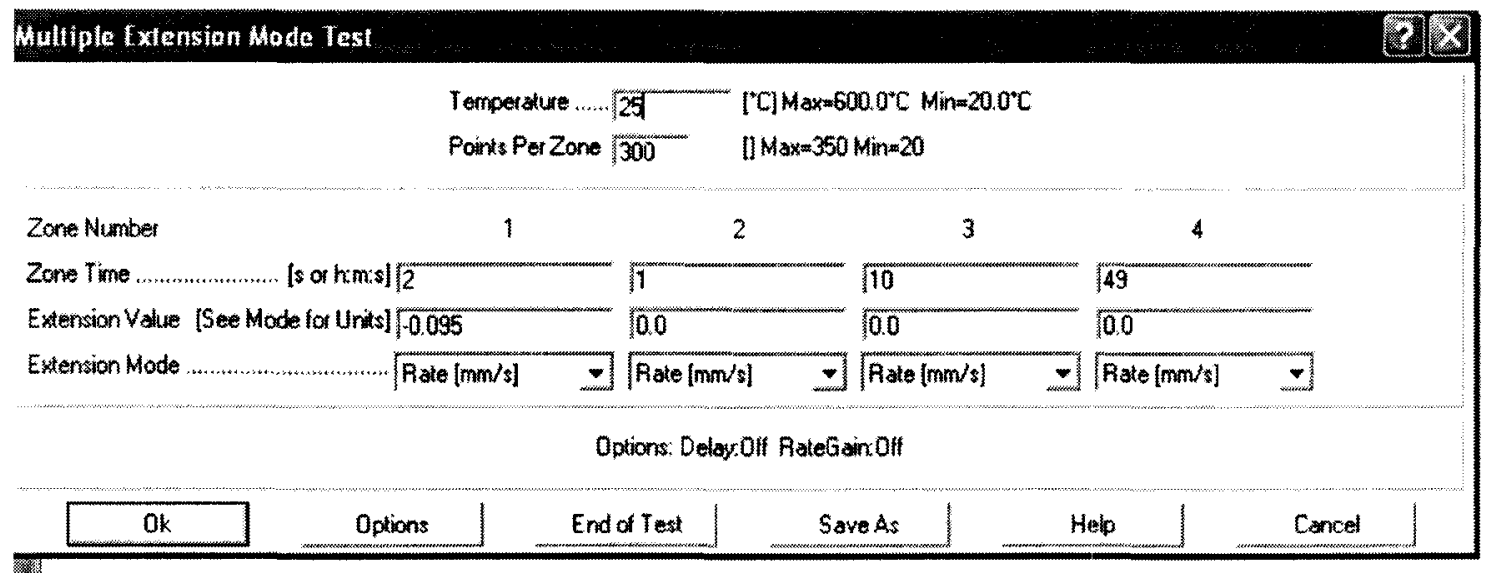

Figure 10. Input values for the typical test using Multiple extension mode. 


\section{ANALYSIS}

In the analysis section the data obtained from the tests are analyzed. The data is extracted and is treated to get the required parameters. An excel sheet is used to plot the required curves and tabulate the parameters.

\section{Indentation Data Analysis}

Once the test is completed, the resulting data (load, displacement, time) must be analyzed to assess the properties of the wire or film. The indentation analysis approach is common for both wires and films. The data is first exported from the Orchestrator 7.0 software to a text file.

An Excel spreadsheet then analyzes the test data and determines appropriate curve fits whose constants describe the test findings. The spreadsheet used to analyze the data was written by Dr. Roger D. Bradshaw. This template reduces the large data set obtained by the DMA to a small number of parameters that accurately describe the obtained loaddisplacement-time data set. The long term goal is to use these parameters to determine fundamental material properties (Young's modulus, creep compliance, etc) based on classical contact mechanics models or finite element studies.(Johnson 1985),(Balta Calleja and Fakirov 2000) This text file consists of the time of a particular measurement $\left(\mathrm{t}_{\mathrm{i}}\right)$ as well as the force $\left(\mathrm{F}_{\mathrm{i}}\right)$ and displacement $\left(\delta_{\mathrm{i}}\right)$ at that moment as shown in Figure 11 (the stress and strain data is not used in this study). Since the specimens are much less 
stiff than the steel fixtures, it is assumed that all of the reported displacement is due to specimen deformation.

\begin{tabular}{|c|c|c|c|c|c|c|}
\hline \multicolumn{7}{|c|}{ 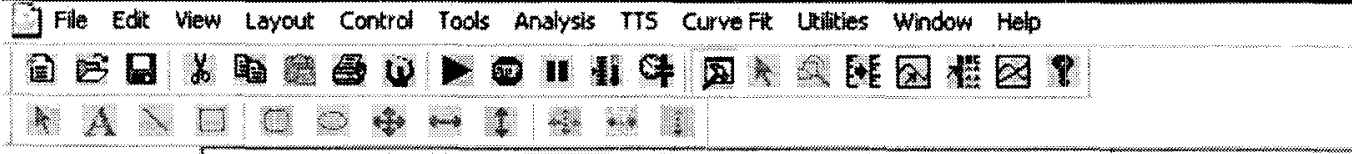 } \\
\hline Time & \multicolumn{2}{|r|}{$\begin{array}{c}\text { A } \\
\text { time } \\
s\end{array}$} & $\begin{array}{c}\mathrm{B} \\
\sigma(\mathrm{t}) \\
\text { dyntem }\end{array}$ & $\begin{array}{l}\mathrm{C} \\
\text { Force } \\
\mathrm{g}\end{array}$ & $\begin{array}{c}D \\
\mathrm{~mm}\end{array}$ & $\begin{array}{c}E \\
\varepsilon(t) \\
\%\end{array}$ \\
\hline \multirow{2}{*}{\begin{tabular}{|c|} 
AxialForce \\
374.30 \\
\end{tabular}} & 10 & 0.09 & .20138 & -16.128 & -0.0015 & -0.6897 \\
\hline & 11 & 0.1 & -23730 & -19.005 & -0.0018 & -0.8122 \\
\hline \multirow{2}{*}{$\frac{\text { Gap }}{24.601}$} & 12 & 0.11 & .27492 & .22 .018 & .0 .0021 & -0.9295 \\
\hline & 13 & 0.12 & .31320 & -25.083 & -0.0023 & -1.0414 \\
\hline \multirow{5}{*}{$\begin{array}{l}\text { Temp } \\
21.88\end{array}$} & 14 & 0.13 & .35232 & -28.216 & .0 .0026 & -1.1529 \\
\hline & 15 & 0.14 & .39111 & -31.323 & .0 .0028 & -1.2721 \\
\hline & 16 & 0.15 & .43257 & -34.644 & -0.0031 & -1.3813 \\
\hline & 17 & 0.16 & .47478 & -38.024 & -0.0033 & -1.4899 \\
\hline & 18 & 0.17 & .51613 & -41.336 & -0.0036 & -1.5939 \\
\hline
\end{tabular}

Figure 11. Screen capture of Orchestrator 7.0 window after test.

The test data is pasted into the Excel analysis spreadsheet. The spreadsheet identifies the moment when the force begins to increase; at this moment, the time $\left(\mathrm{t}^{*}\right)$ and current displacement $\left(\delta^{*}\right)$ value is noted. The spreadsheet then creates a modified displacement vector $\delta_{\mathrm{i}}$, which is simply the displacement since the moment when the force began to increase $\left(\delta_{\mathrm{i}}=\delta_{\mathrm{i}}-\delta^{*}\right)$. The spreadsheet also identifies the maximum load $\left(F_{\max }\right)$ and the time at which it occurs $\left(\mathrm{t}^{\tilde{}}\right)$. All data for times $\mathrm{t}^{*} \leq \mathrm{t} \leq \mathrm{t}^{\sim}$ belong to the load segment (increasing displacement), while all data subsequent to that $\left(t>t^{2}\right)$ is part of the relaxation (or hold) segment (constant displacement). In the load segment, the load versus displacement is studied and fit two ways. In the first, a linear relationship between the 
$25 \%$ and $75 \%$ load values is used; this is similar to what Analog Interfaces had done previously ${ }^{\ddagger \ddagger}$. In the second, a parabolic relationship is used; this typically fits all data very well. A typical result is shown in Figure 12.

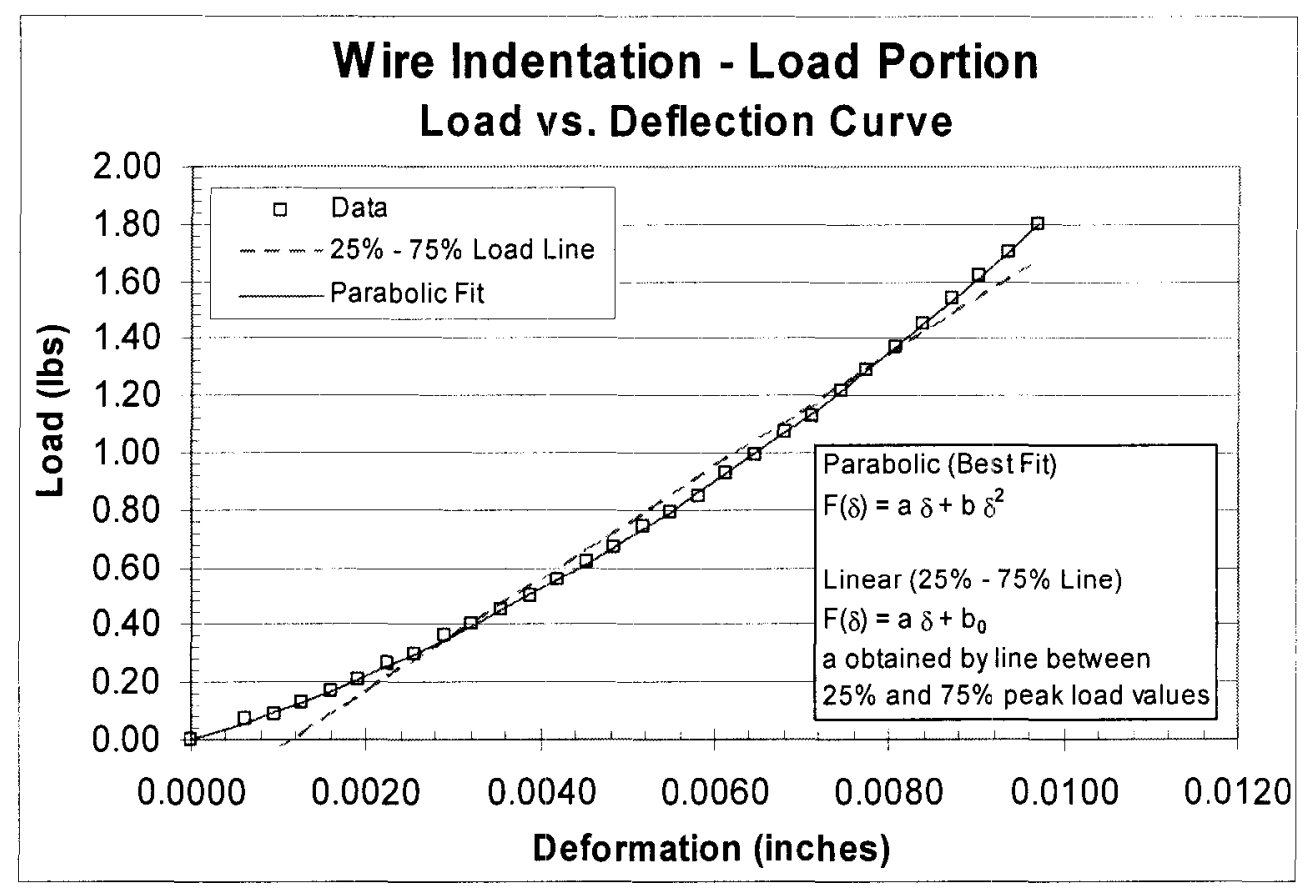

Figure 12. Load versus deformation data and fit for unaged PVC wire

The relaxation data is obtained at constant displacement. As such, it is considered as load versus time elapsed since the displacement was held constant ( $t-t)$. Typical viscoelastic functions such as exponential (Prony) series and stretched exponential (Kohlrausch) series were considered to represent this data; however, these did not perform adequately unless many elements were used. Instead, the data was represented using a $3^{\text {rd }}$ order polynomial in the force vs. log time since hold $\left(\mathrm{t}-\mathrm{t}^{2}\right)$ domain. This

\footnotetext{
站 should be noted that Analog Interfaces refers to this quantity as a "modulus" with units of lbs/inch. In order to avoid confusion with the Young's modulus derived during subsequent modeling efforts, the values associated with the load-displacement data are referred to as stiffnesses rather than moduli.
} 
approach captures the data quite well; of course, other functions could also be used. A typical result is shown in Figure 13.

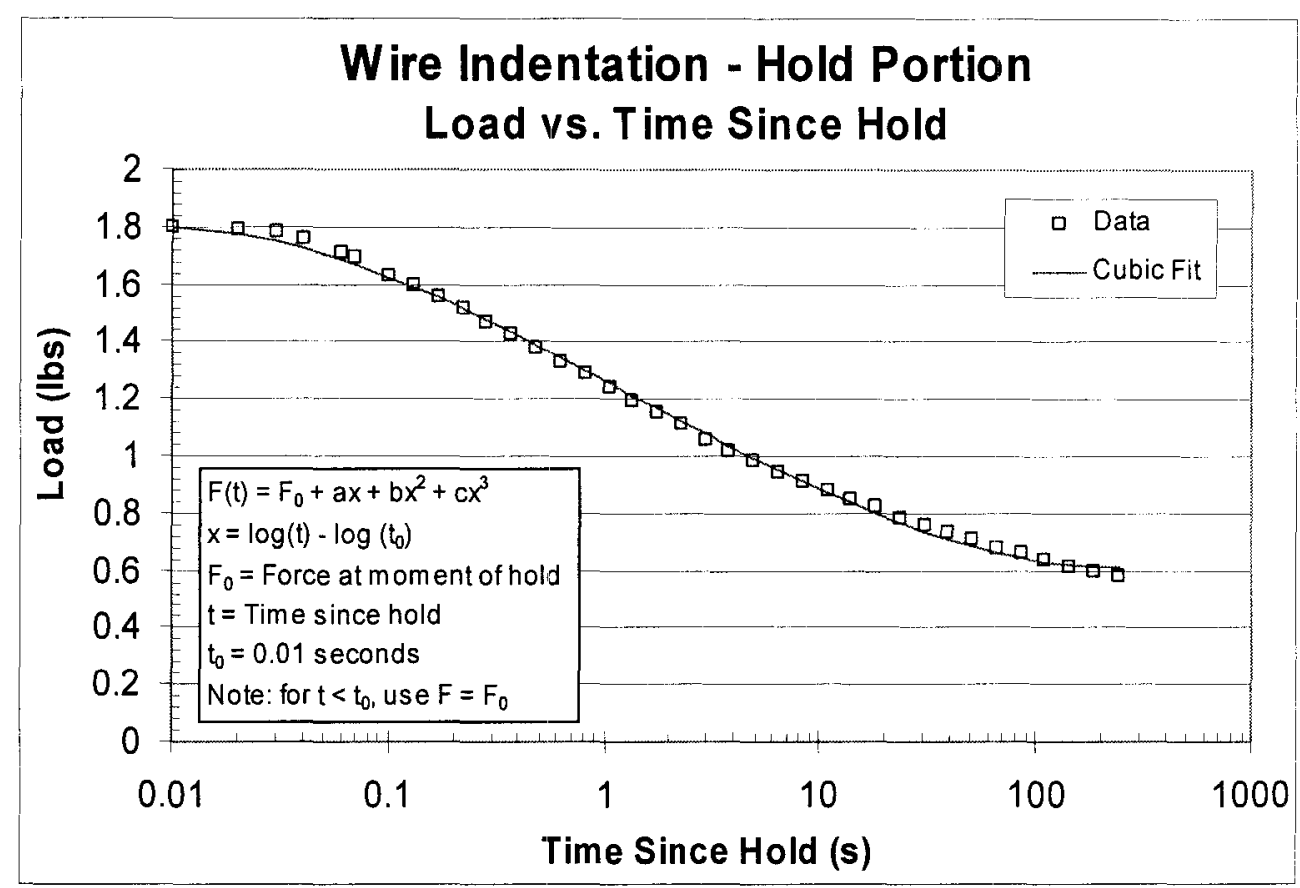

Figure 13. Load versus deformation data and fit for unaged PVC wire

As mentioned above, the spreadsheet approximates the data by several appropriate curve fits. This simplifies future analysis by reducing the amount of information needed to characterize a given test while also leading to various parameters that may be useful in future analysis efforts. A description of the fits is discussed below; this section is largely similar to an earlier FAA report of which the author was a coauthor. (Bradshaw, Nagendran et al. 2005)

First, the load portion of the data is considered. The specimen stiffness $K$ is obtained in accordance with the approach previously used by Analog Interfaces; this is defined by the equation: 


$$
K=\frac{F_{75 \%}-F_{25 \%}}{\delta_{75 \%}-\delta_{25 \%}}
$$

where $F_{25 \%}$ and $F_{75 \%}$ are the force data values equal to approximately $25 \%$ and $75 \%$ of the maximum load $\left(\mathrm{F}_{\max }\right)$, and $\delta_{25 \%}$ and $\delta_{75 \%}$ are the corresponding displacement values at those same moments. Thus, the stiffness $\mathrm{K}$ is the slope of the line connecting the forcedisplacement values at $25 \%$ and $75 \%$ of the maximum load; it has units of $1 \mathrm{~b} / \mathrm{in}$. The line connecting these two force-displacement points is given by:

$$
F(\delta)=\lambda+K \delta
$$

where $\lambda$ is the intercept of the line (predicted force at $\delta=0$ ) and is given by:

$$
\lambda=F_{25 \%}-K \delta_{25 \%}
$$

The values of $K$ and $\lambda$ are obtained by the spreadsheet.

While the two point fit described above provides a single stiffness measure, the line described by that slope does not typically represent the full force-displacement data set. Instead, this data generally looks parabolic in nature. In order to better represent the shape of the force-displacement curve, the spreadsheet also obtains the optimal parameters $a$ and $b$ that represent the data in accordance with the function:

$$
F(\delta)=a \delta+b \delta^{2}
$$

This enforces the condition that $F=0$ at $\delta=0$. These two values are also reported by the spreadsheet and typically provide a curve that is representative of most data sets. The fit is achieved by a linear least squares approach.

The relaxation portion of the test generally has a smooth decline in force when plotted against $\log$ time since the displacement hold $\left(t-t^{\sim}\right)$. Comparing these results across different tests is complicated by the fact the maximum obtained force in each test varies slightly; as such, so do the relaxation curves (they appear to be shifted vertically 
from one another). In order to compensate for this, the spreadsheet also plots the normalized relaxation response, dividing the force throughout the relaxation portion by the maximum force $F_{\max }$ for the same test. This provides a way to easily compare the results from multiple tests on a single specimen; the results are generally quite similar for all tests.

In order to represent the data by a small number of parameters, a $3^{\text {rd }}$ order polynomial is obtained that best fits the data of the form: ${ }^{\S \S}$

$$
F(\xi)=F_{\max }+\bar{\alpha} \xi+\bar{\beta} \xi^{2}+\bar{\gamma} \xi^{3}
$$

where $\xi$ is a measure of the log time since the hold defined as:

$$
\xi=\log \left(t-t^{\sim}\right)-2
$$

The subtraction of 2 in the above equation sets $\xi$ equal to 0 at 0.01 seconds after the maximum force is reached. This is generally the first data point after the maximum force is attained; this function sets the force at that time equal to $F_{\max }$. Note that it is not possible to evaluate this function at $\mathrm{t}^{\sim}$ (since the $\log$ of 0 is negative infinity); for values of $t$ between $\mathrm{t}^{\sim}$ and $\mathrm{t}^{\tau}+0.01$, the force is assumed to be constant and equal to $F_{\max }$. As mentioned above, it is preferable to plot this function normalized by the maximum force $F_{\max }$; in this case, the relaxation data is represented by:

$$
F(\xi) / F_{\max }=1+\alpha \xi+\beta \xi^{2}+\gamma \xi^{3}
$$

\footnotetext{
$\$$ The $3^{\text {rd }}$ order polynomial was chosen after more standard approaches (including a Prony series with a small number of terms and a Kohlrausch series with a small number of terms) failed to adequately capture the shape of the curve. Of course, using a Prony series with a larger number of terms (perhaps 5-10 relaxation times) would be sufficient. However, this leads to more coefficients to track as well as added complexity in finding the fit in Excel. The polynomial approach leads to excellent agreement with only 3 coefficients to be determined. This fit can be subsequently studied using more standard VE approaches if desired.
} 
The spreadsheet determines the optimal values of $\alpha, \beta$ and $\gamma$ to fit a given set of test data.

The coefficients for each of these fits are listed in a section of the spreadsheet; a typical example for both the load and relaxation fits is shown in Table 1.

\begin{tabular}{|c|c|}
\hline \multicolumn{2}{|l|}{ Solution For Load Portion } \\
\hline $\begin{array}{l}\text { Stiffness - } 25 \%-75 \% \text { Load (lb / in) } \\
\text { Intercept For } 25 \%-75 \% \text { Load Stiffness Line (Ibs) }\end{array}$ & $\begin{array}{c}196.04 \\
-0.22731\end{array}$ \\
\hline Parabolic Fit - Stiffness - Linear Term (Ib / in) & 93.16 \\
\hline Parabolic Fit - Stiffness - Parabolic Term (lb / in $\left.{ }^{2}\right)$ & 9500 \\
\hline \multicolumn{2}{|l|}{ Solution For Hold Portion } \\
\hline Cubic Fit - Relaxation - Linear Term (lb / $\log (\mathbf{s}))$ & -0.029243 \\
\hline Cubic Fit - Relaxation - Parabolic Term (Ib / $\left.\log (s)^{2}\right)$ & -0.172617 \\
\hline Cubic Fit - Relaxation - Cubic Term $\left(\operatorname{lb} / \log (s)^{3}\right)$ & 0.0268277 \\
\hline
\end{tabular}

The spreadsheet is setup to analyze a set of data from 5 trials (the typical number of tests for a specimen). The analysis is performed for each trial on its individual tab in Excel. A summary tab presents the results for all tests together as both a table of values for the optimal parameters as well as a series of plots with data from all 5 tests. An example for PVC wire is shown in Figure 14 (force) and Figure 15 (relaxation). The coefficient of variation (CV) for the parameters is also presented; this is defined as the standard deviation of the value in question across the 5 tests divided by the average value (it is a unitless quantity and is reported as a percentage value). In general, this quantity is only informative for the stiffness $\mathrm{K}$. The other values are for one constant as part of a fit involving multiple constants; as such, the $\mathrm{CV}$ is fairly high even though the obtained fits may be quite similar. As such, other CV values are provided for completeness but should be used with caution. The tables corresponding to the data shown above are provided in Table 2 below. 


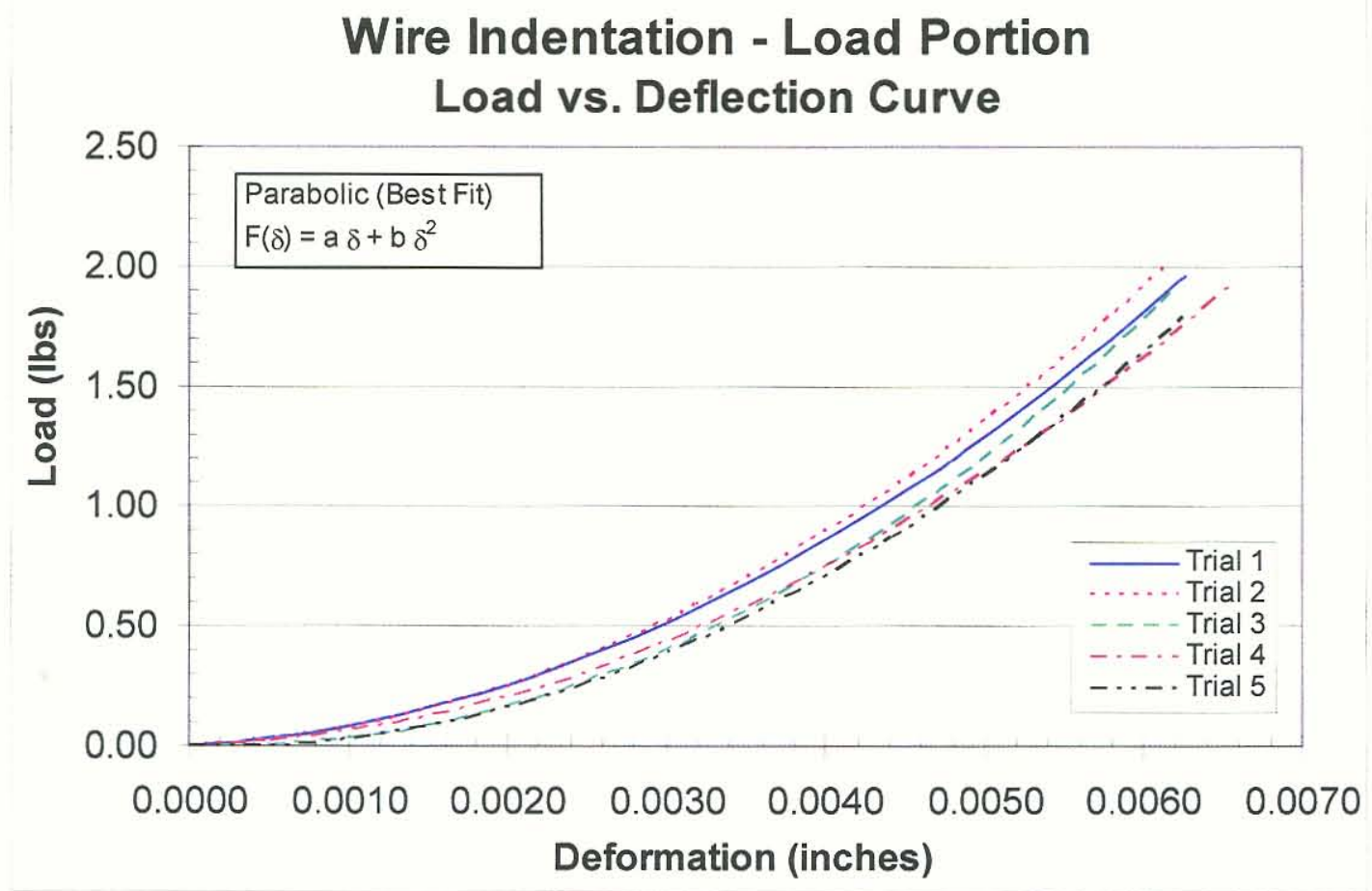

Figure 14. Parabolic curve fits of the load portion data for 5 tests on for unaged 20 gage PVC wire

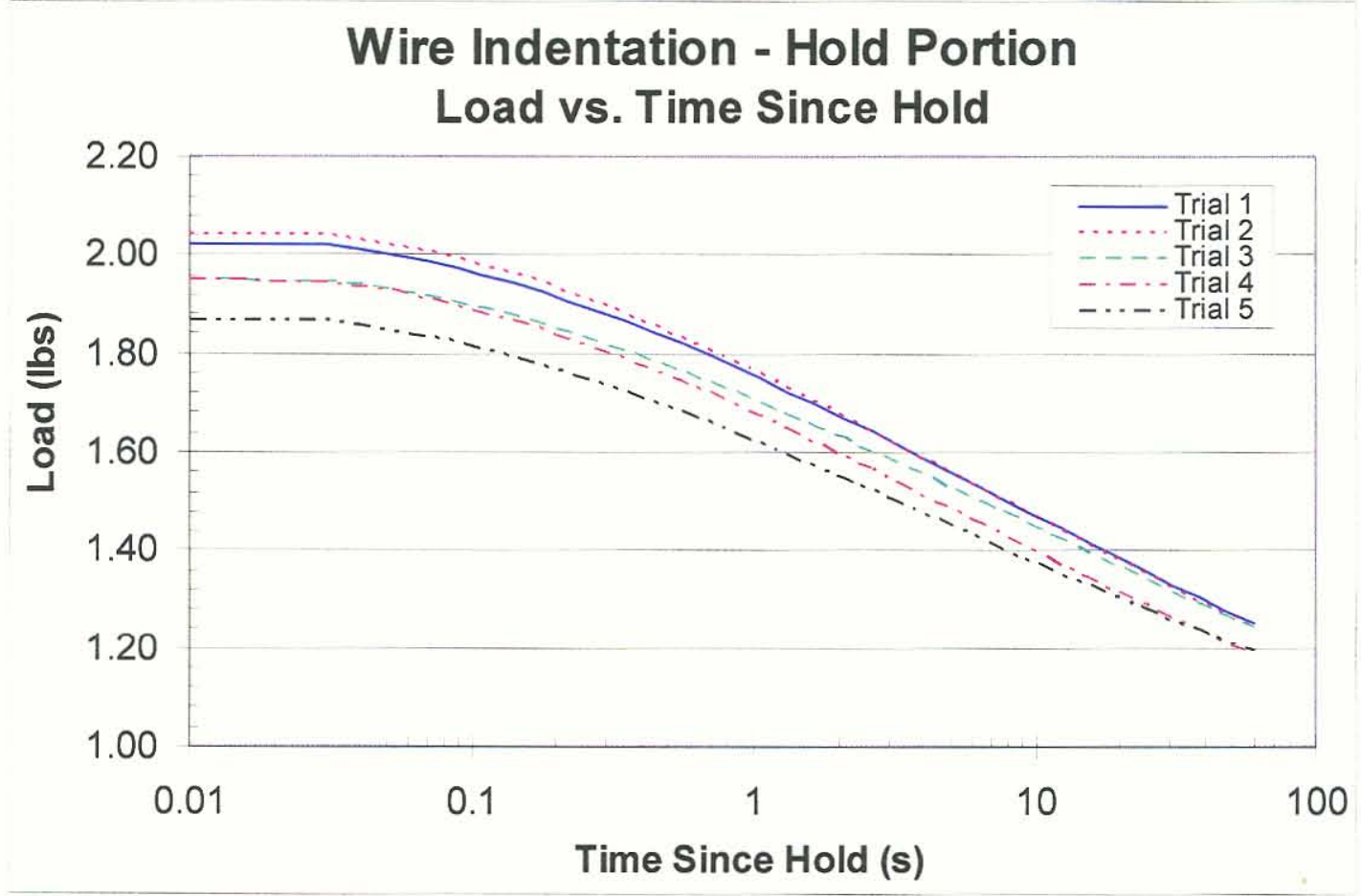

Figure 15. Relaxation data fits fro 5 tests on an unaged 20 gage PVC wire. 


\begin{tabular}{|l|ccccc|cc}
\hline Parameter & Trial 1 & Trial 2 & Trial 3 & Trial 4 & Trial 5 & Average & CV \\
\hline K (lbs/in) & 375.7 & 425.5 & 465.4 & 399.6 & 432.3 & 419.7 & $8.1 \%$ \\
$\lambda(\mathbf{l b s})$ & -0.57628 & -0.74040 & -1.08244 & -0.82694 & -0.98882 & -0.84298 & $23.8 \%$ \\
\hline $\mathbf{a}\left(\mathbf{l b s} / \mathbf{i n}^{2}\right)$ & 39.83 & 30.10 & -30.50 & 18.28 & -18.67 & 7.81 & $394.8 \%$ \\
$\mathbf{b}\left(\mathbf{l b s} / \mathbf{i n}^{2}\right)$ & 43705 & 48211 & 54278 & 41887 & 48867 & 47390 & $10.2 \%$ \\
\hline $\boldsymbol{\alpha}(\mathbf{1} / \log (\mathbf{s}))$ & 0.022838 & 0.029183 & 0.020246 & 0.021459 & 0.022912 & 0.023328 & $14.8 \%$ \\
$\boldsymbol{\beta}\left(\mathbf{1} / \log (\mathbf{s})^{2}\right)$ & -0.057265 & -0.062764 & -0.052940 & -0.059412 & -0.058440 & -0.058164 & $6.1 \%$ \\
$\gamma\left(\mathbf{1} / \log (\mathbf{s})^{3}\right)$ & 0.0064918 & 0.0073285 & 0.0058697 & 0.0069507 & 0.0071664 & 0.0067614 & $8.7 \%$ \\
\hline
\end{tabular}

Table 2. Fit parameters for 5 tests on unaged PVC wire. 


\section{RESULTS}

The results obtained from the analysis are presented in this section. The changes occurring in the wire and the film specimens are discussed. The change in stiffness with aging time is shown by the family of curves generated.

\section{Wire Indentation Analysis}

Indentation tests were performed on the aged wires shown in Figure 2 earlier. The data was analyzed using the analysis spread sheet previously described. The goal of this study was to assess the effect of aging time on the wire insulation material. The stiffness of the wire insulation material increased with aging time, with wire insulation becoming fairly brittle after 10 weeks of aging. Results for one trial at each aging time are shown in Figure 16. To better illustrate the general trend of increase in stiffness with aging times, the data is plotted again in Figure 19 with every other week $\left(2^{\text {nd }}, 6^{\text {th }}, 10^{\text {th }}\right.$ and $14^{\text {th }}$ weeks $)$ eliminated. 


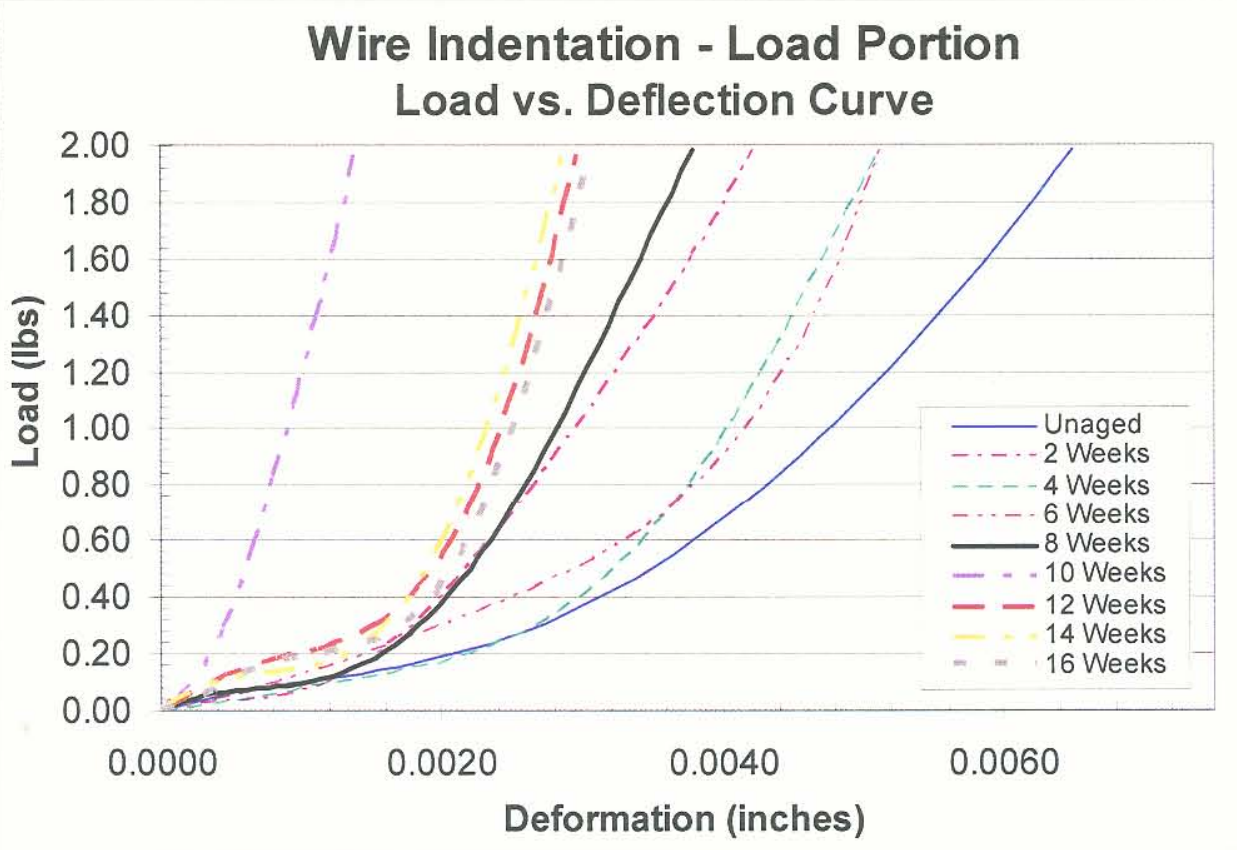

Figure 16. Curve fits of the load portion data for the indentation of 20 gage PVC wire aged at $125^{\circ} \mathrm{C}$ for the period of time indicated.

\section{Wire Indentation - Load Portion} Typical Load vs. Deflection Curve

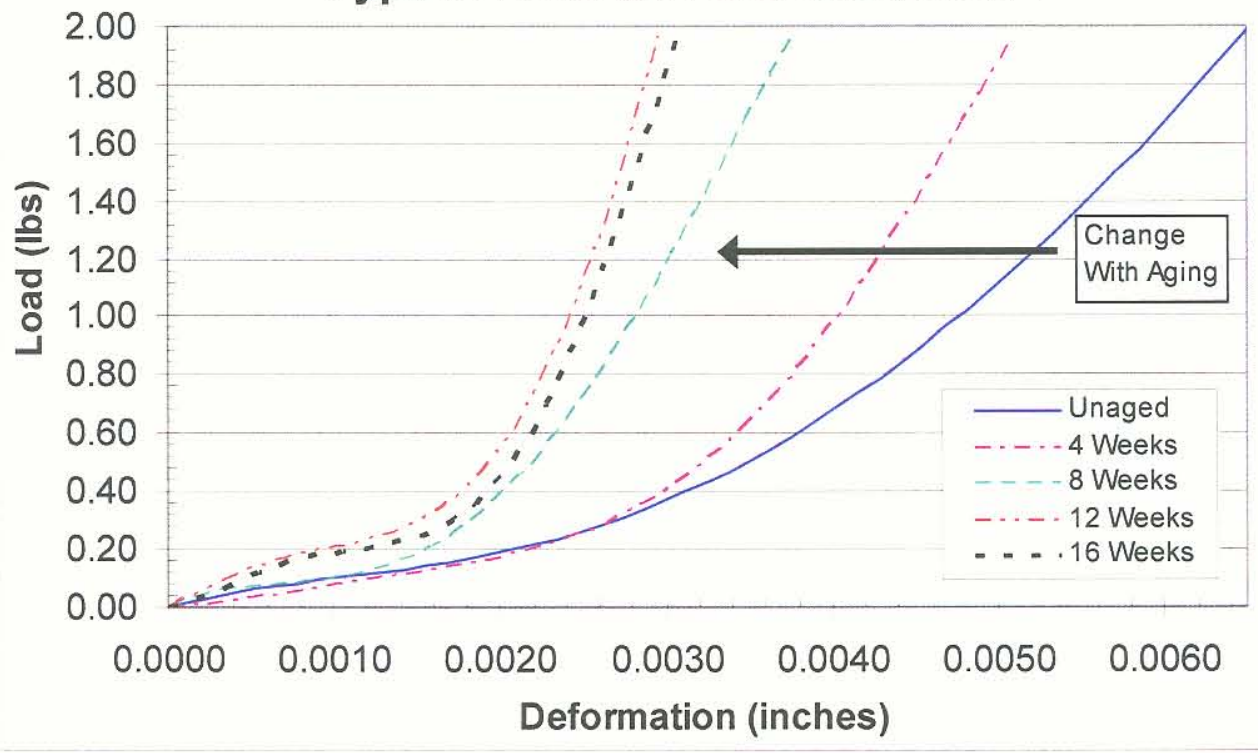

Figure 17. Curve fits of the load portion data for the indentation of 20 gage PVC wire aged at $125^{\circ} \mathrm{C}$ for the period of time indicated (a subset of aging time data shown). 
The stiffness of the aging wires is plotted against aging time. The stiffness value for the $10^{\text {th }}$ week aged wire deviates, from the trend for reasons that are unclear. As such the data corresponding to the $10^{\text {th }}$ week of ageing has been eliminated in the regression fit for the stiffness values shown in Figure 18. It is clear that the trend of increasing stiffness with aging time is established.

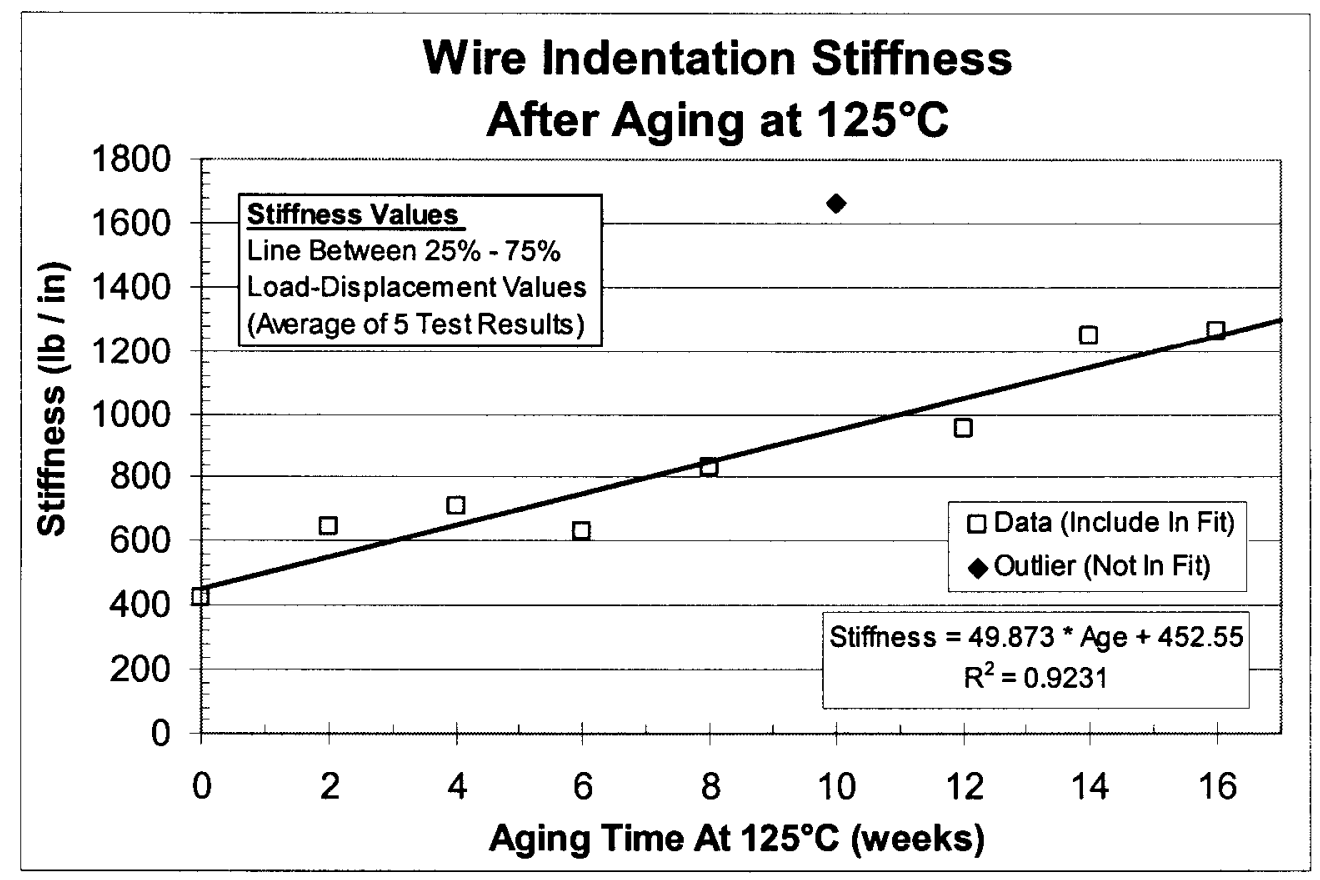

Figure 18. Stiffness $K$ obtained from the indentation of 20 gage PVC wire aged at $125^{\circ} \mathrm{C}$ for the period of time indicated (each result represents an average of 5 tests)

Normalized relaxation data is shown in

Figure 19. (again, only the curves for $0,4,8,12,16$ weeks are shown for clarity). This data shows an unusual result, with the force at the end of the 60 second hold decreasing with increasing aging time for the 0,4 and 8 week aging time specimens. However, the specimens aged 10 weeks and longer at $125^{\circ} \mathrm{C}$ exhibited much less relaxation behavior, with the force at the end of the hold being $90-95 \%$ of the value at the beginning of the indentation hold. 


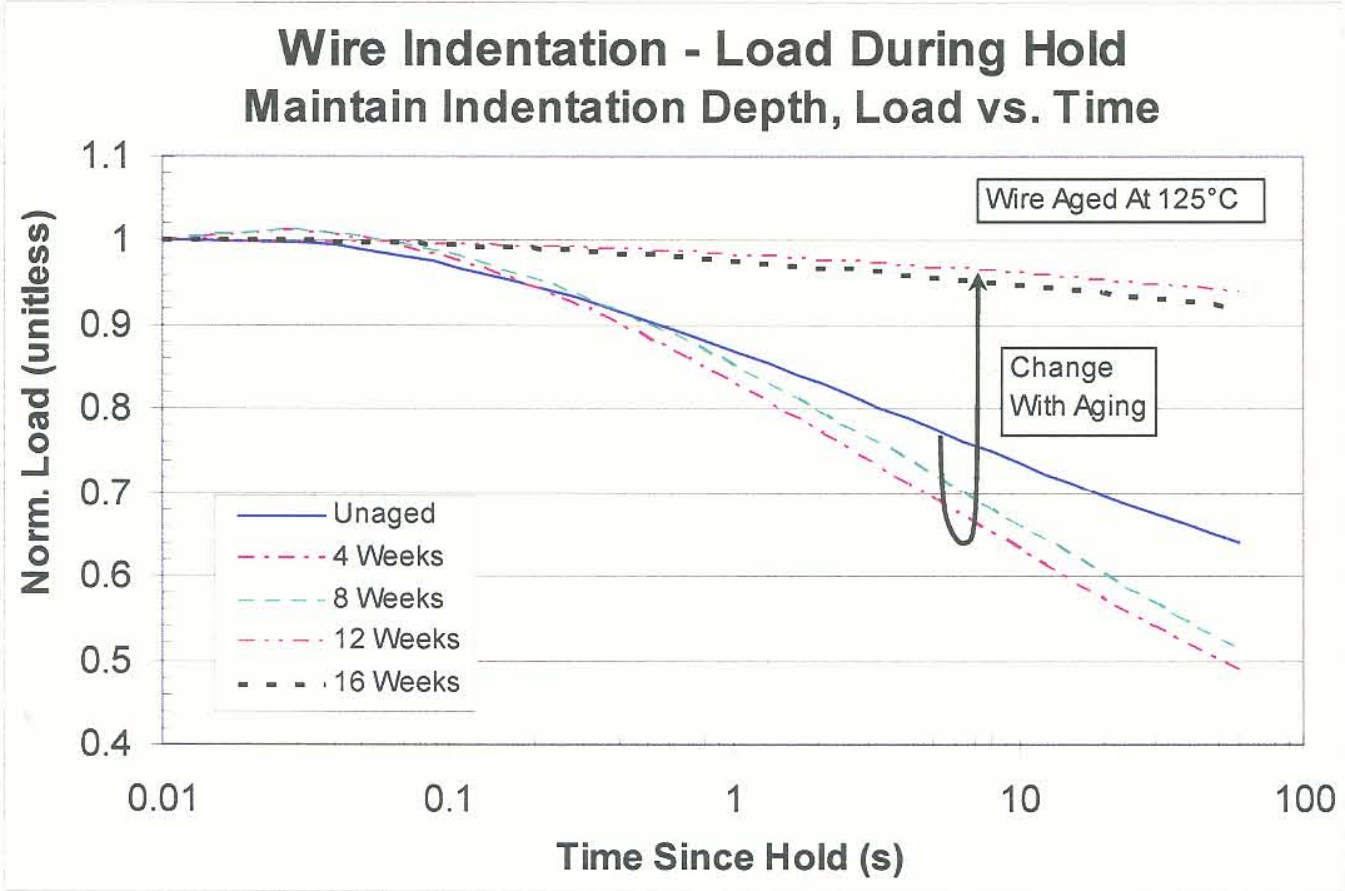

Figure 19. Cubic curve fits of the normalized hold (relaxation) data for the indentation of 20 gage $\mathrm{PVC}$ wire aged at $125^{\circ} \mathrm{C}$ for the period of time indicated (subset of aging data shown)

\begin{tabular}{|c|c|c|c|c|c|}
\hline & 0 weeks & 2 weeks & 4 weeks & 6 weeks & 8 weeks \\
\hline K (Ibs/in) & 419.7 & 647.9 & 712.5 & 632.3 & 833.5 \\
\hline$\lambda$ (lbs) & -0.84298 & -1.00051 & -1.56834 & -1.29442 & -1.41048 \\
\hline$a$ (Ibs/in) & 7.81 & -36.60 & -123.34 & -108.49 & -146.67 \\
\hline $\mathrm{b}\left(\mathrm{lbs} / \mathrm{in}^{2}\right)$ & 47390 & 110768 & 111146 & 103184 & 166691 \\
\hline$\alpha(1 / \log (\mathbf{s}))$ & 0.023328 & 0.069400 & 0.069412 & 0.073240 & 0.067354 \\
\hline$\beta\left(1 / \log (\mathbf{s})^{2}\right)$ & -0.058164 & -0.101568 & -0.101048 & -0.103029 & -0.091743 \\
\hline$\gamma\left(1 / \log (\mathbf{s})^{3}\right)$ & 0.0067614 & 0.0124675 & 0.0123668 & 0.0126365 & 0.0104640 \\
\hline
\end{tabular}

\begin{tabular}{|l|c|c|c|c|}
\hline & 10 weeks & 12 weeks & 14 weeks & 16 weeks \\
\hline $\mathbf{K}(\mathbf{l b s} / \mathrm{in})$ & 1662.1 & 950.9 & 1251.4 & 1264.4 \\
$\lambda(\mathbf{l b s})$ & -0.57551 & -1.03220 & -1.51667 & -1.65890 \\
\hline $\mathbf{a}(\mathbf{l b s} / \mathrm{in})$ & 357.58 & -83.50 & -229.94 & -261.79 \\
$\mathbf{b}\left(\mathbf{l b s} / \mathbf{i n}^{2}\right)$ & 665679 & 252864 & 380153 & 347431 \\
\hline$\alpha(1 / \log (\mathbf{s}))$ & 0.005250 & 0.001834 & 0.004054 & 0.003517 \\
$\beta\left(1 / \log (\mathbf{s})^{2}\right)$ & -0.008800 & -0.005573 & -0.007748 & -0.007485 \\
$\gamma\left(1 / \log (\mathbf{s})^{3}\right)$ & 0.0000757 & 0.0002019 & 0.0001044 & 0.0004194 \\
\hline
\end{tabular}

Table 3. Fit parameters for 20 gage PVC wire aged at $125^{\circ} \mathrm{C}$ for the period indicated (values are an average of 5 tests). 
The color of the wire changed drastically for the $10^{\text {th }}$ week and beyond (see Figure 2). There was a dramatic change in stiffness also. Analog Interfaces was contacted to determine if any changes in the aging temperature / condition may have occurred between 8 and 10 weeks that could be responsible for this finding. It turns out that the wire was aged for the first 8 weeks by The Boeing Company (Commercial Aircraft, Renton, WA) and the remaining 8 weeks were done at the FAA Technical Center. However, during the first 30 minutes in the ovens at the FAA Technical Center, the oven experienced a temperature overshoot, rising to $180-185^{\circ} \mathrm{C}$ over that period (Analog Interfaces 2004). Subsequent aging occurred at $125^{\circ} \mathrm{C}$ without incident. It is reasonable to conclude that this temperature anomaly is likely responsible for the unusual change in relaxation behavior between 8 and 10 weeks of aging; in reality, the specimens at 10+ weeks probably experienced degradation comparable to much longer aging times.

\section{$\underline{\text { PVC film aged at } 105^{\circ} \mathrm{C}}$}

The PVC films aged at $105^{\circ} \mathrm{C}$ are tested as mentioned in the earlier sections. The loads vs. displacement plots were generated and the trend of increasing stiffness with aging times is clearly visible; this is shown in Figure 20 and Figure 21 . The stiffness changes in a relatively smooth manner after aging at $105^{\circ} \mathrm{C}$, approximately doubling in 3 weeks; this is true for both the 0.008 " and 0.019 " thick films; this is shown in Figure 22 and Figure 23 for 0.008 " and 0.019 " films respectively. We expect that the value of K is proportional to the inverse of the thickness. As such we should find a ratio of the stiffness between the two films which is the ratio of thickness 0.019 " $/ 0.008$ " which is equal to 
2.375. The stiffness of the 0.019 " thick film is almost double the stiffness of the 0.008 " thick film.

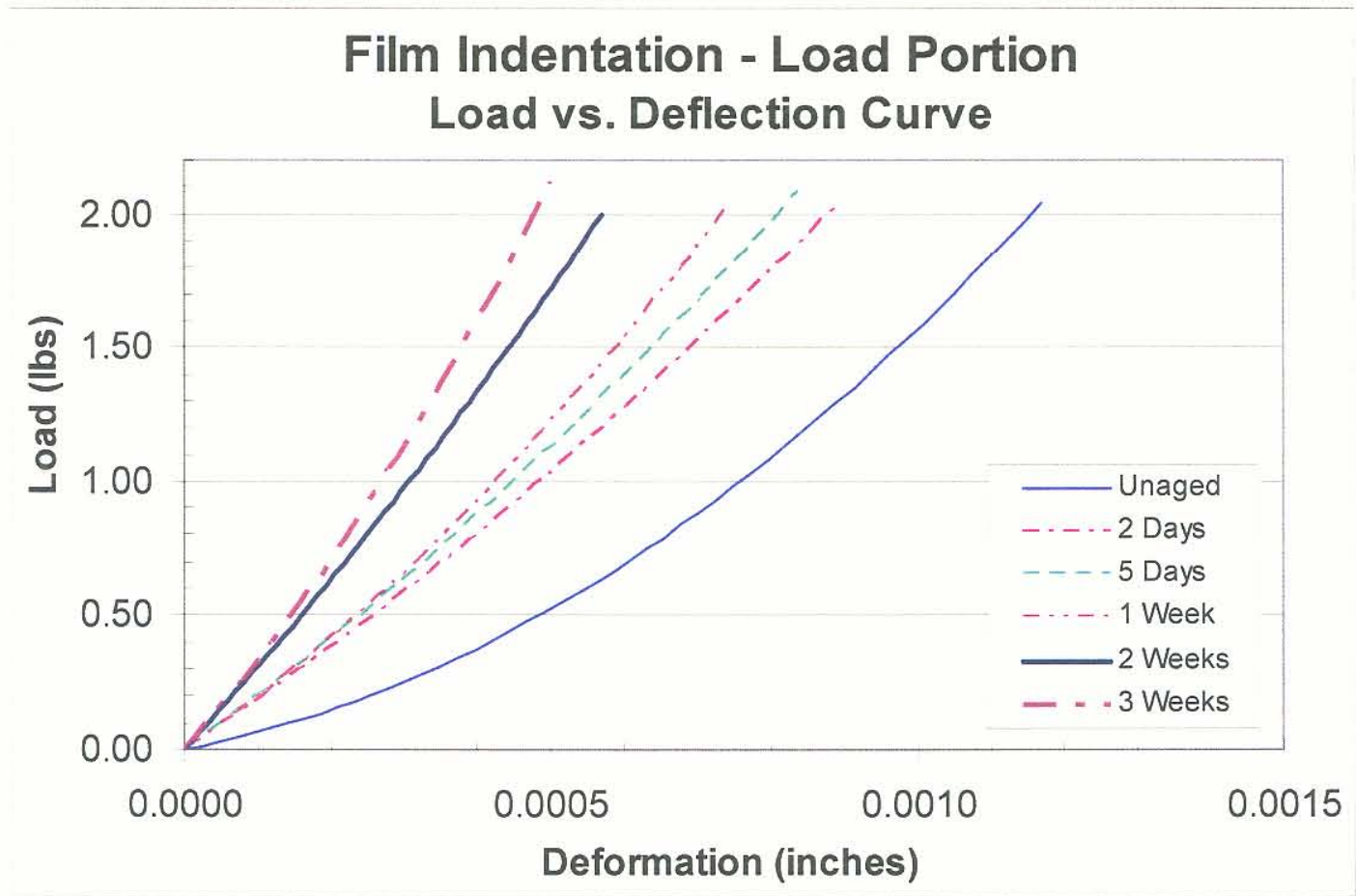

Figure 20. Parabolic curve fits of the load portion data for the indentation of $0.008^{\prime \prime}$ PVC film aged at $105^{\circ} \mathrm{C}$ for the period of time indicated 


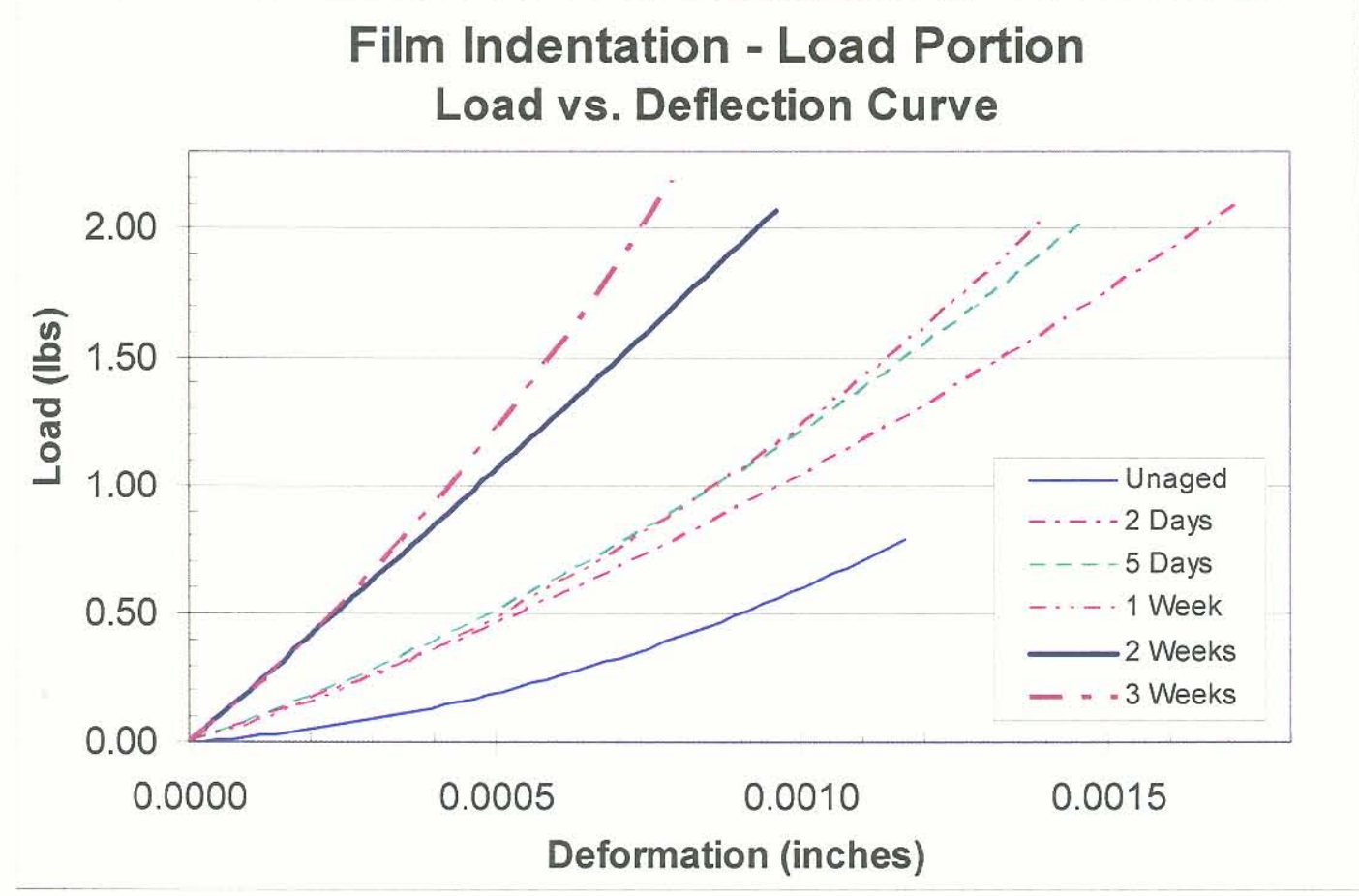

Figure 21. Parabolic curve fits of the load portion data for the indentation of 0.019 " PVC film aged at $105^{\circ} \mathrm{C}$ for the period of time indicated.

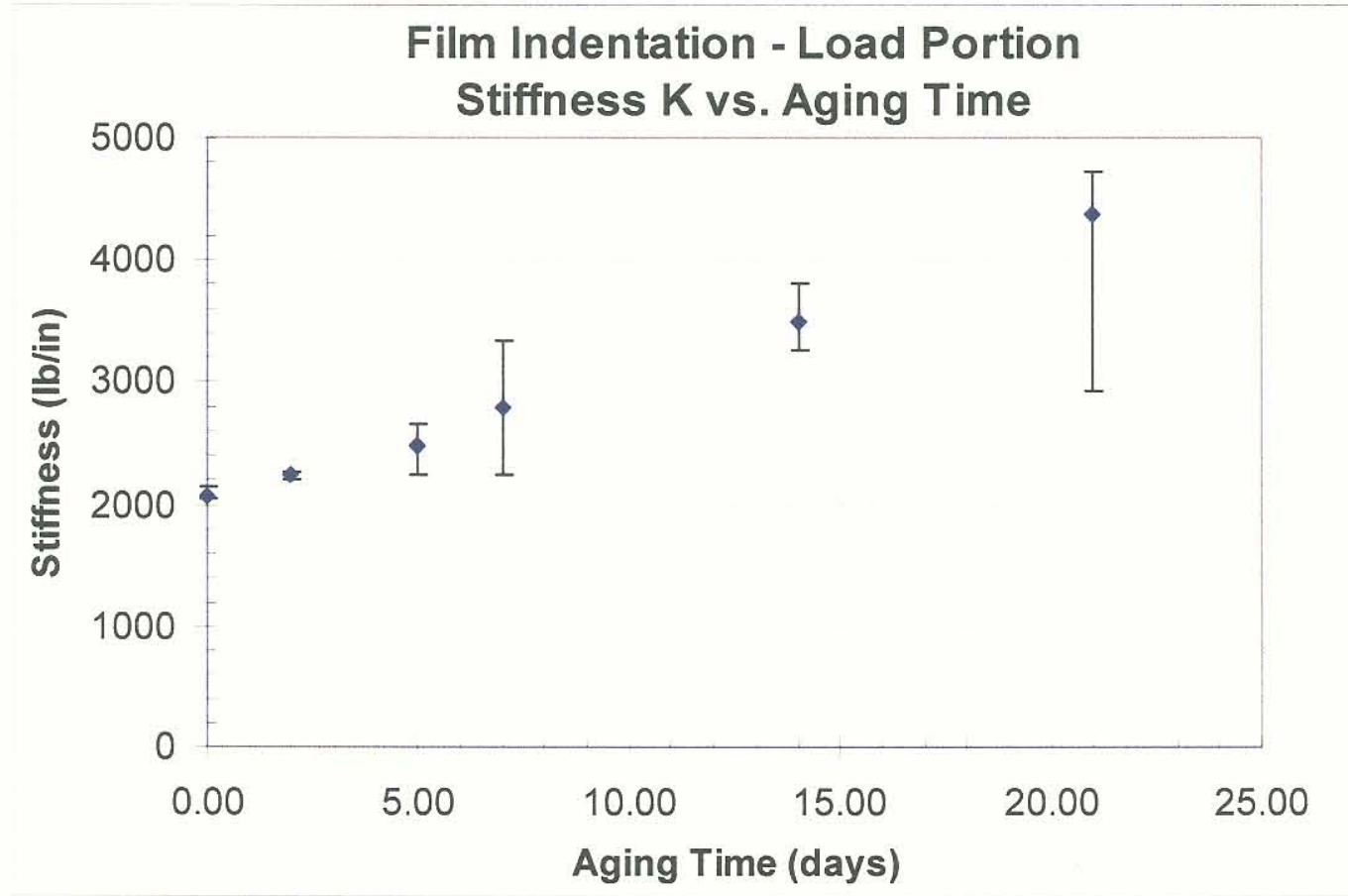

Figure 22. Stiffness $K$ obtained from the indentation of $0.008^{\prime \prime} \mathrm{PVC}$ film aged at $105^{\circ} \mathrm{C}$ for the period of time indicated (average of 5 tests, error bars shown). 


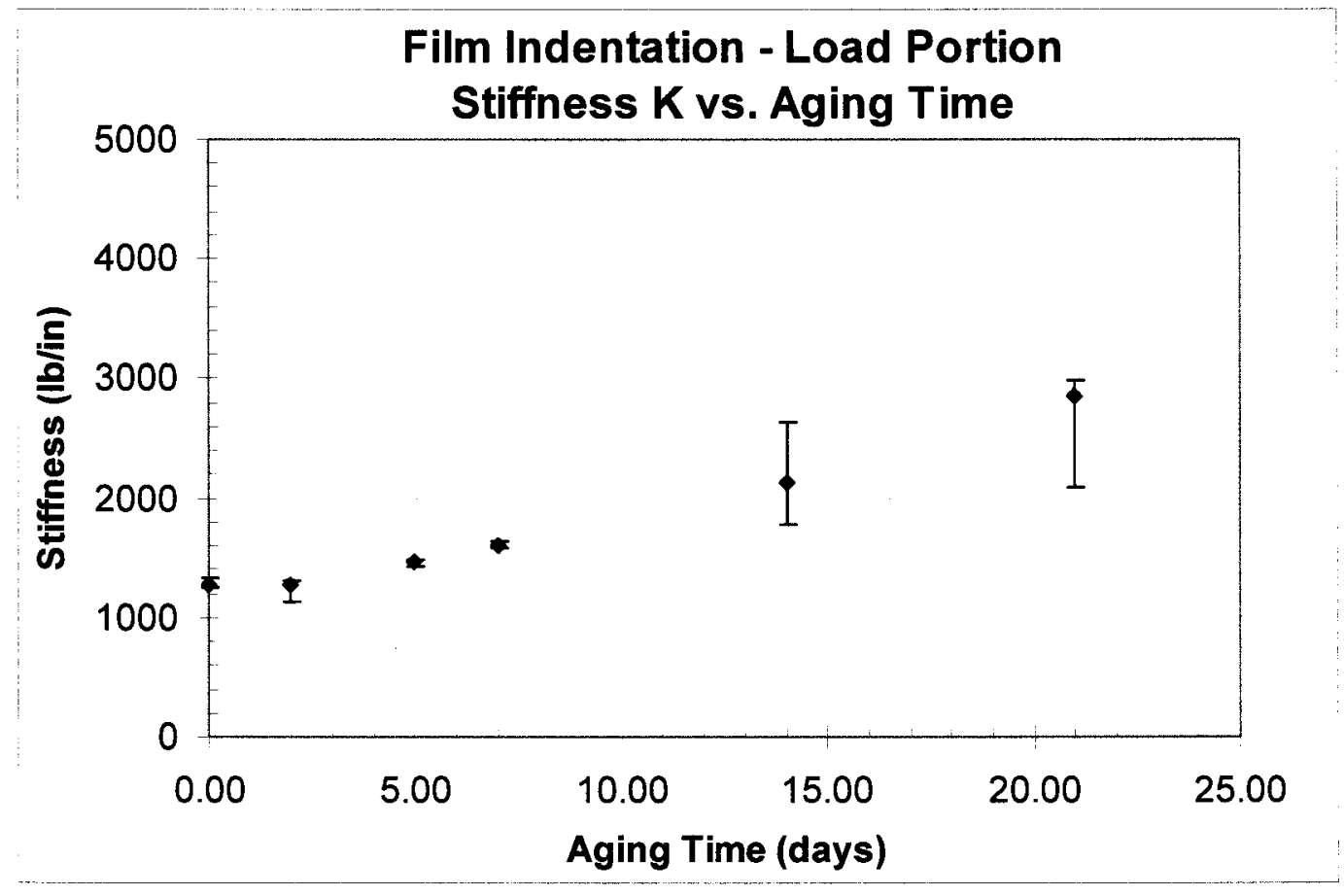

Figure 23. Stiffness $K$ obtained from the indentation of 0.019 " PVC film aged at $105^{\circ} \mathrm{C}$ for the period of time indicated (average of 5 tests, error bars shown).

The normalized relaxation plots for a single test at each aging time are shown for the 0.008 " and $0.019 "$ films in Figure 24 and Figure 25, respectively. Aging at $105^{\circ} \mathrm{C}$ leads to a gradual change in the relaxation response of the material, with the force at the end of the 60 second increasing with aging. The various fit constants (average from 5 tests) are provided for the 0.008 " and 0.019 " films in Table 4 and Table 5, respectively. The changes observed in the films after aging at $105^{\circ} \mathrm{C}$ are likely due to a loss of plasticizer in the PVC film. It could also be related to changes / degradation in the PVC polymer chains but this is believed to be a smaller effect at the temperature studied. 


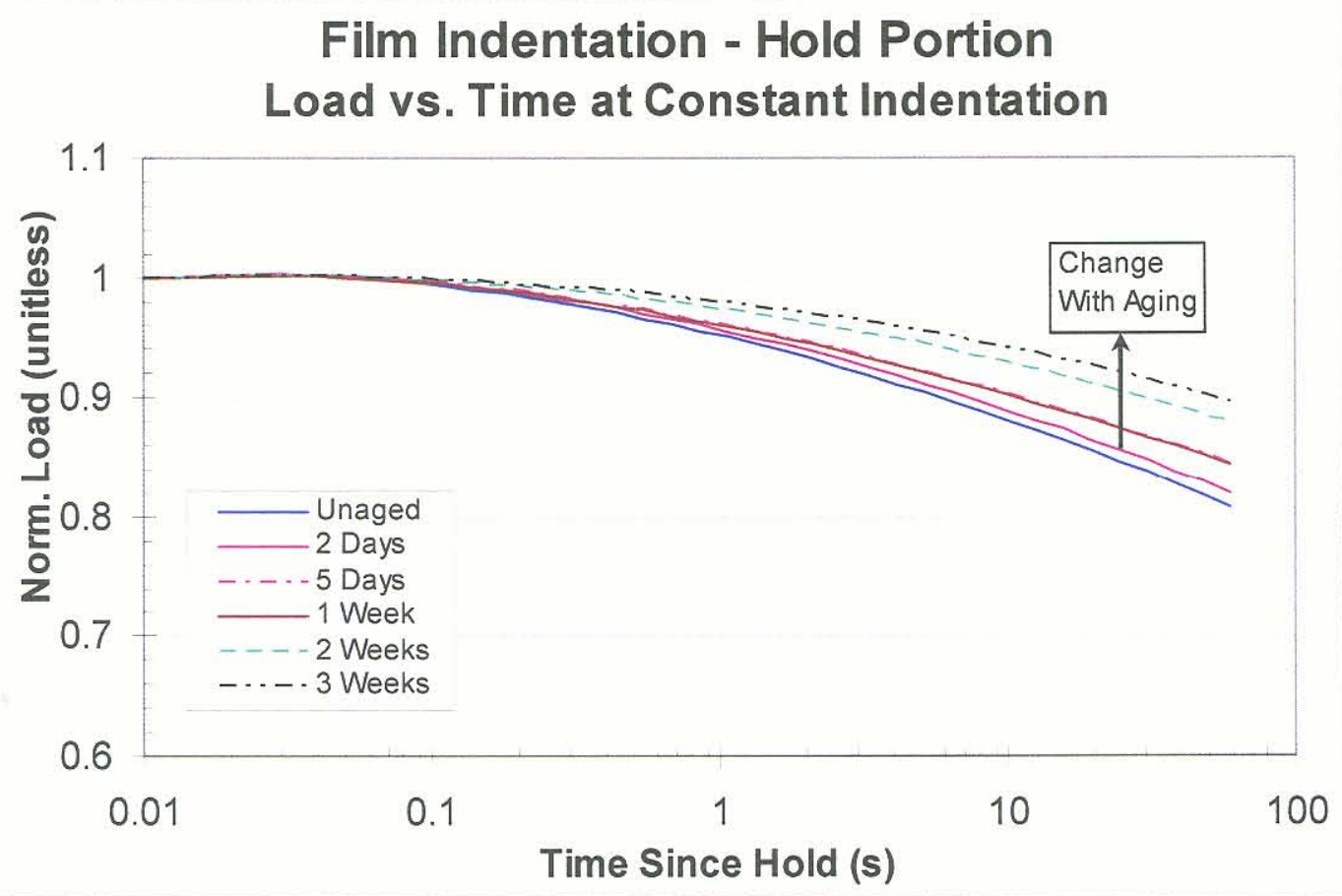

Figure 24. Cubic curve fits of the normalized hold (relaxation) data for the indentation of $0.008^{\prime}$ PVC film aged at $105^{\circ} \mathrm{C}$ for the period of time indicated.

\section{Film Indentation - Hold Portion Load vs. Time at Constant Indentation}

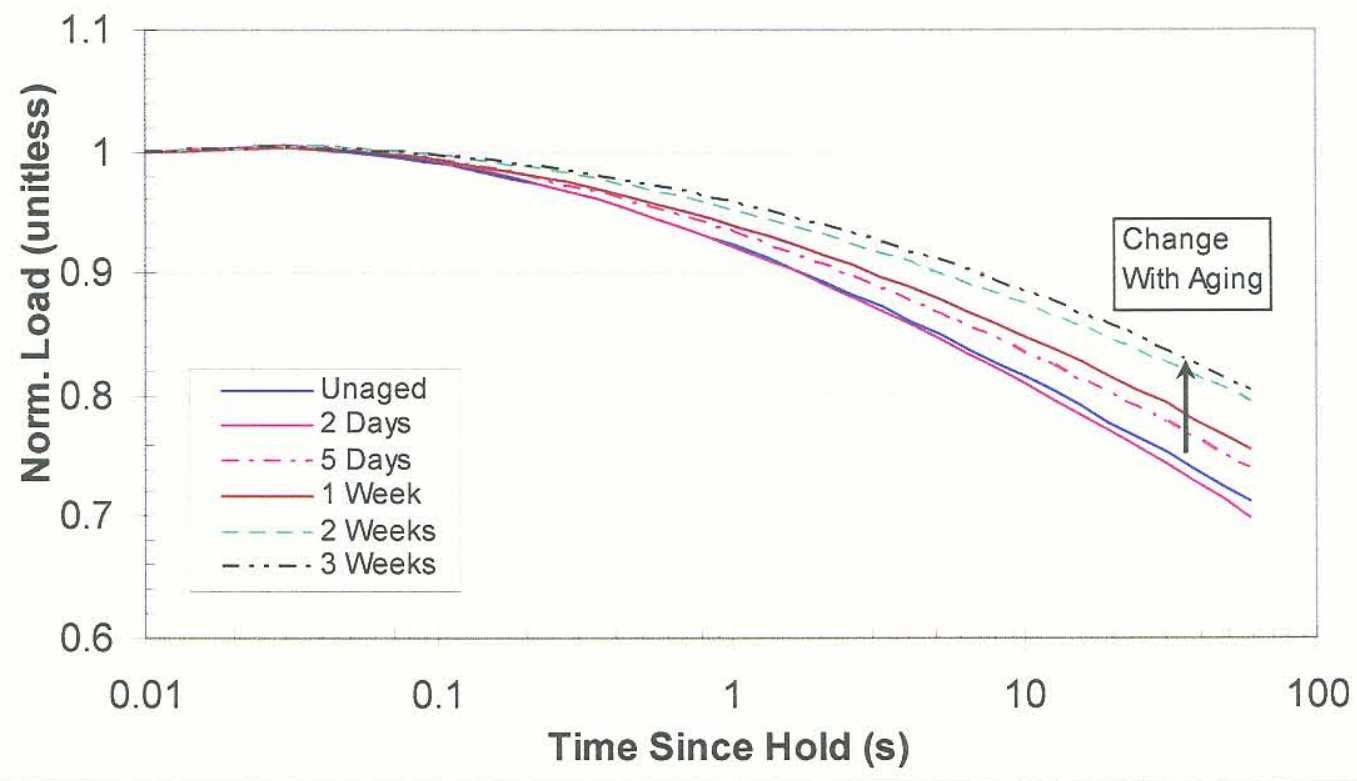

Figure 25. Cubic curve fits of the normalized hold (relaxation) data for the indentation of $0.019^{\prime \prime} \mathrm{PVC}$ film aged at $105^{\circ} \mathrm{C}$ for the period of time indicated. 


\begin{tabular}{|c|c|c|c|c|c|c|}
\hline & 0 days & 2 days & 5 days & 1 week & 2 weeks & 3 weeks \\
\hline K (lbs/in) & 2066.5 & 2225.3 & 2665.7 & 2776.5 & 3792.2 & 3668.9 \\
\hline$\lambda$ (lbs) & -0.50898 & -0.08415 & -0.02850 & -0.14043 & -0.08960 & -0.08474 \\
\hline a (lbs/in) & 521.21 & 1702.69 & 2492.89 & 1868.87 & 3157.07 & 3093.77 \\
\hline$b\left(\mid \mathrm{bs} / \mathrm{in}^{2}\right)$ & 1045901 & 591373 & 158812 & 1153593 & 965712 & 753168 \\
\hline$\alpha(1 / \log (s))$ & 0.013748 & 0.013911 & 0.005174 & 0.004793 & 0.003042 & 0.004627 \\
\hline$\beta\left(1 / \log (s)^{2}\right)$ & -0.020944 & -0.019887 & -0.006499 & -0.005586 & -0.002786 & -0.004472 \\
\hline$\gamma\left(1 / \log (s)^{3}\right)$ & 0.0010315 & 0.0009705 & -0.0031986 & -0.0028860 & -0.0028653 & -0.0025662 \\
\hline
\end{tabular}

Table 4. Fit parameters for $0.008^{\prime \prime}$ PVC film aged at $105^{\circ} \mathrm{C}$ for the period indicated (values are an average of 5 tests).

\begin{tabular}{|c|c|c|c|c|c|c|}
\hline & 0 days & 2 days & 5 days & 1 week & 2 weeks & 3 weeks \\
\hline K (lbs/in) & 1263.9 & 1245.2 & 1466.4 & 1632.5 & 2179.9 & 2915.7 \\
\hline$\lambda$ (lbs) & -0.62931 & -0.18806 & -0.19323 & -0.27219 & -0.05948 & -0.28369 \\
\hline$a$ (lbs/in) & 160.80 & 764.66 & 882.92 & 834.51 & 1845.27 & 1733.92 \\
\hline $\mathrm{b}\left(\mathrm{lbs} / \mathrm{in}^{2}\right)$ & 435029 & 249734 & 357751 & 495075 & 359547 & 1121297 \\
\hline$\alpha(1 / \log (s))$ & 0.024138 & 0.027750 & 0.012464 & 0.009081 & 0.007540 & 0.004834 \\
\hline$\beta\left(1 / \log (s)^{2}\right)$ & -0.036482 & -0.039262 & -0.015627 & -0.011345 & -0.007462 & -0.004621 \\
\hline$\gamma\left(1 / \log (s)^{3}\right)$ & 0.0026320 & 0.0027391 & -0.0038940 & -0.0042751 & -0.0043867 & -0.0032451 \\
\hline
\end{tabular}

Table 5. Fit parameters for 0.019 " $\mathrm{PVC}$ film aged at $105^{\circ} \mathrm{C}$ for the period indicated (values are an average of 5 tests).

\section{PVC film Samples aged at $125^{\circ} \mathrm{C}$}

PVC film samples with two different thicknesses (0.008" and 0.019 ") were also aged at $125^{\circ} \mathrm{C}$ for up to 3 weeks. The collection of curves presented below is identical in style to those at $105^{\circ} \mathrm{C}$ presented in the previous section. The individual loaddisplacement curves (parabolic fit of the data in accordance with Eq. 6) for various aging times are shown for the 0.008 " and 0.019" films in Figure 26 and Figure 27, respectively. It is immediately evident that these curves are quite strange: they do not occur in the anticipated order (increasing stiffness with increasing aging); several contain negative force prediction reports (physically unrealistic); and most have a maximum force value well below the experimental value of approximately $2 \mathrm{lbs}$. 


\section{Film Indentation - Load Portion \\ Load vs. Deflection Curve}

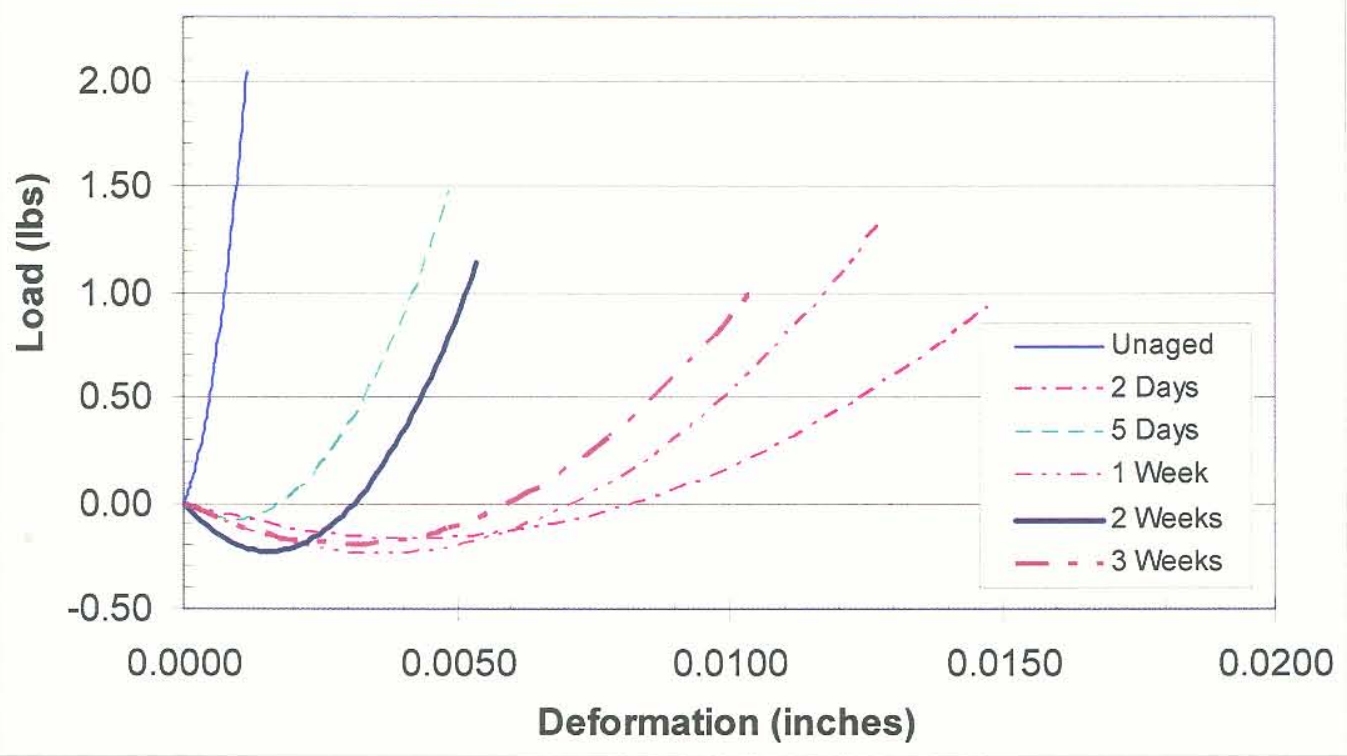

Figure 26. Parabolic curve fits of the load portion data for the indentation of 0.008 " PVC film aged at $125^{\circ} \mathrm{C}$ for the period of time indicated.

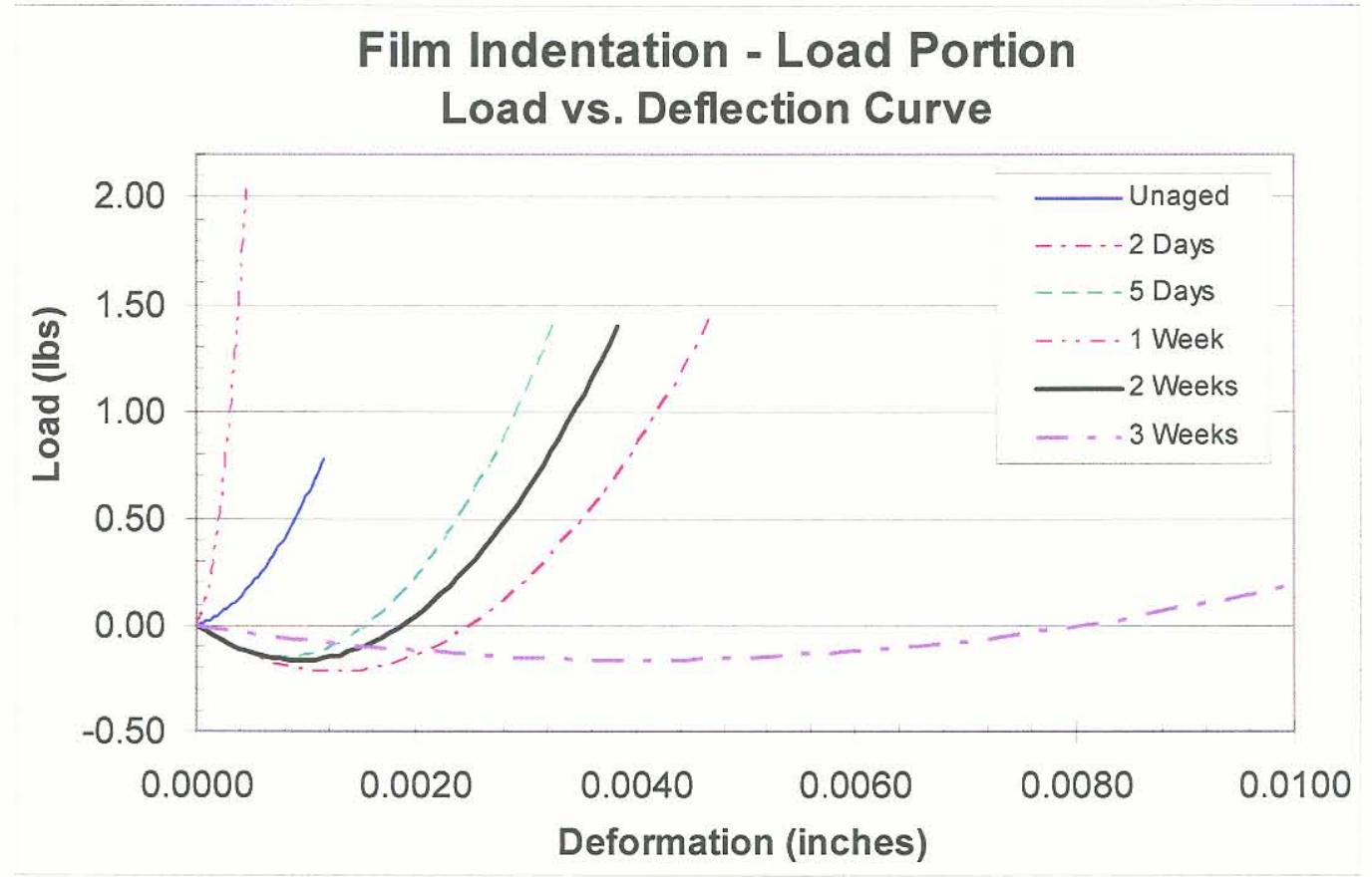

Figure 27. Parabolic curve fits of the load portion data for the indentation of 0.019 " PVC film aged at $125^{\circ} \mathrm{C}$ for the period of time indicated. 
The reason for the unusual curves above is that the load data is very poorly fit by a parabola. To demonstrate this, the experimental data used to generate the preceding plots are shown for the 0.008 " and 0.019 " films in Figure 28 and Figure 29, respectively. The response is fairly soft until a certain displacement is reached (varies from test to test); after that, the response is very stiff. This shape cannot be well captured by a parabolic fit equation; as such, the associated coefficients $(a, b)$ should not be used to approximate the experimental data. This behavior was obtained for almost all specimens aged at $125^{\circ} \mathrm{C}$. The reason for the initially soft response is unclear. One possible explanation is that slight curvature of the specimen leads to partial contact for the early part of the test followed by a very stiff response once the specimen achieves full contact with the spherical indenter and the flat support fixture supporting it. It is evident that tests on specimens with this behavior require either a more complicated fit equation or the data should be worked with directly (i.e. do not use a curve fit to represent the data). 


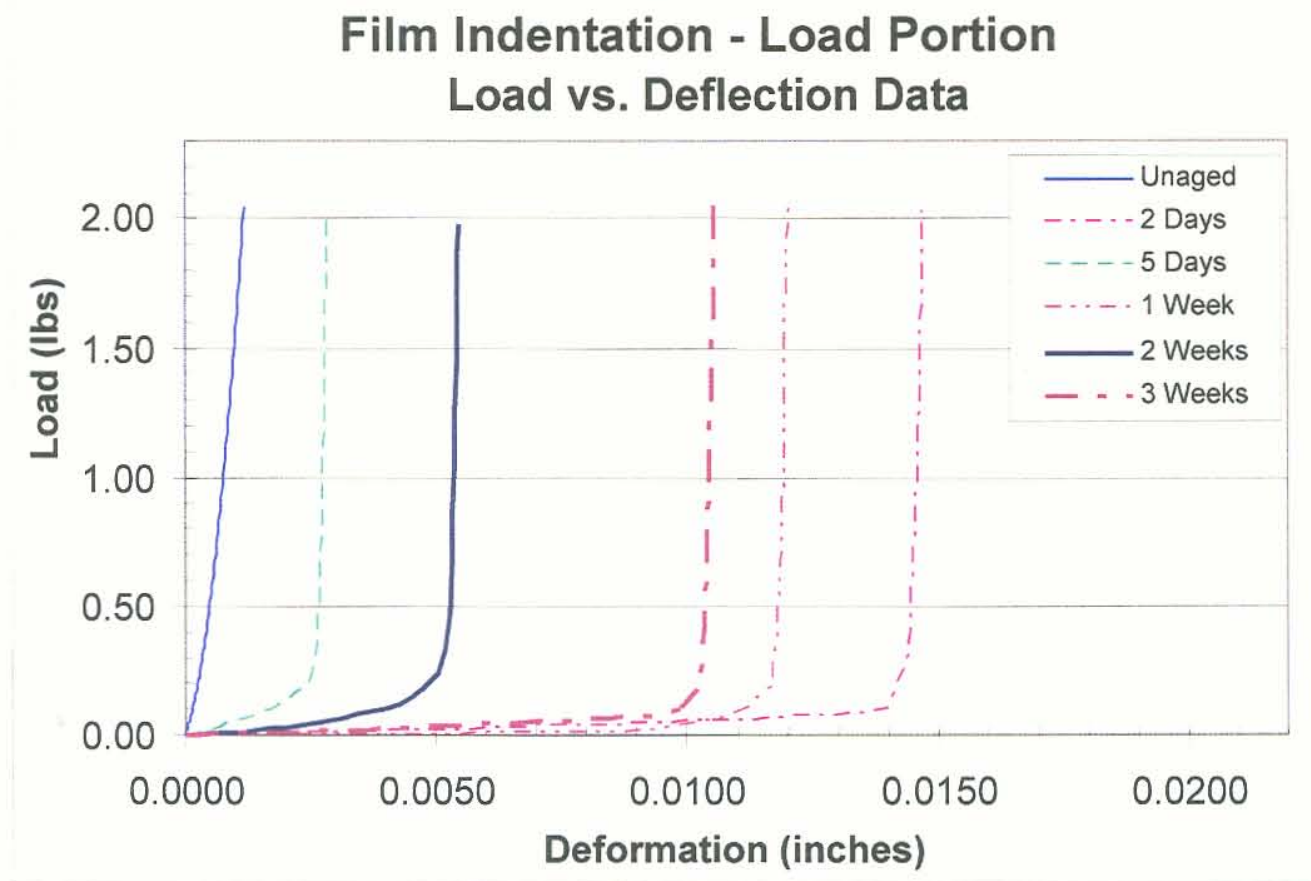

Figure 28. Load portion data for 1 indentation test on $0.008^{\prime \prime} \mathrm{PVC}$ film aged at $125^{\circ} \mathrm{C}$ for the period of time indicated

\section{Film Indentation - Load Portion Load vs. Deflection Data}

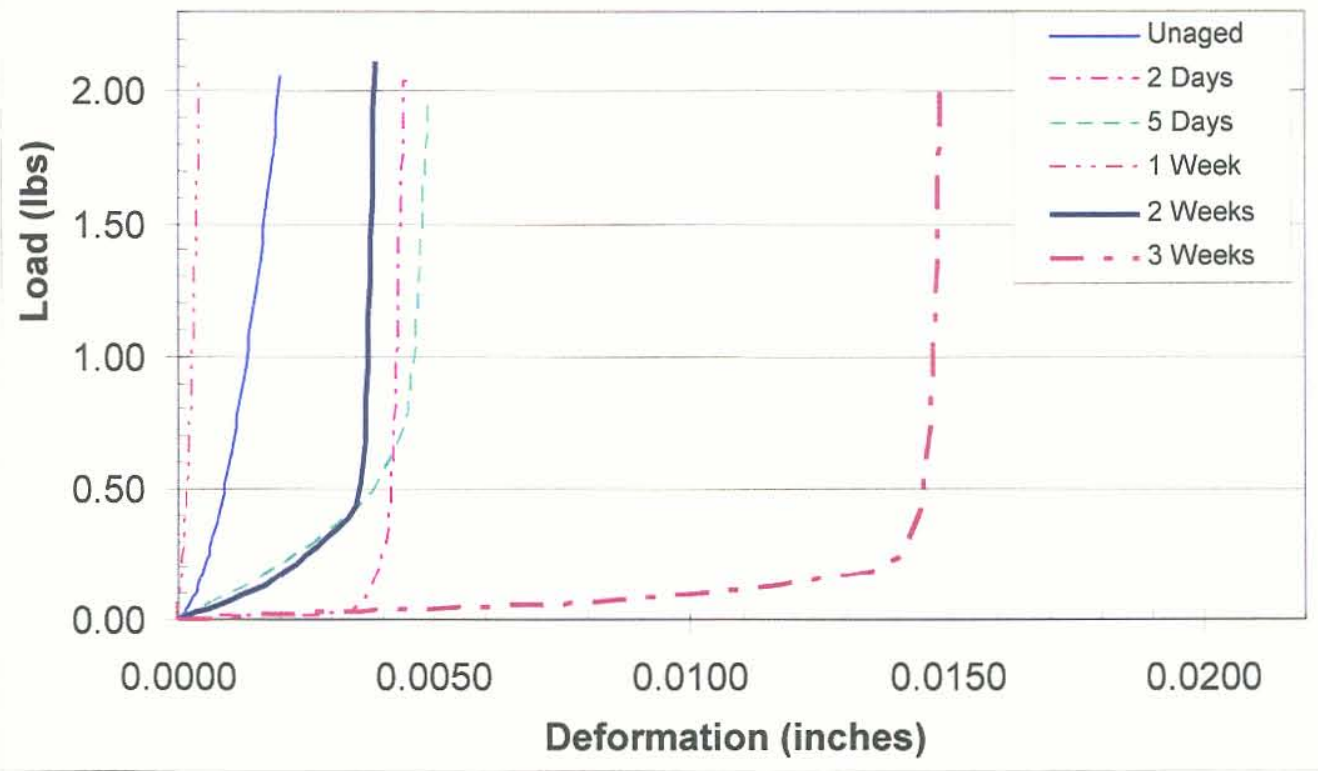

Figure 29. Load portion data for 1 indentation test on 0.019 " $\mathrm{PVC}$ film aged at $125^{\circ} \mathrm{C}$ for the period of time indicated. 
Unlike the parabolic fit (Figure 26 and Figure 27), the stiffness values $(K)$ lead to a good representation of the data in most cases. This is because the specimens generally reached the section with a much stiffer response before $0.5 \mathrm{lbs}$ is achieved (the first point of the $\mathrm{K}$ calculation, see Eq. 3). As such, the slope of the stiffness response line can be well calculated using the values from $0.5-1.5 \mathrm{lbs}(25 \%-75 \%)$. The average stiffness $K$ for the 5 tests at a given aging time is shown for the 0.008 " and 0.46 films in Figure 30 and Figure 31, respectively. As discussed previously, the stiffness of the thin film is roughly double that of the thick film (as expected). Unlike aging at $105^{\circ} \mathrm{C}$, however, the stiffness behavior changes dramatically after aging at $125^{\circ} \mathrm{C}$ for even the shortest aging time and remains approximately constant thereafter; it is likely that plasticizers are eliminated from the material very quickly at this temperature. The values of $K$ also have a great deal of variation; this is likely due to a combination of the very stiff response and variations in the response at $0.5 \mathrm{lbs}$ (i.e. whether the measurement at that moment is on the soft portion of the stiff portion or the load-displacement curve). 


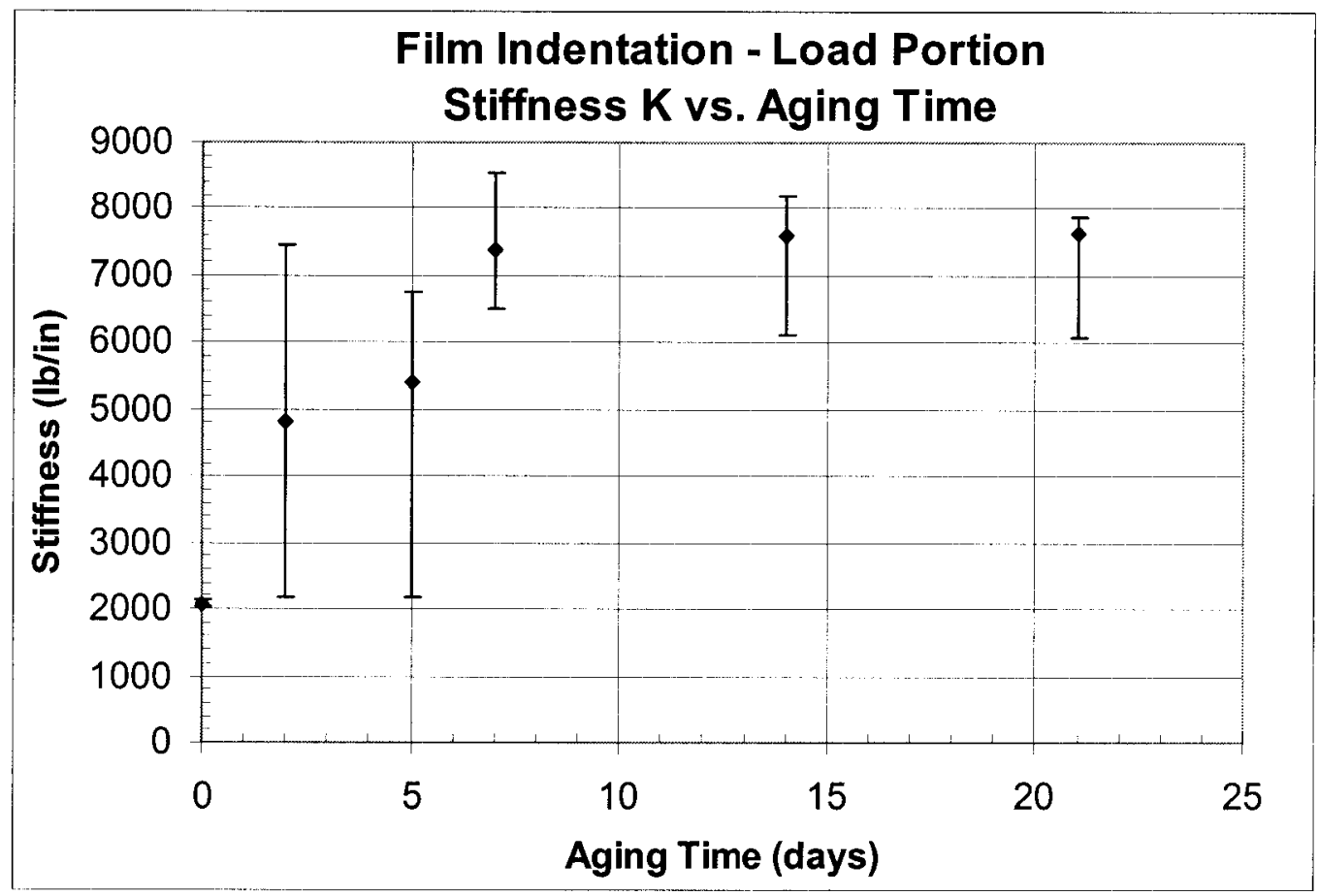

Figure 30. Stiffness $K$ obtained from the indentation of $0.008^{\prime \prime} \mathrm{PVC}$ film aged at $125^{\circ} \mathrm{C}$ for the period of time indicated (average of 5 tests, error bars shown).

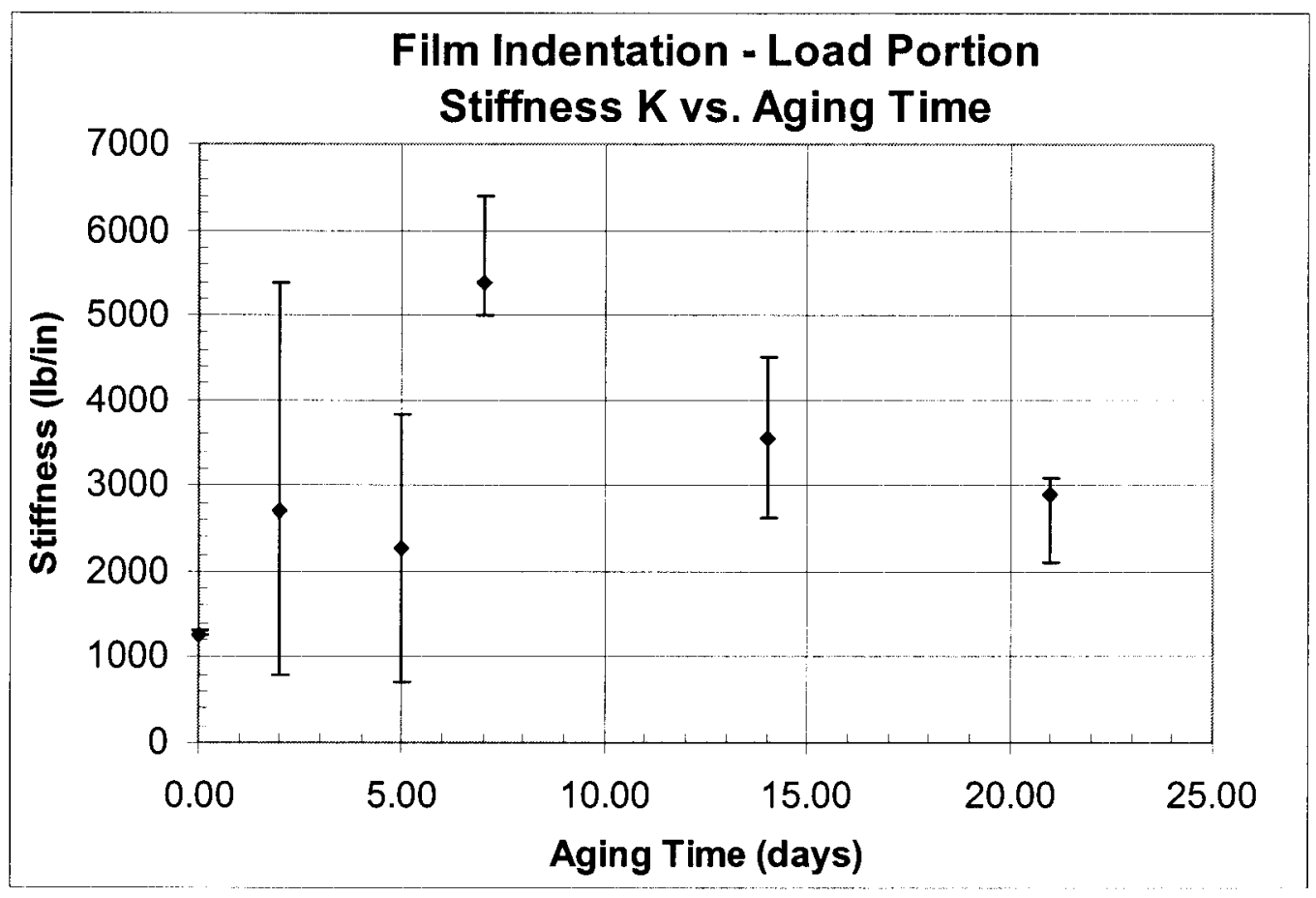

Figure 31. Stiffness $K$ obtained from the indentation of 0.019 " $\mathrm{PVC}$ film aged at $125^{\circ} \mathrm{C}$ for the period of time indicated (average of 5 tests, error bars shown). 
The normalized relaxation plots for a single test at each aging time are shown for the 0.008 " and 0.46 films in Figure 32 and Figure 33, respectively. There is virtually no relaxation after aging at $125 \mathrm{C}$ for 2 days. Given the lack of changes with additional aging (i.e. $K$ is fairly constant in Figure 30 after the first week of aging), this is further evidence that the changes are likely due to plasticizer loss rather than PVC polymer chain damage; if the latter was occurring, ongoing (degradatory) changes with aging would be expected.

The various fit constants (average from 5 tests) are provided for the 0.008 " and 0.019 " films in Table 6 and Table 7, respectively. The coefficients of the parabolic fit equation $(a, b)$ for aged specimens at $125^{\circ} \mathrm{C}$ are grayed out to indicate that the associated values lead to very poor fits of the associated test data.

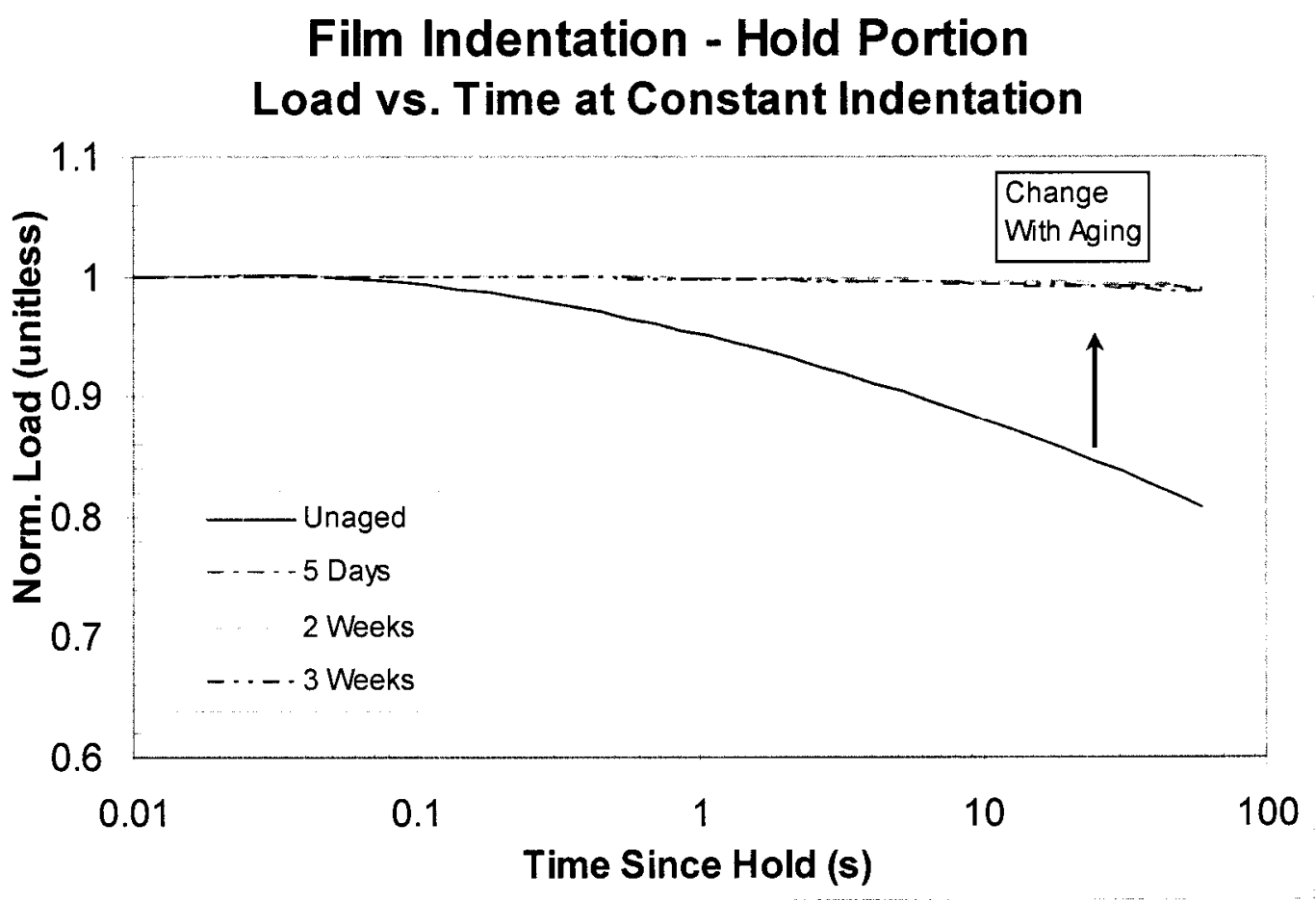

Figure 32. Cubic curve fits of the normalized hold (relaxation) data for the indentation of $0.008^{\prime \prime} \mathrm{PVC}$ film aged at $125^{\circ} \mathrm{C}$ for the period of time indicated. 


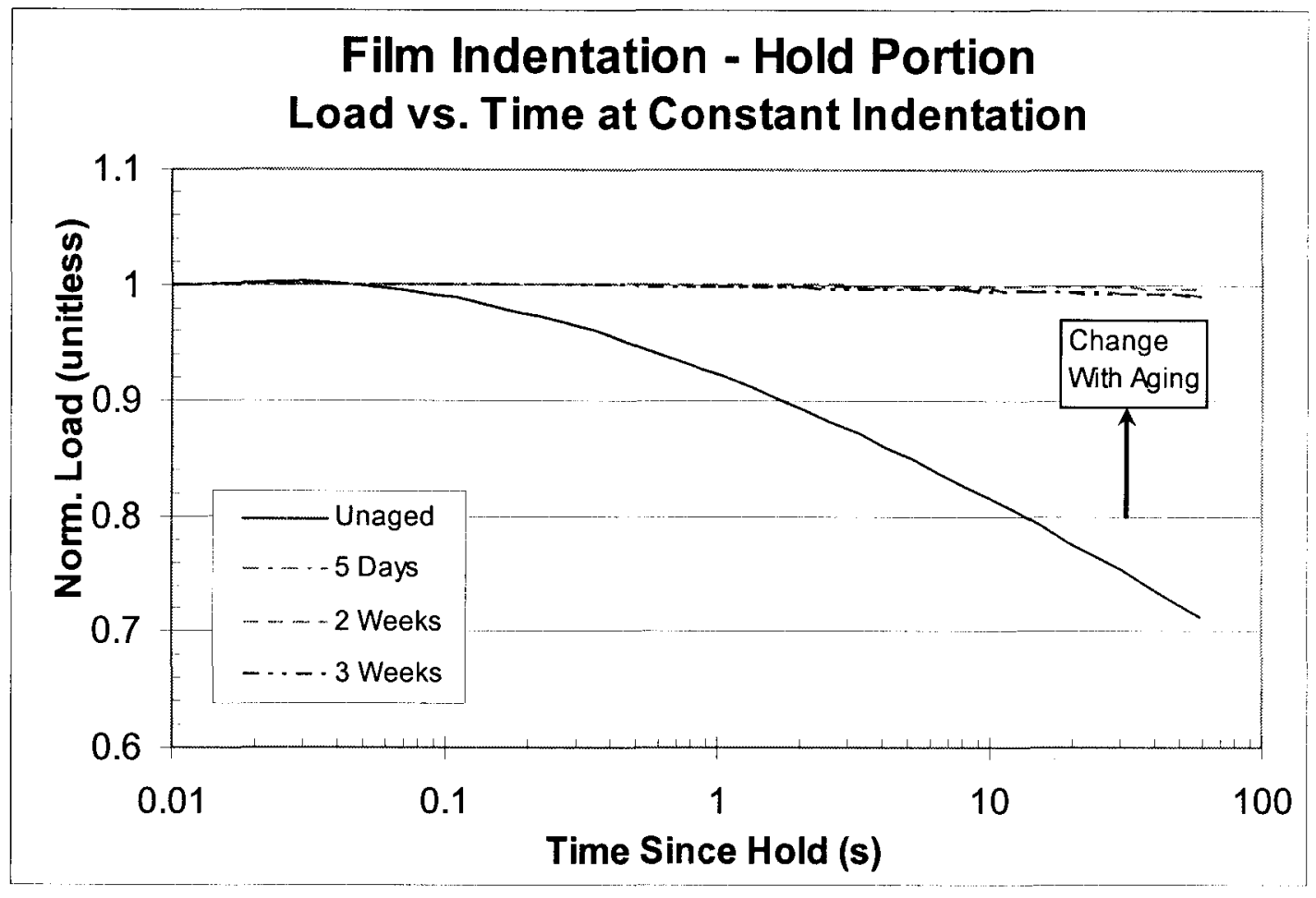

Figure 33. Cubic curve fits of the normalized hold (relaxation) data for the indentation of $0.019^{\prime \prime} \mathrm{PVC}$ film aged at $125^{\circ} \mathrm{C}$ for the period of time indicated.

\begin{tabular}{|l|cccccc|}
\hline & 0 days & 2 days & 5 days & 1 week & 2 weeks & 3 weeks \\
\hline $\mathbf{K}(\mathbf{l b s} / \mathrm{in})$ & 2066.5 & 6298.5 & 4516.4 & 6986.4 & 6112.7 & 7260.5 \\
$\lambda(\mathbf{l b s})$ & -0.50898 & -87.99133 & -12.66830 & -82.48127 & -31.68001 & -78.30393 \\
\hline $\mathbf{a}(\mathbf{I b s} / \mathrm{in})$ & 521.21 & -98.17 & -398.10 & -125.34 & -265.89 & -119.01 \\
$\mathbf{b}\left(\operatorname{lbs} / \mathbf{i n}^{2}\right)$ & 1045901 & 11850 & 244142 & 17577 & 85669 & 19210 \\
\hline$\alpha(1 / \log (\mathbf{s}))$ & 0.013748 & -0.000396 & 0.000117 & -0.000528 & -0.000241 & -0.000562 \\
$\beta\left(1 / \log (\mathbf{s})^{2}\right)$ & -0.020944 & -0.000162 & -0.000529 & -0.000010 & -0.000166 & 0.000039 \\
$\gamma\left(\mathbf{1} \log (\mathbf{s})^{3}\right)$ & 0.0010315 & -0.0001192 & -0.0000164 & -0.0001094 & -0.0000570 & -0.0001231 \\
\hline
\end{tabular}

Table 6. Fit parameters for $0.008^{\prime \prime} \mathrm{PVC}$ film aged at $125^{\circ} \mathrm{C}$ for the period indicated (values are an average of 5 tests; gray values lead to poor fits of test data.

\begin{tabular}{|l|cccccc|}
\hline & 0 days & 2 days & 5 days & 1 week & 2 weeks & 3 weeks \\
\hline K (Ibs/in) & 1263.9 & 4175.2 & 1460.1 & 5465.0 & 4120.2 & 2522.9 \\
$\lambda($ (bs) & -0.62931 & -15.16399 & -4.15707 & -1.05285 & -17.20622 & -21.45254 \\
\hline $\mathbf{a}(\mathbf{l b s} / \mathrm{in})$ & 160.80 & -574.22 & -270.43 & 126.55 & -292.19 & -192.34 \\
$\mathbf{b}\left(\operatorname{lbs} / \mathrm{in}^{2}\right)$ & 435029 & 280978 & 159350 & 7439431 & 137535 & 48809 \\
\hline$\alpha(1 / \log (\mathbf{s}))$ & 0.024138 & -0.000142 & -0.000281 & 0.000338 & -0.000224 & -0.000198 \\
$\beta\left(1 / \log (\mathbf{s})^{2}\right)$ & -0.036482 & 0.000207 & -0.000092 & -0.000432 & -0.000068 & -0.000167 \\
$\gamma\left(1 / \log (\mathbf{s})^{3}\right)$ & 0.0026320 & -0.0001117 & -0.0001918 & -0.0000256 & -0.0000589 & -0.0001061 \\
\hline
\end{tabular}

Table 7. Fit parameters for 0.019 "PVC film aged at $125^{\circ} \mathrm{C}$ for the period indicated (values are an average of 5 tests; gray values lead to poor fits of test data) 


\section{DMA Stiffness issues}

Early in this research project, notable differences in were observed between the stiffness obtained for various specimens using the DMA and the anticipated values for the specimen. It was determined that the discrepancy was likely due to inappropriate treatment of the transducer stiffness of the DMA. When the DMA has a specimen under load, both the specimen and the transducer in the DMA (which measures the load) deflect. The DMA software is supposed to separate the deformation of the transducer from the results so that the reported deflection is only that taking place in the specimen. This was apparently not the case using the software as received, however.

A great deal of time was spent consulting the manufacturer (TA Instruments) to resolve this problem. To confirm the problem, calibration tests were done using a rectangular steel shim $(0.500$ in wide $\times 0.030$ in thick $)$ under 3 point bending $(0.984$ in span); this shim is provided with the 3 point bending fixture for calibration purposes. The theoretical stiffness was computed using the beam bending equation for the deflection of a simply supported beam with a point load at the center.

$$
y=\frac{P L^{3}}{48 E I}=\frac{P L^{3}}{4 E w t^{3}}=\frac{P}{K}
$$

where $\mathrm{L}, \mathrm{w}$ and $\mathrm{t}$ are the span, width and thickness of the beam, respectively, and $\mathrm{E}$ is the modulus of elasticity (assumed to be $29 \mathrm{Msi}$ ). The measured stiffness value $\mathrm{K}$ was 500 $\mathrm{lb} /$ in compared to the theoretical value of $1680 \mathrm{lb} / \mathrm{in}$ (a difference of 70 percent). Clearly there was a problem with the results.

To correct this issue, TA Instruments incorporated changes to the Orchestrator software in version 7.0. However, certain test modes in the DMA continued to observe stiffness values that were clearly inconsistent with the known stiffness. TA Instruments 
provided a firmware update for the RSA3 in September, 2005 to resolve the remaining issues. This firmware update is only to be used for transient tests as the stiffness issue described here is already correctly treated in dynamic tests.

To validate the results obtained by the DMA, a series of tests were performed by the author and Rajeswara Reddy Resapu on the steel shim specimen and the measured stiffness values were compared with the theoretical values. An example of force versus theoretical and measured displacements is as shown in Figure 34. The slope of the theoretical and measured cases is the beam stiffness $\mathrm{K}$ in Eq. (10); clearly the values are quite similar (following an initial soft stiffness as the shim specimen became fully engaged). The measured stiffness between 2 and $6 \mathrm{lbs}$ is $1707 \mathrm{lb} / \mathrm{in}$ while the theoretical stiffness is $1680 \mathrm{lb} / \mathrm{in}$; this difference of 1.52 percent is clearly within the error limits of the experiment. These values are quite different than the $500 \mathrm{lb} / \mathrm{in}$ finding achieved with the DMA in the original configuration (also shown in Figure 34). As such, it is demonstrated that the RSA3 with Orchestrator 7.0 and appropriate firmware update is accurately measuring the stiffness of the test specimen. 


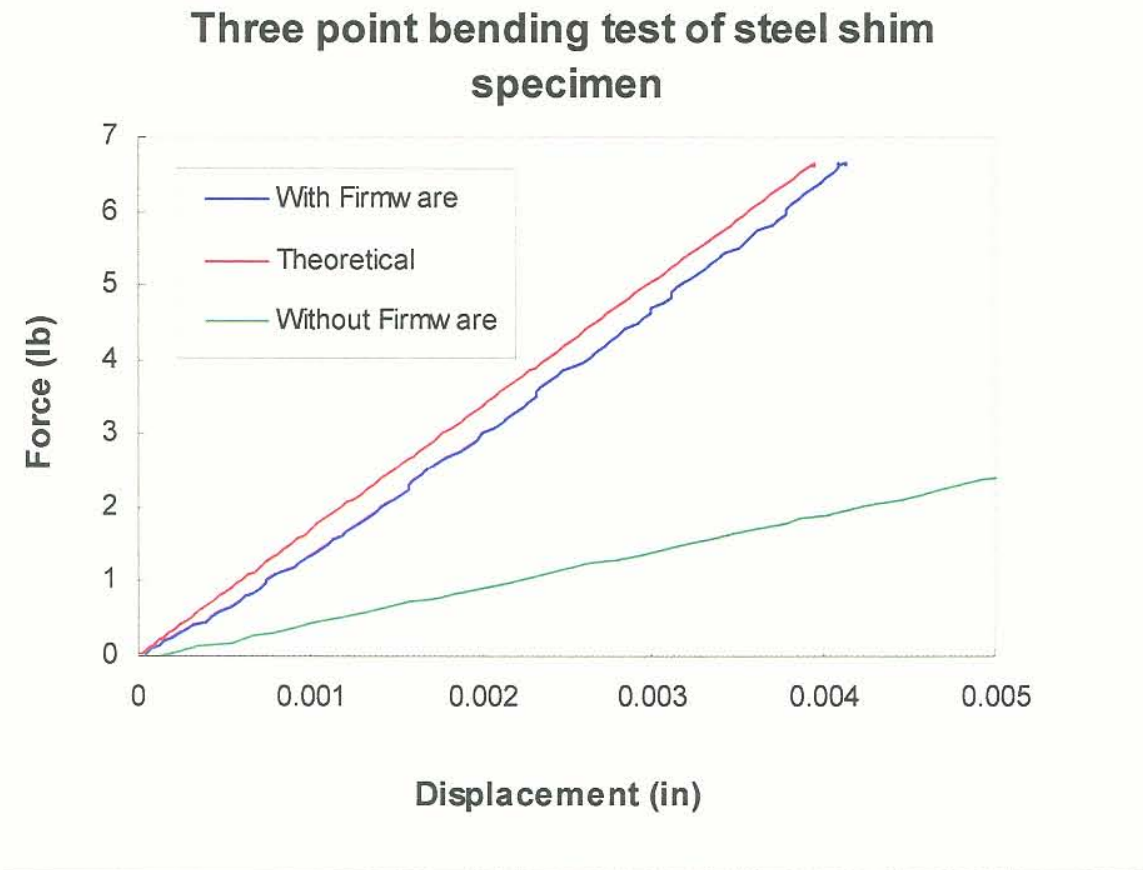

Figure 34. Force versus displacement for a steel shim in 3 point bending using two test approaches (with firmware, without firmware) compared to theoretical prediction.

During the relaxation phase of the indentation tests, the test protocol calls for the displacement to be maintained constant. Again early in the research project, it was noted that the displacement did not remain constant at the commanded value but instead changed slightly with time. Essentially, the total machine displacement (the combined deformation from the transducer stiffness and the specimen stiffness) was being held constant. Thus, as specimen relaxed, the DMA moved the indenter to keep this deformation sum at a constant value. This issue was also resolved by installing the new Orchestration 7.0 software and firmware update provided by TA Instruments. The displacement was maintained constant at the commanded value during the relaxation phase following the firmware installation. 


\section{CONCLUSION}

Pristine and aged PVC wire and film specimens were indented to study the force and relaxation response. Data obtained by the DMA was analyzed using an Excel sheet that was written to determine the associated parameters. The load phase response and the relaxation phase response are considered separately. A table of parameters was generated for every trial. The summary of all the tests are plotted on a single graph to establish the findings for a given specimen. These were then compared to consider the effect of aging on the material response.

The results presented above give a clear indication that the stiffness of the polymer insulation of aircraft wire and polymer films change with aging for the specimens considered. Furthermore, the temperature at which the specimens were aged also affected the stiffness; specifically the stiffness increases with an increase in temperature and aging time. Based upon previous work, the stiffness increase can be further correlated to the degradation in polymers and wire insulation material. This concept, and the associated family of curves generated to analyze test data, can be used as a measure of degradation. The ultimate goal of such a method is to provide an approach that can be used to assess the state of degradation of aircraft wire in the field. While further testing and development are necessary to achieve this goal, the results of this thesis are promising in this regard. 
While performing tests using the DMA, certain issues related to inherent stiffness of the instrument had to be resolved. The stiffness values obtained from the DMA included the system stiffness, which had to be separated out to accurately characterize the material response. A system firmware was installed to overcome this issue. Tests were conducted later and compared to the theoretical stiffness values. 


\section{REFERENCES}

Analog Interfaces, I. (2004). Report on temperature overshoot in the oven during the 10th week of wire aging, personal communication between R.D. Bradshaw and B. Denny on: 1 .

Anastasi, R. F. and E. I. Madaras (2005). "Application of ultrasonic guided waves for aging wire insulation assessment." American Society for Nondestructive Testing, Columbus v 63(n 2): p 143-147.

Balta Calleja, F. J. and S. Fakirov (2000). Microhardness of Polymers. Cambridge, UK, Cambridge University Press.

Bradshaw, R. D., K. B. Nagendran, et al. (2005). Aging of Polymeric Insulation in Aircraft Wiring: Mechanical and Electrical Property Characterization and Correlation, a report to FAATC, Atlantic City, NJ.

Brinson, L. C., R. D. Bradshaw, et al. (2004). Aging of Polymeric Insulation in Aircraft Wiring: Mechanical and Electrical Property Characterization and Correlation, report submitted to FAATC, Atlantic City, NJ.

Denny, B. (2004). Material Testing Research and Indenter Equipment Modifications for determining Aging of Wires (Cables) in Aircraft (Report Number DOT/FAA/AR04/17). FAATC, Atlantic City, NJ.

FAA (1998). Aging Transport Nonstructural Systems Plan., Federal Aviation Administration: $\mathrm{p} 55$.

Johnson, K. L. (1985). Contact Mechanics. Cambridge, UK, Cambridge University Press.

Leob, B. (1999). Testimony, Director, Office of Aviation Safety, National

Transportation Safety Board, in Subcommittee on Oversight, Investigations, and Emergency Management Committee. Washington D. C.

TA Instruments (2003). RSA III, Rheometric Series User Manual. New Castle, DE, TA Instruments-Waters LLC.

Teal, C. and C. Saterlee (2000). Managed aircraft wiring health directly relates to improved avionics performance. 19th Digital Avionics Systems Conference (DASC), Philadelphia, PA, USA, Institute of Electrical and Electronics Engineers Inc., Piscataway, NJ, USA. 


\begin{abstract}
APPENDIX
Contained within this appendix is full documentation of each specimen test. The curves are generated for the individual aging time (which is a collection of five trials on one single specimen). The curves for the aged wires as well as the films (of two different thicknesses and at two different temperatures) are shown. The tables corresponding to the curves giving the various parameters $(K, \alpha, \beta)$ etc for the five trials, the average and the $\mathrm{CV}$ are also shown next to the set of curves.
\end{abstract}

For each temperature and aging time, two load-displacement plots are provided: 1) the actual test data and 2) the parabolic curve fits obtained in accordance with Eq. 6 . For the $105^{\circ} \mathrm{C}$ data, these will be virtually identical. However, for $125^{\circ} \mathrm{C}$ data there will be clear differences as the data is not well fit by a parabola (indeed, higher order polynomials do not do a good job in general for this data). In these cases, the stiffness $K$ is in fairly good agreement with the data as it is calculated using data from approximately 0.50 and $1.50 \mathrm{lbs}$; these points usually lie on a reasonably straight section of the loaddisplacement curve. The relaxation data is presented in separate sections. In this case, the cubic fit of the data is shown. 


\section{Gage PVC Wire Aged At $125^{\circ} \mathrm{C}$}

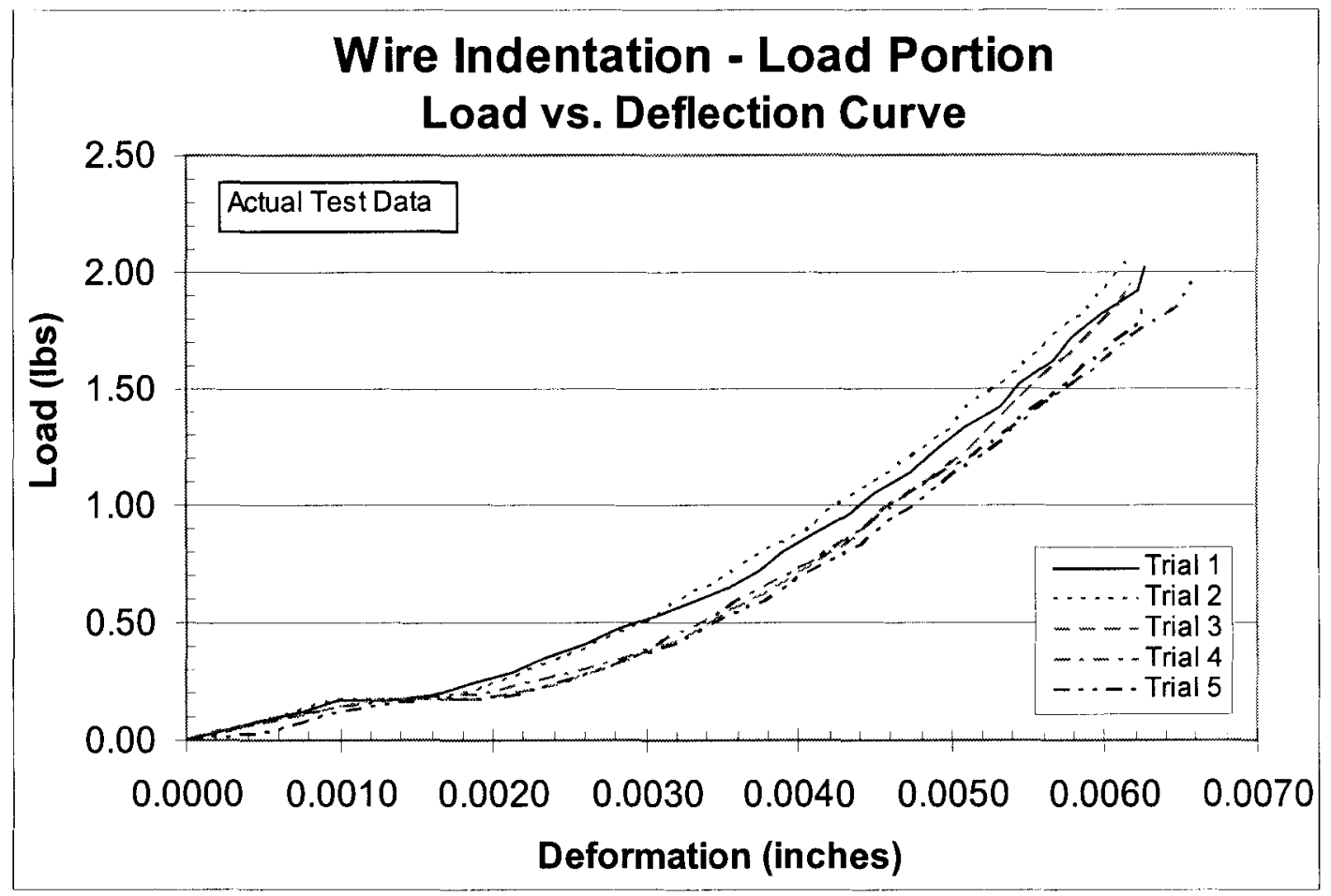

Figure 35. Load-displacement data for unaged 20 gage PVC wire 


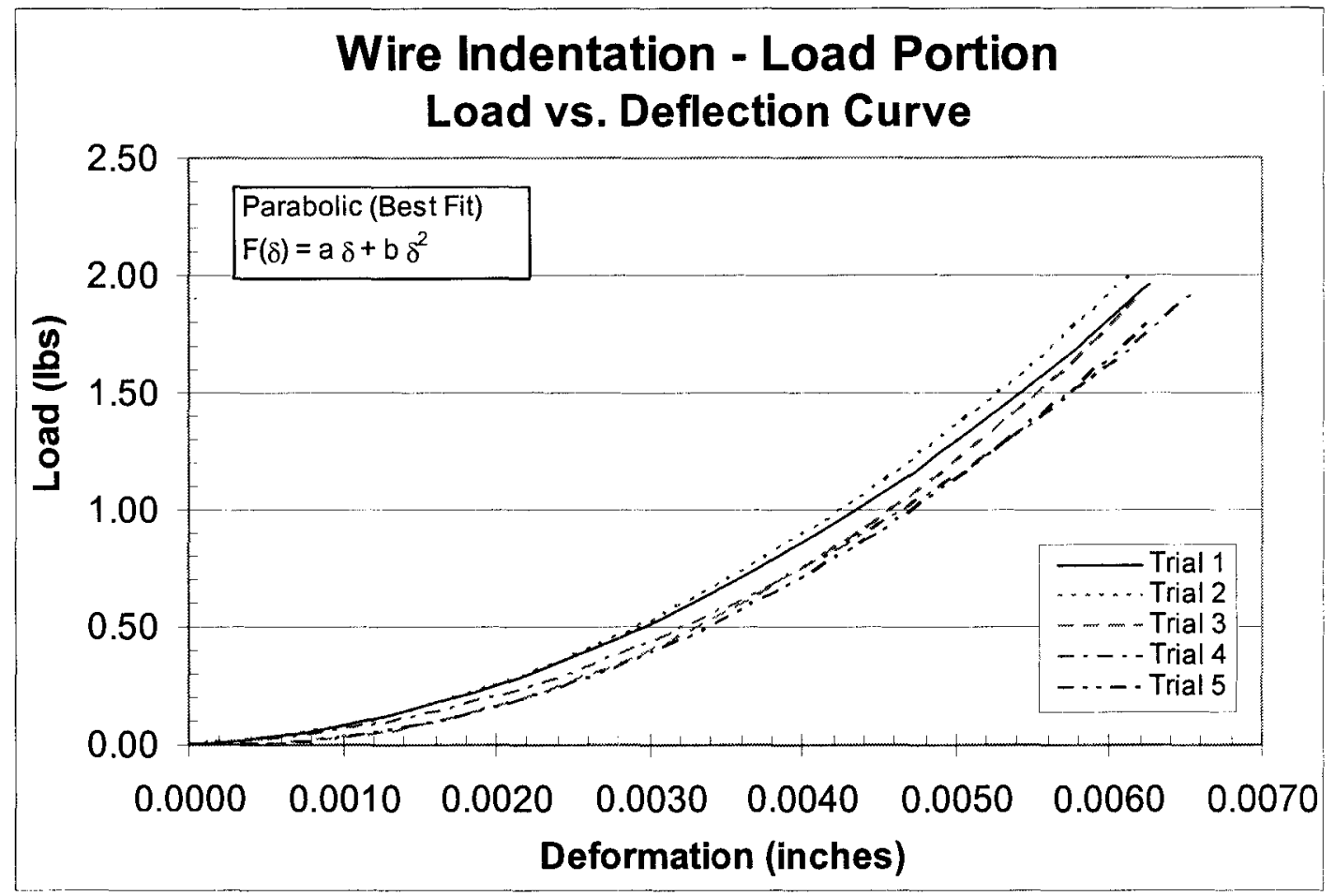

Figure 36. Load-displacement fits for unaged 20 gage PVC wire

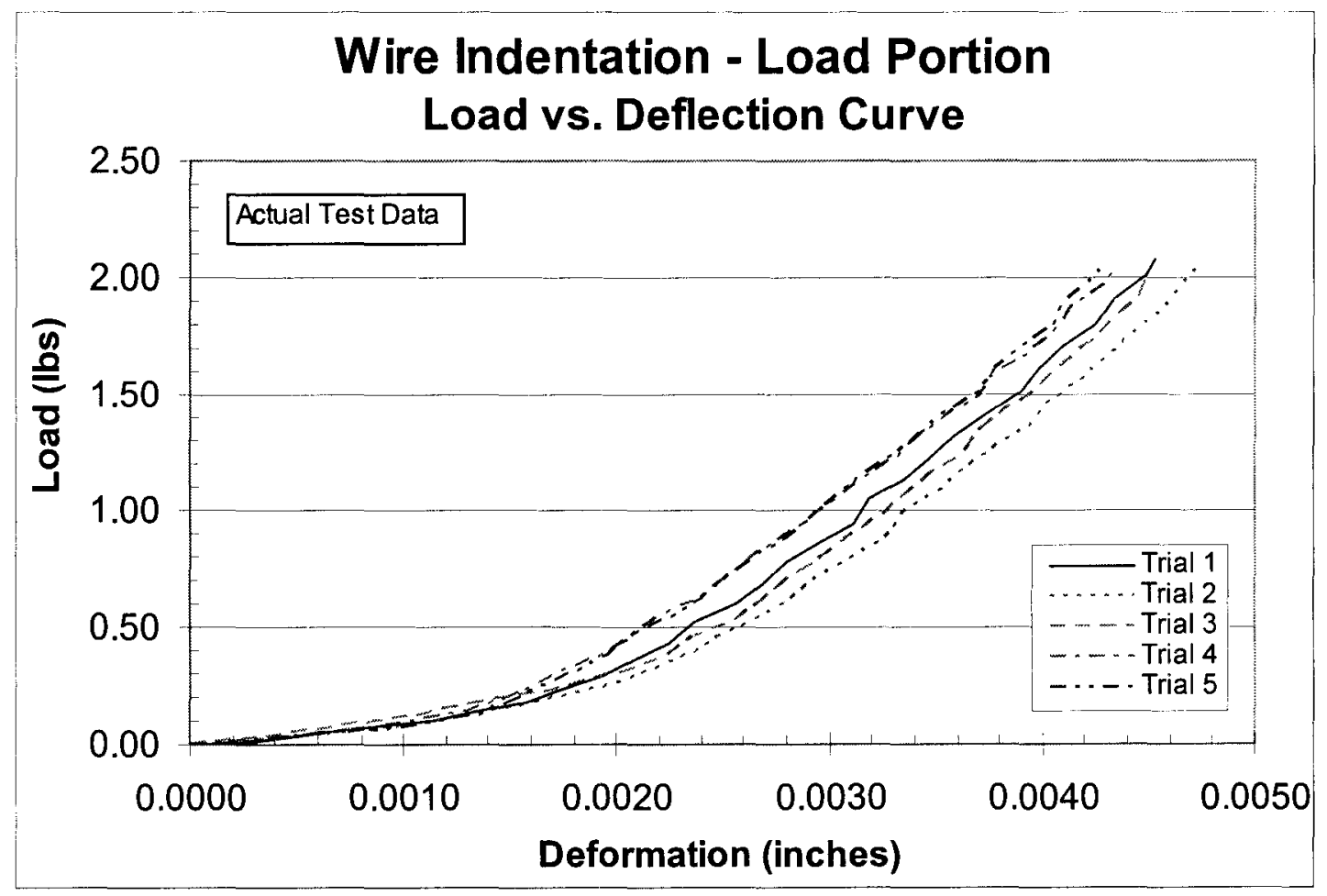

Figure 37. Load-displacement data for 20 gage PVC wire aged for 2 weeks at $125^{\circ} \mathrm{C}$ 


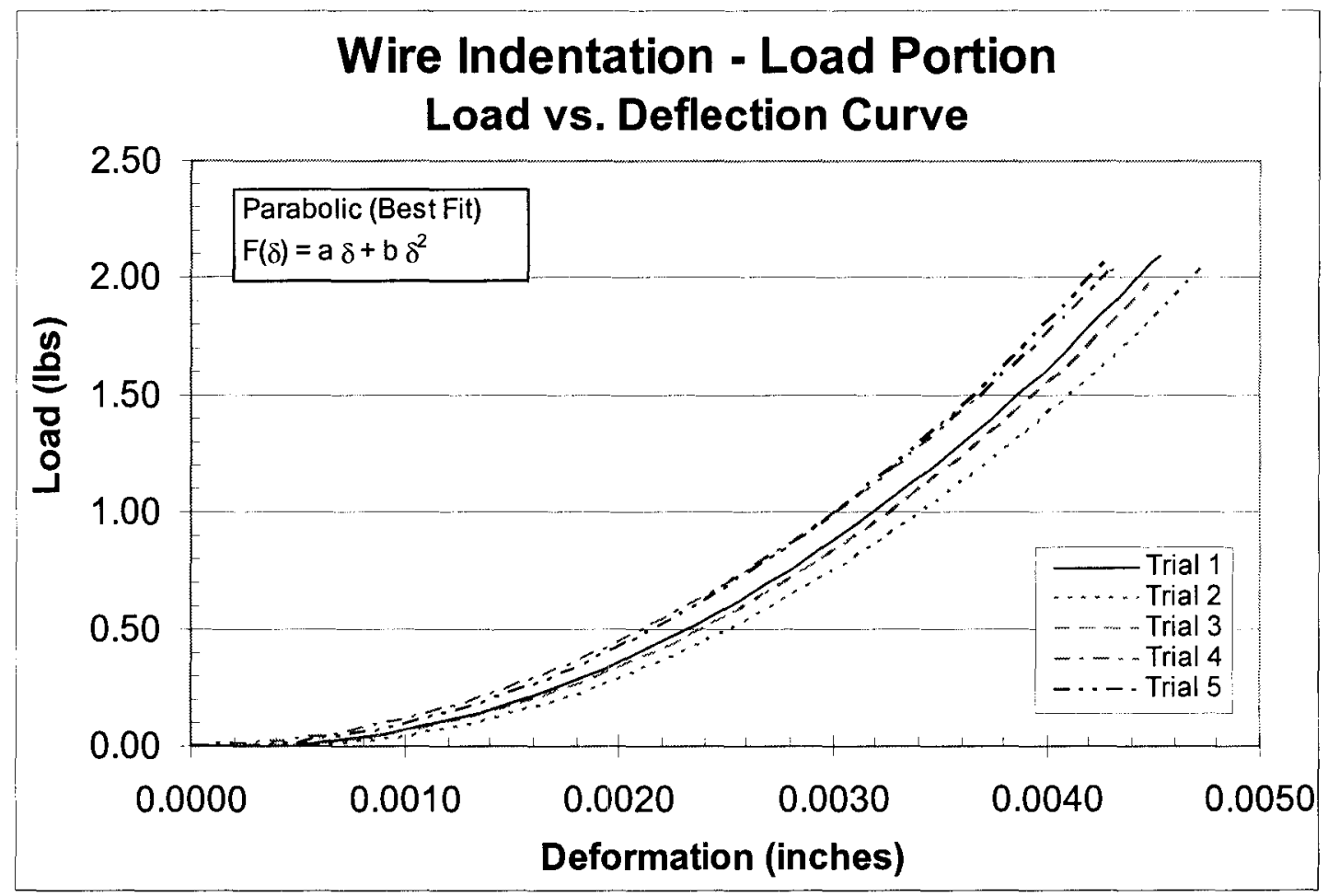

Figure 38. Load-displacement fits for 20 gage PVC wire aged for 2 weeks at $125^{\circ} \mathrm{C}$

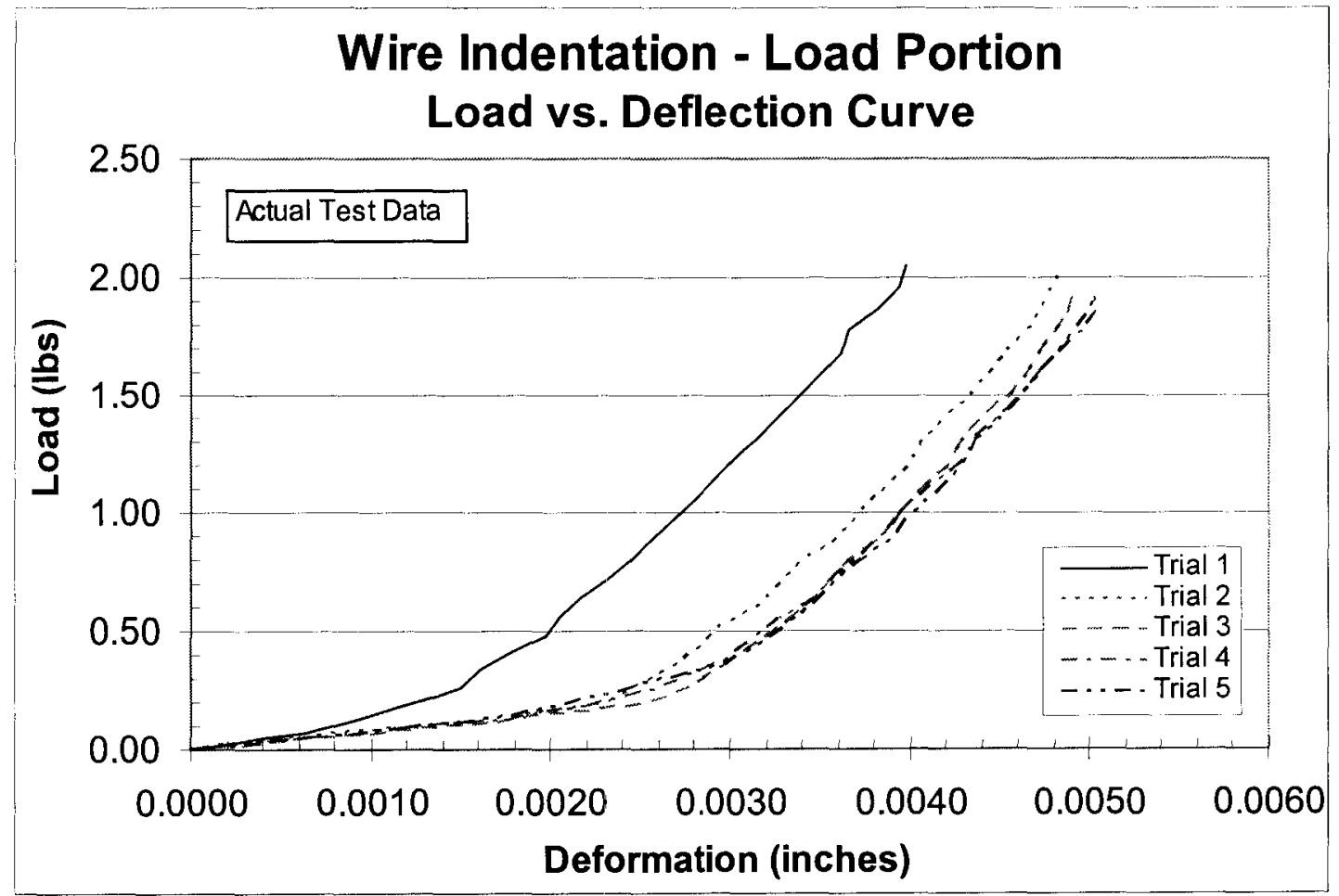

Figure 39. Load-displacement data for 20 gage PVC wire aged for 4 weeks at $125^{\circ} \mathrm{C}$ 


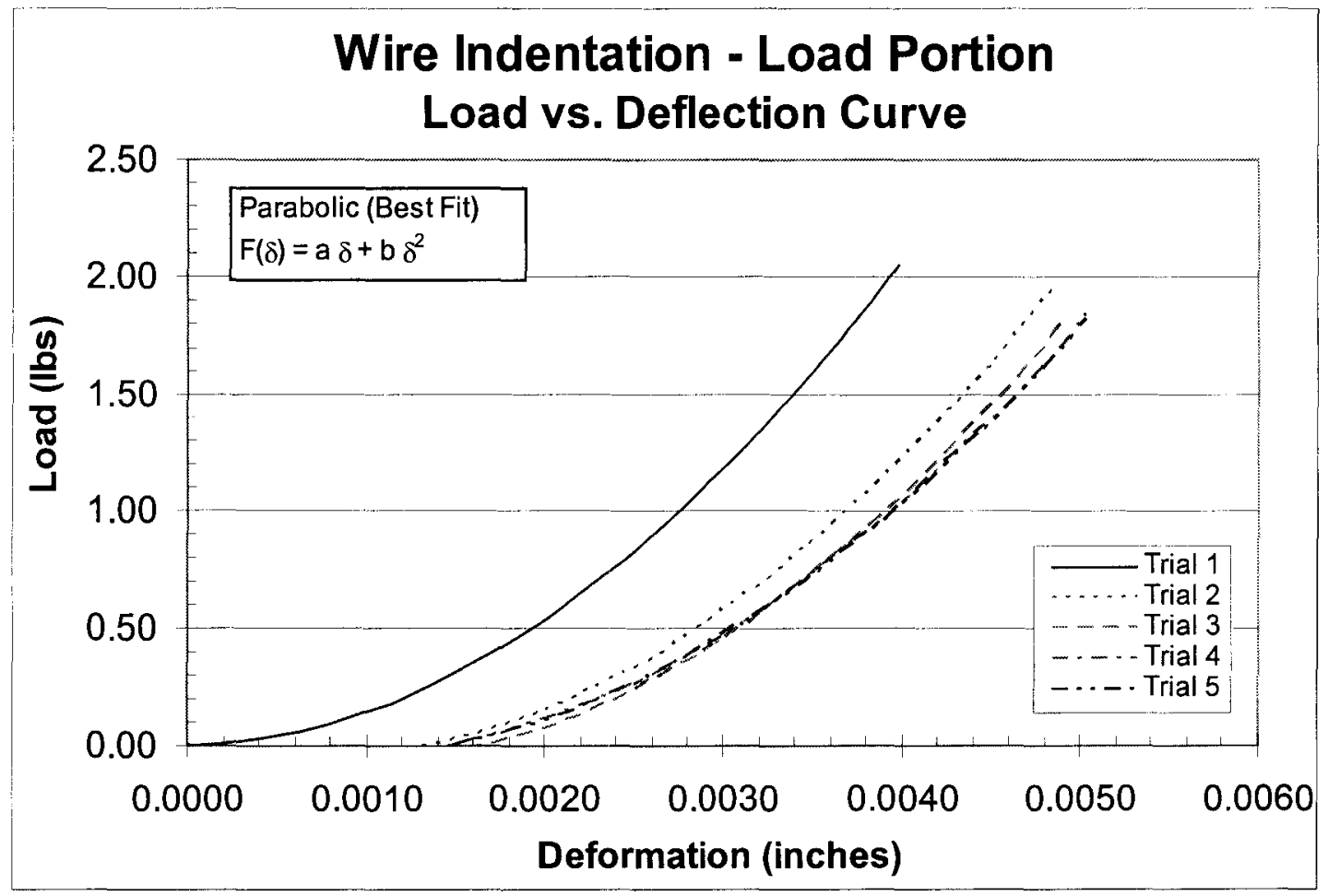

Figure 40. Load-displacement fits for 20 gage PVC wire aged for 4 weeks at $125^{\circ} \mathrm{C}$

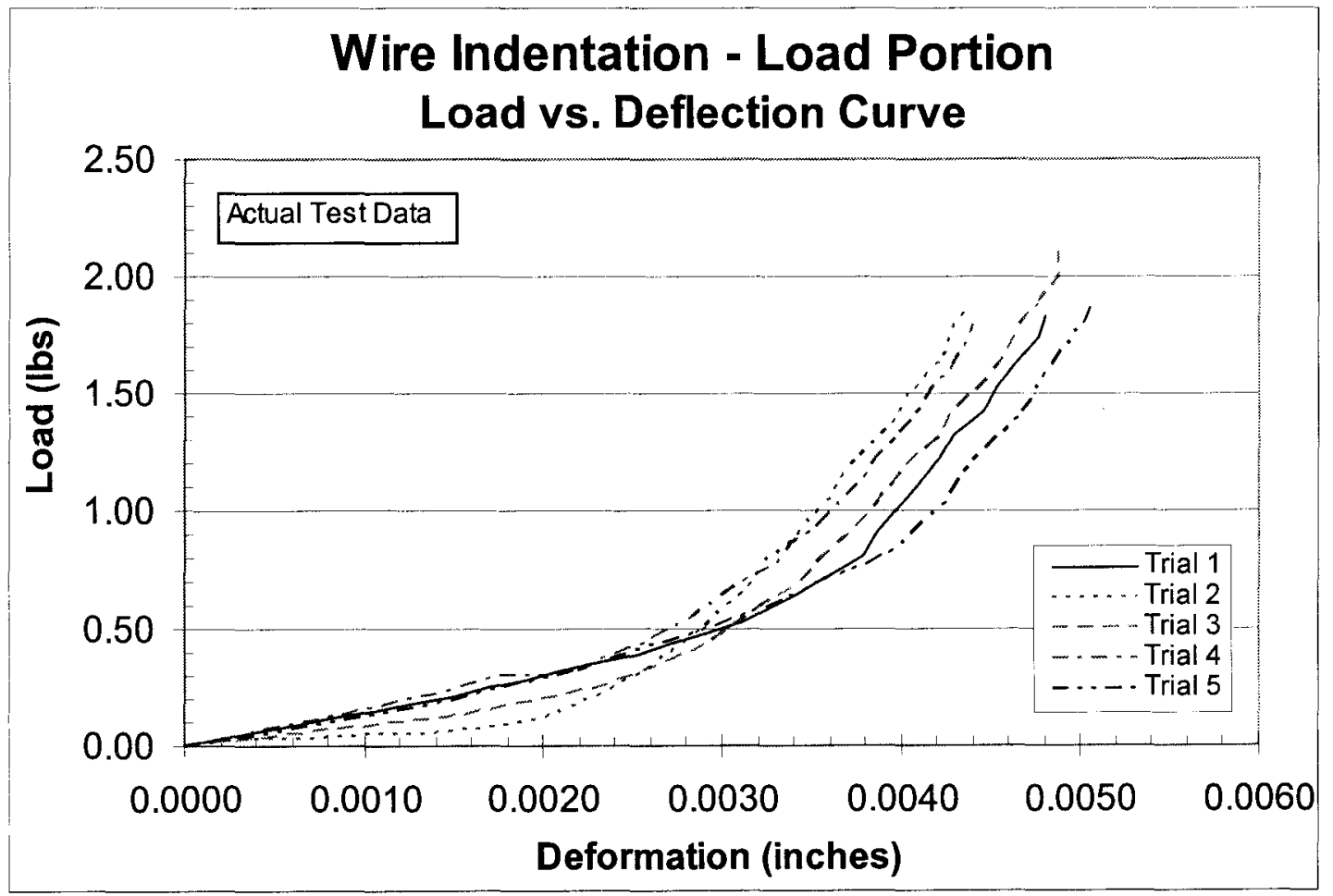

Figure 41. Load-displacement data for 20 gage PVC wire aged for 6 weeks at $125^{\circ} \mathrm{C}$ 


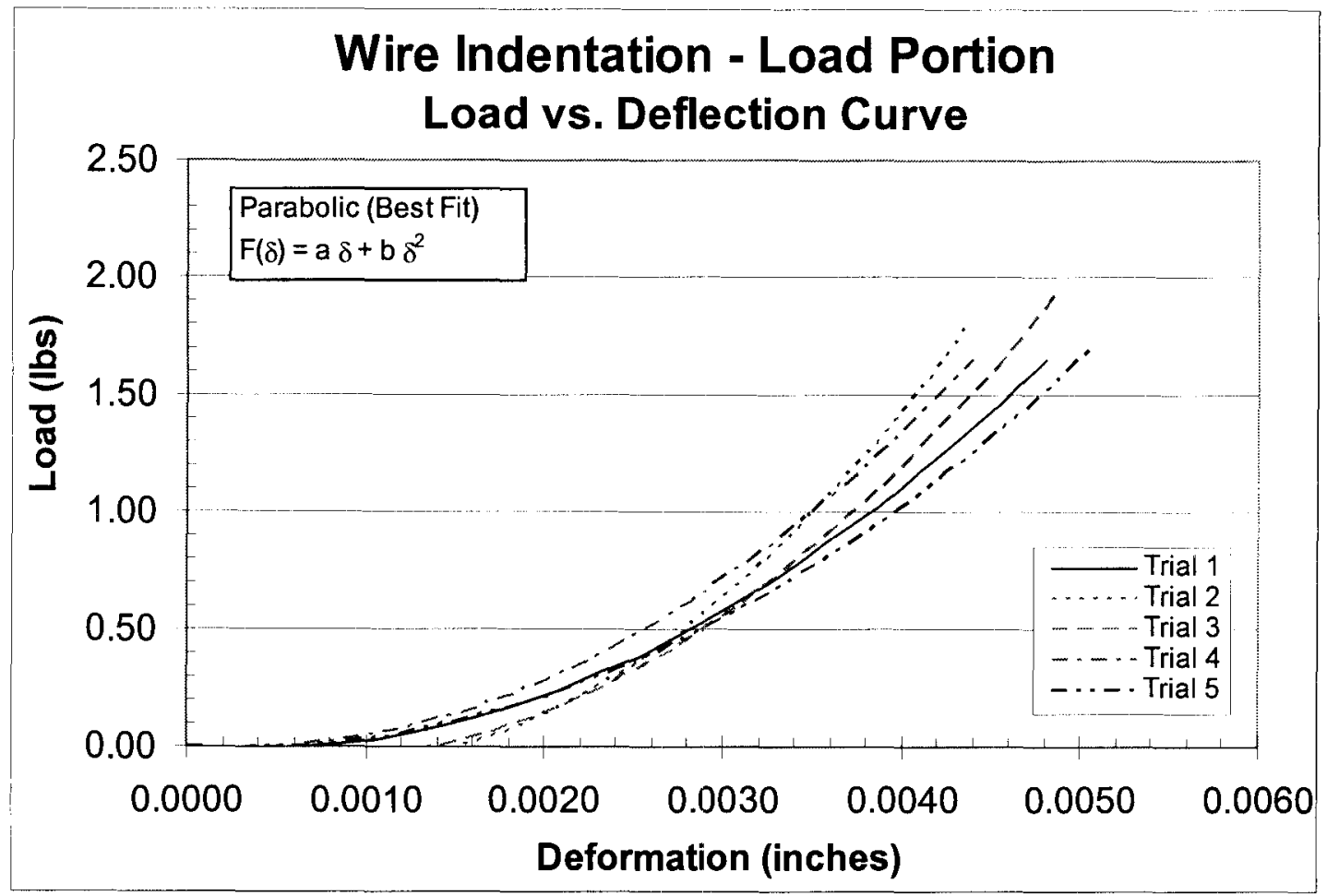

Figure 42. Load-displacement fits for 20 gage PVC wire aged for 6 weeks at $125^{\circ} \mathrm{C}$

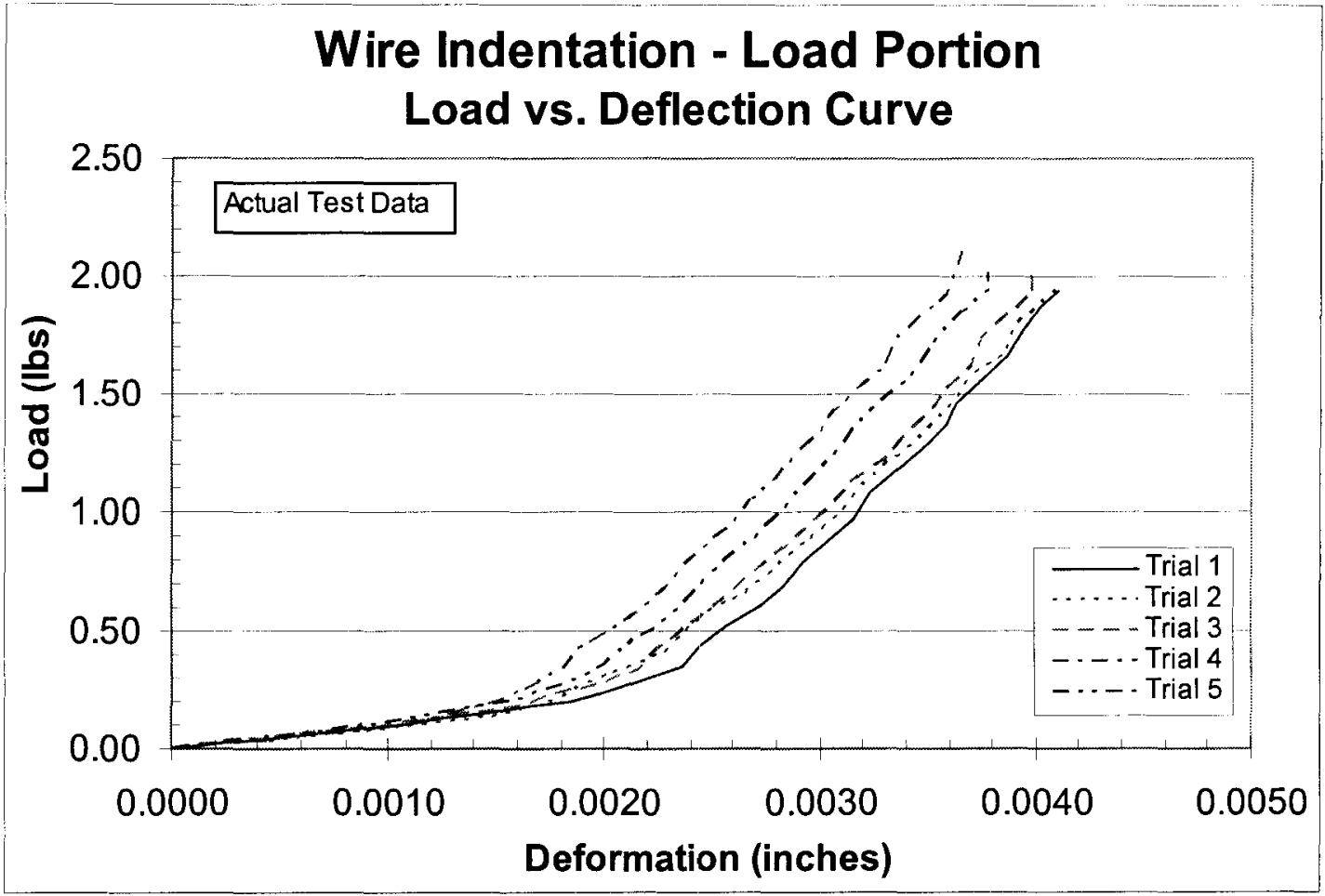

Figure 43. Load-displacement data for 20 gage PVC wire aged for 8 weeks at $125^{\circ} \mathrm{C}$ 


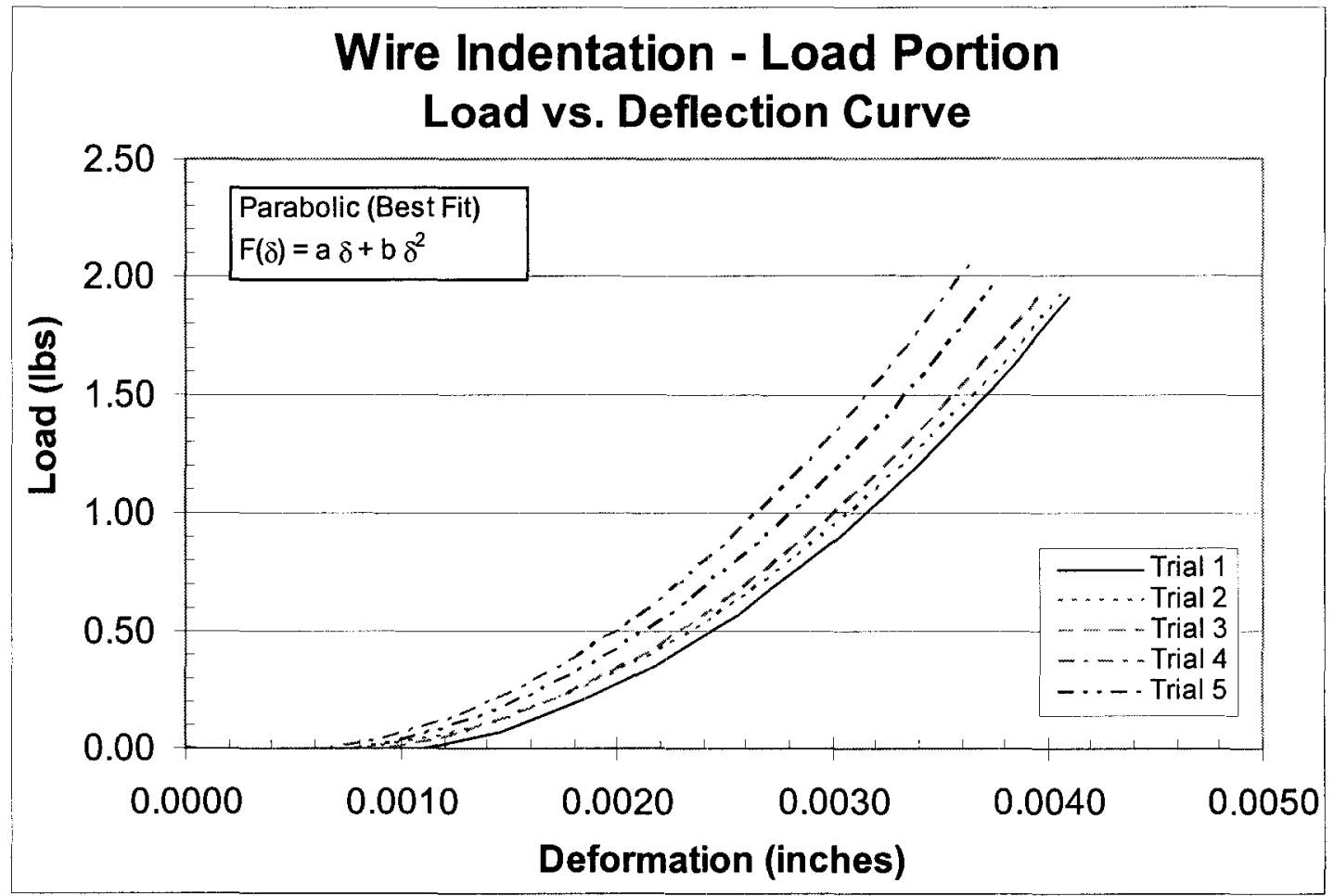

Figure 44. Load-displacement fits for 20 gage PVC wire aged for 8 weeks at $125^{\circ} \mathrm{C}$

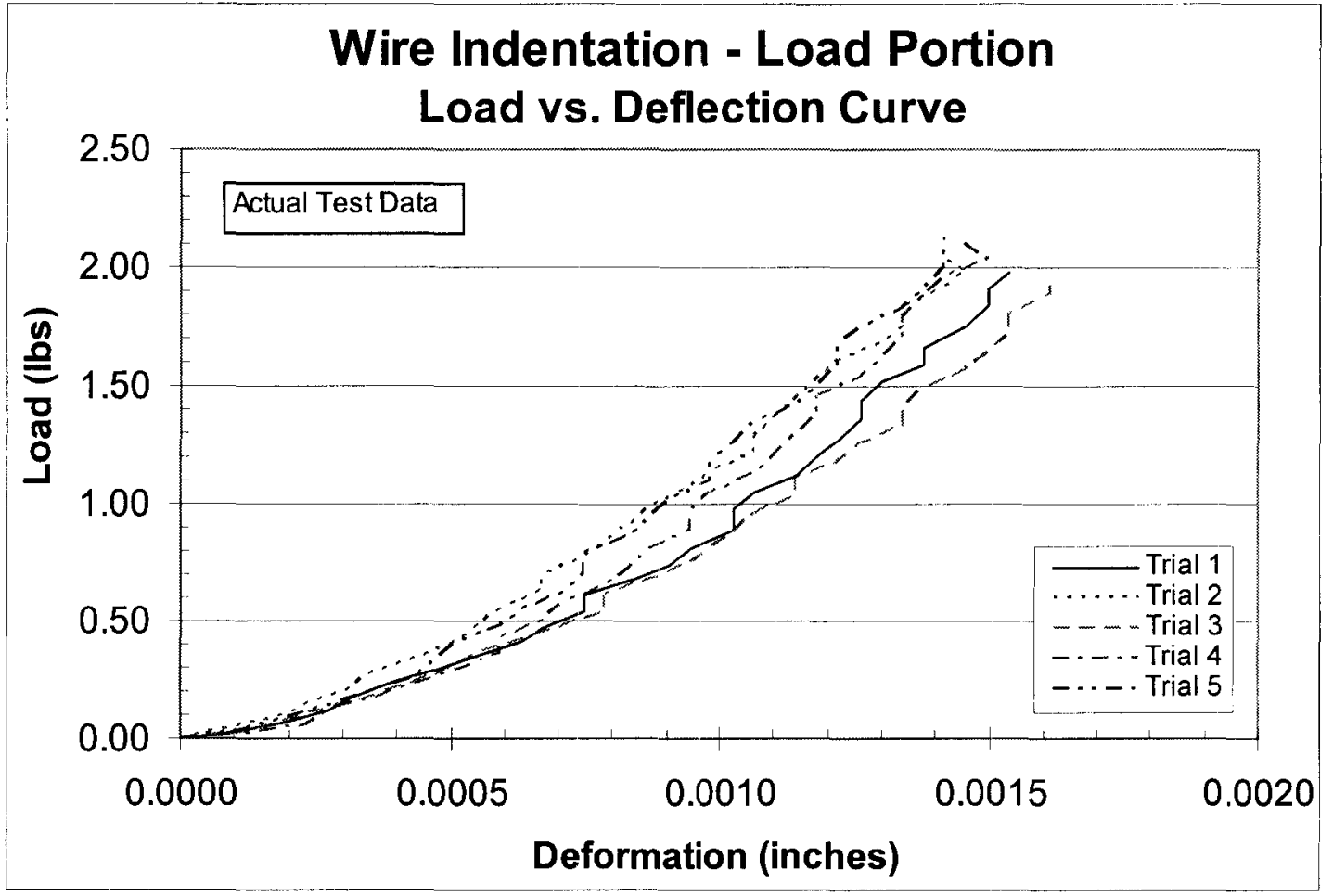

Figure 45. Load-displacement data for 20 gage PVC wire aged for 10 weeks at $125^{\circ} \mathrm{C}$ 


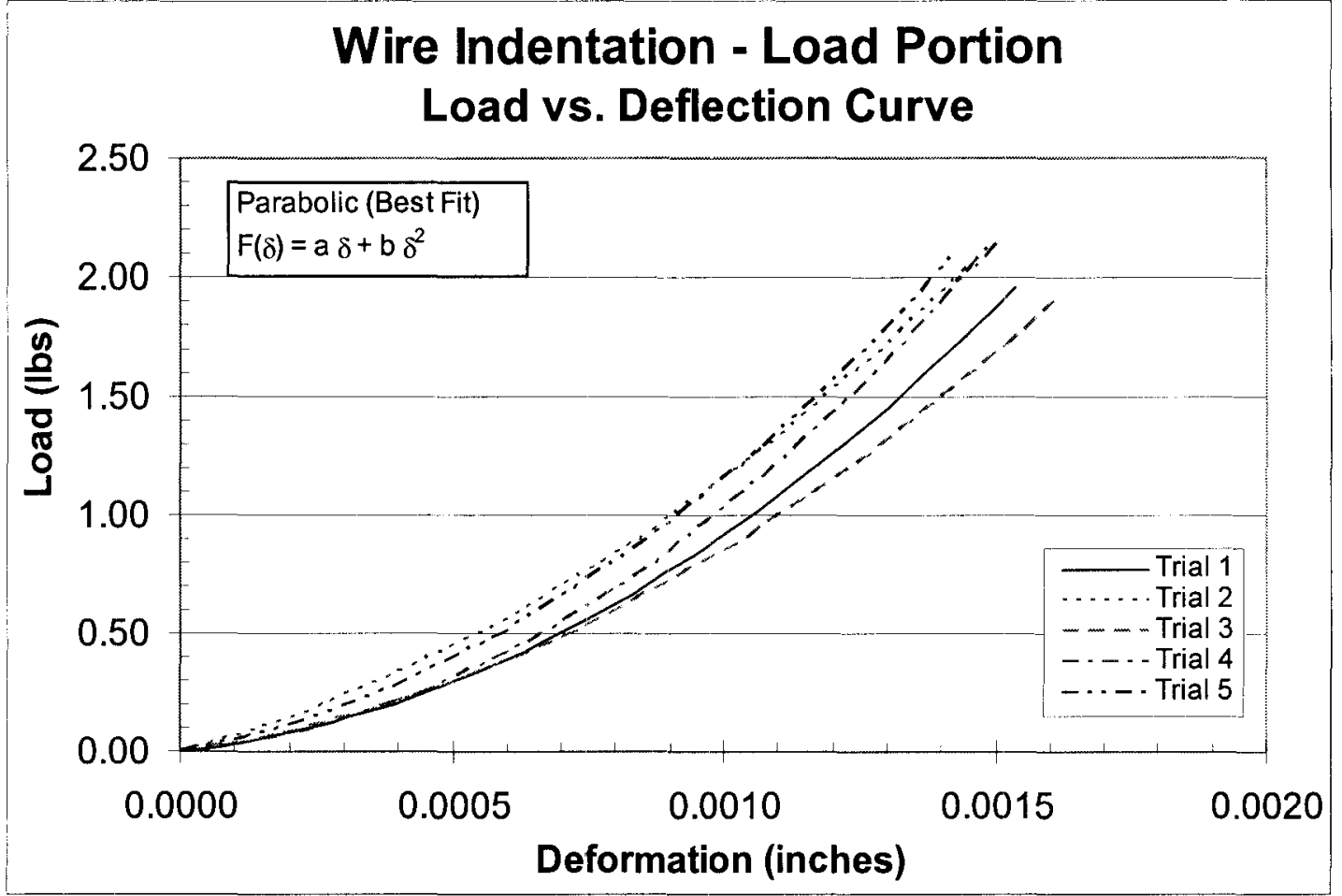

Figure 46. Load-displacement fits for 20 gage PVC wire aged for 10 weeks at $125^{\circ} \mathrm{C}$

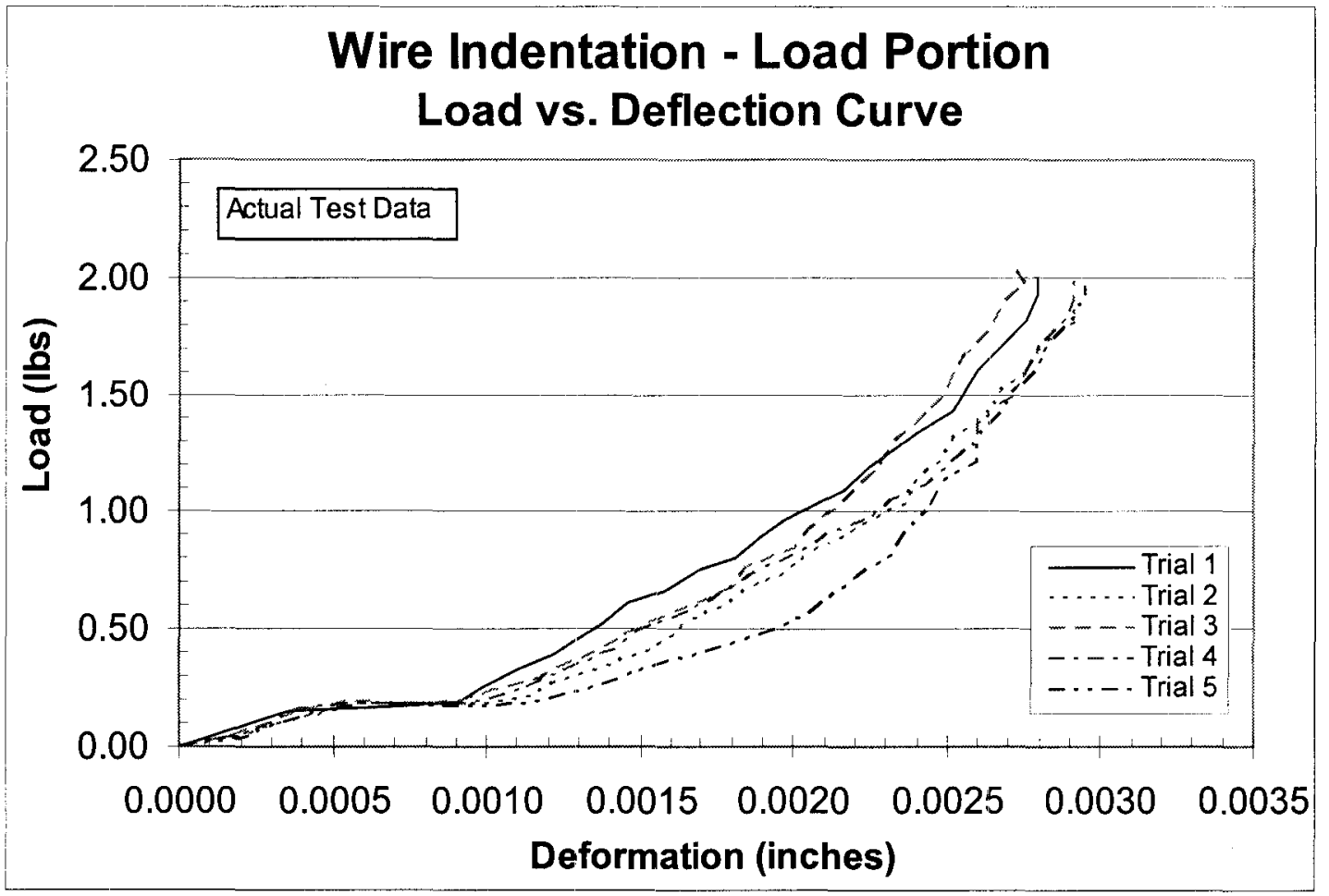

Figure 47. Load-displacement data for 20 gage PVC wire aged for 12 weeks at $125^{\circ} \mathrm{C}$ 


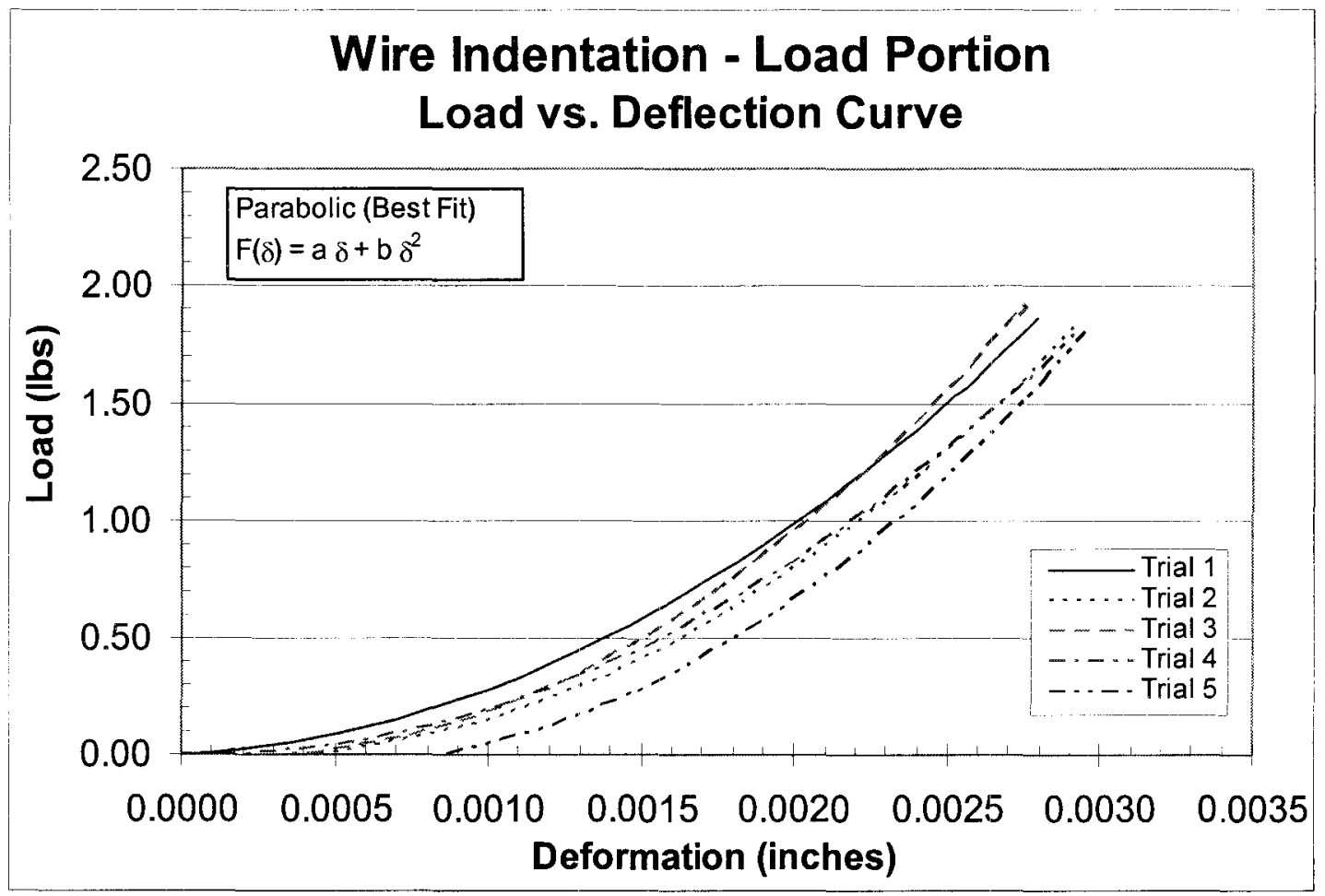

Figure 48. Load-displacement fits for 20 gage PVC wire aged for 12 weeks at $125^{\circ} \mathrm{C}$

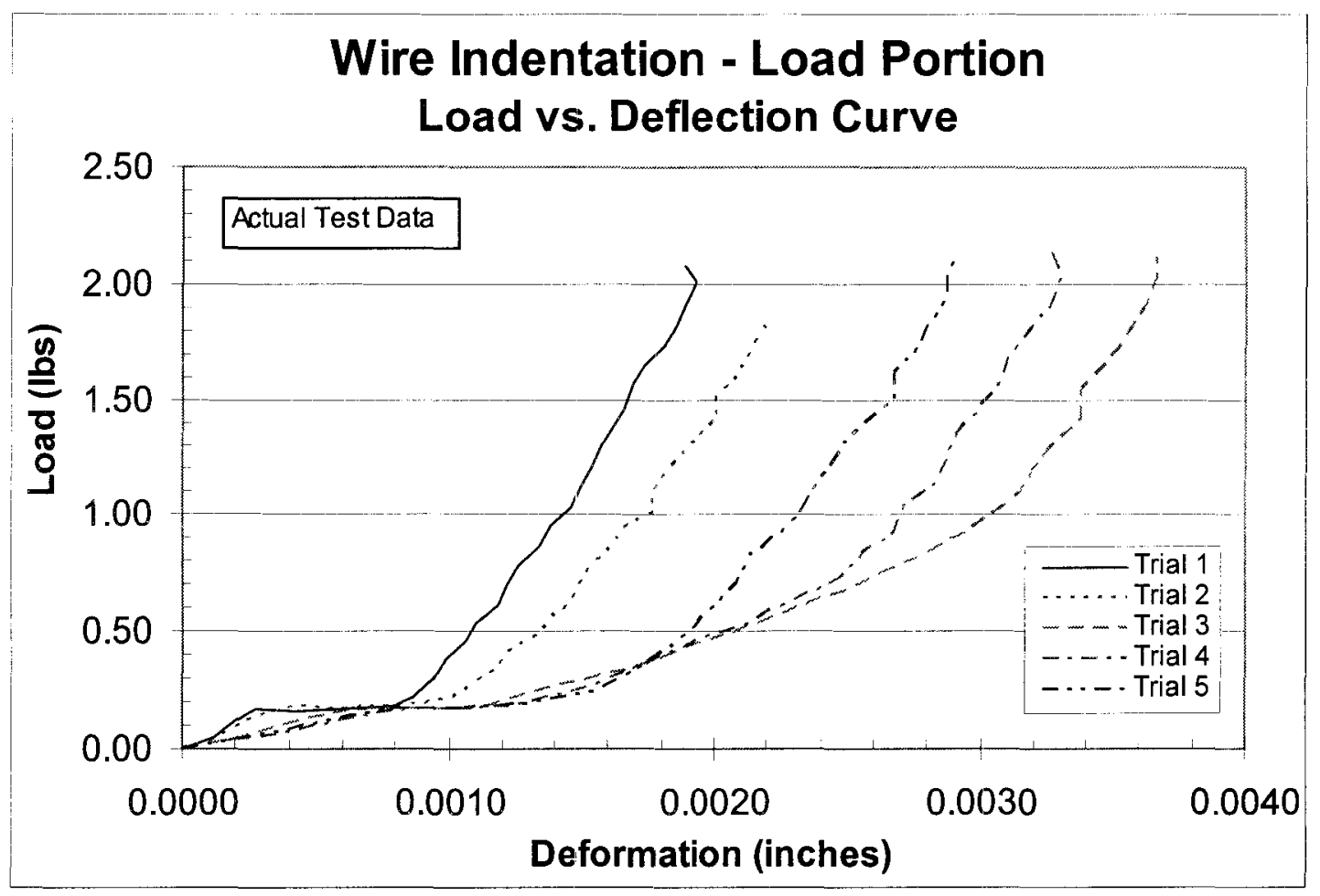

Figure 49. Load-displacement data for 20 gage PVC wire aged for 14 weeks at $125^{\circ} \mathrm{C}$ 


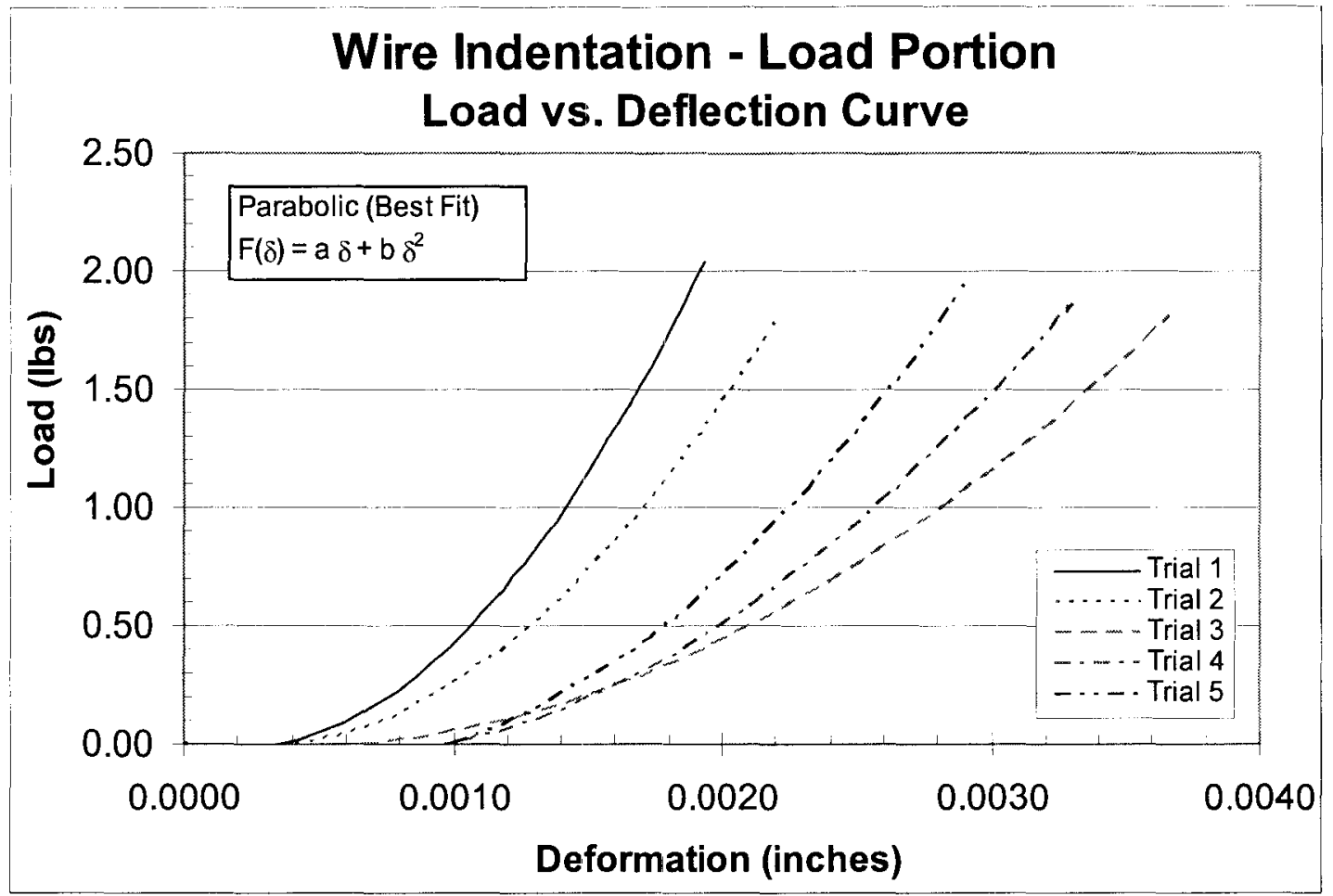

Figure 50. Load-displacement fits for 20 gage PVC wire aged for 14 weeks at $125^{\circ} \mathrm{C}$

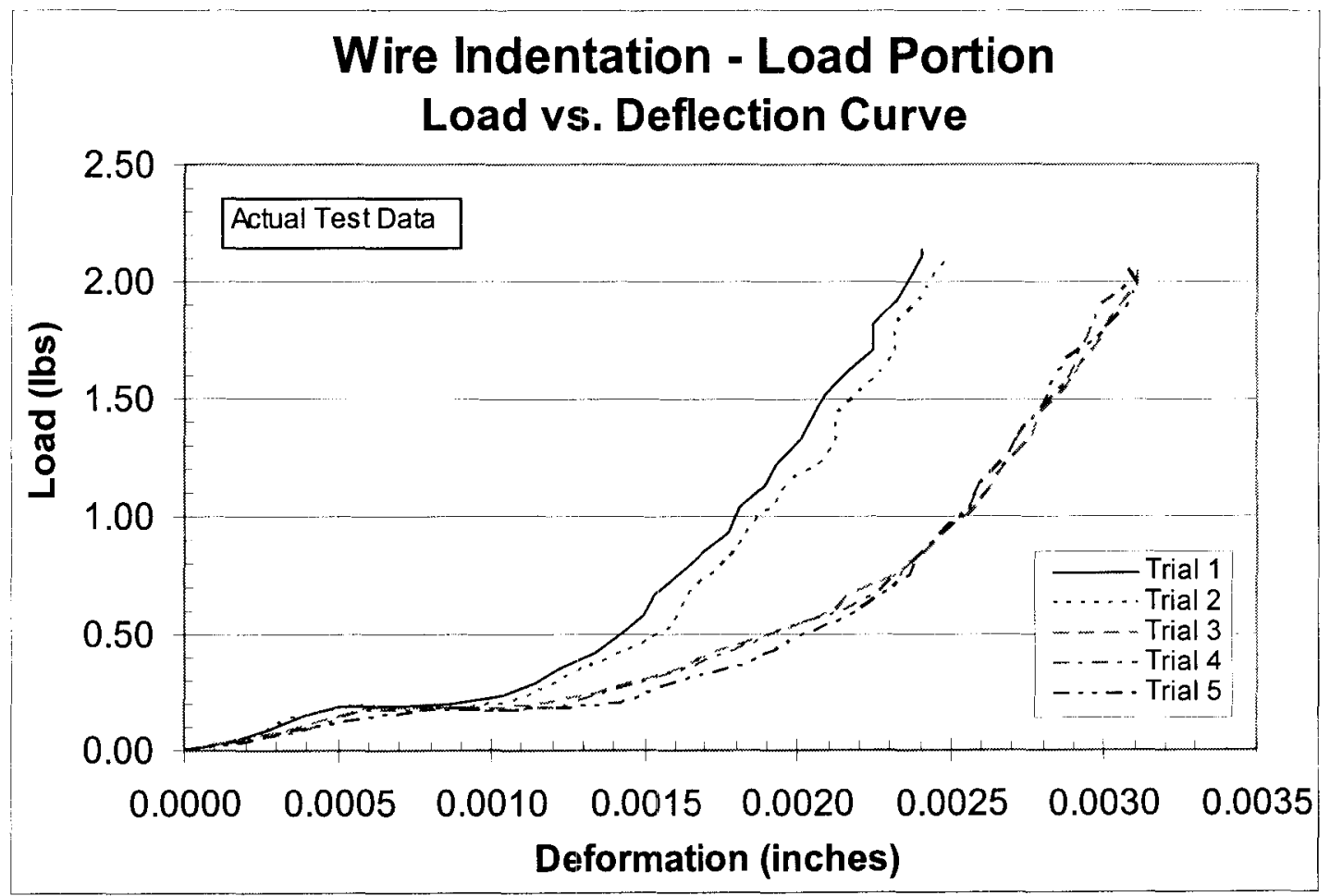

Figure 51. Load-displacement data for 20 gage PVC wire aged for 16 weeks at $125^{\circ} \mathrm{C}$ 


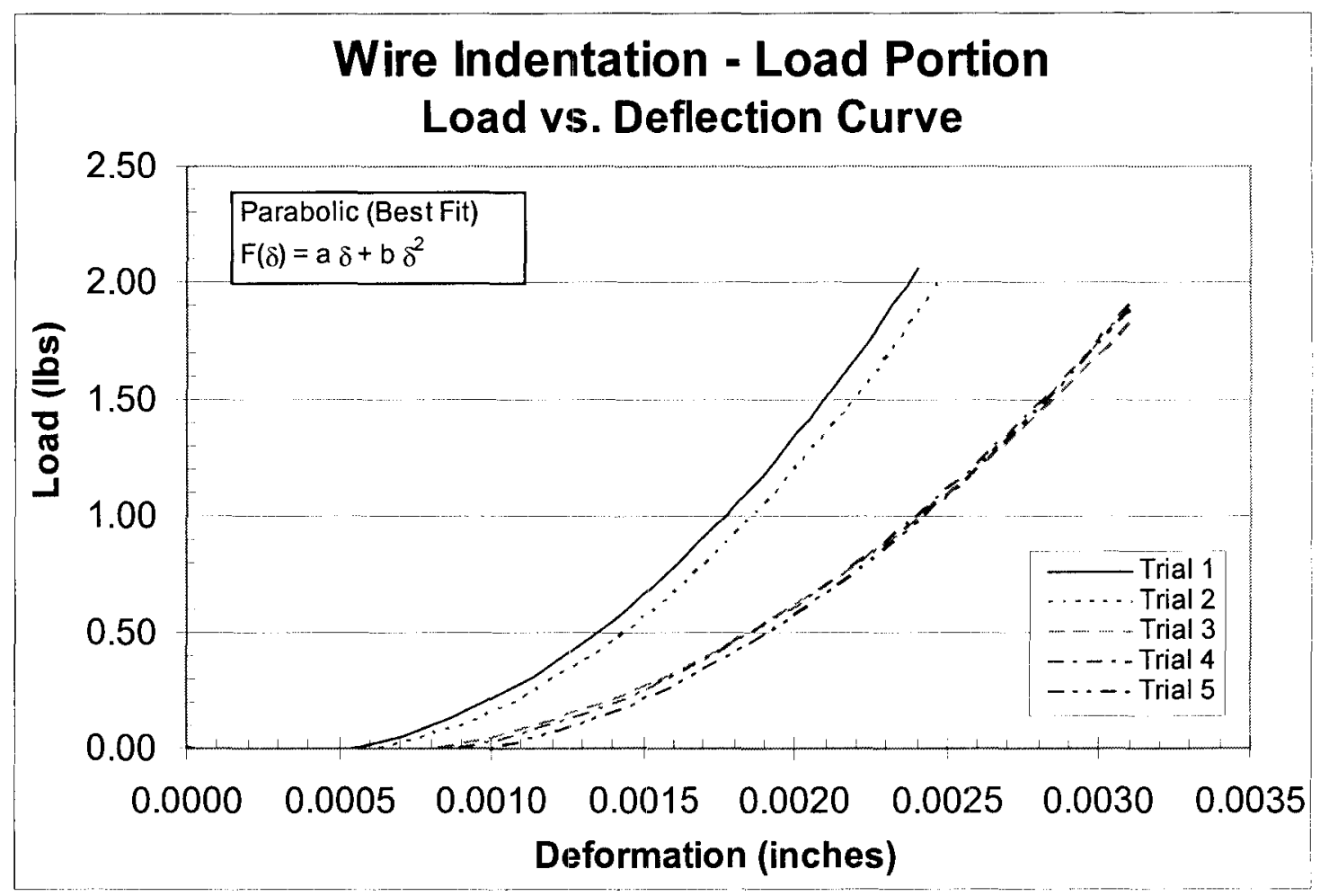

Figure 52. Load-displacement fits for 20 gage PVC wire aged for 16 weeks at $125^{\circ} \mathrm{C}$ 


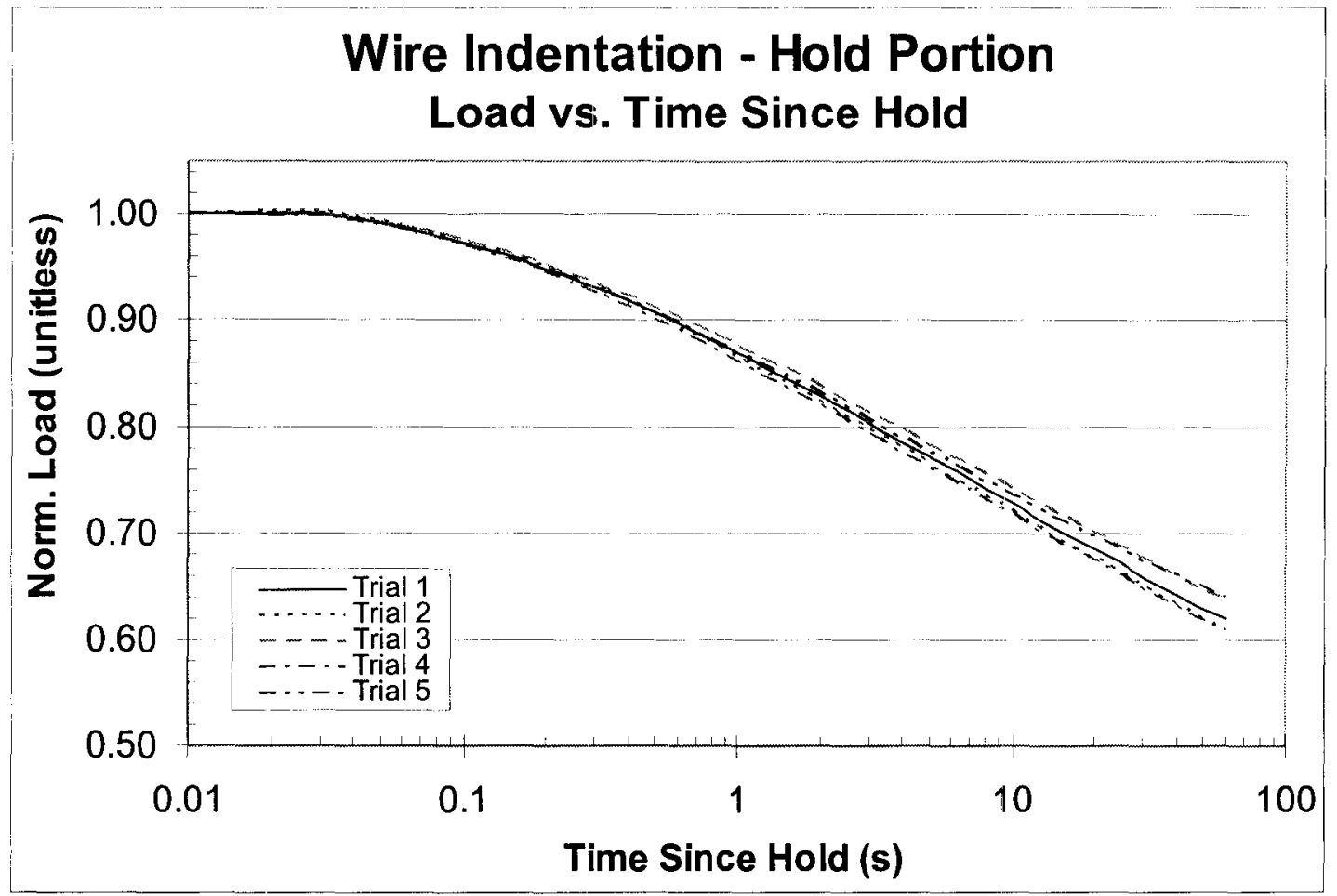

Figure 53. Normalized relaxation fits for unaged 20 gage PVC wire

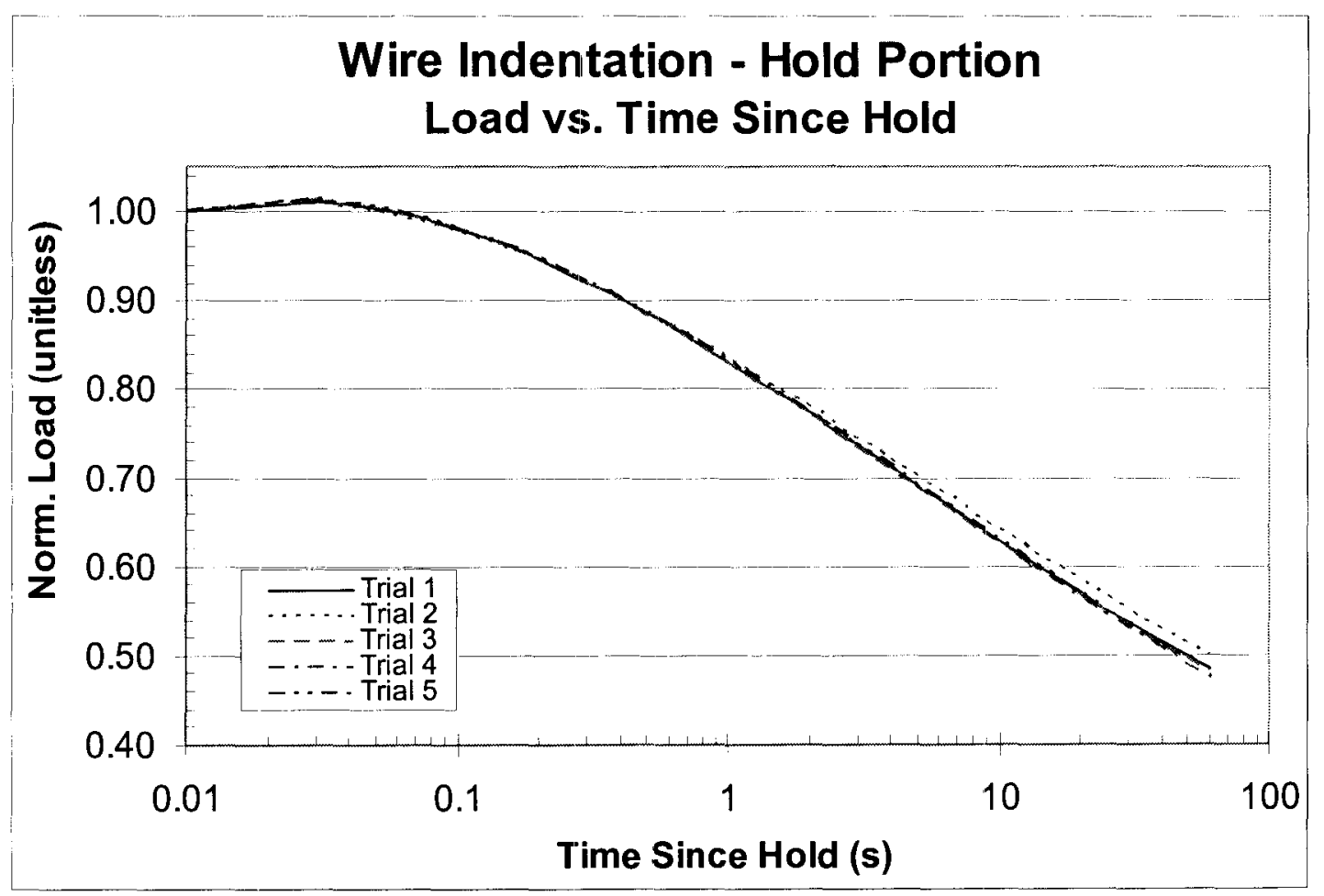

Figure 54. Normalized relaxation fits for 20 gage PVC wire aged for 2 weeks at $125^{\circ} \mathrm{C}$ 


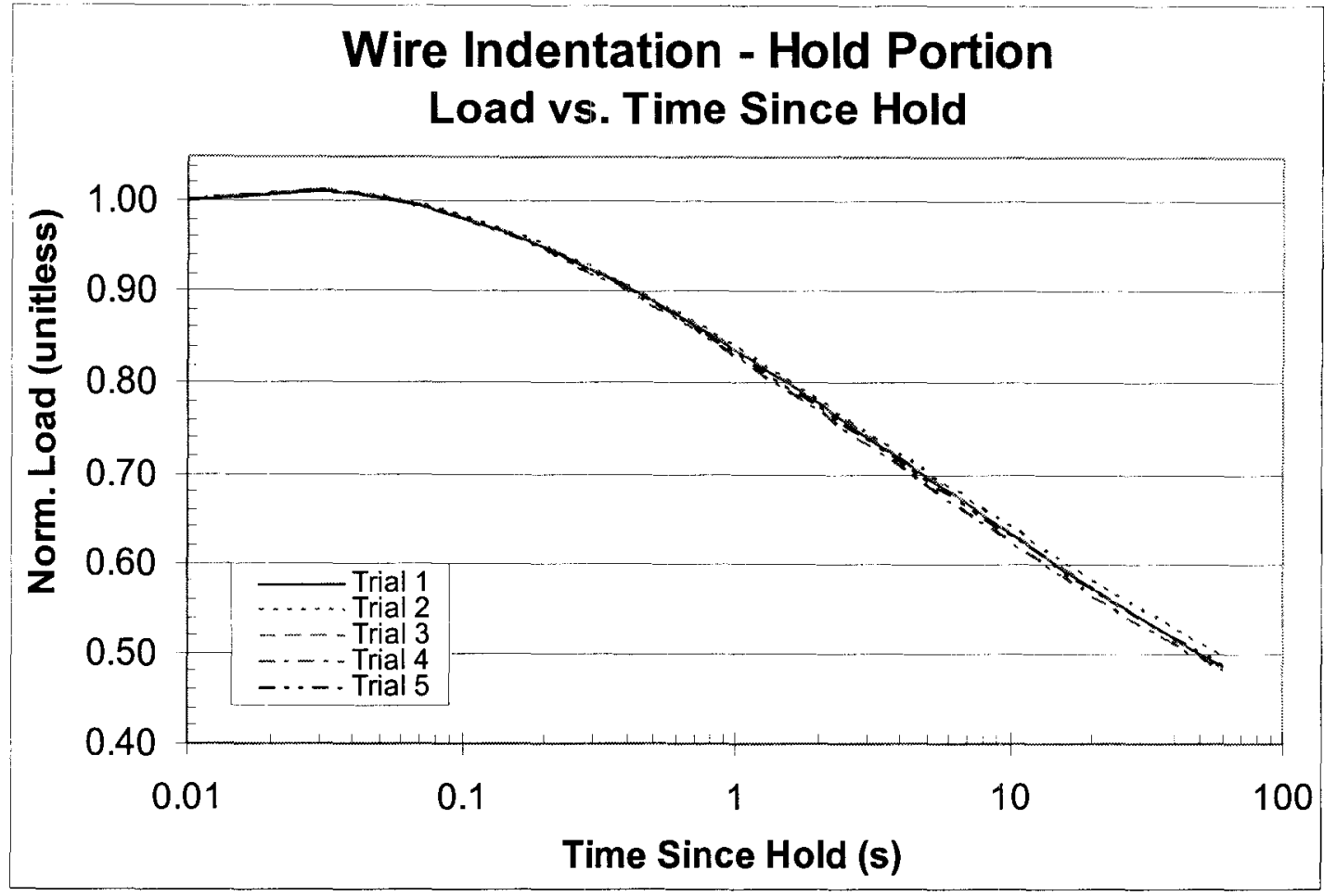

Figure 55. Normalized relaxation fits for 20 gage PVC wire aged for 4 weeks at $125^{\circ} \mathrm{C}$

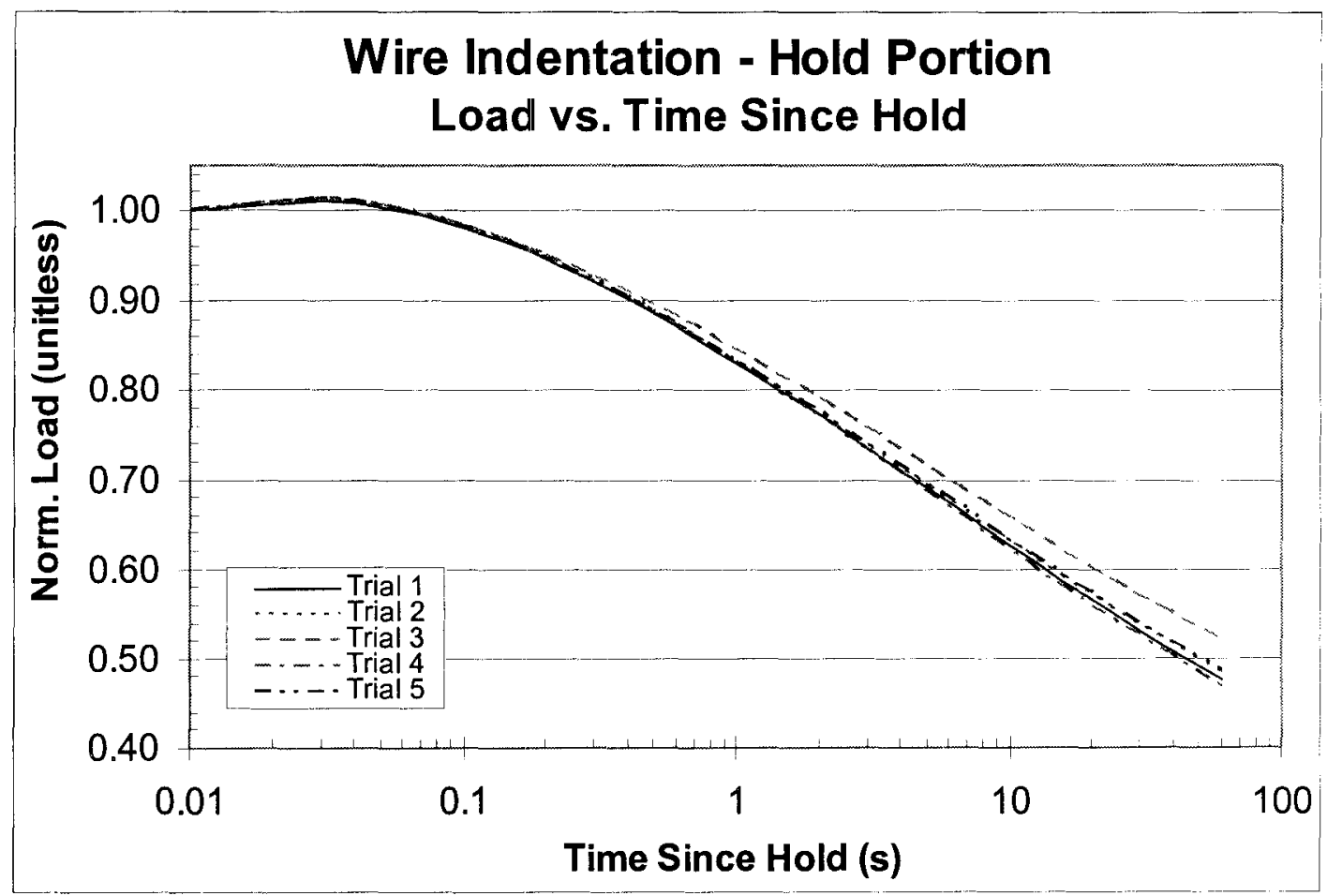

Figure 56. Normalized relaxation fits for 20 gage PVC wire aged for 6 weeks at $125^{\circ} \mathrm{C}$ 


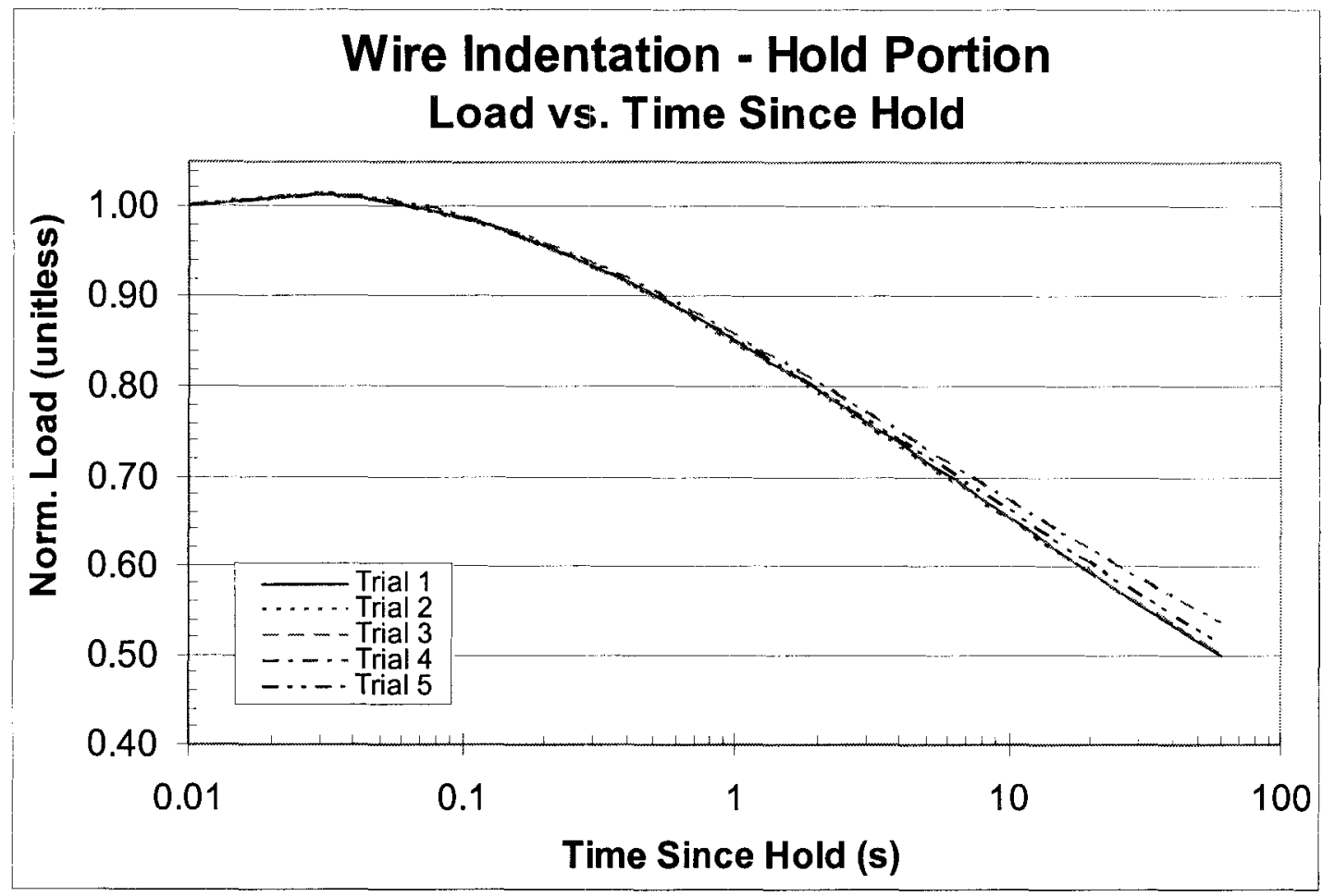

Figure 57. Normalized relaxation fits for 20 gage PVC wire aged for 8 weeks at $125^{\circ} \mathrm{C}$

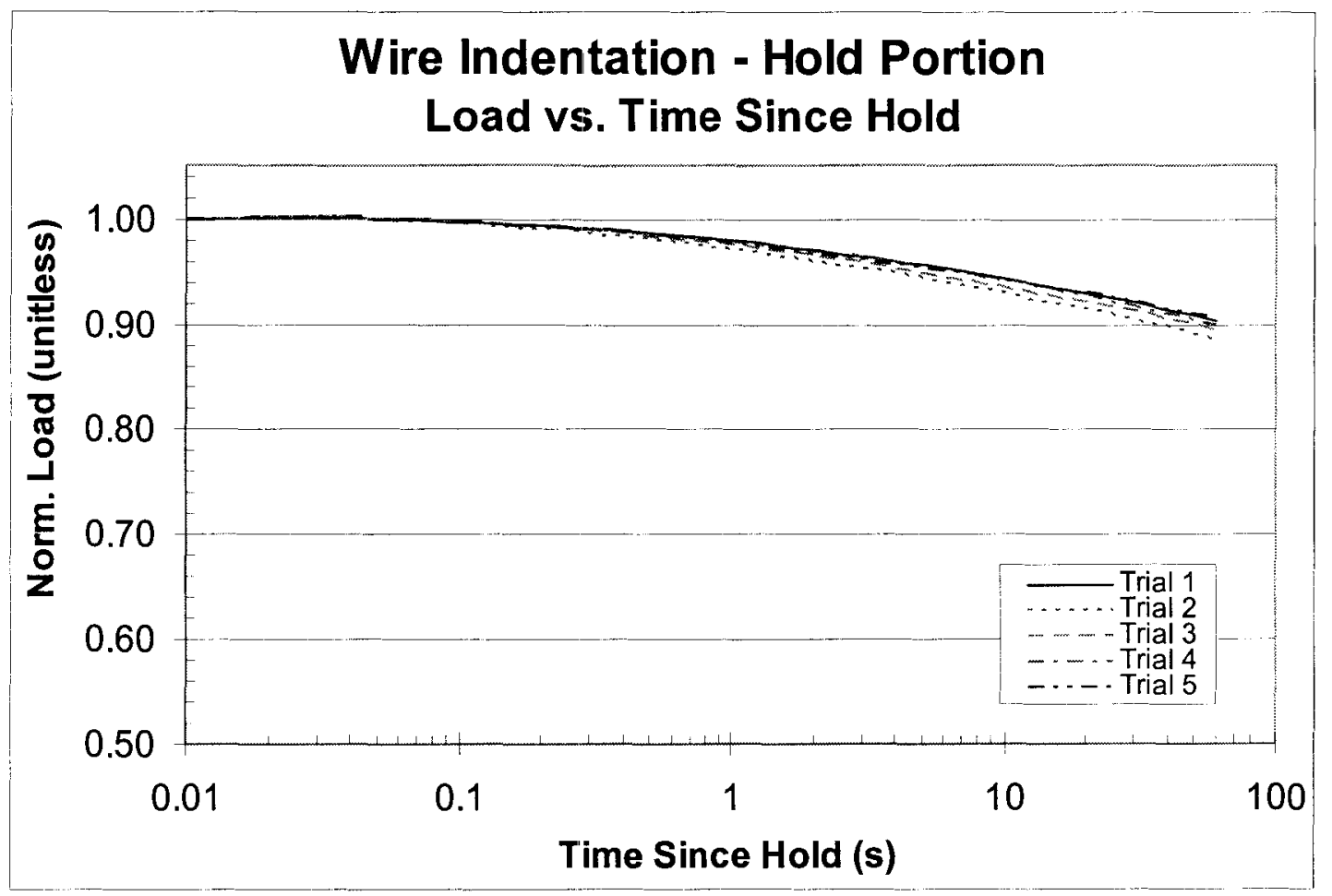

Figure 58. Normalized relaxation fits for 20 gage $\mathrm{PVC}$ wire aged for 10 weeks at $125^{\circ} \mathrm{C}$ 


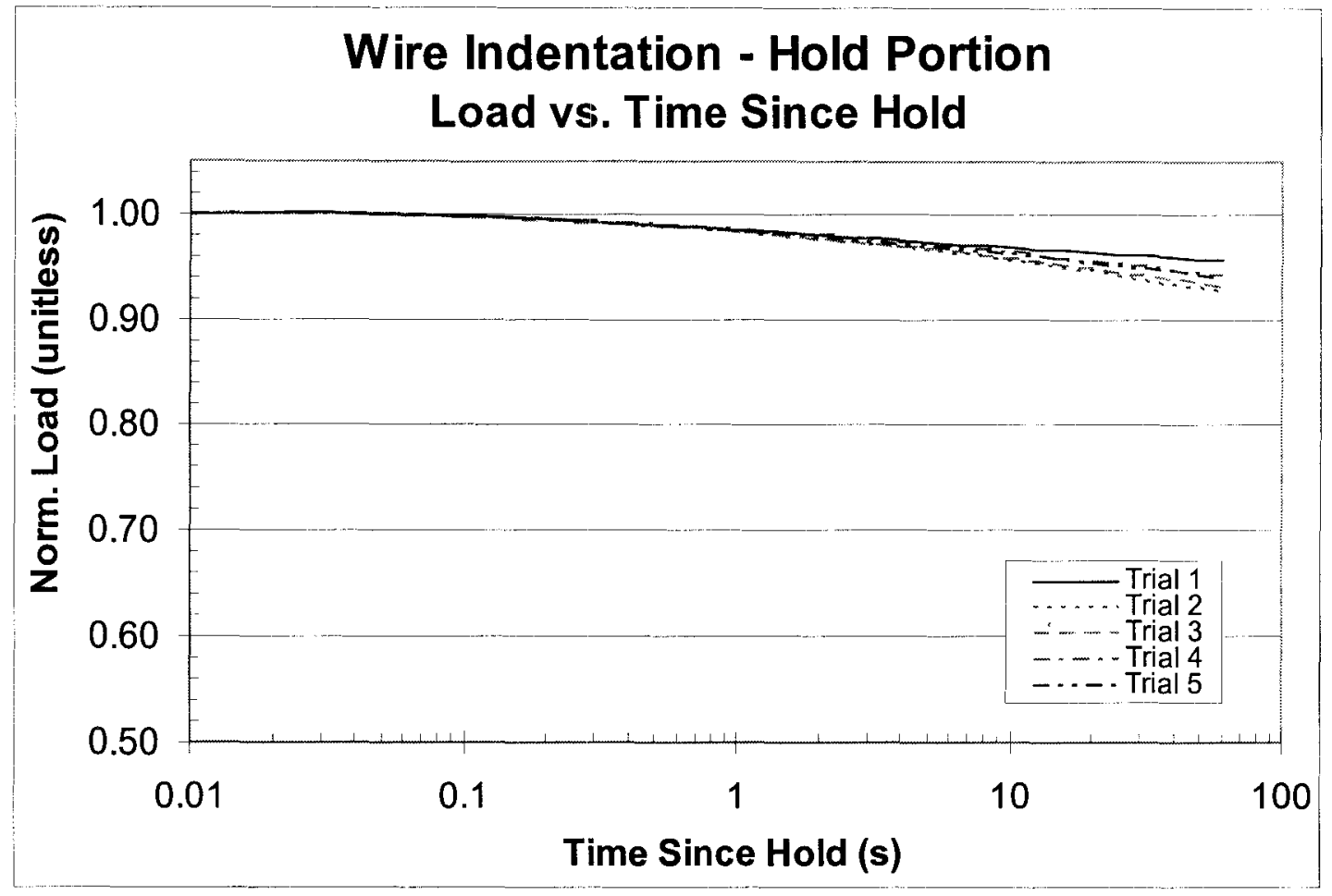

Figure 59. Normalized relaxation fits for 20 gage $\mathrm{PVC}$ wire aged for 12 weeks at $125^{\circ} \mathrm{C}$

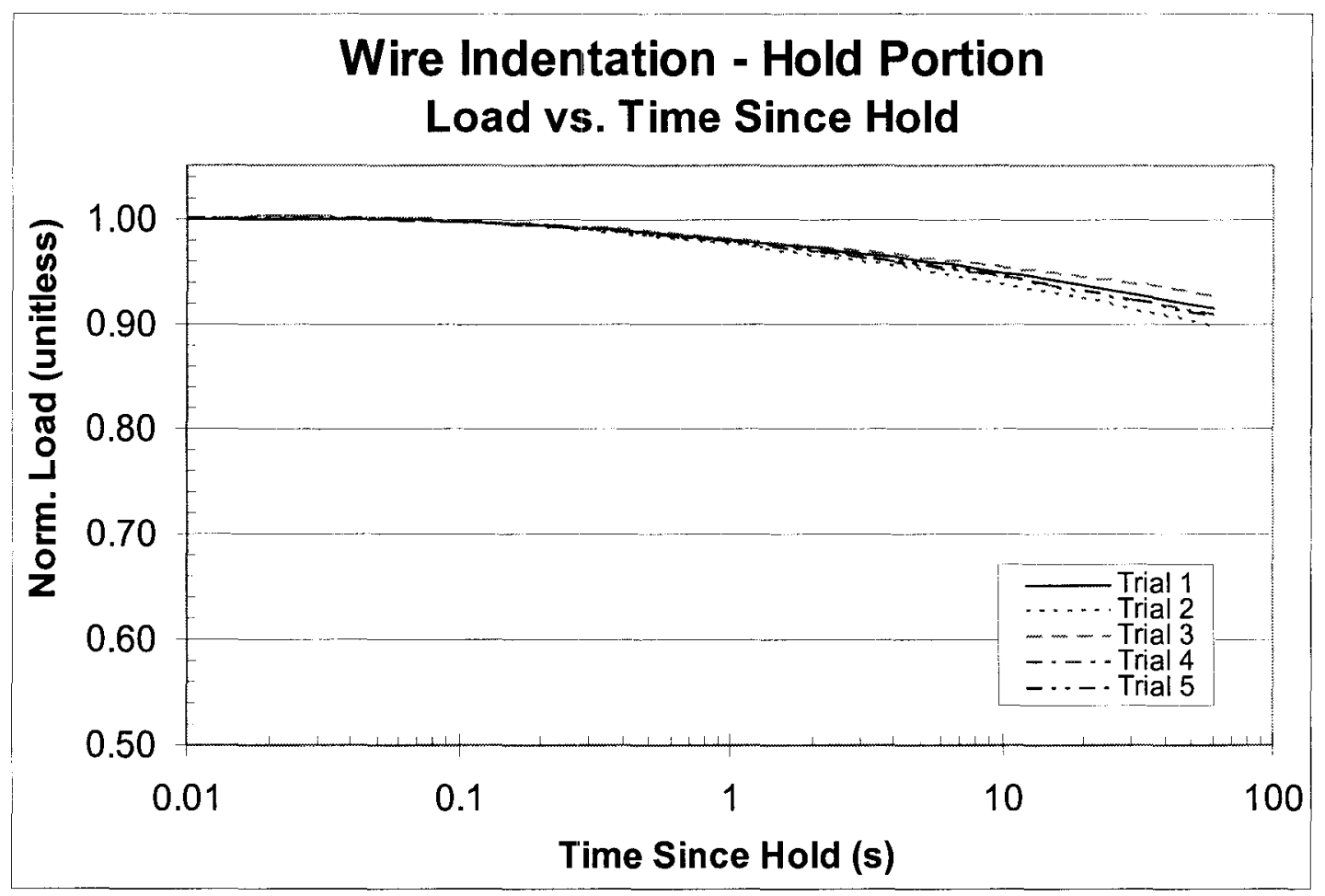

Figure 60. Normalized relaxation fits for 20 gage PVC wire aged for 14 weeks at $125^{\circ} \mathrm{C}$ 


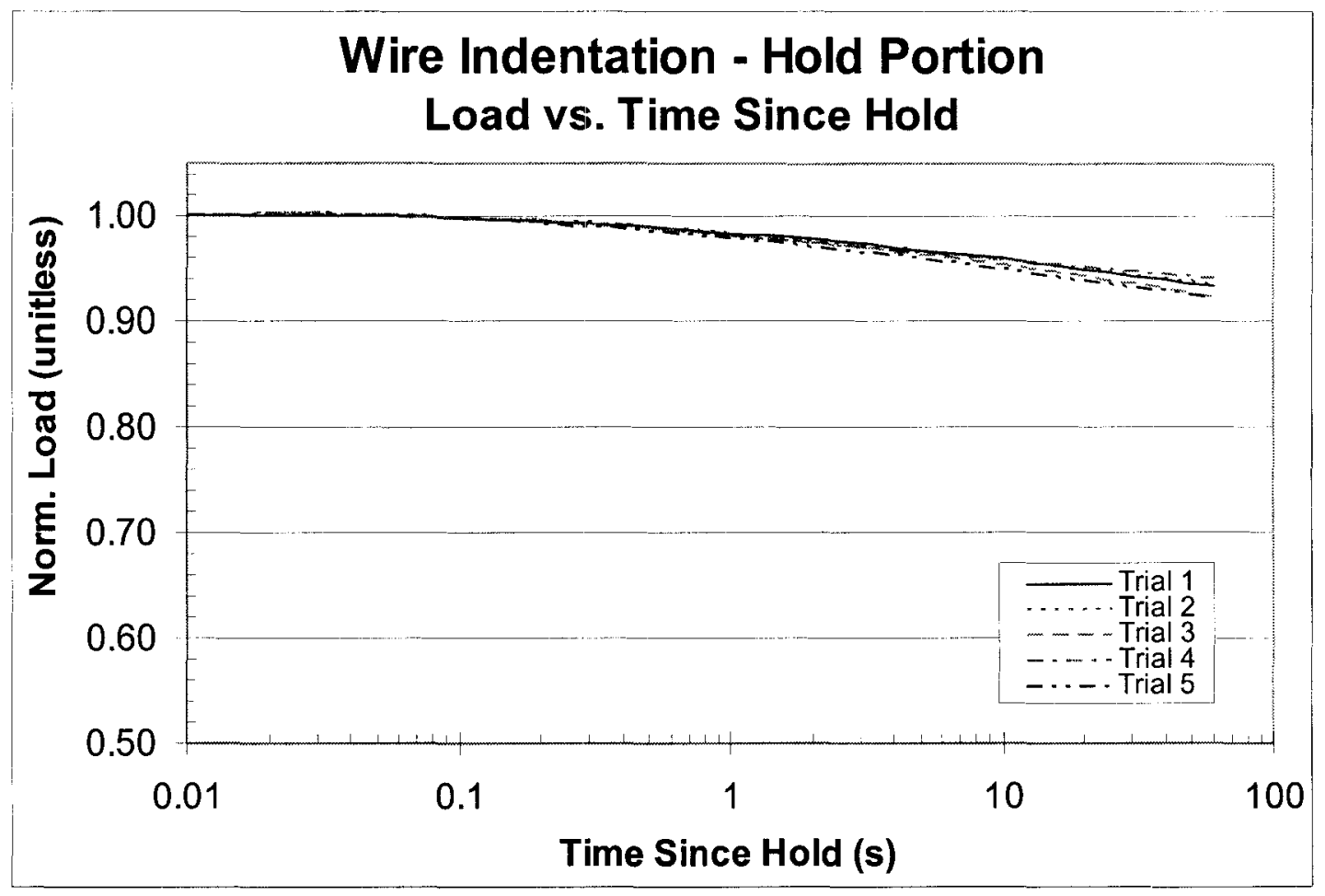

Figure 61. Normalized relaxation fits for 20 gage PVC wire aged for 16 weeks at $125^{\circ} \mathrm{C}$

\begin{tabular}{|l|ccccc|c|}
\hline & Trial 1 & Trial 2 & Trial 3 & Trial 4 & Trial 5 & Average \\
\hline $\mathbf{k}($ Ibs/in) & 375.7 & 425.5 & 465.4 & 399.6 & 432.3 & 419.7 \\
$\lambda(\operatorname{lbs})$ & -0.57628 & -0.74040 & -1.08244 & -0.82694 & -0.98882 & -0.84298 \\
\hline $\mathbf{a}(\mathbf{l b s} / \mathrm{in})$ & 39.83 & 30.10 & -30.50 & 18.28 & -18.67 & 7.81 \\
$\mathbf{b}\left(\operatorname{lbs} / \mathrm{in}^{2}\right)$ & 43705 & 48211 & 54278 & 41887 & 48867 & 47390 \\
\hline$\alpha(\operatorname{lb} / \log (\mathbf{s}))$ & 0.022838 & 0.029183 & 0.020246 & 0.021459 & 0.022912 & 0.023328 \\
$\beta\left(\operatorname{lb} / \log (\mathbf{s})^{2}\right)$ & -0.057265 & -0.062764 & -0.052940 & -0.059412 & -0.058440 & -0.058164 \\
$\gamma\left(\operatorname{lb} / \log (\mathbf{s})^{3}\right)$ & 0.0064918 & 0.0073285 & 0.0058697 & 0.0069507 & 0.0071664 & 0.0067614 \\
\hline
\end{tabular}

Table 8. Data fit coefficients for unaged 20 gage PVC wire

\begin{tabular}{|l|ccccc|c|}
\hline & Trial 1 & Trial 2 & Trial 3 & Trial 4 & Trial 5 & Average \\
\hline $\mathbf{k}(\mathbf{l b s} / \mathrm{in})$ & 648.0 & 646.7 & 667.8 & 631.5 & 645.4 & 647.9 \\
$\lambda(\mathbf{l b s})$ & -1.02069 & -1.13964 & -1.11868 & -0.84324 & -0.88029 & -1.00051 \\
\hline $\mathbf{a}(\mathbf{I b s} / \mathrm{in})$ & -42.60 & -66.35 & -52.48 & 4.77 & -26.33 & -36.60 \\
$\mathbf{b}\left(\mathbf{I b s} / \mathbf{i n}^{2}\right)$ & 111568 & 105097 & 109716 & 108467 & 118990 & 110768 \\
\hline$\alpha(\mathbf{l b} / \log (\mathbf{s}))$ & 0.070995 & 0.060174 & 0.071584 & 0.071479 & 0.072767 & 0.069400 \\
$\beta\left(\operatorname{lb} / \log (\mathbf{s})^{2}\right)$ & -0.103106 & -0.093905 & -0.104659 & -0.102620 & -0.103552 & -0.101568 \\
$\gamma\left(\operatorname{lb} / \log (\mathbf{s})^{3}\right)$ & 0.0127829 & 0.0113451 & 0.0130596 & 0.0124210 & 0.0127290 & 0.0124675 \\
\hline
\end{tabular}

Table 9. Data fit coefficients for 20 gage $\mathrm{PVC}$ wire aged for 2 weeks at $125^{\circ} \mathrm{C}$ 


\begin{tabular}{|l|ccccc|c|}
\hline & Trial 1 & Trial 2 & Trial 3 & Trial 4 & Trial 5 & Average \\
\hline $\mathbf{k}(\mathrm{lbs} / \mathrm{in})$ & 720.8 & 706.2 & 750.6 & 678.2 & 706.7 & 712.5 \\
$\lambda(\mathrm{lbs})$ & -0.93900 & -1.56731 & -1.90333 & -1.64517 & -1.78691 & -1.56834 \\
\hline $\mathbf{a}(\mathbf{I b s} / \mathrm{in})$ & 19.42 & -155.49 & -188.40 & -145.67 & -146.56 & -123.34 \\
$\mathbf{b}\left(\mathrm{lbs} / \mathrm{in}^{2}\right)$ & 124712 & 115457 & 113558 & 101168 & 100834 & 111146 \\
\hline$\alpha(\mathrm{lb} / \log (\mathbf{s}))$ & 0.067941 & 0.069976 & 0.067833 & 0.071058 & 0.070254 & 0.069412 \\
$\beta\left(\operatorname{lb} / \log (\mathbf{s})^{2}\right)$ & -0.098827 & -0.099972 & -0.098806 & -0.104977 & -0.102660 & -0.101048 \\
$\gamma\left(\operatorname{lb} / \log (\mathbf{s})^{3}\right)$ & 0.0118559 & 0.0122449 & 0.0118081 & 0.0131742 & 0.0127510 & 0.0123668 \\
\hline
\end{tabular}

Table 10. Data fit coefficients for 20 gage PVC wire aged for 4 weeks at $125^{\circ} \mathrm{C}$

\begin{tabular}{|l|ccccc|c|}
\hline & Trial 1 & Trial 2 & Trial 3 & Trial 4 & Trial 5 & Average \\
\hline $\mathbf{k}(\mathbf{l b s} / \mathrm{in})$ & 562.0 & 789.4 & 742.6 & 605.1 & 462.5 & 632.3 \\
$\lambda(\mathbf{l b s})$ & -1.09161 & -1.74924 & -1.76415 & -1.09375 & -0.77337 & -1.29442 \\
\hline $\mathbf{a}(\mathbf{I b s} / \mathrm{in})$ & -58.79 & -224.10 & -157.87 & -58.06 & -43.62 & -108.49 \\
$\mathbf{b}\left(\mathbf{l b s} / \mathbf{i n}^{2}\right)$ & 83942 & 145111 & 113866 & 98236 & 74766 & 103184 \\
\hline$\alpha(\mathbf{l b} / \log (\mathbf{s}))$ & 0.070686 & 0.076607 & 0.067055 & 0.078552 & 0.073302 & 0.073240 \\
$\beta\left(\operatorname{lb} / \log (\mathbf{s})^{2}\right)$ & -0.102124 & -0.105864 & -0.095357 & -0.108317 & -0.103484 & -0.103029 \\
$\gamma\left(\operatorname{lb} / \log (\mathbf{s})^{3}\right)$ & 0.0123759 & 0.0130967 & 0.0116450 & 0.0133240 & 0.0127408 & 0.0126365 \\
\hline
\end{tabular}

Table 11. Data fit coefficients for 20 gage PVC wire aged for 6 weeks at $125^{\circ} \mathrm{C}$

\begin{tabular}{|l|ccccc|c|}
\hline & Trial 1 & Trial 2 & Trial 3 & Trial 4 & Trial 5 & Average \\
\hline $\mathbf{k}(\mathbf{l b s} / \mathrm{in})$ & 816.5 & 775.4 & 809.3 & 888.7 & 877.8 & 833.5 \\
$\lambda(\mathbf{l b s})$ & -1.55973 & -1.35817 & -1.41410 & -1.30756 & -1.41283 & -1.41048 \\
\hline $\mathbf{a}(\mathbf{l b s} / \mathrm{in})$ & -178.05 & -134.05 & -152.48 & -128.62 & -140.16 & -146.67 \\
$\mathbf{b}\left(\mathbf{l b s} /\right.$ in $\left.^{2}\right)$ & 157183 & 149006 & 160678 & 190329 & 176261 & 166691 \\
\hline$\alpha(\operatorname{lb} / \log (\mathbf{s}))$ & 0.068575 & 0.071129 & 0.064782 & 0.068829 & 0.063453 & 0.067354 \\
$\beta\left(\operatorname{lb} / \log (\mathbf{s})^{2}\right)$ & -0.091590 & -0.096073 & -0.090349 & -0.091937 & -0.088765 & -0.091743 \\
$\gamma\left(\operatorname{lb} / \log (\mathbf{s})^{3}\right)$ & 0.0101457 & 0.0111956 & 0.0100793 & 0.0109048 & 0.0099944 & 0.0104640 \\
\hline
\end{tabular}

Table 12. Data fit coefficients for 20 gage PVC wire aged for 8 weeks at $125^{\circ} \mathrm{C}$

\begin{tabular}{|l|ccccc|c|}
\hline & Trial 1 & Trial 2 & Trial 3 & Trial 4 & Trial 5 & Average \\
\hline $\mathbf{k}(\mathrm{Ibs} / \mathrm{in})$ & 1633.5 & 1672.8 & 1490.3 & 1752.5 & 1761.1 & 1662.1 \\
$\lambda(\mathbf{l b s})$ & -0.62250 & -0.44636 & -0.57804 & -0.67064 & -0.56000 & -0.57551 \\
\hline $\mathbf{a}(\mathbf{I b s} / \mathrm{in})$ & 250.57 & 608.63 & 311.38 & 202.04 & 415.30 & 357.58 \\
$\mathbf{b}\left(\mathbf{l b s} / \mathrm{in}^{2}\right)$ & 669107 & 552908 & 540387 & 824487 & 741505 & 665679 \\
\hline$\alpha(\mathrm{lb} / \log (\mathbf{s}))$ & 0.004385 & 0.006351 & 0.006822 & 0.002630 & 0.006061 & 0.005250 \\
$\beta\left(\operatorname{lb} / \log (\mathbf{s})^{2}\right)$ & -0.006797 & -0.011320 & -0.010373 & -0.005762 & -0.009750 & -0.008800 \\
$\gamma\left(\operatorname{lb} / \log (\mathbf{s})^{3}\right)$ & -0.0002928 & 0.0004535 & 0.0003250 & -0.0005267 & 0.0004194 & 0.0000757 \\
\hline
\end{tabular}

Table 13. Data fit coefficients for 20 gage PVC wire aged for 10 weeks at $125^{\circ} \mathrm{C}$ 


\begin{tabular}{|l|ccccc|c|}
\hline & Trial 1 & Trial 2 & Trial 3 & Trial 4 & Trial 5 & Average \\
\hline $\mathbf{k}(\mathbf{I b s} / \mathrm{in})$ & 795.9 & 915.3 & 973.6 & 829.6 & 1239.9 & 950.9 \\
$\lambda(\mathbf{l b s})$ & -0.57384 & -1.00054 & -0.93329 & -0.75392 & -1.89939 & -1.03220 \\
\hline $\mathbf{a}(\mathbf{l b s} / \mathrm{in})$ & 67.10 & -98.37 & -115.13 & -23.96 & -247.14 & -83.50 \\
$\mathbf{b}\left(\mathbf{l b s} / \mathbf{i n}^{2}\right)$ & 213610 & 247673 & 294441 & 218988 & 289610 & 252864 \\
\hline$\alpha(\operatorname{lb} / \log (\mathbf{s}))$ & 0.004153 & 0.001420 & 0.000939 & 0.001641 & 0.001017 & 0.001834 \\
$\beta\left(\operatorname{lb} / \log (\mathbf{s})^{2}\right)$ & -0.007997 & -0.004794 & -0.004957 & -0.005133 & -0.004983 & -0.005573 \\
$\gamma\left(\operatorname{lb} / \log (\mathbf{s})^{3}\right)$ & 0.0010181 & -0.0002199 & -0.0000493 & 0.0001437 & 0.0001170 & 0.0002019 \\
\hline
\end{tabular}

Table 14. Data fit coefficients for 20 gage PVC wire aged for 12 weeks at $125^{\circ} \mathrm{C}$

\begin{tabular}{|l|ccccc|c|}
\hline & Trial 1 & Trial 2 & Trial 3 & Trial 4 & Trial 5 & Average \\
\hline $\mathbf{k}(\mathbf{I b s} / \mathrm{in})$ & 1709.4 & 1315.6 & 808.2 & 1105.2 & 1318.5 & 1251.4 \\
$\lambda(\mathbf{l b s})$ & -1.36182 & -1.19340 & -1.18813 & -1.82011 & -2.01990 & -1.51667 \\
\hline $\mathbf{a}(\mathbf{I b s} / \mathrm{in})$ & -246.82 & -208.37 & -113.49 & -237.14 & -343.89 & -229.94 \\
$\mathbf{b}\left(\mathbf{l b s} / \mathbf{i n}^{2}\right)$ & 676241 & 465379 & 166178 & 243846 & 349122 & 380153 \\
\hline$\alpha(\mathbf{l b} / \log (\mathbf{s}))$ & 0.003062 & 0.004701 & 0.004683 & 0.004604 & 0.003221 & 0.004054 \\
$\beta\left(\operatorname{lb} / \log (\mathbf{s})^{2}\right)$ & -0.006093 & -0.009014 & -0.008180 & -0.008526 & -0.006927 & -0.007748 \\
$\gamma\left(\operatorname{lb} / \log (\mathbf{s})^{3}\right)$ & -0.0001968 & 0.0001573 & 0.0004759 & 0.0002236 & -0.0001379 & 0.0001044 \\
\hline
\end{tabular}

Table 15. Data fit coefficients for 20 gage PVC wire aged for 14 weeks at $125^{\circ} \mathrm{C}$

\begin{tabular}{|l|ccccc|c|}
\hline & Trial 1 & Trial 2 & Trial 3 & Trial 4 & Trial 5 & Average \\
\hline $\mathbf{k}(\mathbf{l b s} / \mathrm{in})$ & 1536.4 & 1472.0 & 1025.3 & 1059.2 & 1228.8 & 1264.4 \\
$\lambda(\mathbf{l b s})$ & -1.68252 & -1.70851 & -1.42696 & -1.49836 & -1.97816 & -1.65890 \\
\hline $\mathbf{a}(\mathbf{l b s} / \mathbf{i n})$ & -251.39 & -293.27 & -210.74 & -252.84 & -300.70 & -261.79 \\
$\mathbf{b}\left(\mathbf{l b s} / \mathbf{i n}^{2}\right)$ & 461594 & 445650 & 258301 & 278323 & 293289 & 347431 \\
\hline $\boldsymbol{\alpha}(\mathbf{l b} / \log (\mathbf{s}))$ & 0.002609 & 0.003708 & 0.001937 & 0.005309 & 0.004021 & 0.003517 \\
$\beta\left(\operatorname{lb} / \log (\mathbf{s})^{2}\right)$ & -0.005727 & -0.007272 & -0.005797 & -0.009690 & -0.008940 & -0.007485 \\
$\gamma\left(\operatorname{lb} / \log (\mathbf{s})^{3}\right)$ & 0.0000699 & 0.0004177 & -0.0000619 & 0.0010663 & 0.0006049 & 0.0004194 \\
\hline
\end{tabular}

Table 16. Data fit coefficients for 20 gage PVC wire aged for 16 weeks at $125^{\circ} \mathrm{C}$

Unaged 0.008" and 0.019" PVC Film 


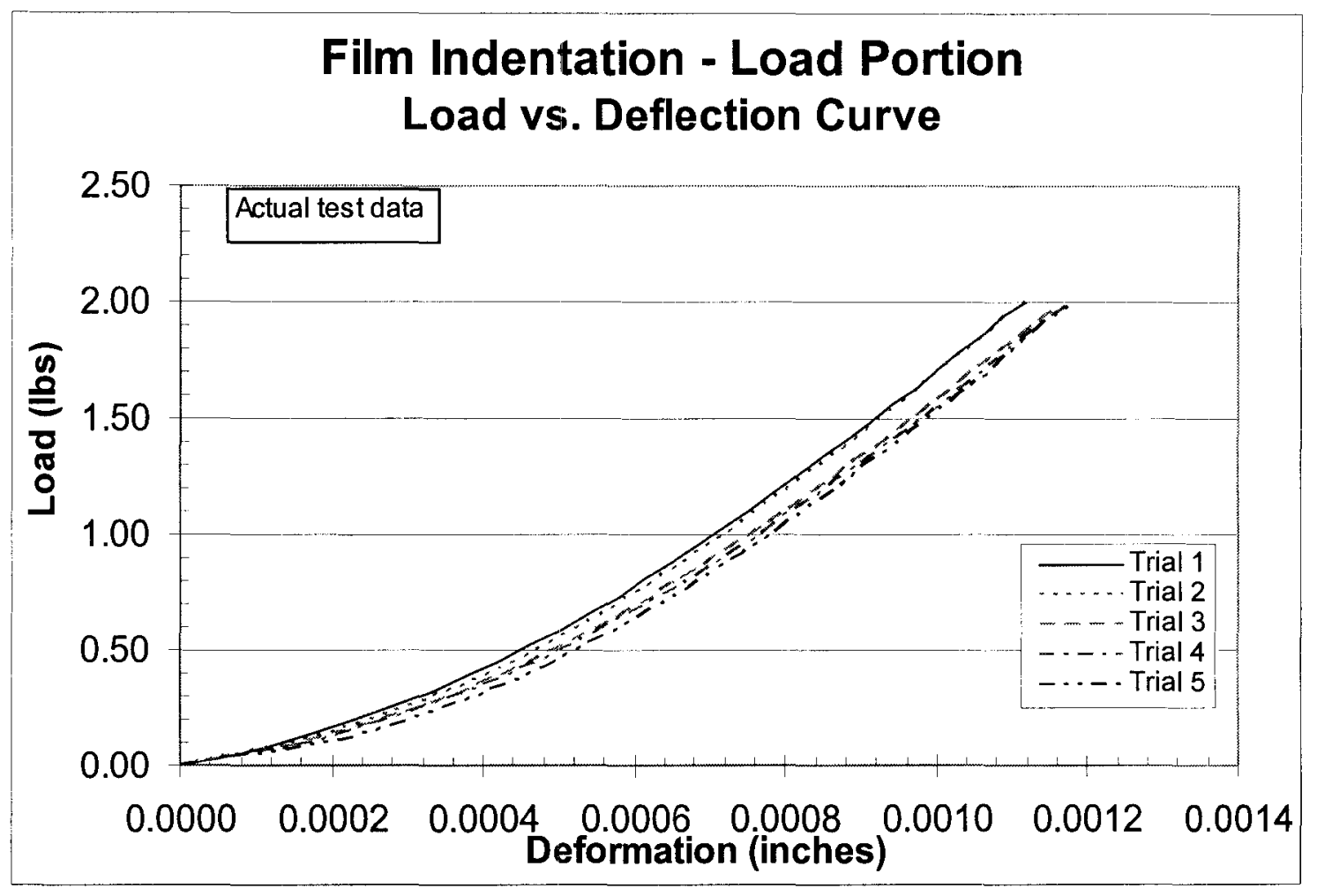

Figure 62. Load-displacement data for unaged 0.008 " PVC film

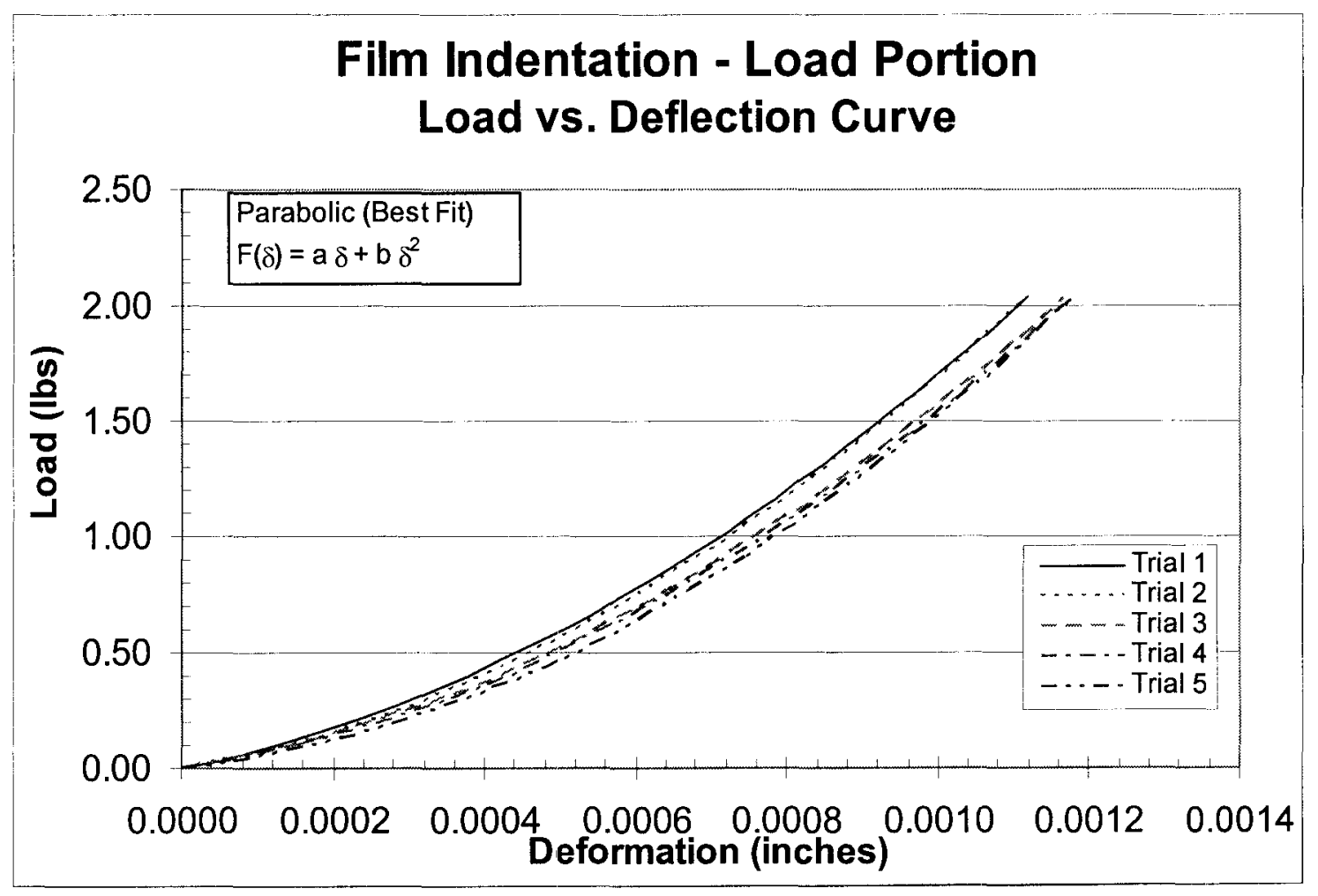

Figure 63. Load-displacement fits for unaged 0.008” PVC film 


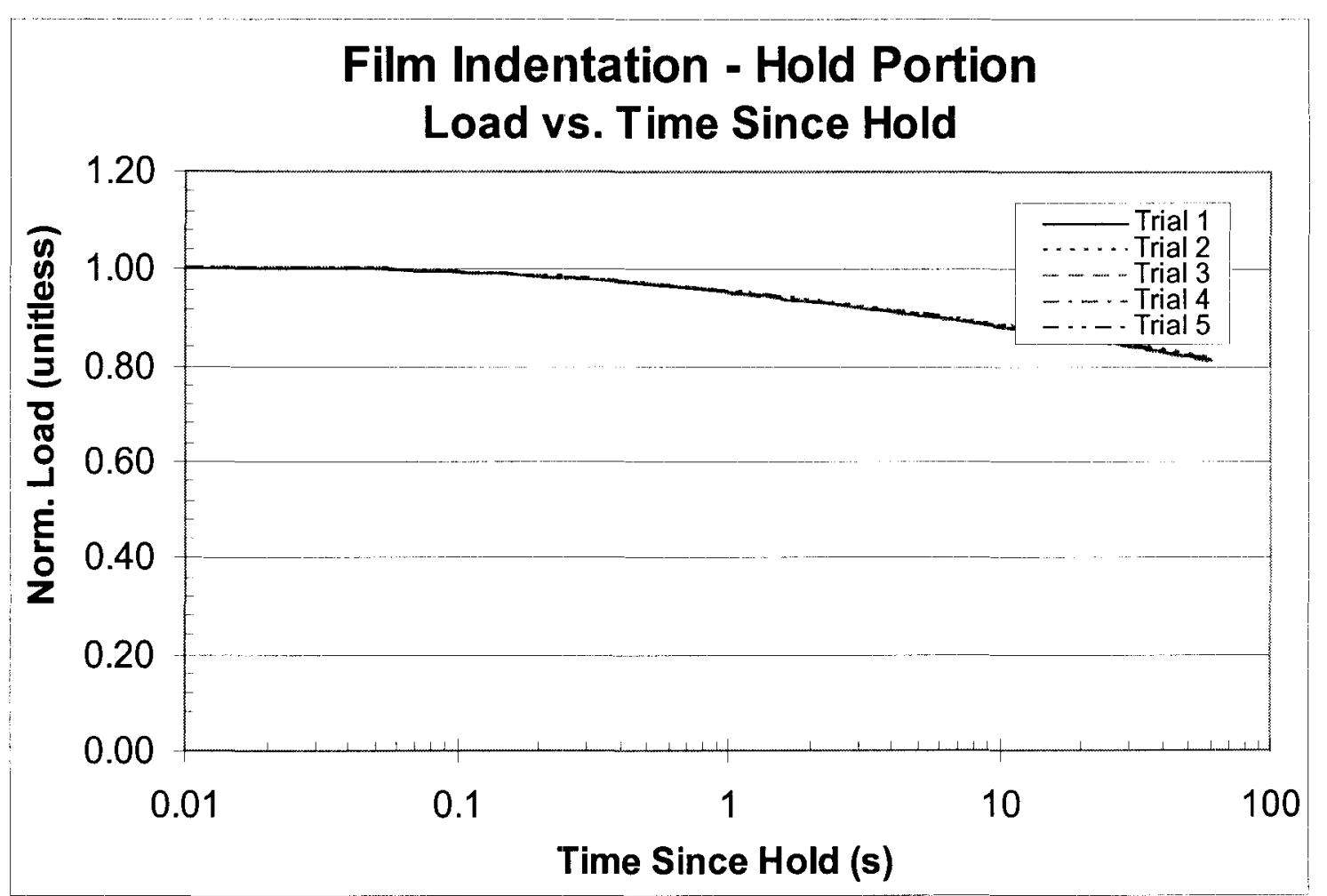

Figure 64. Normalized relaxation fits for unaged 0.008 " PVC film

\begin{tabular}{|l|ccccc|c|}
\hline & Trial 1 & Trial 2 & Trial 3 & Trial 4 & Trial 5 & Average \\
\hline $\mathbf{k}(\mathbf{l b s} / \mathbf{i n})$ & 2106.6 & 2150.0 & 2066.5 & 2046.8 & 2125.6 & 2099.1 \\
$\lambda(\mathbf{l b s})$ & -0.43538 & -0.49580 & -0.50898 & -0.51249 & -0.60839 & -0.51221 \\
\hline $\mathbf{a}(\mathbf{l b s} / \mathbf{i n})$ & 674.93 & 565.01 & 521.21 & 478.34 & 355.93 & 519.09 \\
$\mathbf{b}\left(\mathbf{l b s} / \mathbf{i n}^{2}\right)$ & 1031929 & 1127521 & 1045901 & 1063204 & 1164673 & 1086646 \\
\hline$\alpha(\mathbf{l b} / \log (\mathbf{s}))$ & 0.014822 & 0.014171 & 0.013748 & 0.013222 & 0.013853 & 0.013963 \\
$\beta\left(\mathbf{l b} / \log (\mathbf{s})^{2}\right)$ & -0.021196 & -0.020153 & -0.020944 & -0.020357 & -0.020330 & -0.020596 \\
$\gamma\left(\mathbf{l b} / \mathbf{l o g}(\mathbf{s})^{3}\right)$ & 0.0010835 & 0.0009477 & 0.0010315 & 0.0009518 & 0.0009791 & 0.0009987 \\
\hline
\end{tabular}

Table 17. Data fit coefficients for unaged 0.008" PVC film. 


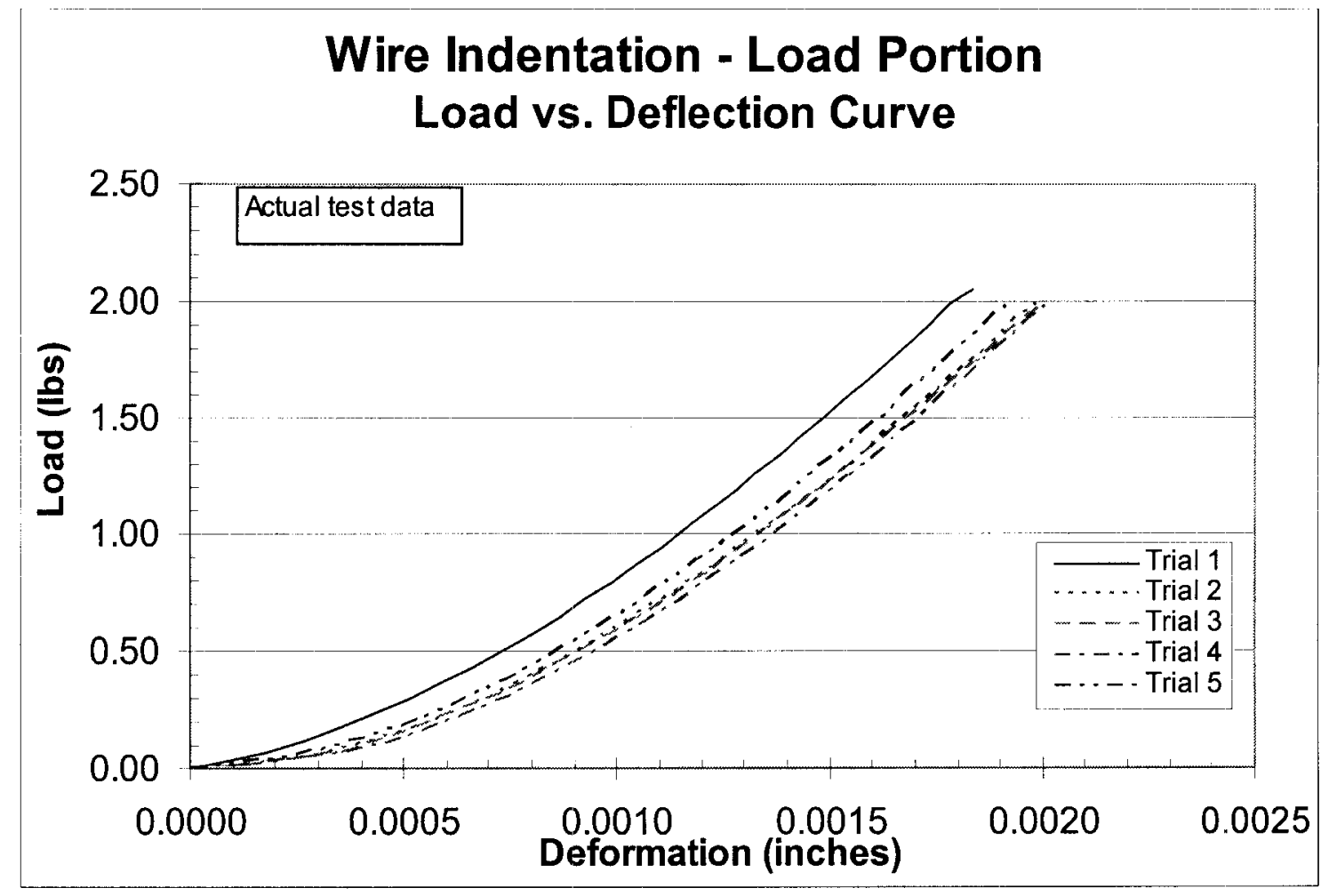

Figure 65. Load-displacement data for unaged 0.019 " PVC film.

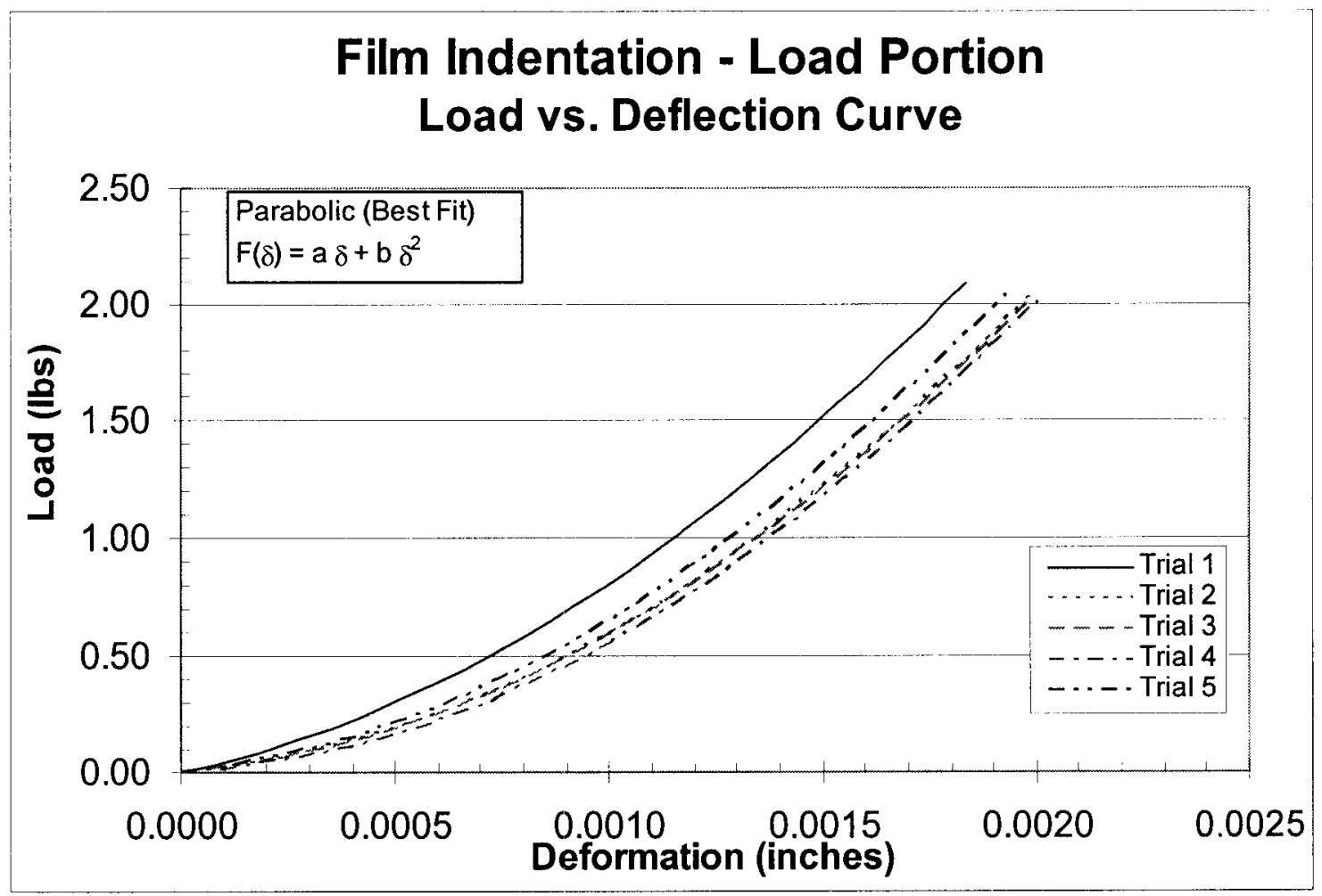

Figure 66. Load-displacement fits for unaged 0.019" PVC film 


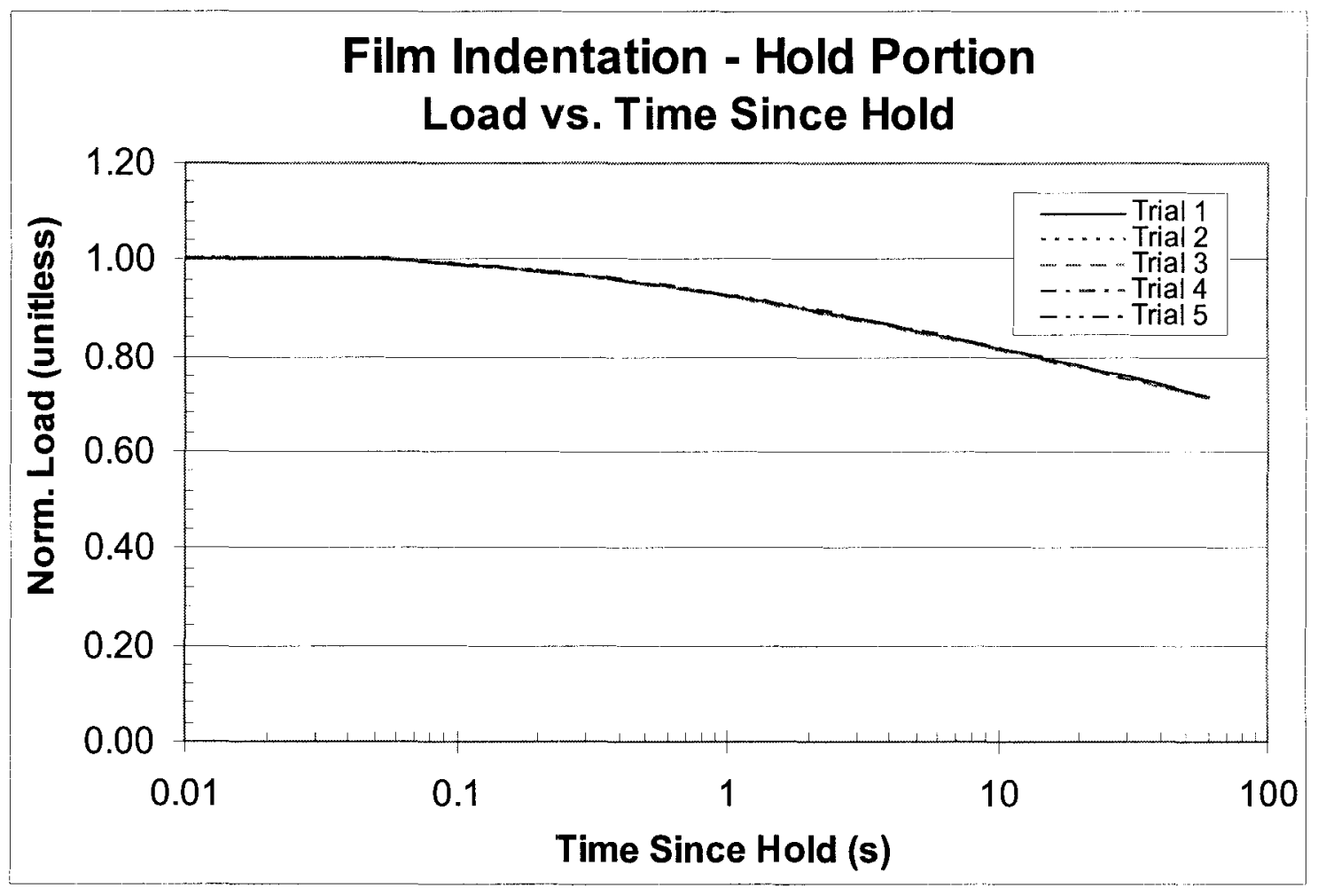

Figure 67. Normalized relaxation fits for 0.019 ” PVC film unaged

\begin{tabular}{|l|ccccc|c|}
\hline & Trial 1 & Trial 2 & Trial 3 & Trial 4 & Trial 5 & Average \\
\hline $\mathbf{k}(\mathbf{l b s} / \mathrm{in})$ & 1323.6 & 1263.9 & 1250.9 & 1287.4 & 1290.5 & 1283.3 \\
$\lambda(\mathbf{l b s})$ & -0.46723 & -0.62931 & -0.62302 & -0.71713 & -0.59513 & -0.60636 \\
\hline $\mathbf{a}(\mathbf{l b s} / \mathrm{in})$ & 404.05 & 160.80 & 156.95 & 100.89 & 207.87 & 206.11 \\
$\mathbf{b}\left(\operatorname{lbs} / \mathbf{i n}^{2}\right)$ & 401954 & 435029 & 430841 & 451290 & 441440 & 432111 \\
\hline$\alpha(\operatorname{lb} / \log (\mathbf{s}))$ & 0.024052 & 0.024138 & 0.025048 & 0.025232 & 0.024252 & 0.024545 \\
$\beta\left(\operatorname{lb} / \log (\mathbf{s})^{2}\right)$ & -0.035431 & -0.036482 & -0.037320 & -0.037200 & -0.036065 & -0.036499 \\
$\gamma\left(\operatorname{lb} / \log (\mathbf{s})^{3}\right)$ & 0.0024491 & 0.0026320 & 0.0027588 & 0.0027241 & 0.0025156 & 0.0026159 \\
\hline
\end{tabular}

Table 18. Data fit coefficients for unaged 0.019 " PVC film. 


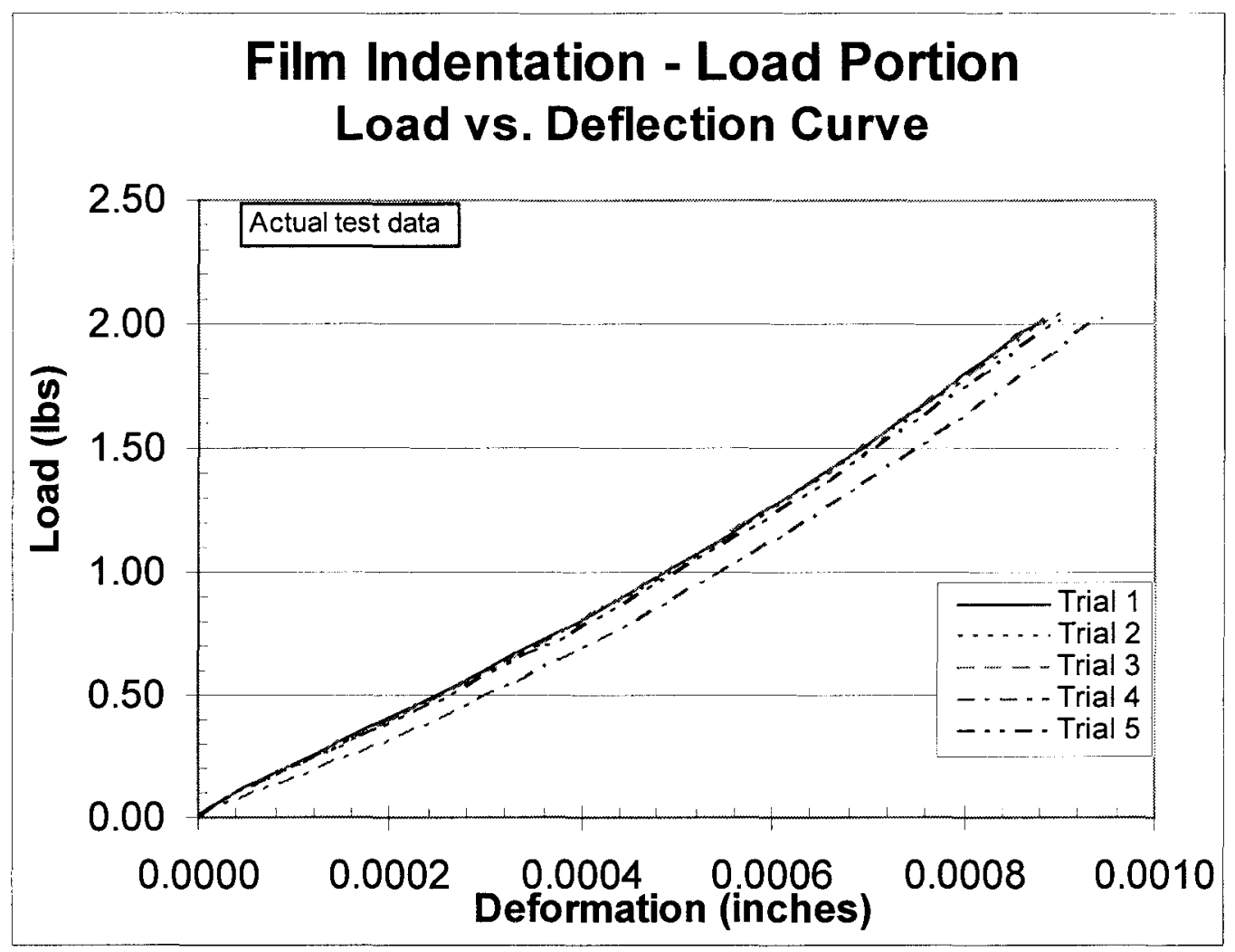

Figure 68. Load-displacement data for $0.008^{\prime \prime} \mathrm{PVC}$ film aged for 2 days at $105^{\circ} \mathrm{C}$.

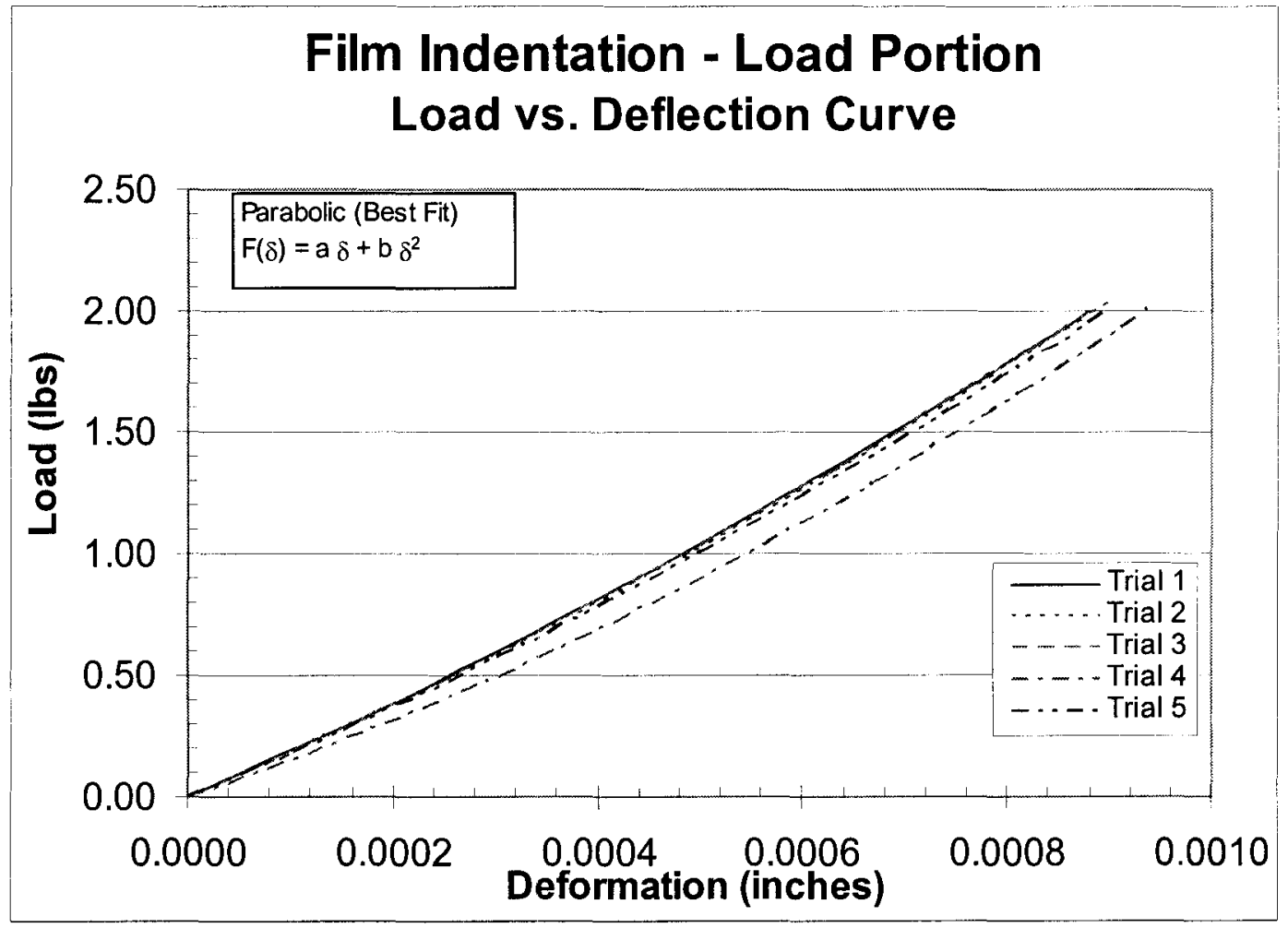

Figure 69. Load-displacement fits for $0.008^{\prime \prime} \mathrm{PVC}$ film aged for 2 days at $105^{\circ} \mathrm{C}$. 


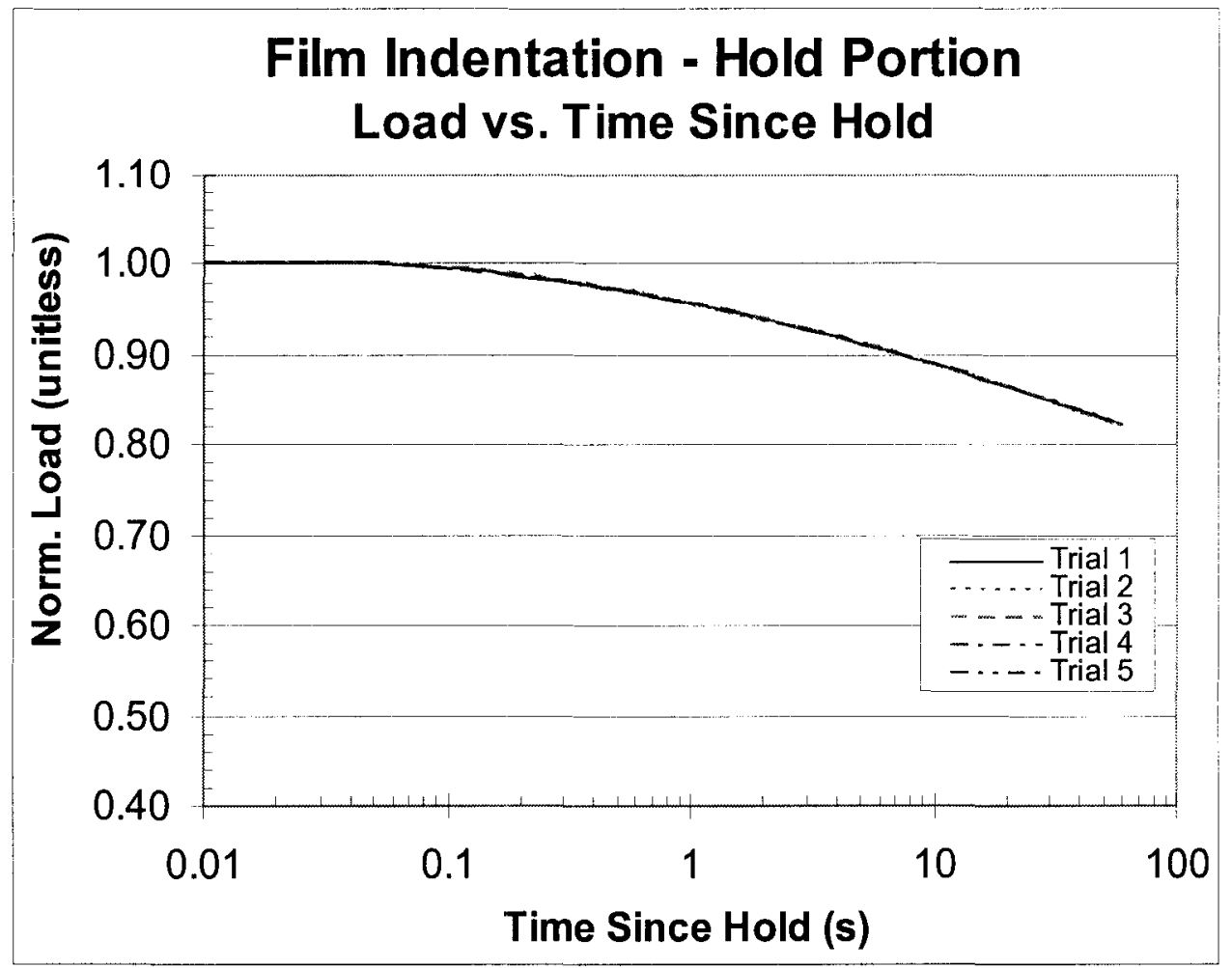

Figure 70 . Normalized relaxation fits for $0.008^{\prime \prime} \mathrm{PVC}$ film aged for 2 days at $105^{\circ} \mathrm{C}$.

\begin{tabular}{|l|ccccc|c|}
\hline & Trial 1 & Trial 2 & Trial 3 & Trial 4 & Trial 5 & Average \\
\hline $\mathbf{k}(\mathbf{l b s} / \mathrm{in})$ & 2212.9 & 2244.8 & 2243.6 & 2213.0 & 2212.3 & 2225.3 \\
$\lambda(\mathbf{b s})$ & -0.04076 & -0.07098 & -0.06604 & -0.16384 & -0.07912 & -0.08415 \\
\hline $\mathbf{a}(\mathbf{l b s} / \mathrm{in})$ & 1834.17 & 1771.99 & 1784.70 & 1399.79 & 1722.84 & 1702.69 \\
$\mathbf{b}\left(\mathbf{l b s} / \mathbf{i n}^{2}\right)$ & 500335 & 550608 & 552732 & 790529 & 562663 & 591373 \\
\hline$\alpha(\mathbf{b} / \log (\mathbf{s}))$ & 0.014616 & 0.013112 & 0.013990 & 0.014015 & 0.013821 & 0.013911 \\
$\beta \boldsymbol{\beta}\left(\mathbf{l b} / \log (\mathbf{s})^{2}\right)$ & -0.020310 & -0.019528 & -0.019462 & -0.020158 & -0.019979 & -0.019887 \\
$\gamma\left(\mathbf{l b} / \log (\mathbf{s})^{3}\right)$ & 0.0010727 & 0.0009117 & 0.0008244 & 0.0010184 & 0.0010254 & 0.0009705 \\
\hline
\end{tabular}

Table 19. Data fit coefficients for $0.008^{\prime \prime} P V C$ film aged for 2 days at $105^{\circ} \mathrm{C}$ 


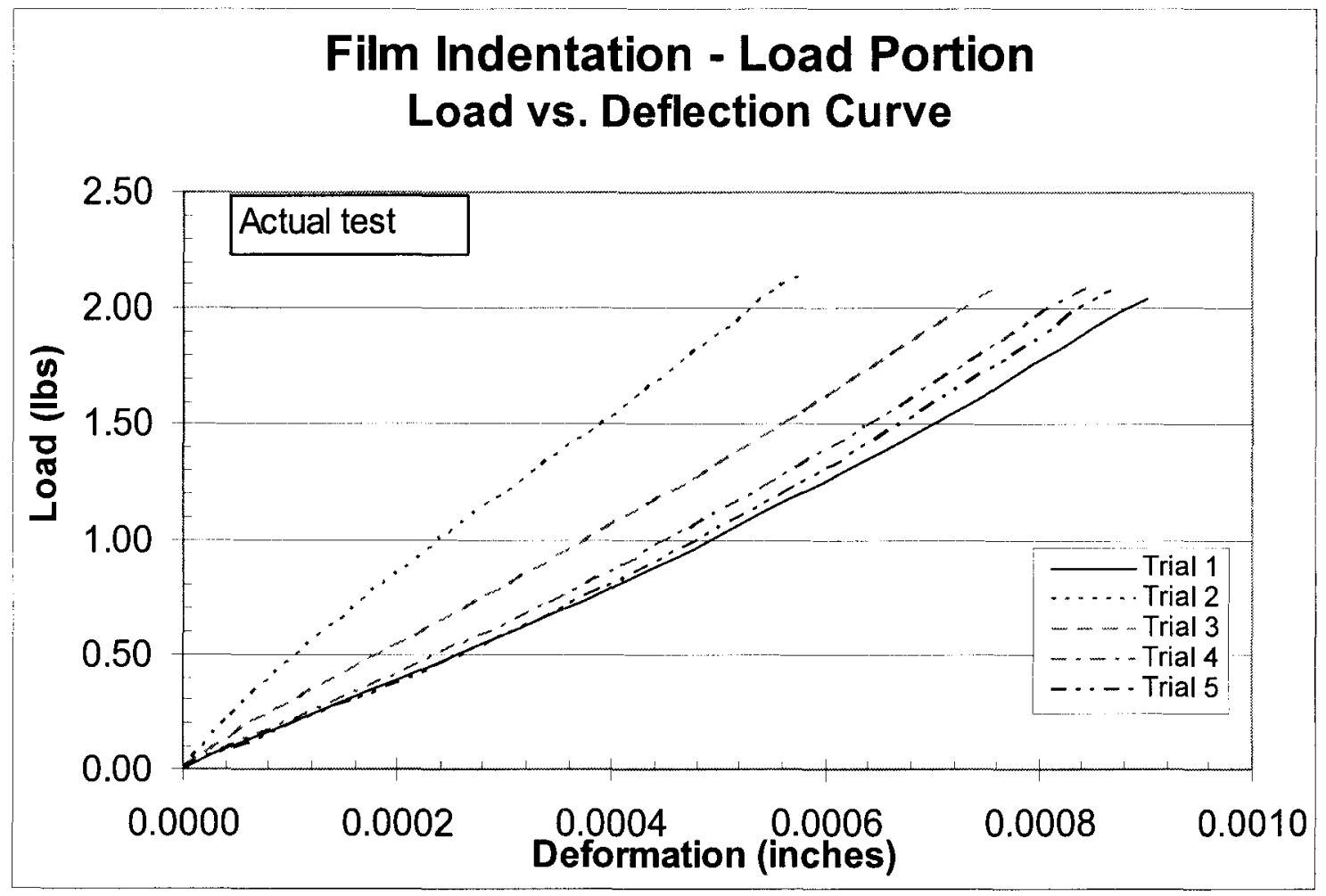

Figure 71 . Load-displacement fits for $0.008^{\prime \prime}$ PVC film aged for 5 days at $105^{\circ} \mathrm{C}$.

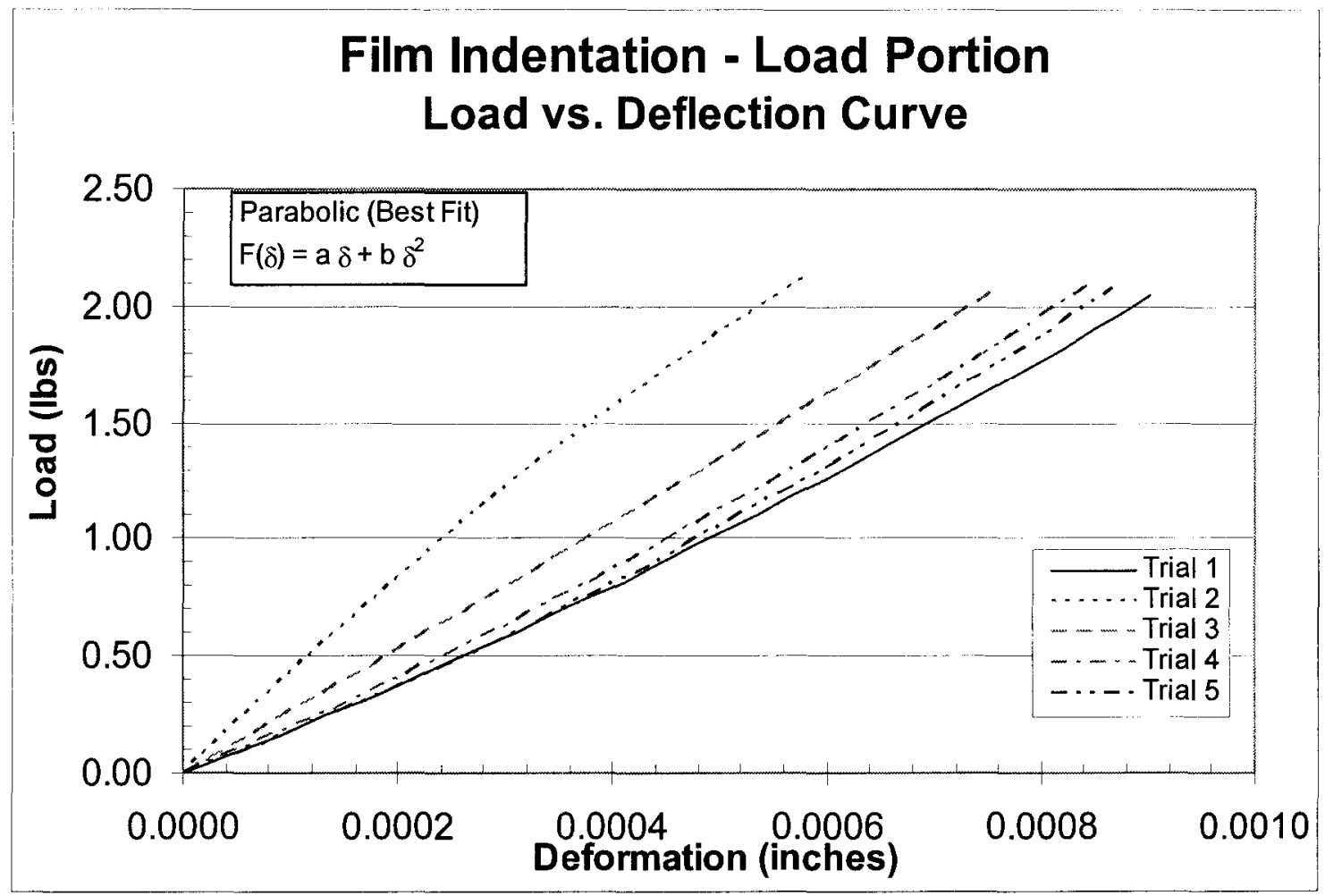

Figure 72. Load-displacement data for $0.008^{\prime \prime} \mathrm{PVC}$ film aged for 5 days at $105^{\circ} \mathrm{C}$ 


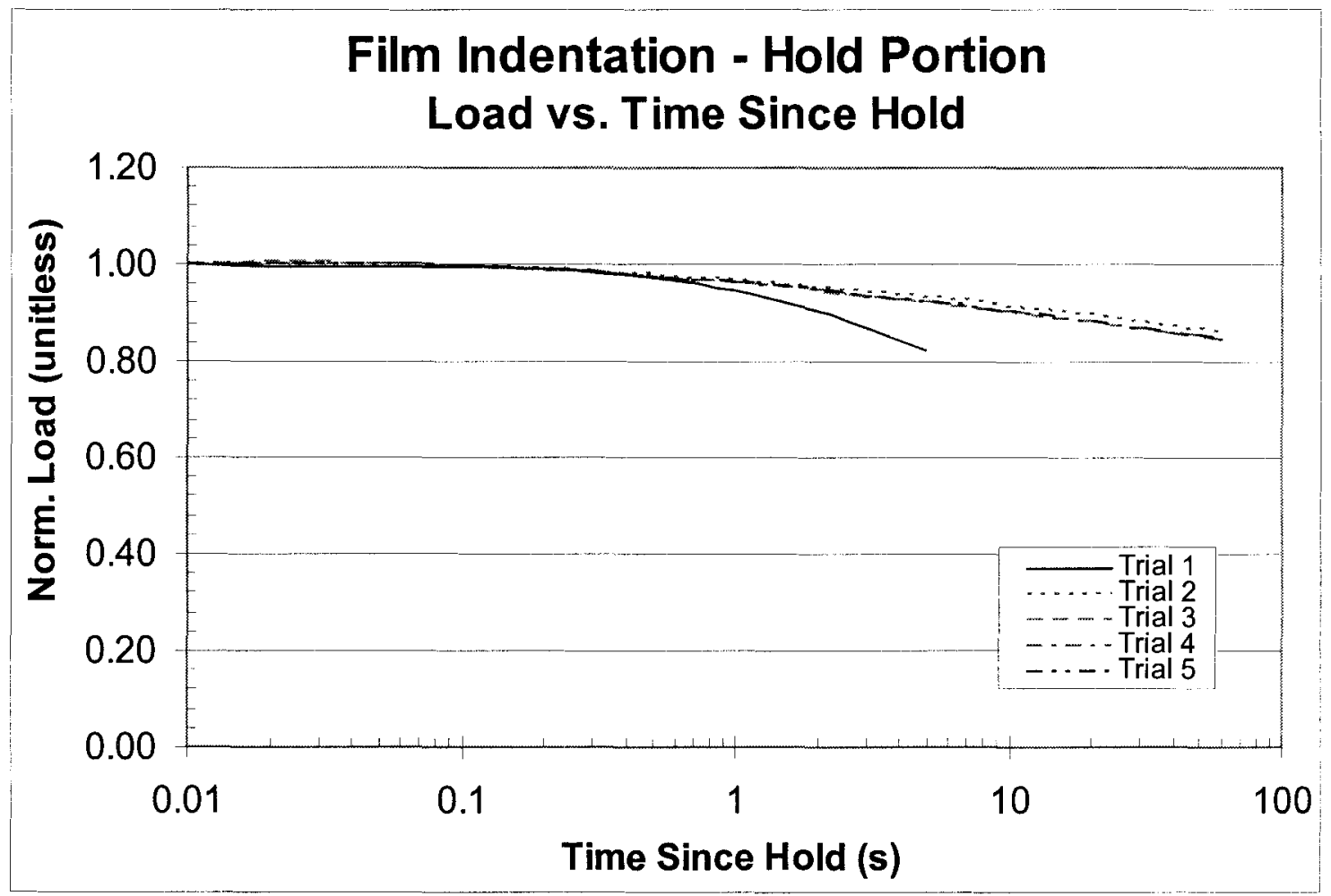

Figure 73. Normalized relaxation fits for $0.008^{\prime \prime} \mathrm{PVC}$ film aged for 5 days at $105^{\circ} \mathrm{C}$

\begin{tabular}{|c|c|c|c|c|c|c|}
\hline & Trial 1 & Trial 2 & Trial 3 & Trial 4 & Trial 5 & Average \\
\hline k (Ibs/in) & 2244.8 & 3506.1 & 2662.9 & 2477.2 & 2437.5 & 2665.7 \\
\hline$\lambda$ (Ibs) & -0.07098 & 0.13111 & 0.01324 & -0.08765 & -0.12823 & -0.02850 \\
\hline a (Ibs/in) & 1771.99 & 4501.96 & 2590.91 & 1908.64 & 1690.93 & 2492.89 \\
\hline$b\left(\mathrm{lbs} / \mathrm{in}^{2}\right)$ & 550608 & -1443625 & 186169 & 680871 & 820037 & 158812 \\
\hline$\alpha(\operatorname{lb} / \log (\mathrm{s}))$ & -0.023540 & 0.010409 & 0.014263 & 0.012433 & 0.012303 & 0.005174 \\
\hline$\beta\left(\operatorname{lb} / \log (s)^{2}\right)$ & 0.038477 & -0.014887 & -0.019633 & -0.018263 & -0.018190 & -0.006499 \\
\hline$\gamma\left(\mathrm{lb} / \log (\mathrm{s})^{3}\right)$ & -0.0200910 & 0.0006528 & 0.0012990 & 0.0010741 & 0.0010721 & -0.0031986 \\
\hline
\end{tabular}

Table 20. Data fit coefficients for $0.008^{\prime \prime} \mathrm{PVC}$ film aged for 5 days at $105^{\circ} \mathrm{C}$ 


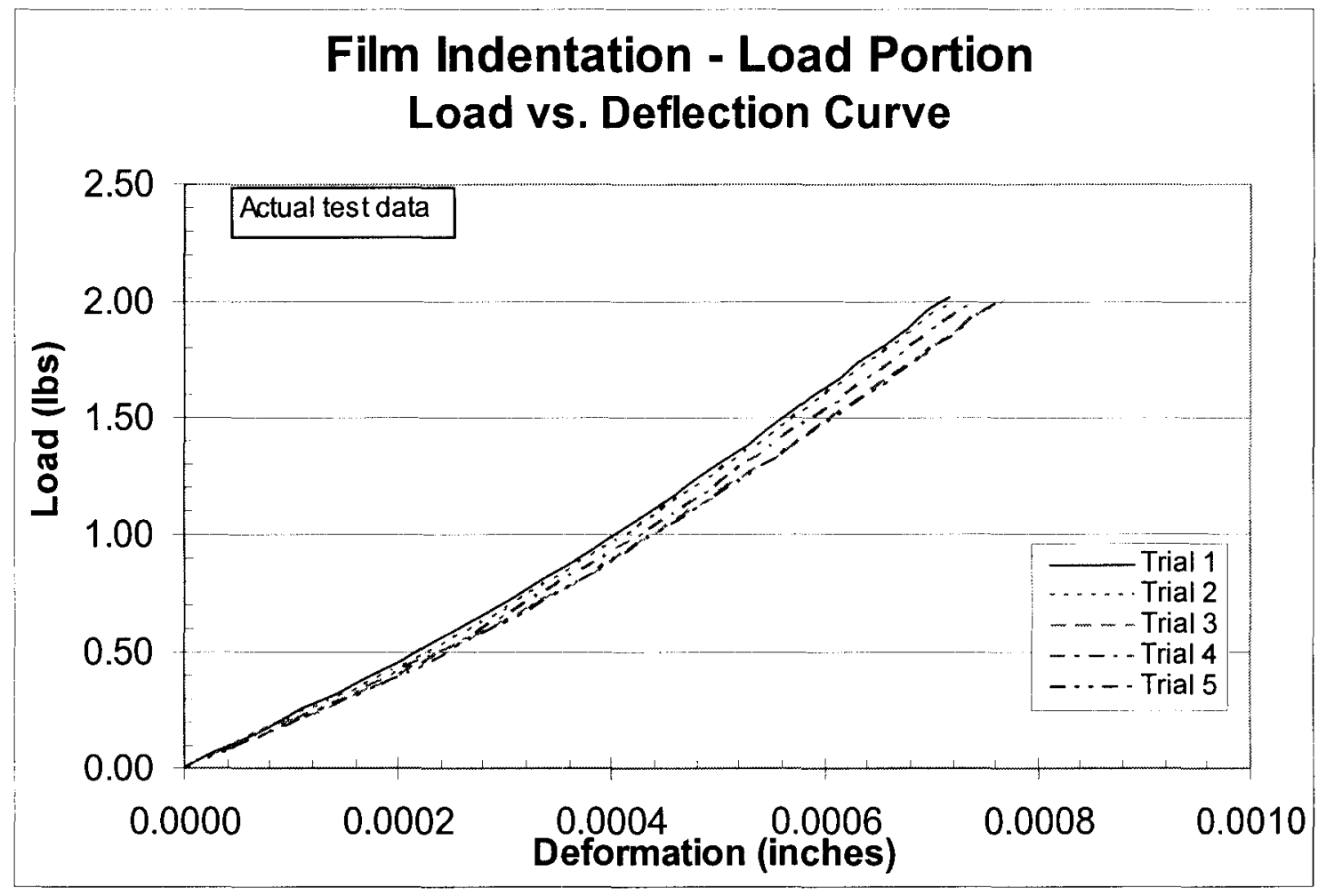

Figure 74. Load-displacement fits for $0.008^{\prime \prime}$ PVC film aged for 1 week at $105^{\circ} \mathrm{C}$.

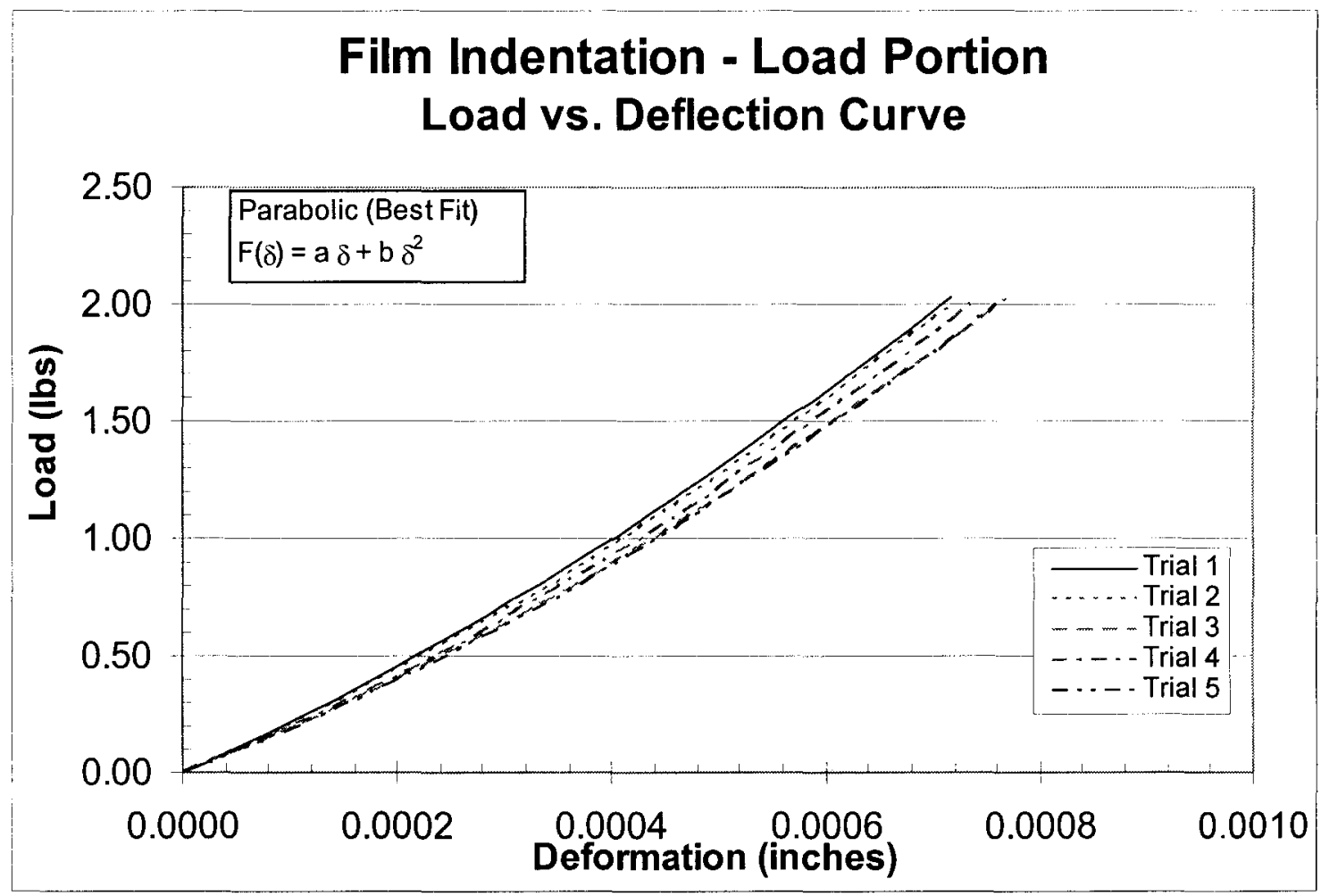

Figure 75. Load-displacement fits for $0.008^{\prime \prime}$ PVC film aged for 1 week at $105^{\circ} \mathrm{C}$. 


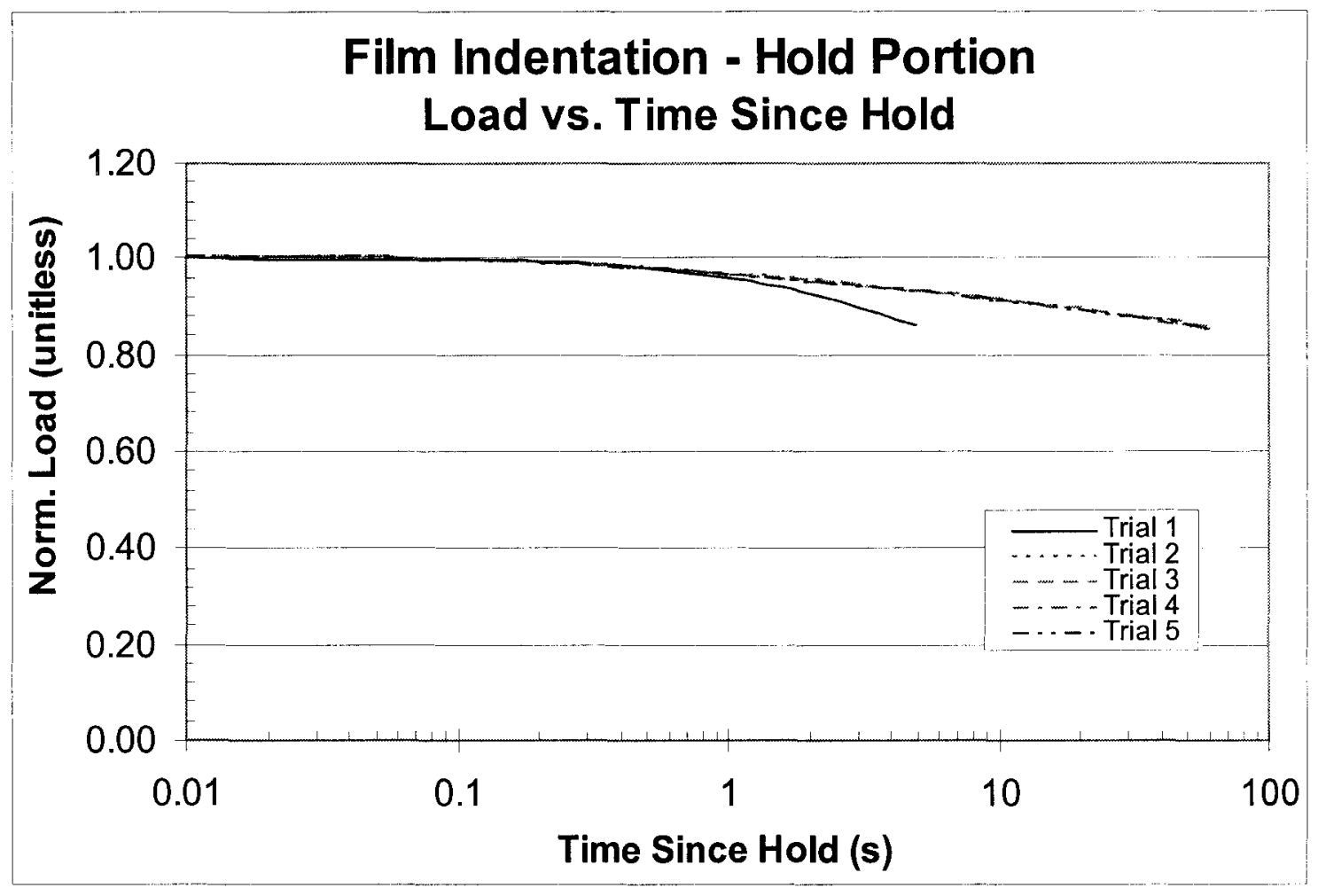

Figure 76. Normalized relaxation fits for $0.008^{\prime \prime} \mathrm{PVC}$ film aged for 1 week at $105^{\circ} \mathrm{C}$.

\begin{tabular}{|l|ccccc|c|}
\hline & Trial 1 & Trial 2 & Trial 3 & Trial 4 & Trial 5 & Average \\
\hline $\mathbf{k}(\mathbf{l b s} / \mathrm{in})$ & 2867.8 & 2844.8 & 2666.5 & 2791.7 & 2711.5 & 2776.5 \\
$\lambda(\mathbf{l b s})$ & -0.11494 & -0.14036 & -0.13642 & -0.14673 & -0.16369 & -0.14043 \\
\hline $\mathbf{a}(\mathbf{l b s} / \mathrm{in})$ & 2064.83 & 1944.13 & 1776.99 & 1824.41 & 1733.99 & 1868.87 \\
$\mathbf{b}\left(\mathrm{lbs} / \mathbf{i n}^{2}\right)$ & 1071674 & 1181946 & 1118532 & 1210840 & 1184972 & 1153593 \\
\hline$\alpha(\mathrm{lb} / \log (\mathbf{s}))$ & -0.019282 & 0.011118 & 0.011218 & 0.010542 & 0.010367 & 0.004793 \\
$\beta \boldsymbol{\beta}\left(\mathrm{lb} / \log (\mathbf{s})^{2}\right)$ & 0.032444 & -0.014796 & -0.015591 & -0.015087 & -0.014898 & -0.005586 \\
$\gamma\left(\operatorname{lb} / \log (\mathbf{s})^{\mathbf{3}}\right)$ & -0.0165984 & 0.0004203 & 0.0007133 & 0.0005111 & 0.0005238 & -0.0028860 \\
\hline
\end{tabular}

Table 21. Data fit coefficients for $0.008^{\prime \prime} \mathrm{PVC}$ film aged for 1 week at $105^{\circ} \mathrm{C}$ 


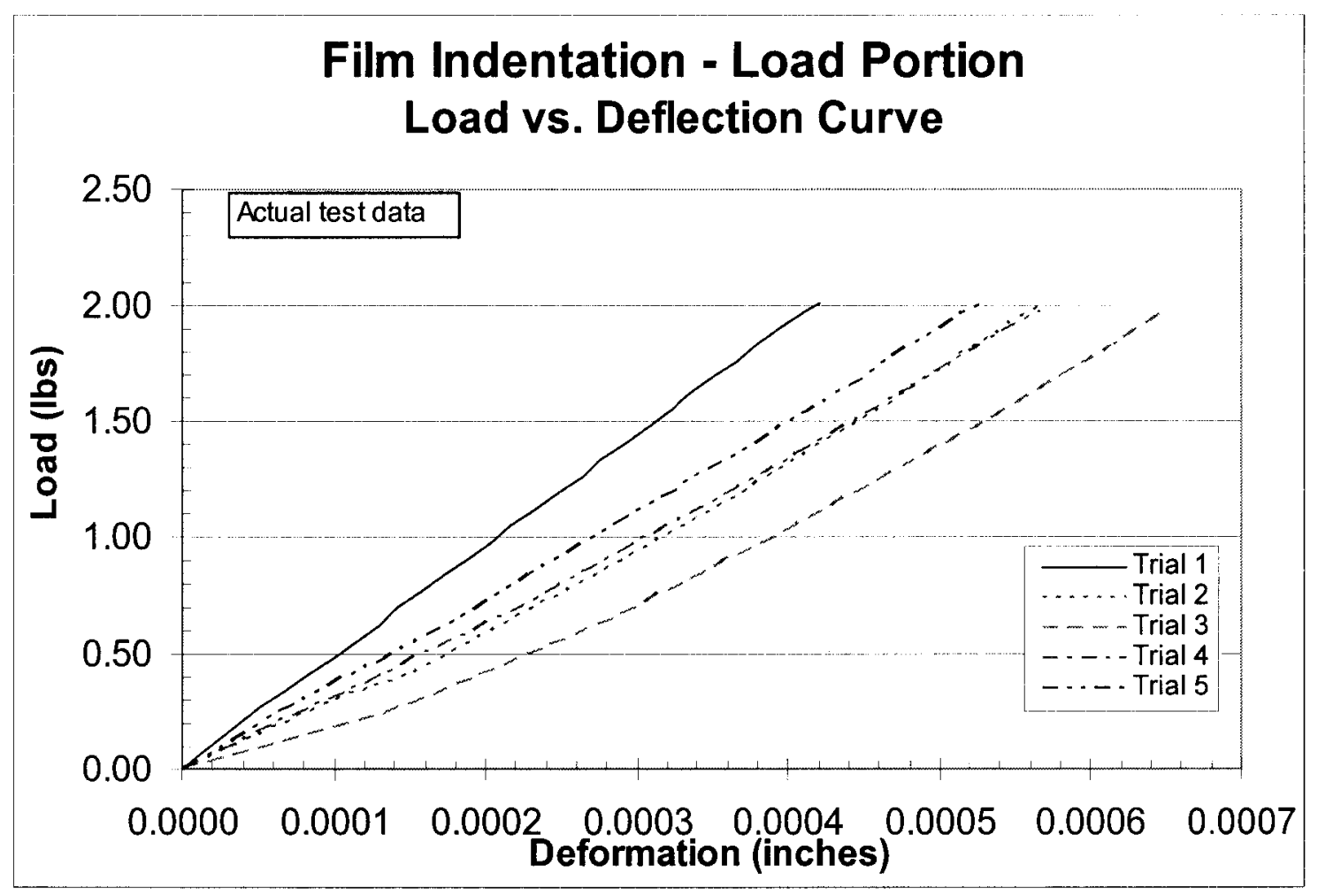

Figure 77 . Load-displacement fits for $0.008^{\prime}$ PVC film aged for 2 weeks at $105^{\circ} \mathrm{C}$.

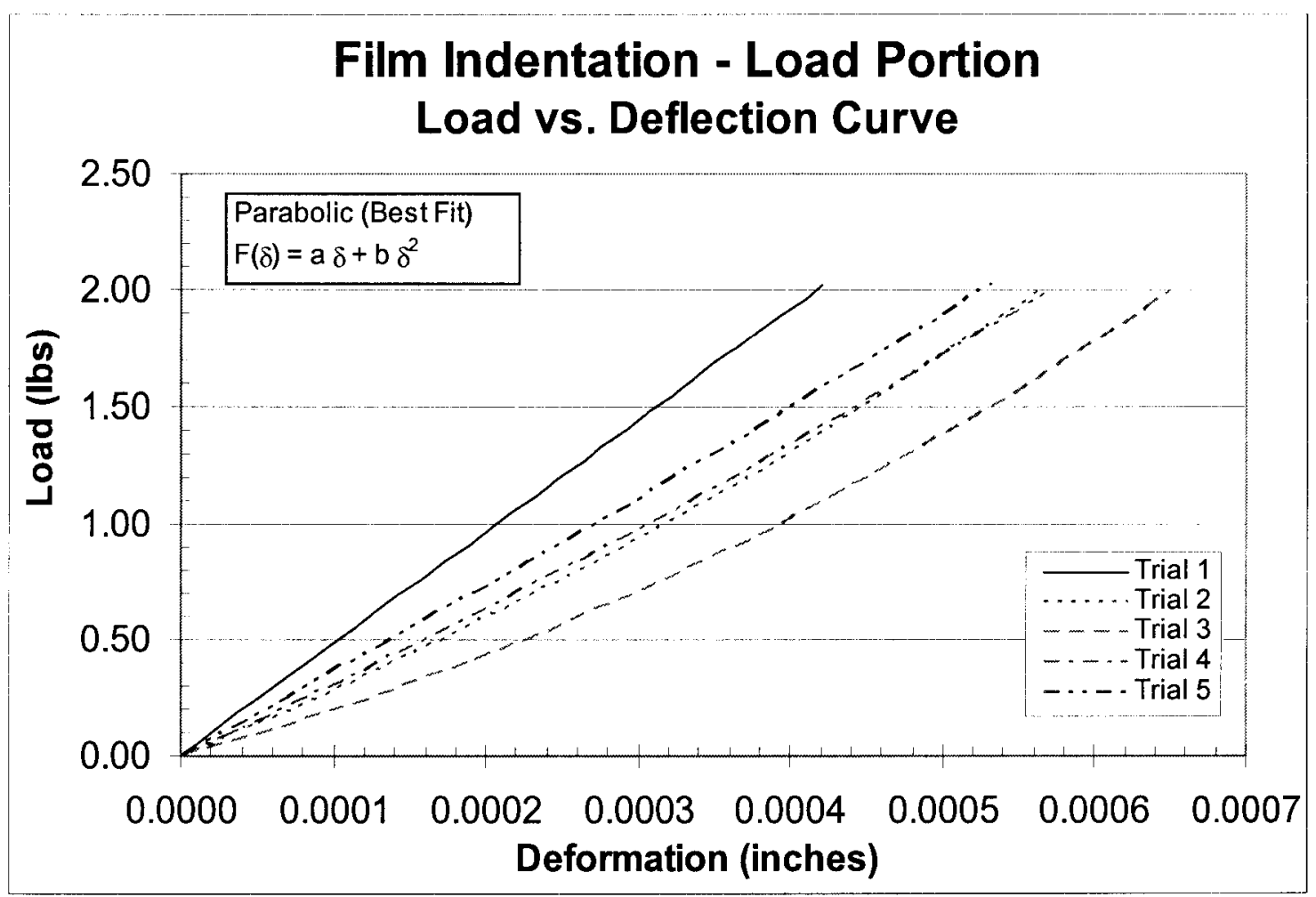

Figure 78. Load-displacement fits for $0.008^{\prime \prime}$ PVC film aged for 2 weeks at $105^{\circ} \mathrm{C}$. 


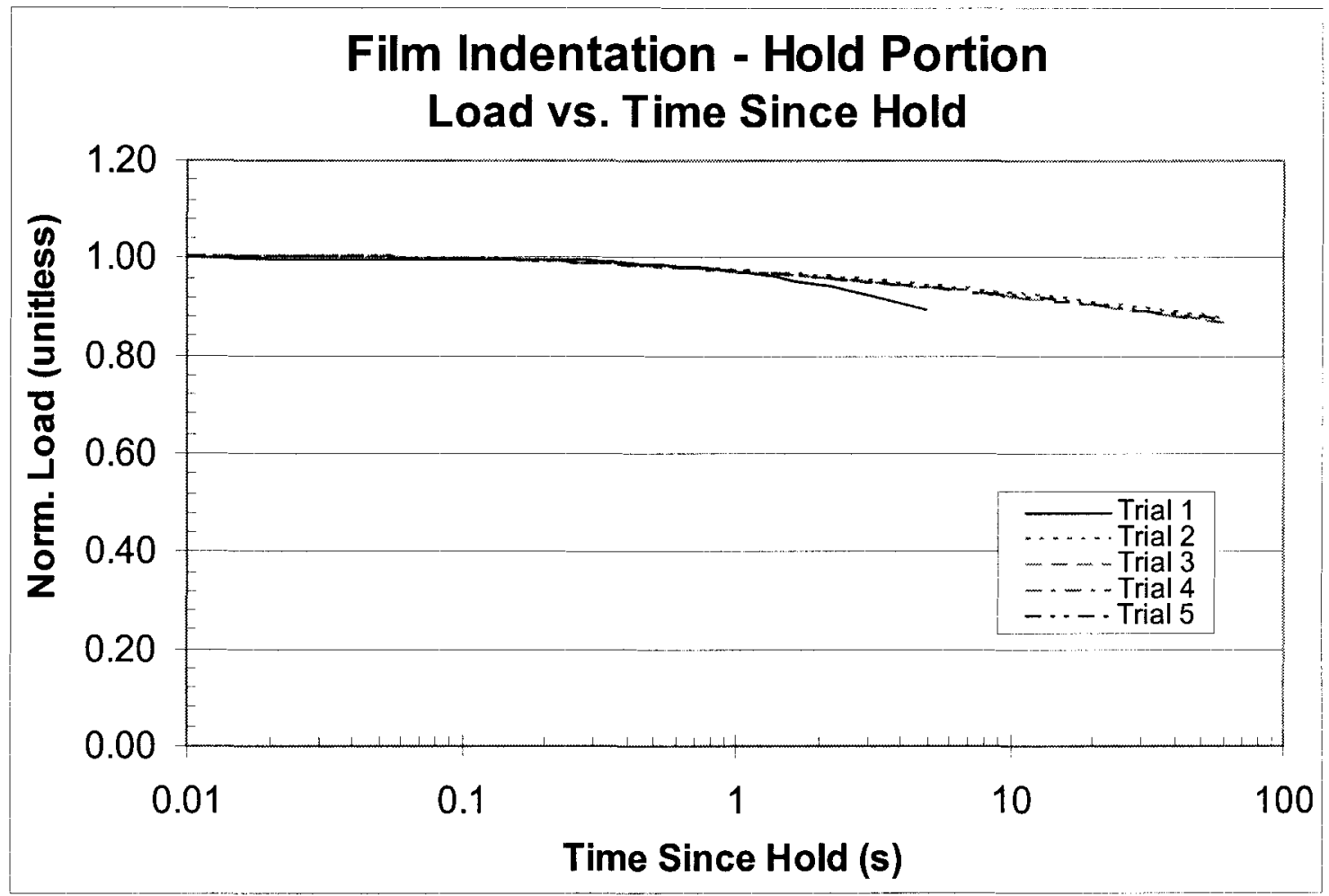

Figure 79. Normalized relaxation fits for $0.008^{\prime \prime} \mathrm{PVC}$ film aged for 2 weeks at $105^{\circ} \mathrm{C}$.

\begin{tabular}{|l|ccccc|c|}
\hline & Trial 1 & Trial 2 & Trial 3 & Trial 4 & Trial 5 & Average \\
\hline $\mathbf{k}(\mathbf{l b s} / \mathrm{in})$ & 4745.6 & 3664.0 & 3261.7 & 3488.9 & 3800.8 & 3792.2 \\
$\lambda(\mathbf{l b s})$ & 0.01669 & -0.14569 & -0.24071 & -0.05325 & -0.02504 & -0.08960 \\
\hline $\mathbf{a}(\mathbf{l b s} / \mathbf{i n})$ & 4878.45 & 2629.27 & 1750.96 & 2976.25 & 3550.43 & 3157.07 \\
$\mathbf{b}\left(\mathbf{l b s} / \mathbf{i n}^{2}\right)$ & -195522 & 1614595 & 2011083 & 923517 & 474886 & 965712 \\
\hline$\alpha(\mathbf{l b} / \log (\mathbf{s}))$ & -0.016984 & 0.007589 & 0.008204 & 0.008291 & 0.008111 & 0.003042 \\
$\beta\left(\operatorname{lb} / \log (\mathbf{s})^{2}\right)$ & 0.029443 & -0.010123 & -0.011348 & -0.011113 & -0.010789 & -0.002786 \\
$\gamma\left(\operatorname{lb} / \log (\mathbf{s})^{3}\right)$ & -0.0139389 & -0.0001267 & -0.0000357 & -0.0001203 & -0.0001050 & -0.0028653 \\
\hline
\end{tabular}

Table 22. Data fit coefficients for $0.008^{\prime \prime}$ PVC film aged for 2 weeks at $105^{\circ} \mathrm{C}$ 


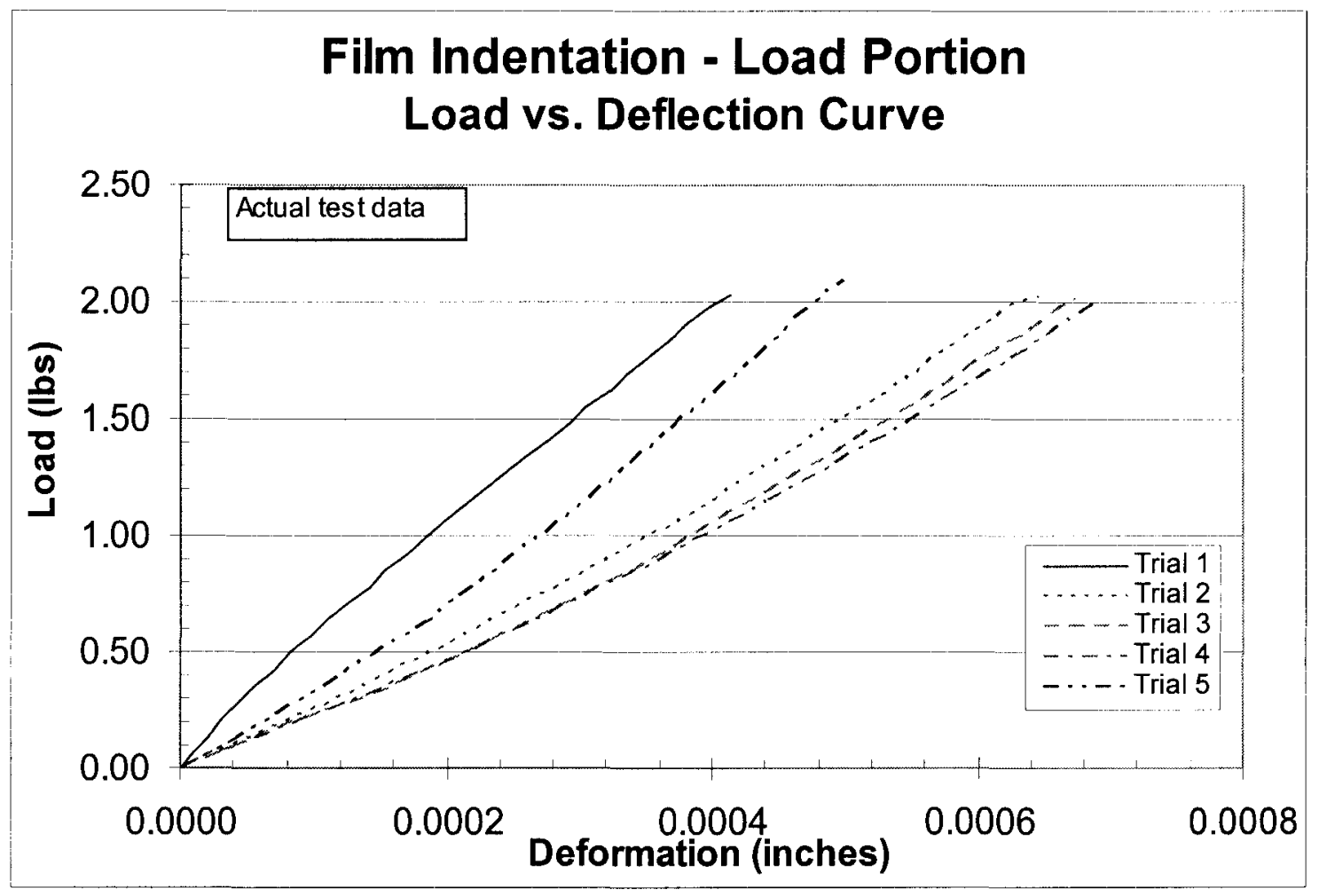

Figure 80 . Load-displacement fits for $0.008^{\prime}$ PVC film aged for 3 weeks at $105^{\circ} \mathrm{C}$.

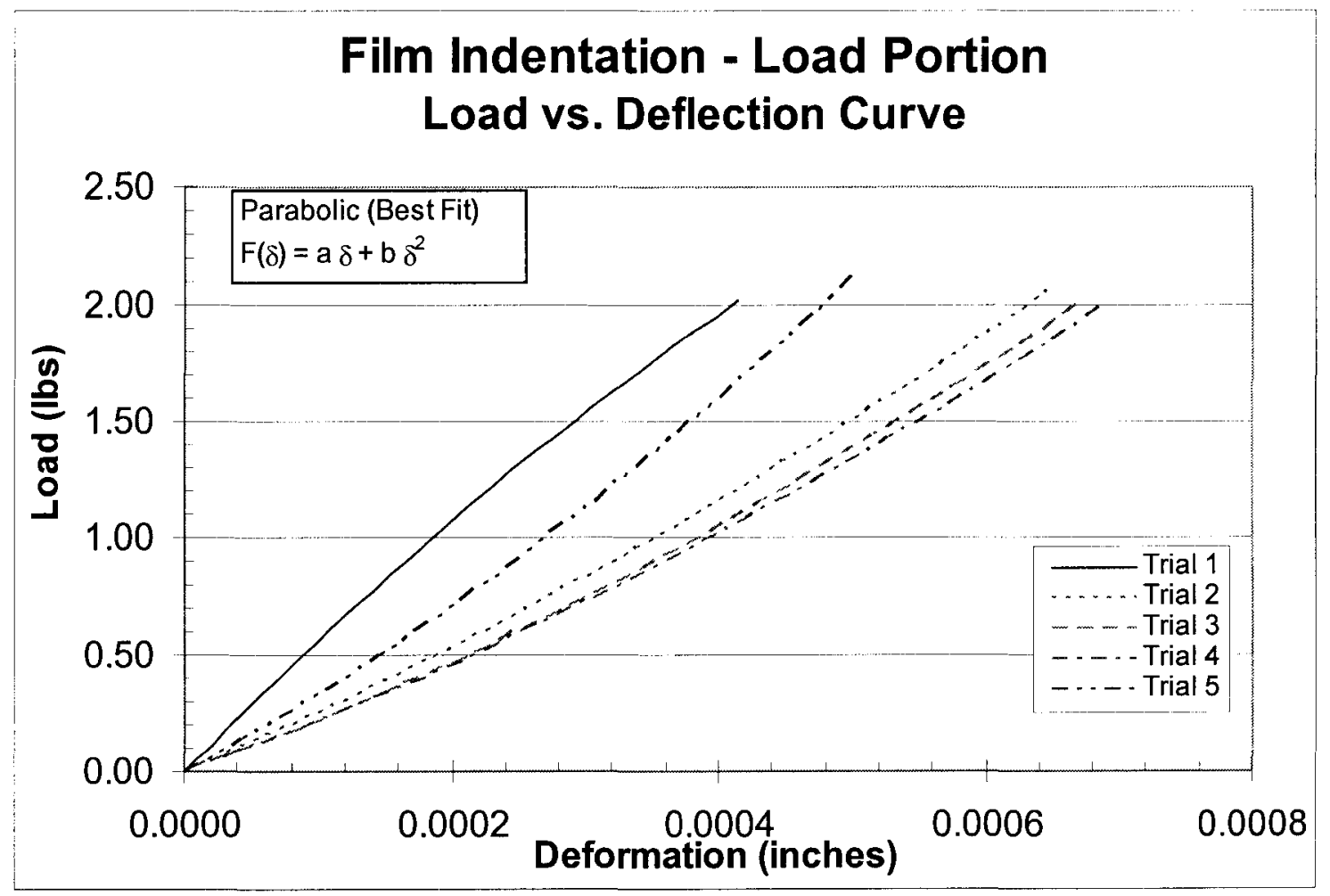

Figure 81. Load-displacement fits for $0.008^{\prime}$ PVC film aged for 3 weeks at $105^{\circ} \mathrm{C}$. 


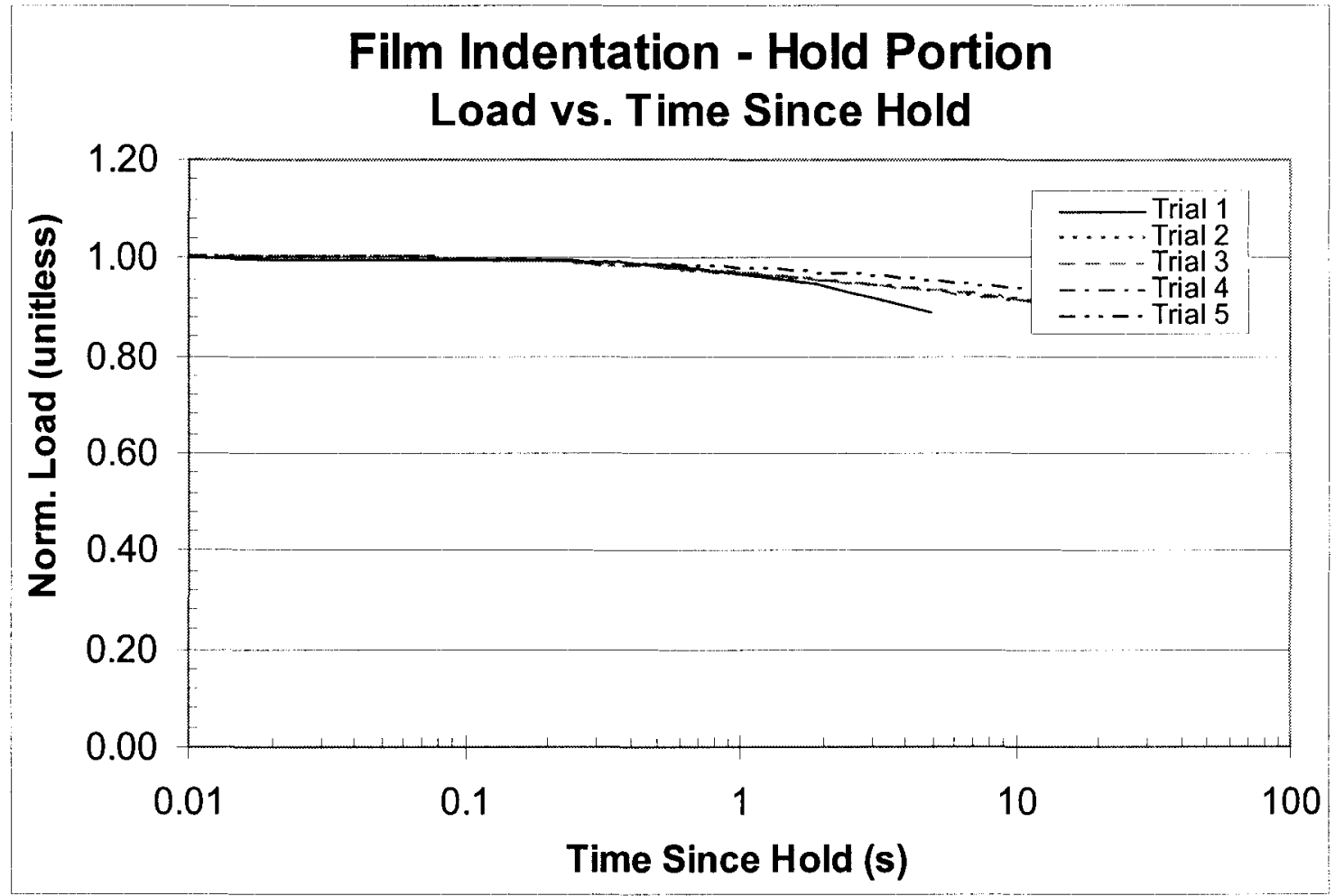

Figure 82. Normalized relaxation fits for $0.008^{\prime \prime} \mathrm{PVC}$ film aged for 3 weeks at $105^{\circ} \mathrm{C}$.

\begin{tabular}{|l|ccccc|c|}
\hline & Trial 1 & Trial 2 & Trial 3 & Trial 4 & Trial 5 & Average \\
\hline $\mathbf{k}(\mathbf{l b s} / \mathrm{in})$ & 4727.3 & 3231.8 & 3076.2 & 2934.2 & 4374.9 & 3668.9 \\
$\lambda(\mathbf{l b s})$ & 0.10456 & -0.10445 & -0.15008 & -0.12451 & -0.14922 & -0.08474 \\
\hline $\mathbf{a}(\mathbf{l b s} / \mathrm{in})$ & 5848.71 & 2423.55 & 2065.50 & 2065.77 & 3065.29 & 3093.77 \\
$\mathbf{b}\left(\mathbf{l b s} / \mathbf{i n}^{2}\right)$ & -2350856 & 1179357 & 1394975 & 1205911 & 2336454 & 753168 \\
\hline$\alpha(\mathbf{l b} / \log (\mathbf{s}))$ & -0.014074 & 0.009455 & 0.010639 & 0.011288 & 0.005828 & 0.004627 \\
$\beta\left(\operatorname{lb} / \log (\mathbf{s})^{2}\right)$ & 0.026349 & -0.012918 & -0.013765 & -0.014834 & -0.007192 & -0.004472 \\
$\gamma\left(\operatorname{lb} / \log (\mathbf{s})^{3}\right)$ & -0.0133910 & 0.0001815 & 0.0003060 & 0.0004983 & -0.0004260 & -0.0025662 \\
\hline
\end{tabular}

Table 23. Data fit coefficients for $0.008^{\prime \prime} \mathrm{PVC}$ film aged for 3 weeks at $105^{\circ} \mathrm{C}$ 


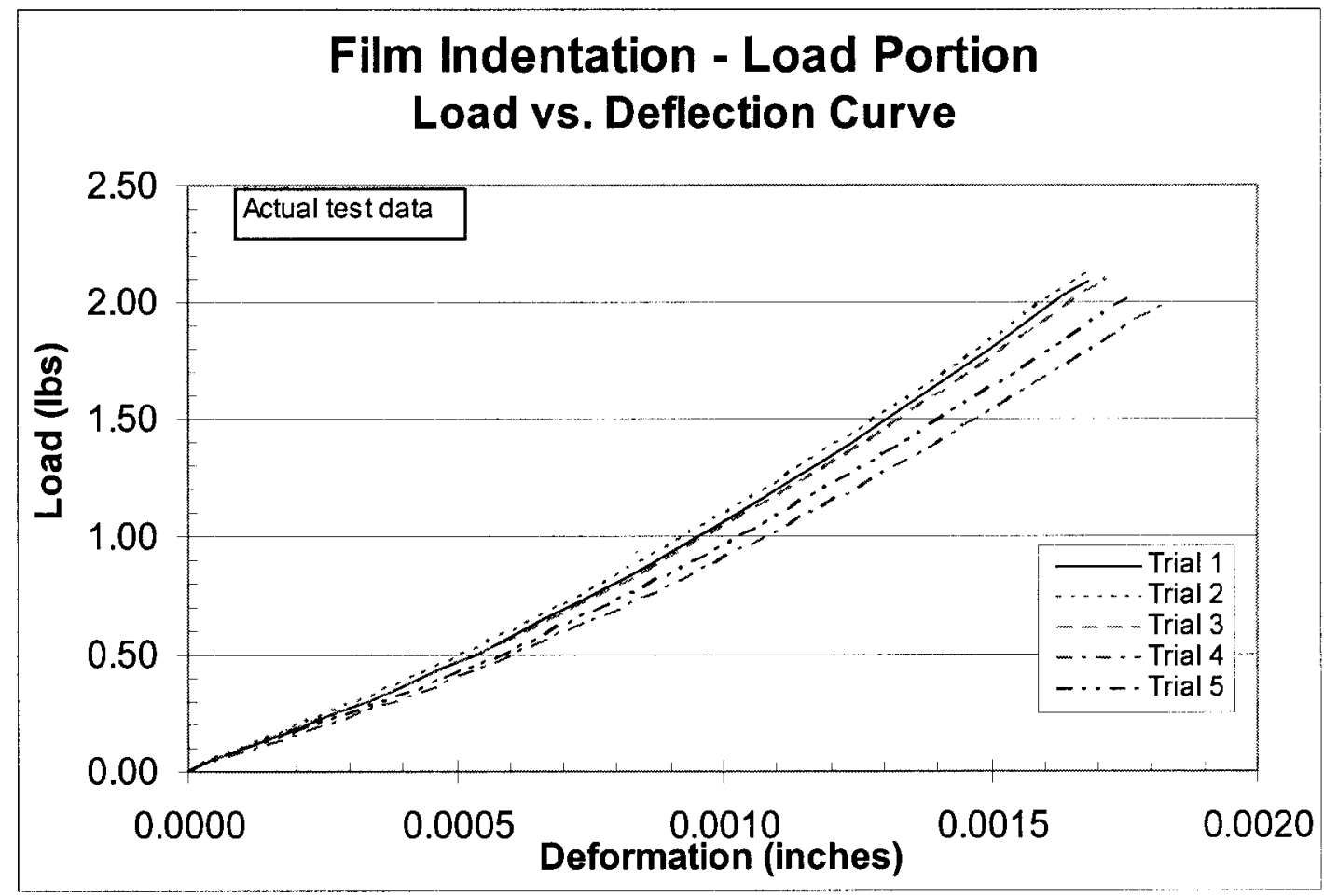

Figure 83. Load-displacement data for 0.019 " PVC film aged for 2 days at $105^{\circ} \mathrm{C}$.

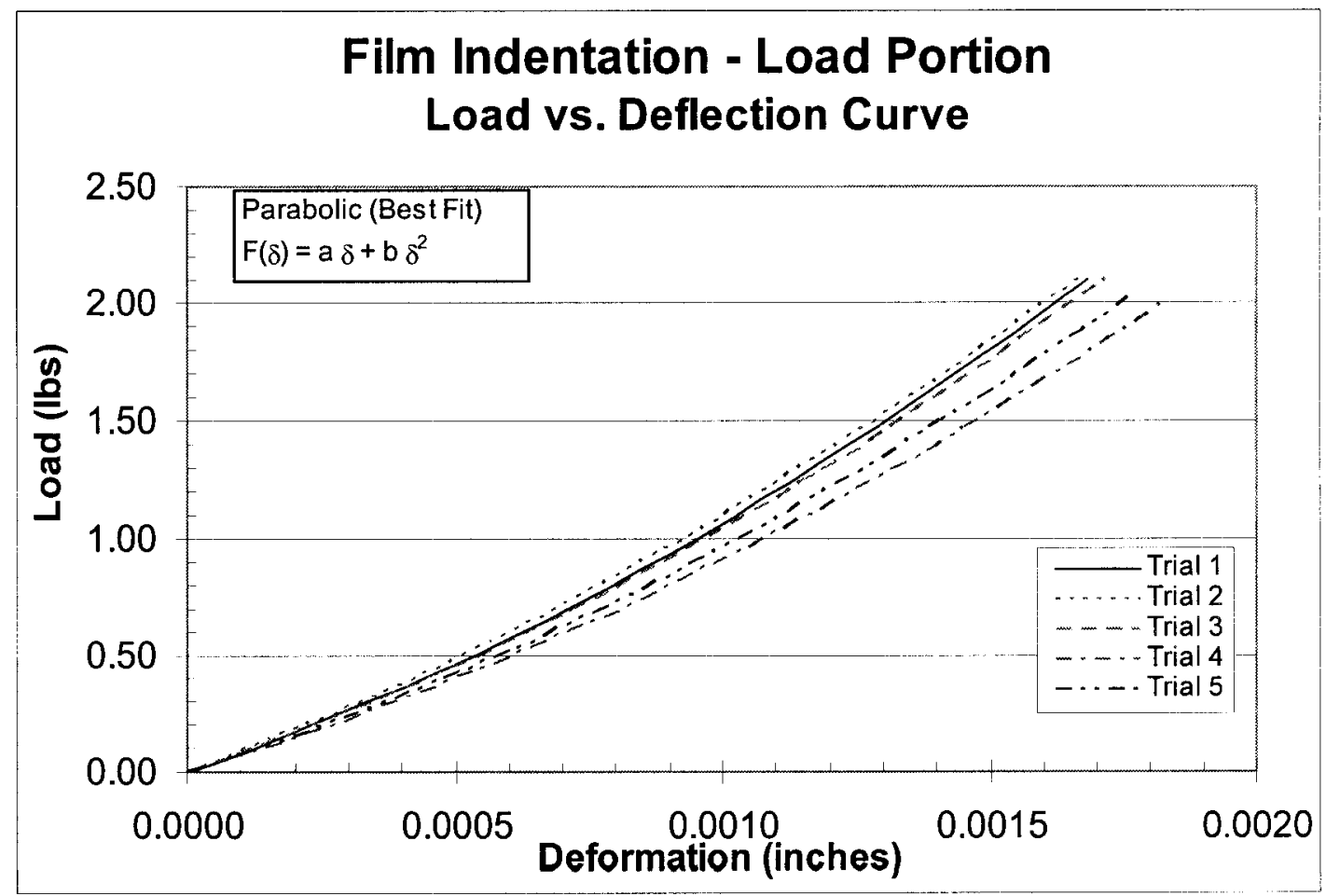

Figure 84. Load-displacement fits for 0.019 " PVC film aged for 2 days at $105^{\circ} \mathrm{C}$. 


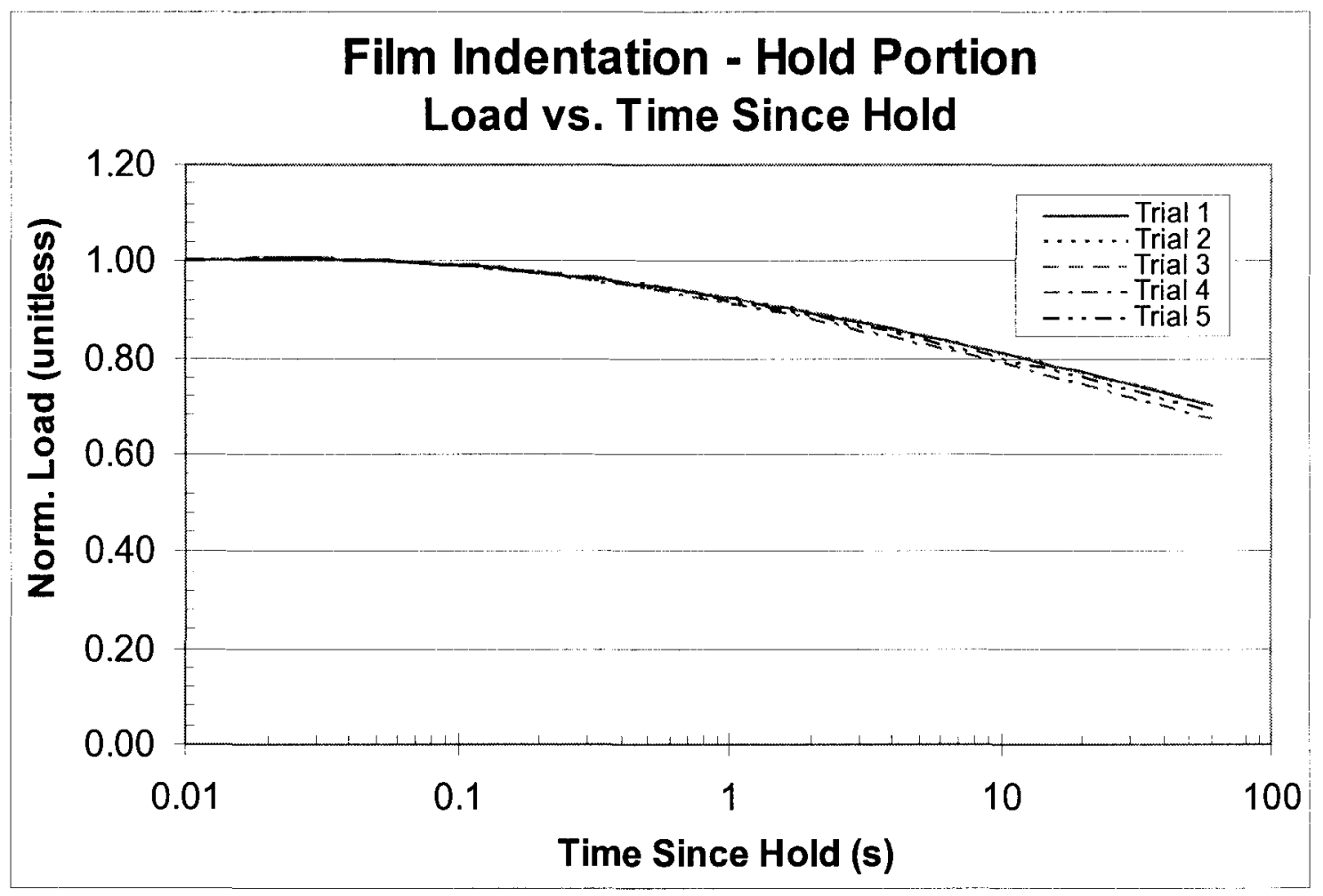

Figure 85. Normalized relaxation fits for 0.019 " PVC film aged for 2 days at $105^{\circ} \mathrm{C}$.

\begin{tabular}{|c|c|c|c|c|c|c|}
\hline & Trial 1 & Trial 2 & Trial 3 & Trial 4 & Trial 5 & Average \\
\hline k (Ibs/in) & 1299.9 & 1307.8 & 1276.7 & 1137.7 & 1204.2 & 1245.2 \\
\hline$\lambda$ (lbs) & -0.19105 & -0.17271 & -0.19318 & -0.18536 & -0.19799 & -0.18806 \\
\hline a (lbs/in) & 793.59 & 846.05 & 780.58 & 683.31 & 719.78 & 764.66 \\
\hline b $\left(\mathrm{lbs} / \mathrm{in}^{2}\right)$ & 271226 & 251022 & 258949 & 224734 & 242739 & 249734 \\
\hline$\alpha(\operatorname{lb} / \log (s))$ & 0.026623 & 0.025439 & 0.026096 & 0.030928 & 0.029665 & 0.027750 \\
\hline$\beta\left(\mathrm{lb} / \log (\mathrm{s})^{2}\right)$ & -0.037082 & -0.036416 & -0.037168 & -0.043884 & -0.041760 & -0.039262 \\
\hline$\gamma\left(\mathrm{lb} / \log (\mathrm{s})^{3}\right)$ & 0.0024087 & 0.0022792 & 0.0024391 & 0.0033804 & 0.0031883 & 0.0027391 \\
\hline
\end{tabular}

Table 24. Data fit coefficients for 0.019 " PVC film aged for 2 days at $105^{\circ} \mathrm{C}$ 


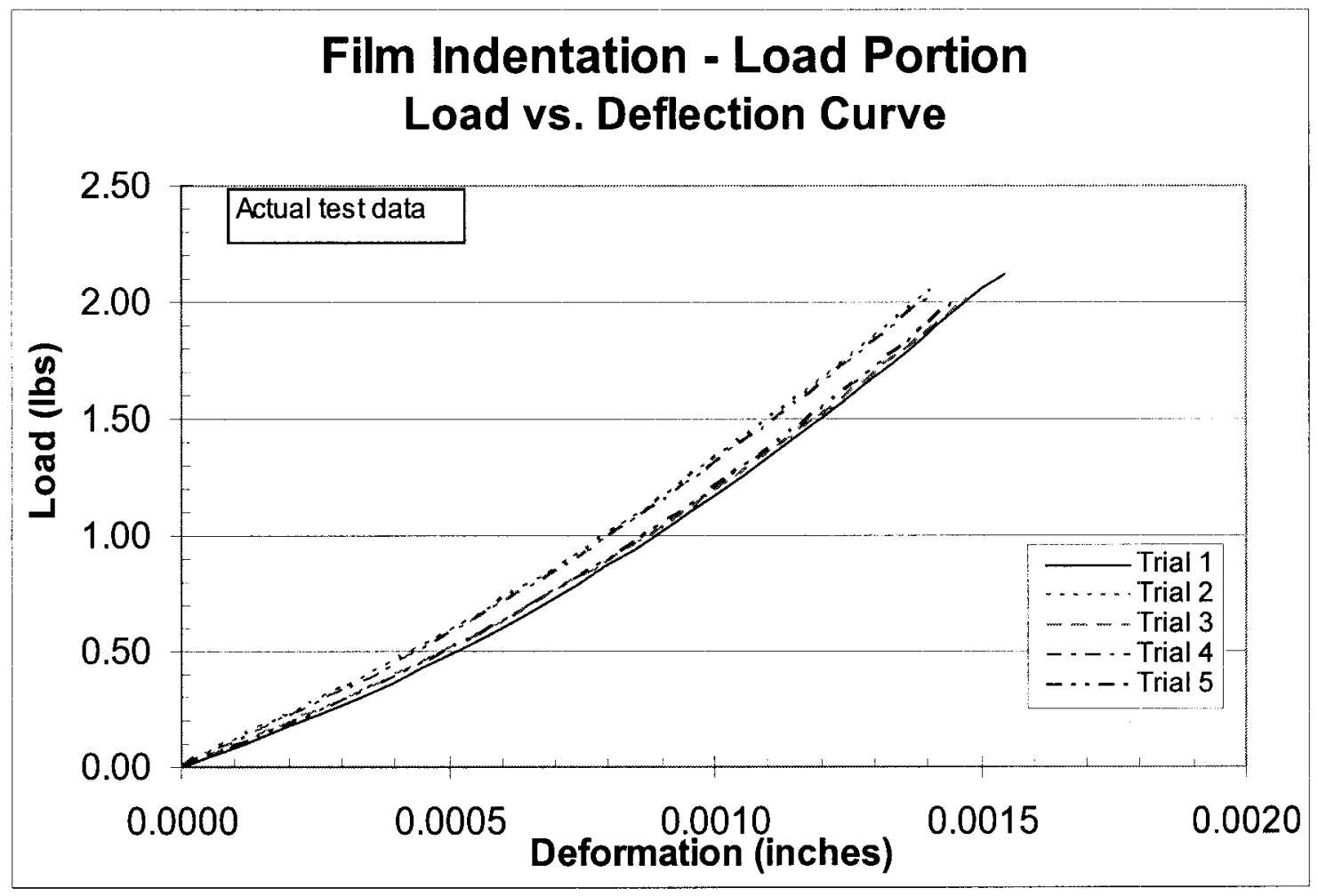

Figure 86. Load-displacement fits for 0.019 " PVC film aged for 5 days at $105^{\circ} \mathrm{C}$.

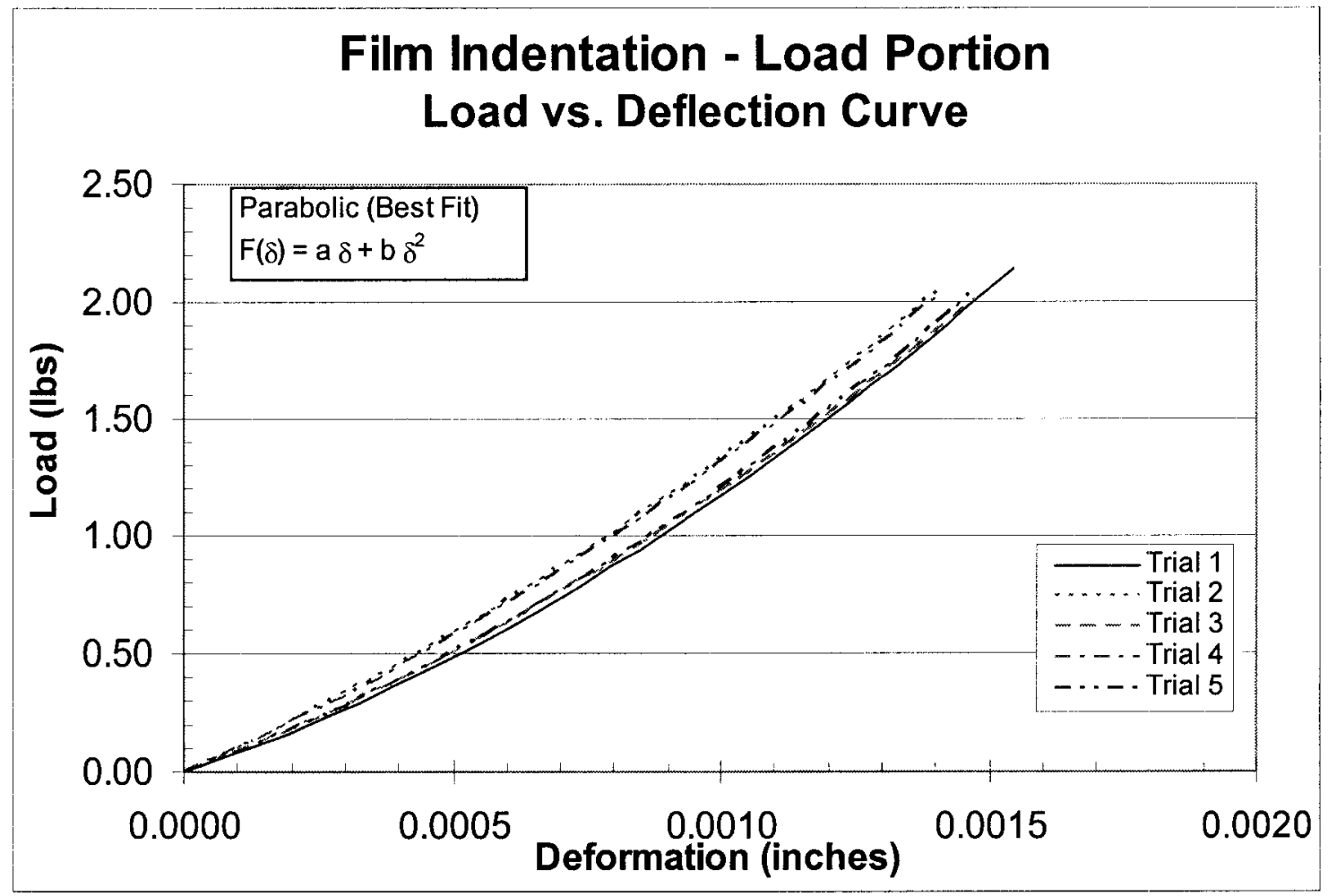

Figure 87. Load-displacement fits for $0.019^{\prime \prime}$ PVC film aged for 5 days at $105^{\circ} \mathrm{C}$. 


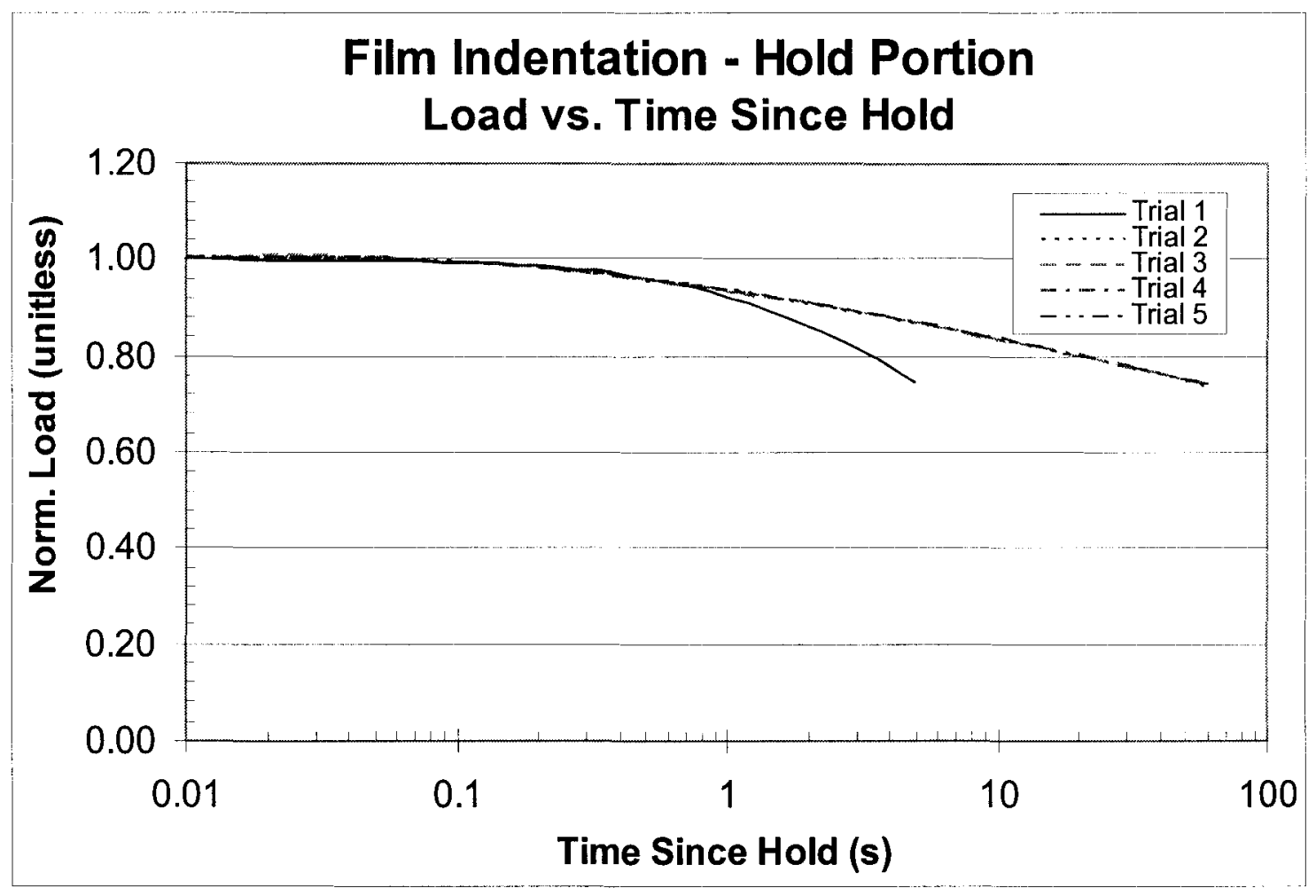

Figure 88. Normalized relaxation fits for 0.019 " PVC film aged for 5 days at $105^{\circ} \mathrm{C}$.

\begin{tabular}{|c|c|c|c|c|c|c|}
\hline & Trial 1 & Trial 2 & Trial 3 & Trial 4 & Trial 5 & Average \\
\hline k (Ibs/in) & 1476.5 & 1493.5 & 1421.6 & 1480.2 & 1460.0 & 1466.4 \\
\hline$\lambda$ (lbs) & -0.26123 & -0.14161 & -0.19758 & -0.14756 & -0.21817 & -0.19323 \\
\hline a (Ibs/in) & 771.68 & 1018.19 & 827.92 & 984.08 & 812.74 & 882.92 \\
\hline b $\left(\mathrm{lbs} / \mathrm{in}^{2}\right)$ & 397728 & 311792 & 362717 & 324817 & 391698 & 357751 \\
\hline$\alpha(\operatorname{lb} / \log (\mathrm{s}))$ & -0.029427 & 0.023398 & 0.024165 & 0.021444 & 0.022736 & 0.012464 \\
\hline$\beta\left(\mathrm{lb} / \log (\mathrm{s})^{2}\right)$ & 0.050862 & -0.032434 & -0.033840 & -0.030677 & -0.032044 & -0.015627 \\
\hline$\gamma\left(\mathrm{lb} / \log (\mathrm{s})^{3}\right)$ & -0.0278557 & 0.0020635 & 0.0024273 & 0.0018577 & 0.0020372 & -0.0038940 \\
\hline
\end{tabular}

Table 25. Data fit coefficients for 0.019 " PVC film aged for 5 days at $105^{\circ} \mathrm{C}$ 


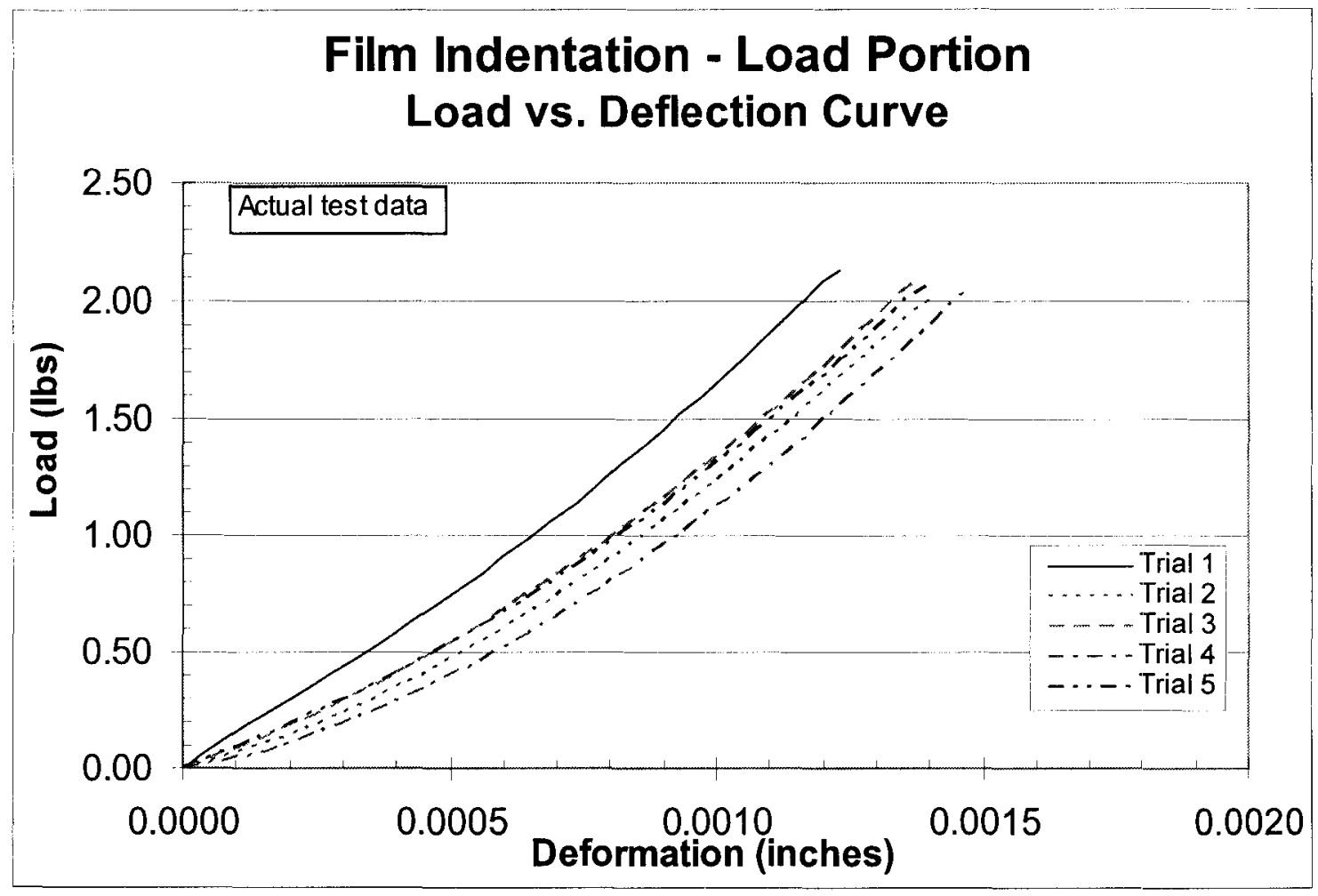

Figure 89. Load-displacement fits for 0.019 " PVC film aged for 1 week at $105^{\circ} \mathrm{C}$

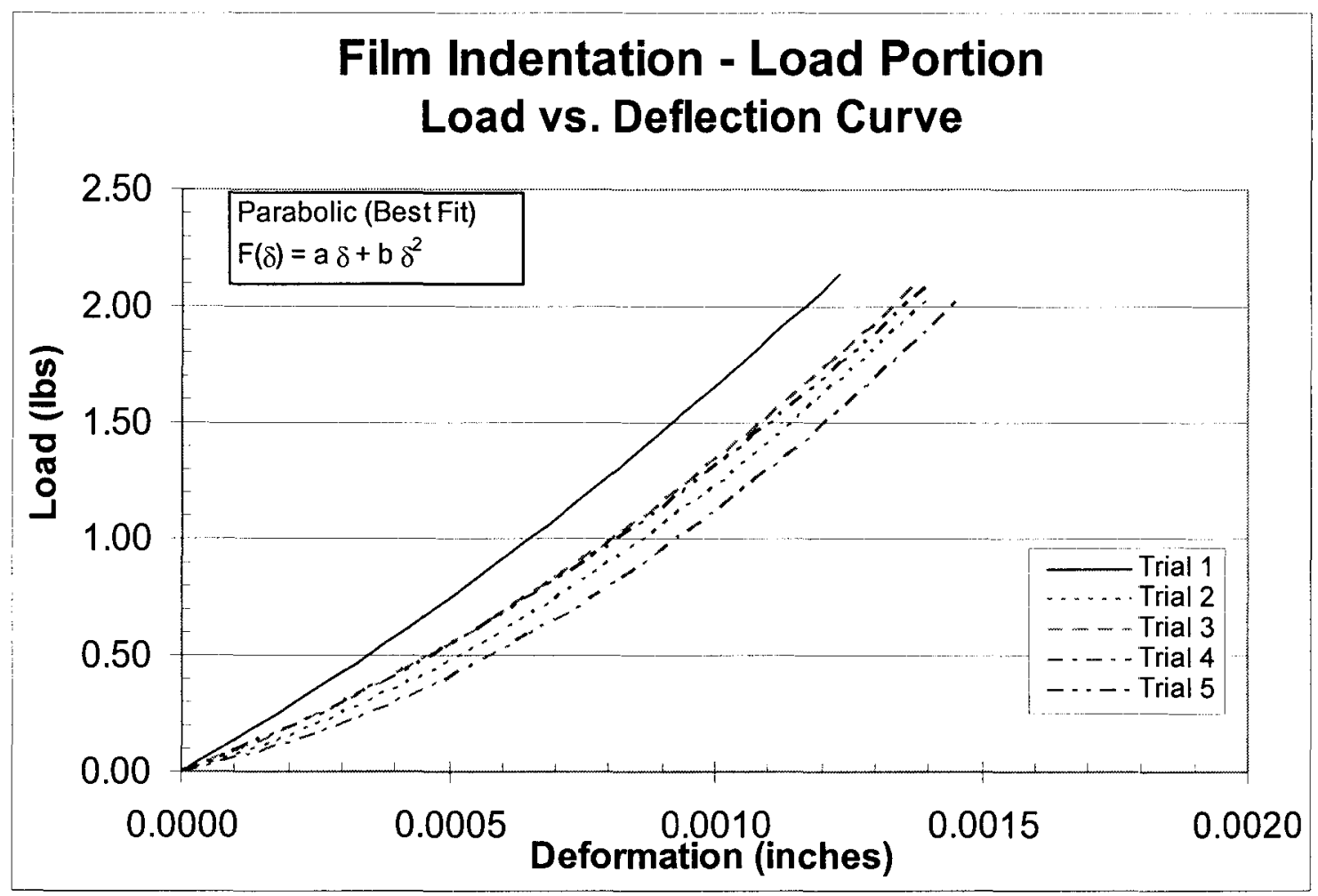

Figure 90. Load-displacement fits for 0.019 " PVC film aged for 1 week at $105^{\circ} \mathrm{C}$ 


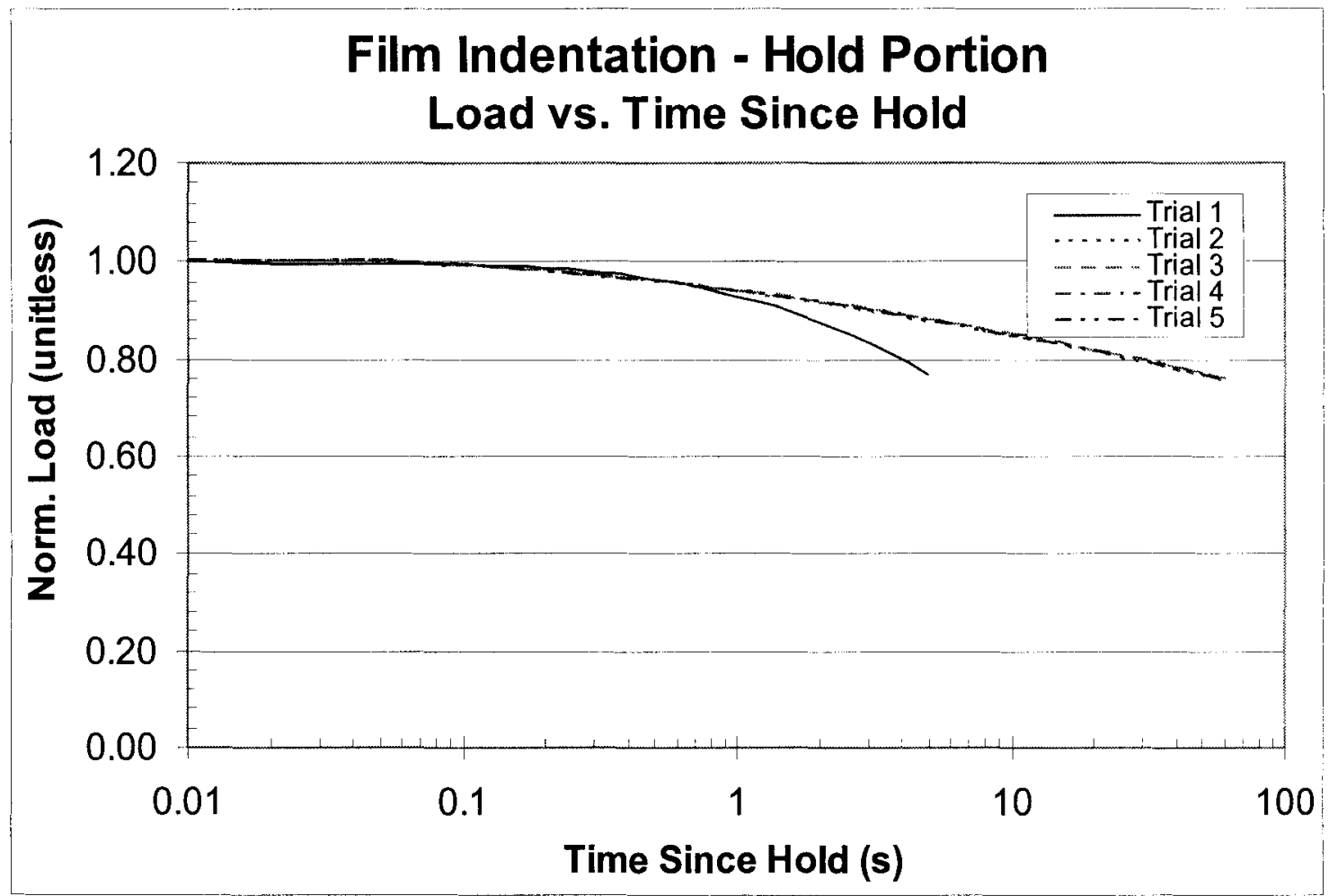

Figure 91. Normalized relaxation fits for 0.019 ” PVC film aged for 1 week at $105^{\circ} \mathrm{C}$.

\begin{tabular}{|l|ccccc|c|}
\hline & Trial 1 & Trial 2 & Trial 3 & Trial 4 & Trial 5 & Average \\
\hline $\mathbf{k}(\mathbf{l b s} / \mathrm{in})$ & 1744.7 & 1601.6 & 1634.1 & 1585.4 & 1596.8 & 1632.5 \\
$\lambda(\mathbf{l b s})$ & -0.09533 & -0.33183 & -0.26970 & -0.41063 & -0.25348 & -0.27219 \\
\hline $\mathbf{a}(\mathbf{l b s} / \mathrm{in})$ & 1322.12 & 665.89 & 834.53 & 503.89 & 846.09 & 834.51 \\
$\mathbf{b}\left(\mathbf{l b s} / \mathbf{i n}^{2}\right)$ & 335705 & 564758 & 499863 & 611083 & 463967 & 495075 \\
\hline$\alpha(\operatorname{lb} / \log (\mathbf{s}))$ & -0.030299 & 0.018727 & 0.017609 & 0.020340 & 0.019030 & 0.009081 \\
$\beta\left(\operatorname{lb} / \log (\mathbf{s})^{2}\right)$ & 0.051564 & -0.026898 & -0.025724 & -0.028138 & -0.027526 & -0.011345 \\
$\gamma\left(\operatorname{lb} / \log (\mathbf{s})^{3}\right)$ & -0.0267834 & 0.0012727 & 0.0011189 & 0.0015862 & 0.0014303 & -0.0042751 \\
\hline
\end{tabular}

Table 26. Data fit coefficients for 0.019 " PVC film aged for 1 week at $105^{\circ} \mathrm{C}$ 


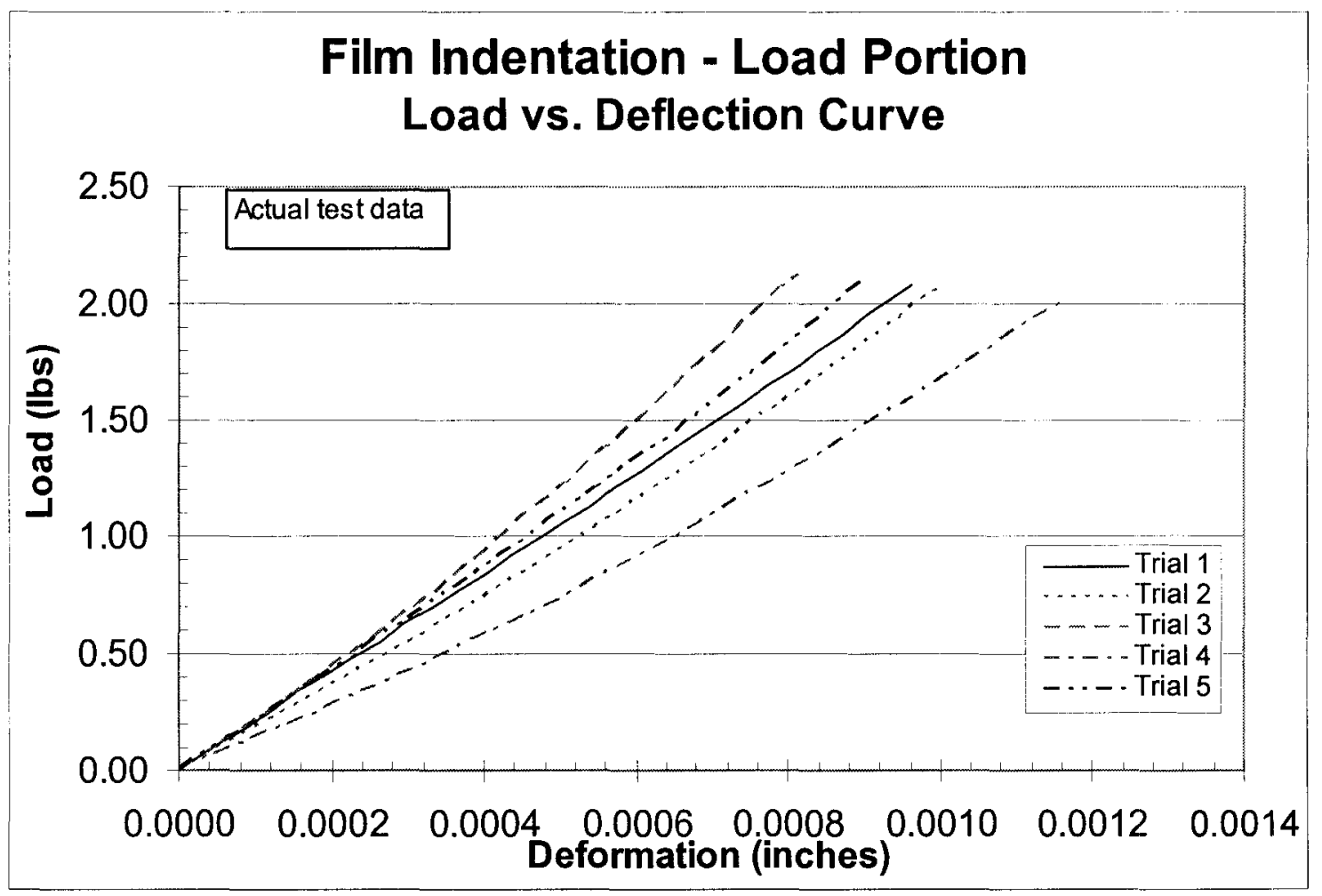

Figure 92. Load-displacement fits for 0.019" PVC film aged for 2 weeks at $105^{\circ} \mathrm{C}$.

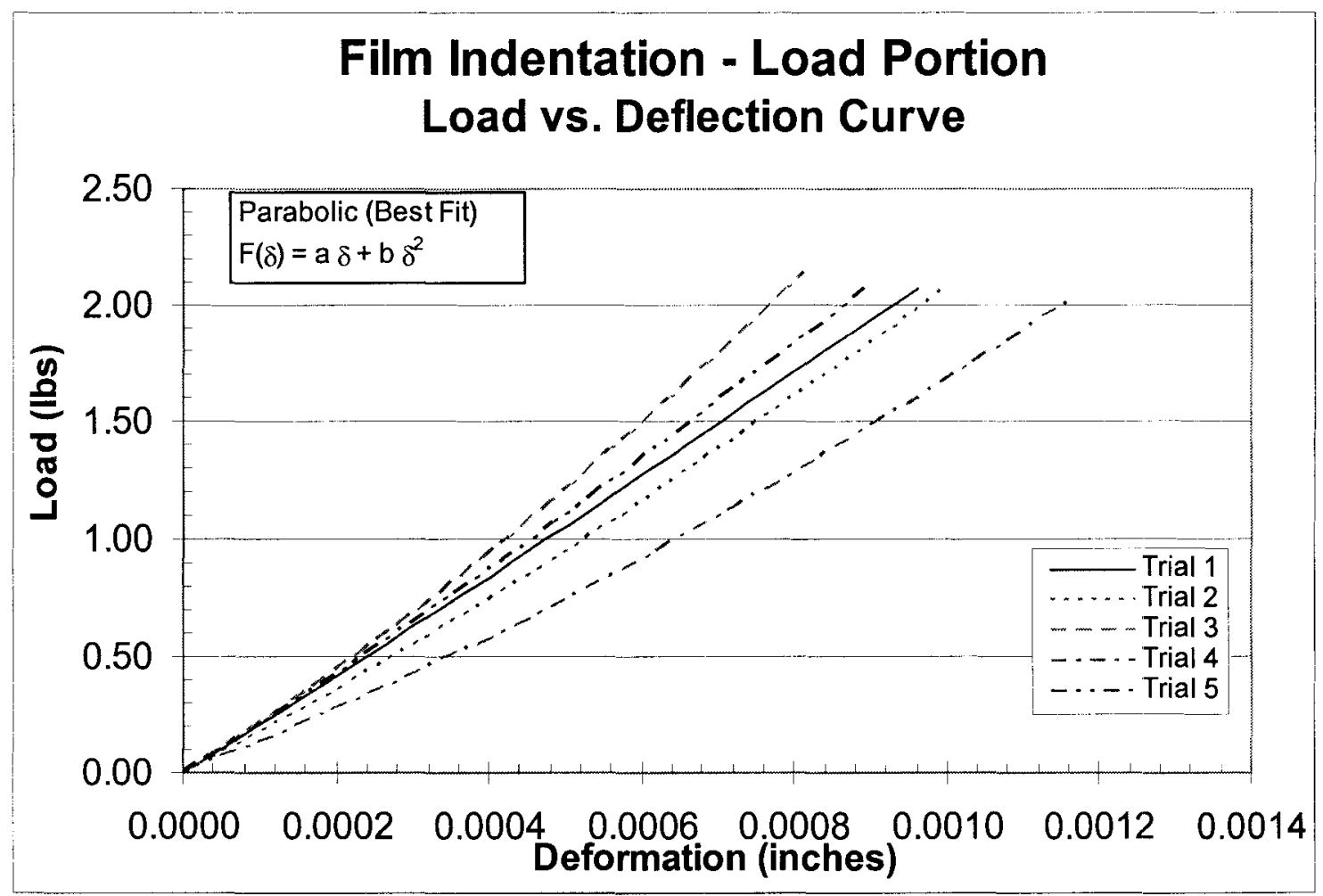

Figure 93. Load-displacement fits for 0.019 " PVC film aged for 2 weeks at $105^{\circ} \mathrm{C}$. 


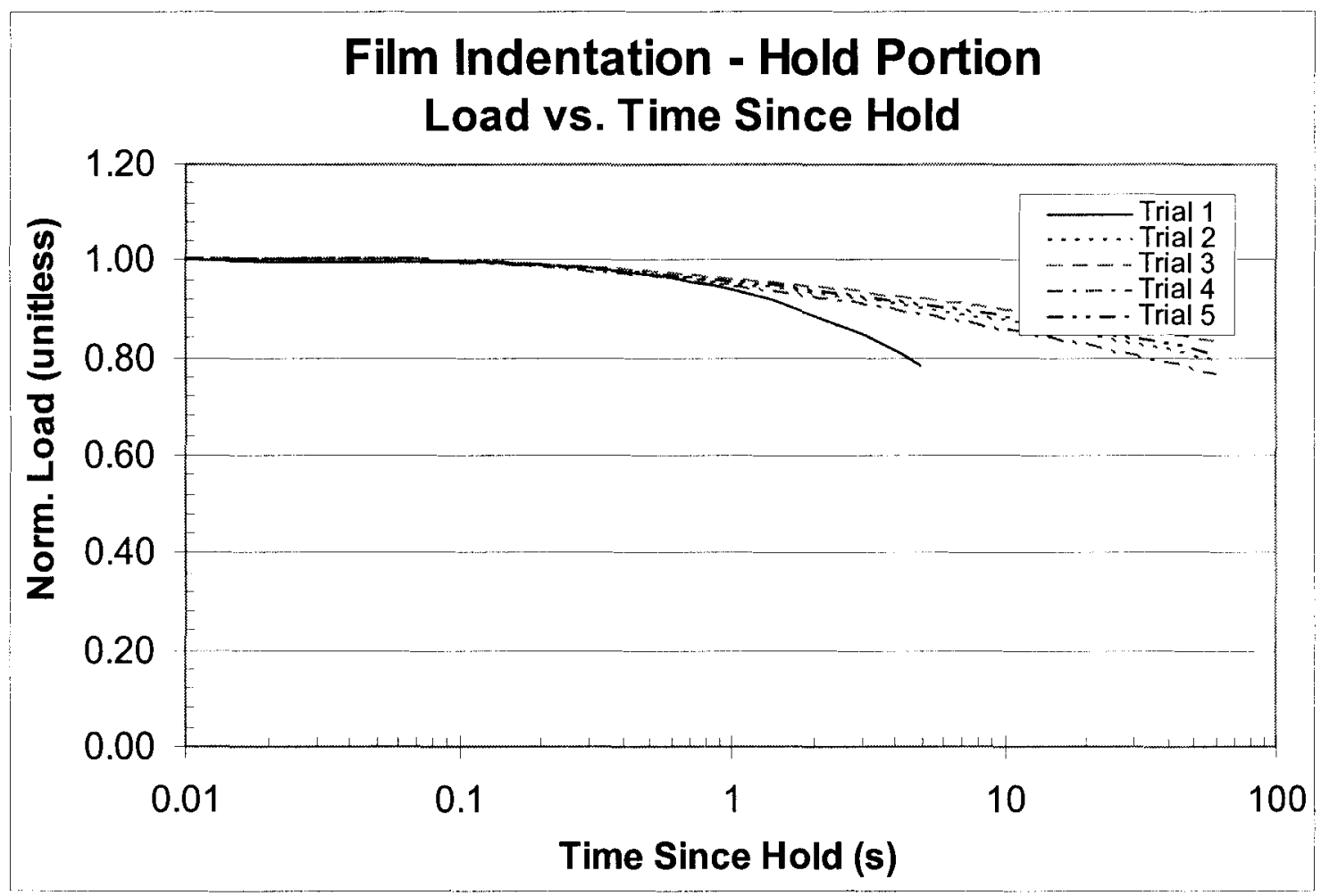

Figure 94. Normalized relaxation fits for 0.019 " PVC film aged for 2 weeks at $105^{\circ} \mathrm{C}$.

\begin{tabular}{|l|ccccc|c|}
\hline & Trial 1 & Trial 2 & Trial 3 & Trial 4 & Trial 5 & Average \\
\hline $\mathbf{k}(\mathbf{l b s} / \mathrm{in})$ & 2121.8 & 2065.2 & 2645.6 & 1778.2 & 2288.6 & 2179.9 \\
$\lambda(\mathbf{l b s})$ & 0.00535 & -0.05942 & -0.09348 & -0.11867 & -0.03117 & -0.05948 \\
\hline $\mathbf{a}(\mathbf{l b s} / \mathrm{in})$ & 2058.71 & 1720.76 & 2083.81 & 1297.71 & 2065.36 & 1845.27 \\
$\mathbf{b}\left(\mathrm{lbs} / \mathrm{in}^{2}\right)$ & 103031 & 354496 & 672215 & 381320 & 286675 & 359547 \\
\hline$\alpha(\mathrm{lb} / \log (\mathbf{s}))$ & -0.028031 & 0.017540 & 0.014064 & 0.017894 & 0.016234 & 0.007540 \\
$\beta\left(\operatorname{lb} / \log (\mathbf{s})^{2}\right)$ & 0.049312 & -0.023020 & -0.018192 & -0.024453 & -0.020956 & -0.007462 \\
$\gamma\left(\operatorname{lb} / \log (\mathbf{s})^{3}\right)$ & -0.0253789 & 0.0010494 & 0.0007112 & 0.0008872 & 0.0007975 & -0.0043867 \\
\hline
\end{tabular}

Table 27. Data fit coefficients for 0.019 ” PVC film aged for 2 weeks at $105^{\circ} \mathrm{C}$ 


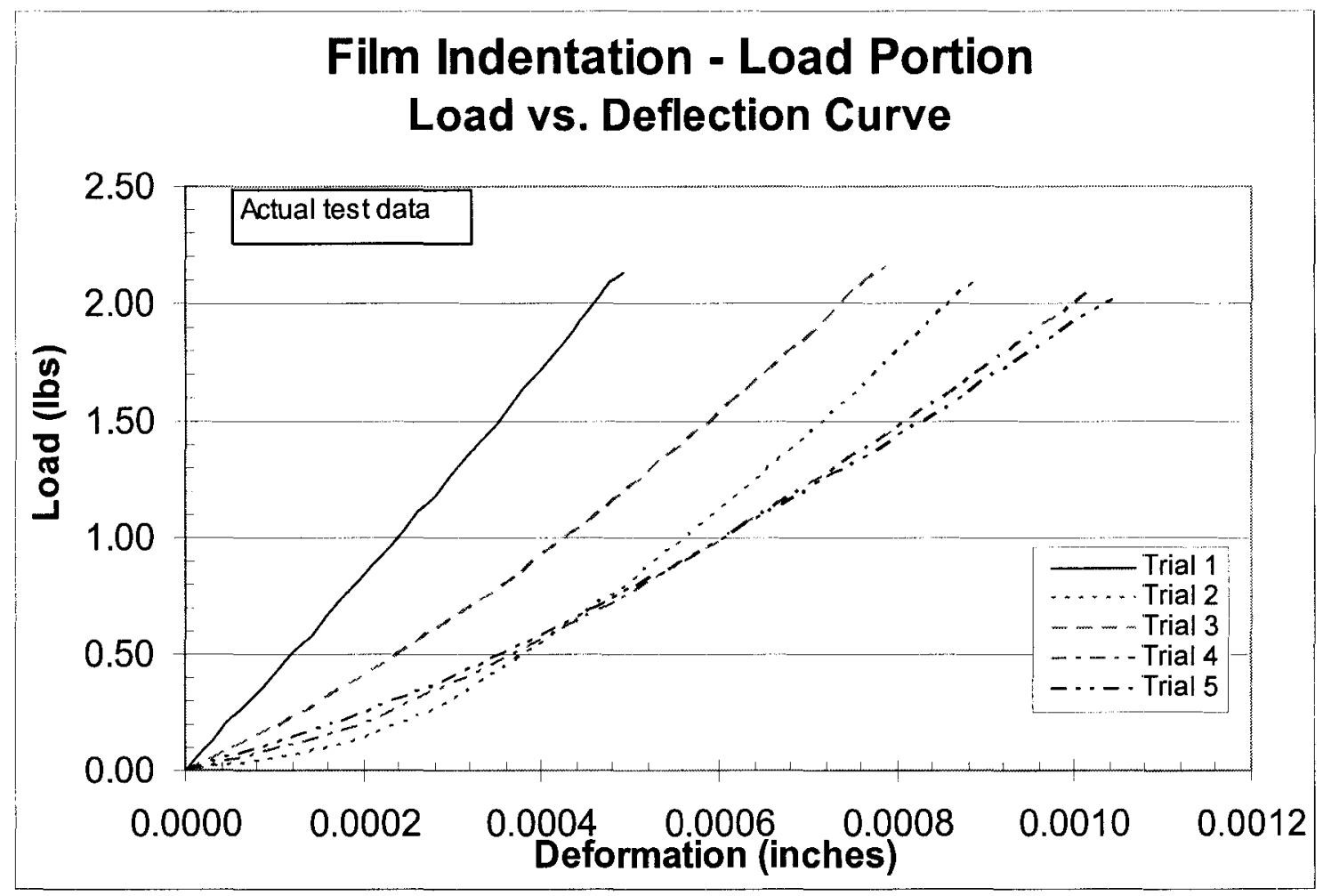

Figure 95. Load-displacement data for 0.019" PVC film aged for 3 weeks at $105^{\circ} \mathrm{C}$.

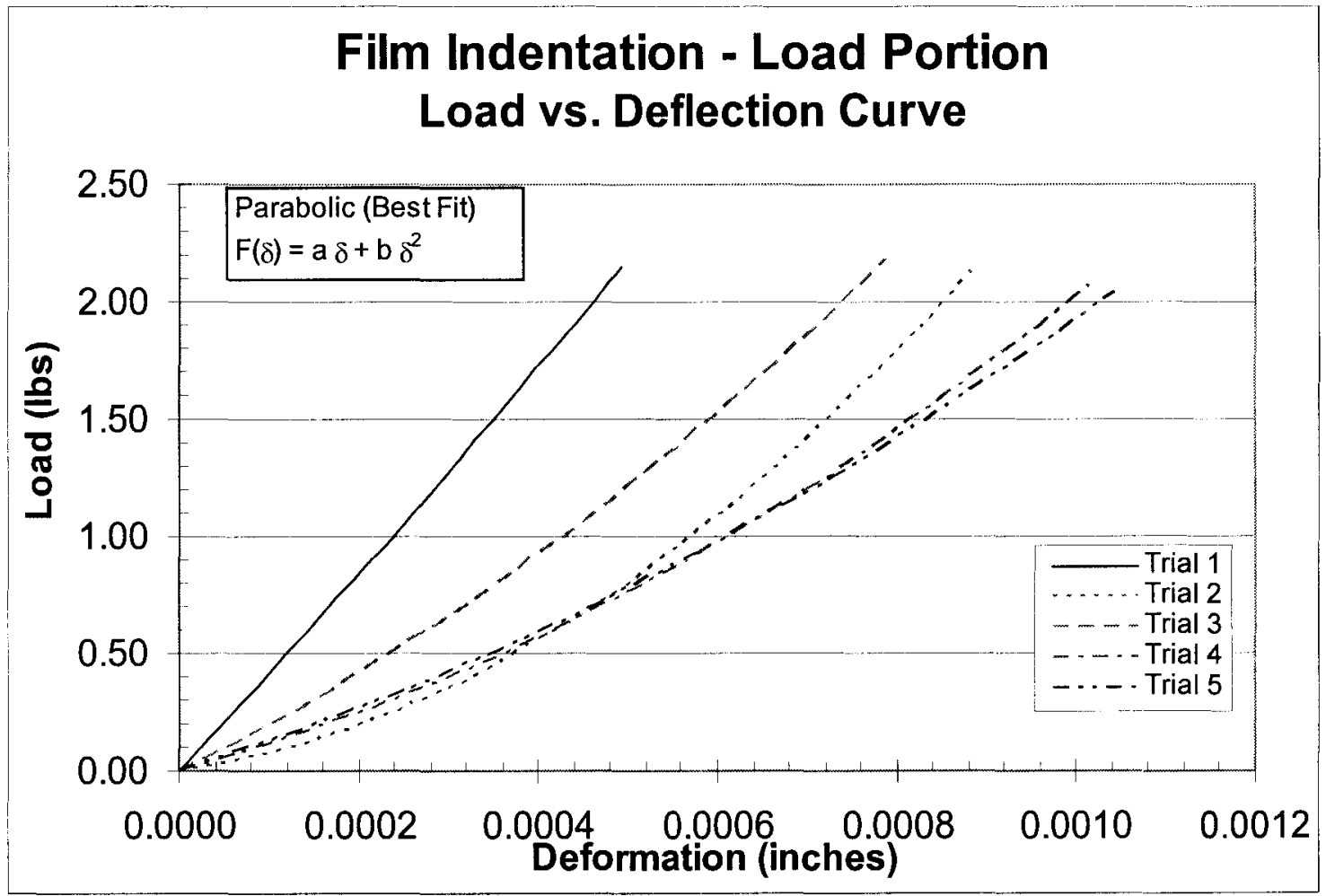

Figure 96. Load-displacement data for $0.019^{\prime}$ PVC film aged for 3 weeks at $105^{\circ} \mathrm{C}$ 


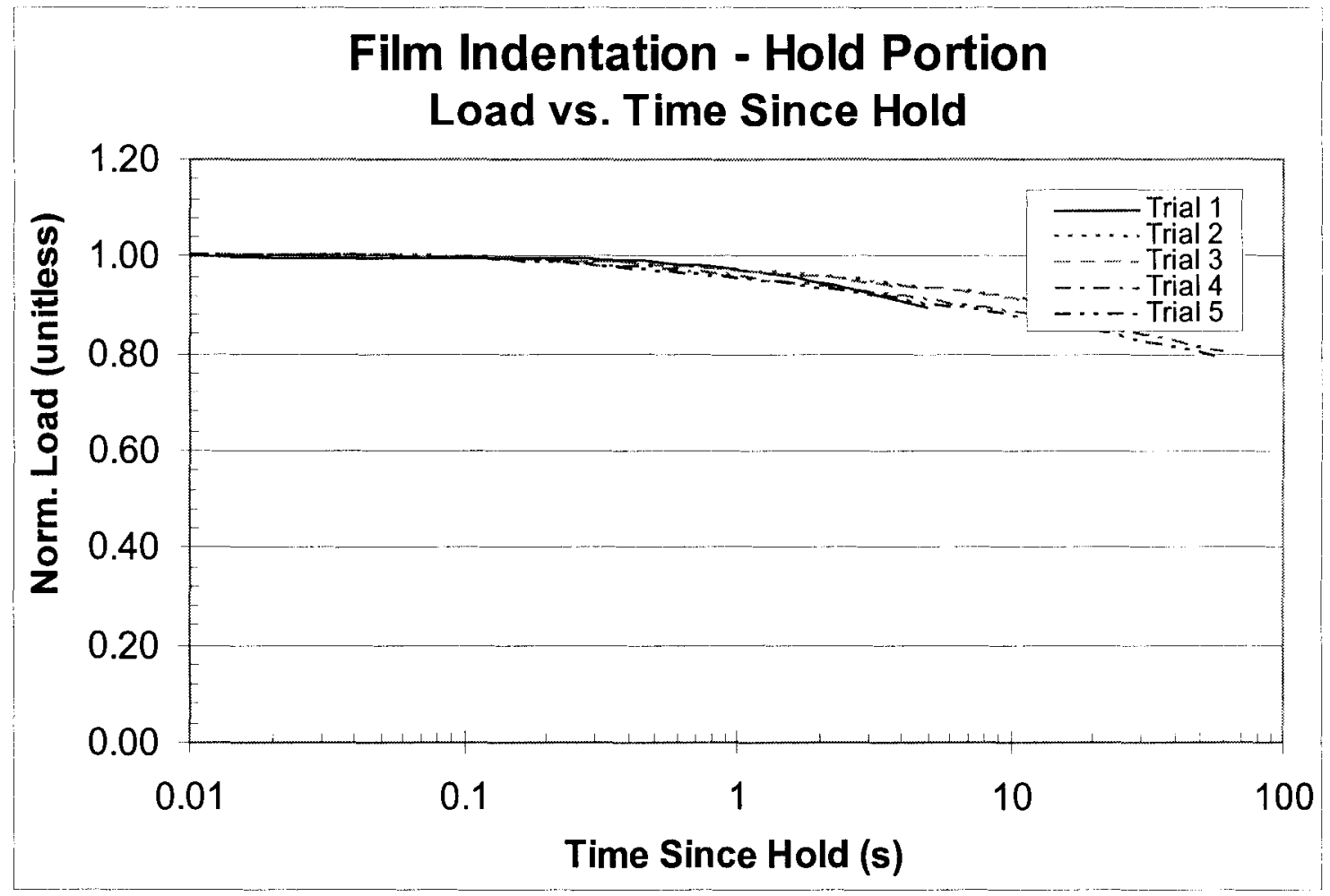

Figure 97. Normalized relaxation fits for 0.019 " PVC film aged for 3 weeks at $105^{\circ} \mathrm{C}$.

\begin{tabular}{|l|ccccc|c|}
\hline & Trial 1 & Trial 2 & Trial 3 & Trial 4 & Trial 5 & Average \\
\hline $\mathbf{k}(\mathrm{lbs} / \mathrm{in})$ & 4383.5 & 2991.9 & 2856.2 & 2249.1 & 2097.9 & 2915.7 \\
$\lambda(\mathrm{lbs})$ & -0.02832 & -0.63838 & -0.18196 & -0.32624 & -0.24352 & -0.28369 \\
\hline $\mathbf{a}(\mathrm{Ibs} / \mathrm{in})$ & 4096.79 & 542.29 & 1830.11 & 1019.07 & 1181.32 & 1733.92 \\
$\mathbf{b}\left(\mathrm{lbs} / \mathrm{in}^{2}\right)$ & 554136 & 2120748 & 1185279 & 1002860 & 743462 & 1121297 \\
\hline$\alpha(\mathrm{lb} / \log (\mathbf{s}))$ & -0.018946 & 0.008147 & 0.007679 & 0.012880 & 0.014412 & 0.004834 \\
$\beta\left(\operatorname{lb} / \log (\mathbf{s})^{2}\right)$ & 0.032048 & -0.009907 & -0.009708 & -0.016679 & -0.018858 & -0.004621 \\
$\gamma\left(\operatorname{lb} / \log (\mathbf{s})^{3}\right)$ & -0.0146466 & -0.0007204 & -0.0007887 & -0.0001402 & 0.0000707 & -0.0032451 \\
\hline
\end{tabular}

Table 28. Data fit coefficients for 0.019 " PVC film aged for 3 weeks at $105^{\circ} \mathrm{C}$ 


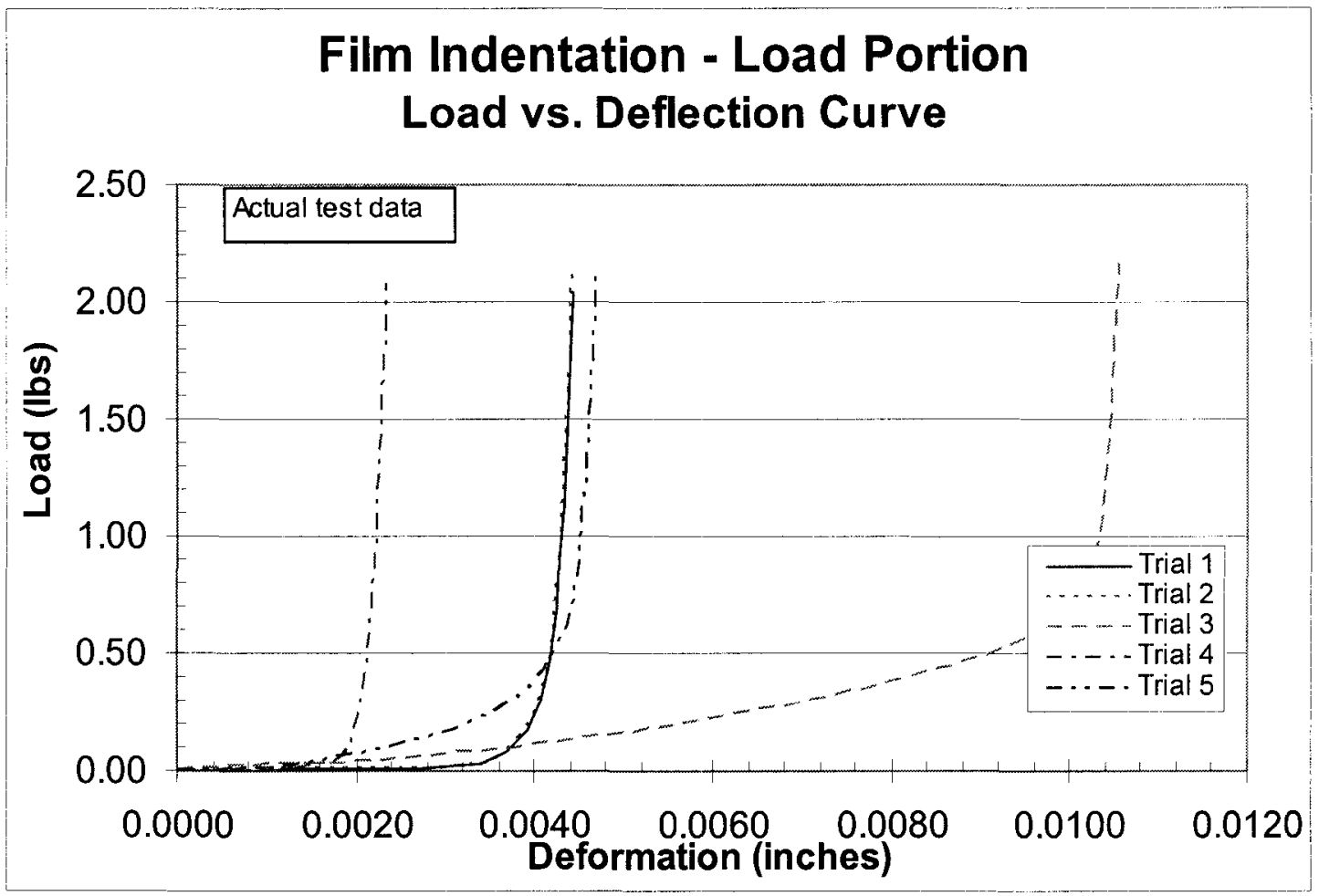

Figure 98. Load-displacement data for $0.008^{\prime \prime} \mathrm{PVC}$ film aged for 2 days at $125^{\circ} \mathrm{C}$

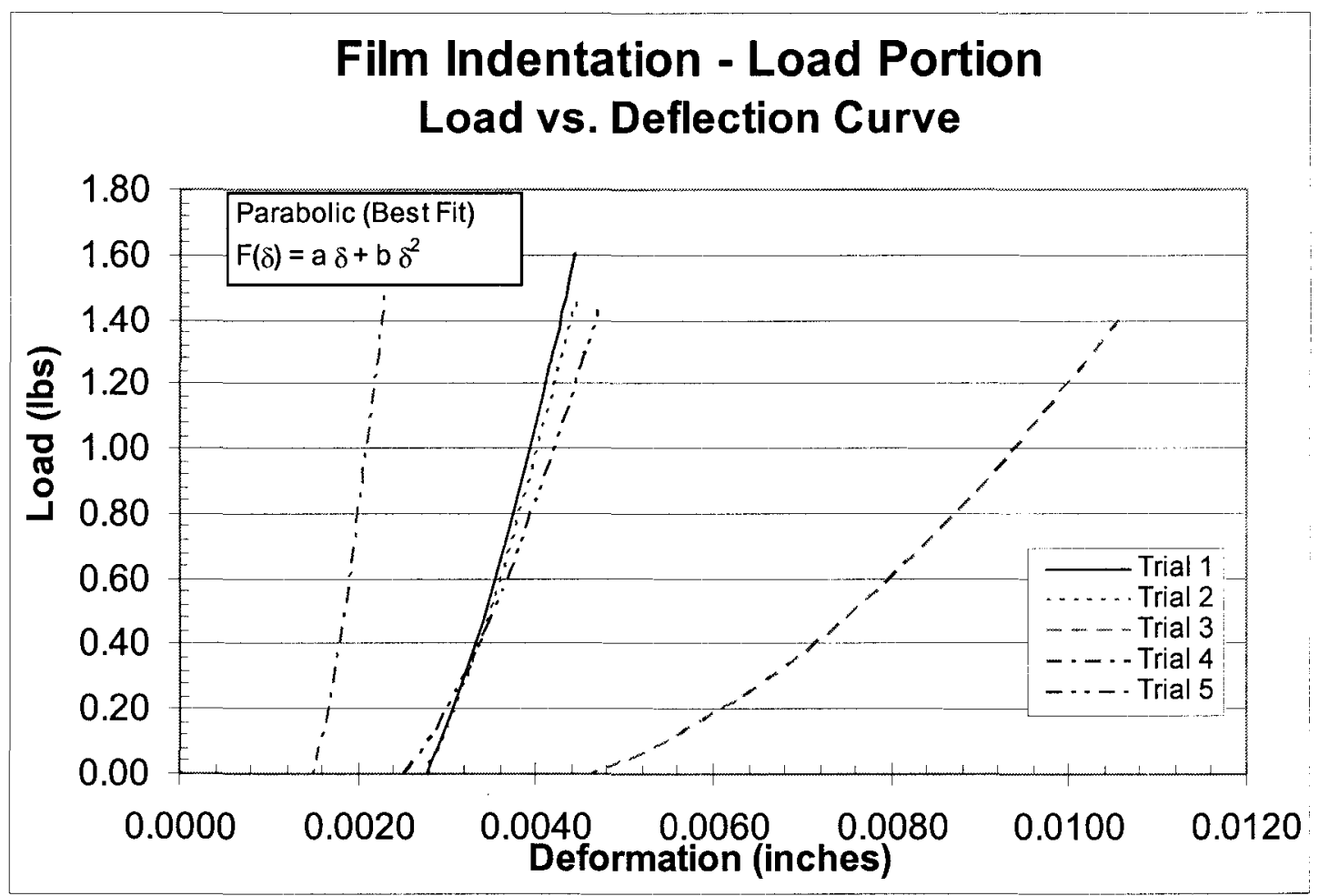

Figure 99. Load-displacement data for 0.008 " $\mathrm{PVC}$ film aged for 2 days at $125^{\circ} \mathrm{C}$ 


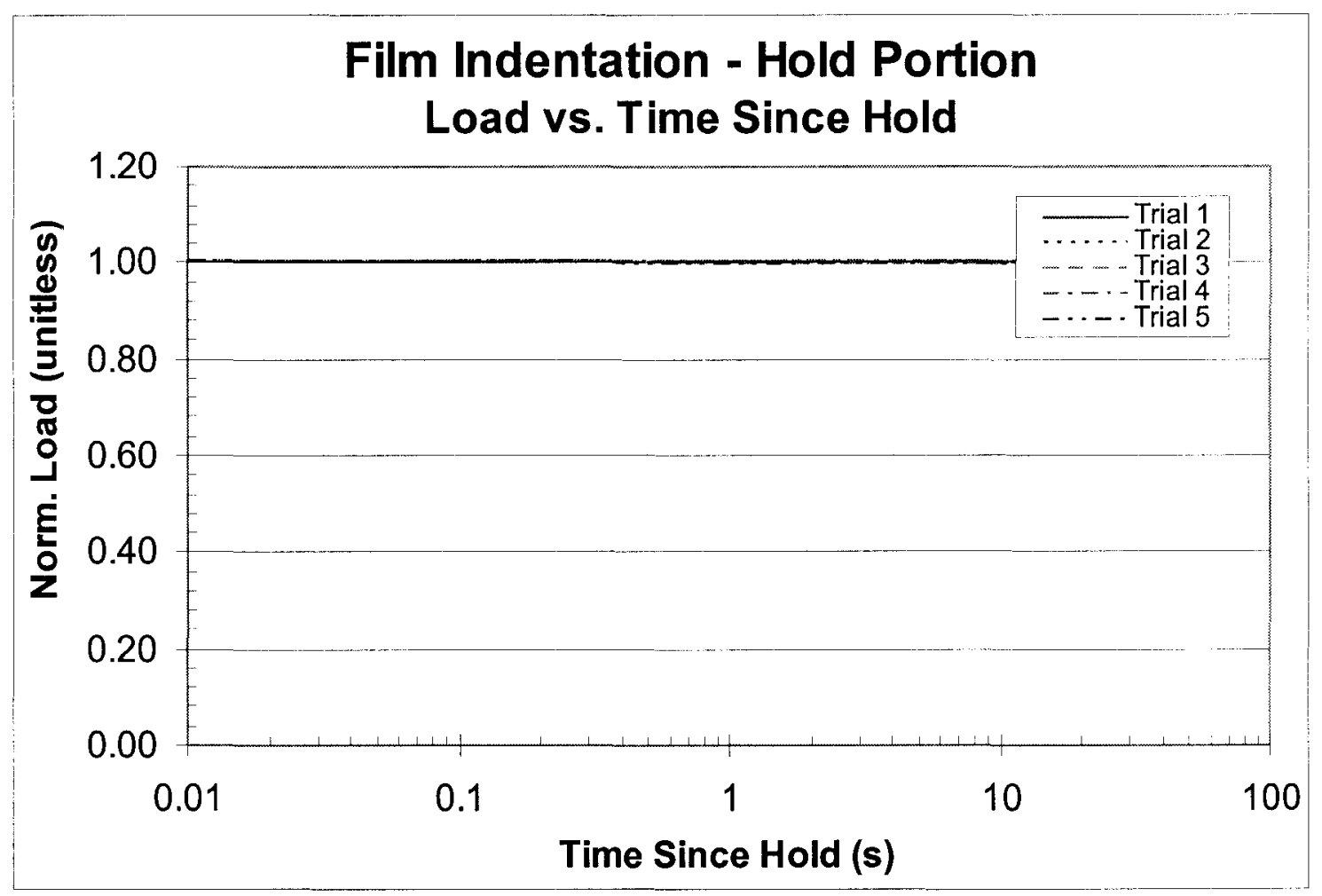

Figure 100. Normalized relaxation fits for $0.206 \mathrm{~mm}$ PVC film aged for 2 days at $125^{\circ} \mathrm{C}$.

\begin{tabular}{|l|ccccc|c|}
\hline & Trial 1 & Trial 2 & Trial 3 & Trial 4 & Trial 5 & Average \\
\hline $\mathbf{k}(\mathbf{l b s} / \mathrm{in})$ & 7163.2 & 7455.7 & 4814.4 & 5370.1 & 6688.9 & 6298.5 \\
$\lambda(\mathbf{l b s})$ & -98.75904 & -102.50540 & -69.18995 & -77.54381 & -91.95845 & -87.99133 \\
\hline $\mathbf{a}(\mathbf{l b s} / \mathrm{in})$ & -94.15 & -123.83 & -82.52 & -94.53 & -95.84 & -98.17 \\
$\mathbf{b}\left(\mathbf{l b s} / \mathbf{i n}^{2}\right)$ & 11480 & 15029 & 9850 & 10929 & 11960 & 11850 \\
\hline$\alpha(\mathbf{l b} / \log (\mathbf{s}))$ & -0.000369 & -0.000760 & 0.001055 & -0.001544 & -0.000363 & -0.000396 \\
$\beta\left(\operatorname{lb} / \log (\mathbf{s})^{2}\right)$ & -0.000379 & 0.000260 & -0.001194 & 0.000635 & -0.000130 & -0.000162 \\
$\gamma\left(\operatorname{lb} / \log (\mathbf{s})^{3}\right)$ & -0.0000699 & -0.0001928 & 0.0000379 & -0.0002376 & -0.0001336 & -0.0001192 \\
\hline
\end{tabular}

Table 29. Data fit coefficients for $0.008^{\prime \prime} \mathrm{PVC}$ film aged for 2 days at $125^{\circ} \mathrm{C}$ 


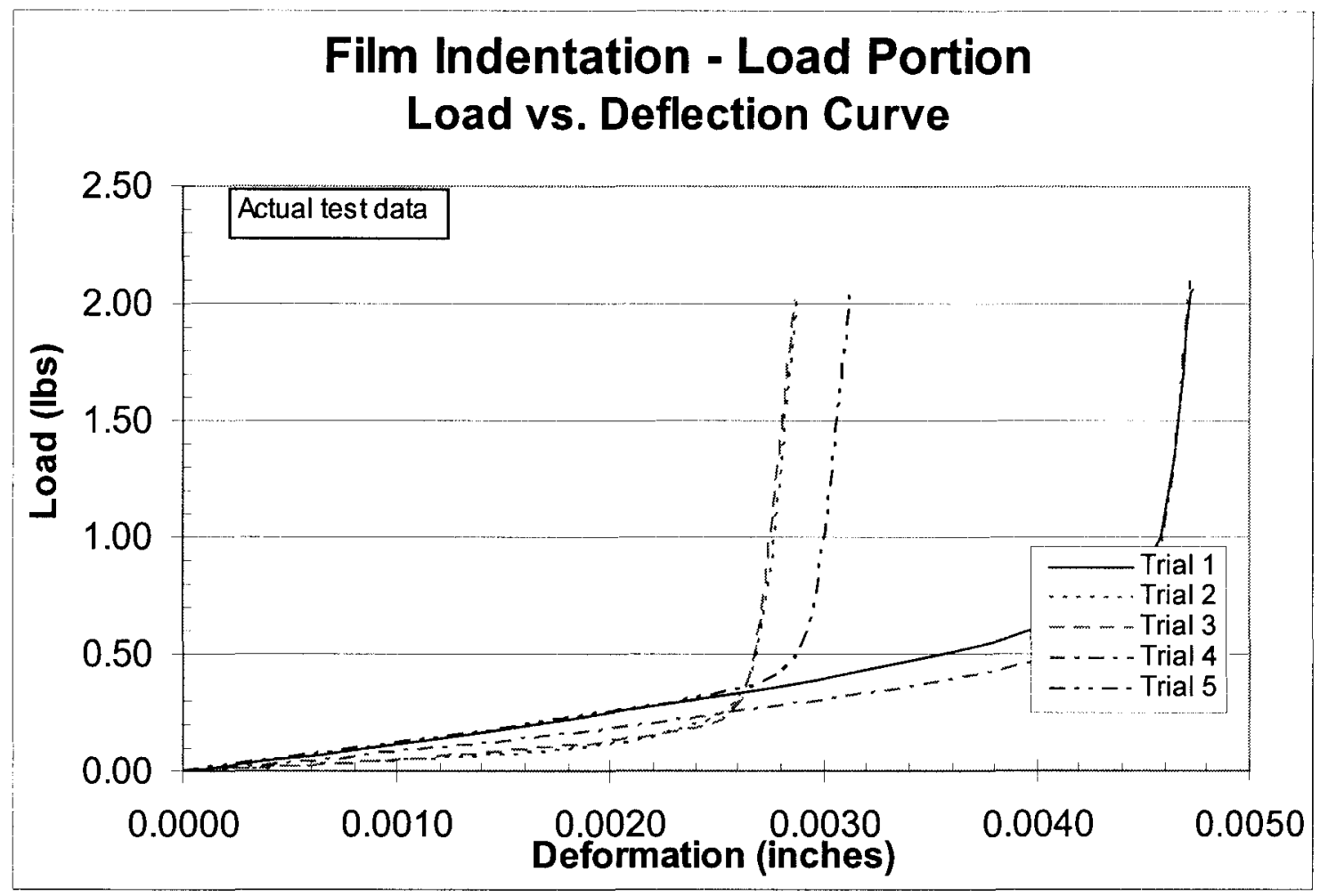

Figure 101. Load-displacement fits for $0.008^{\prime \prime} \mathrm{PVC}$ film aged for 5 days at $125^{\circ} \mathrm{C}$

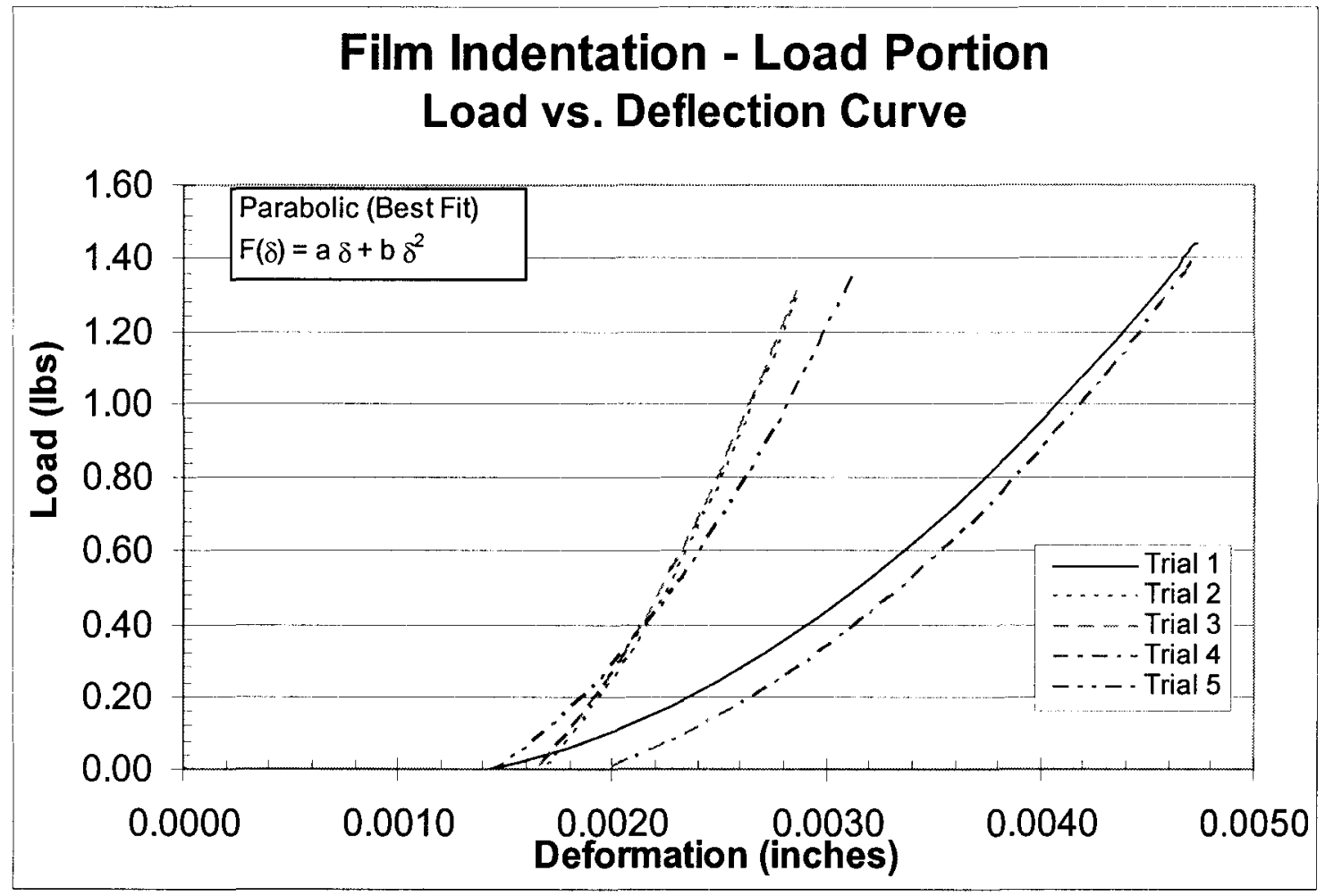

Figure 102. Load-displacement fits for $0.008^{\prime \prime} \mathrm{PVC}$ film aged for 5 days at $125^{\circ} \mathrm{C}$ 


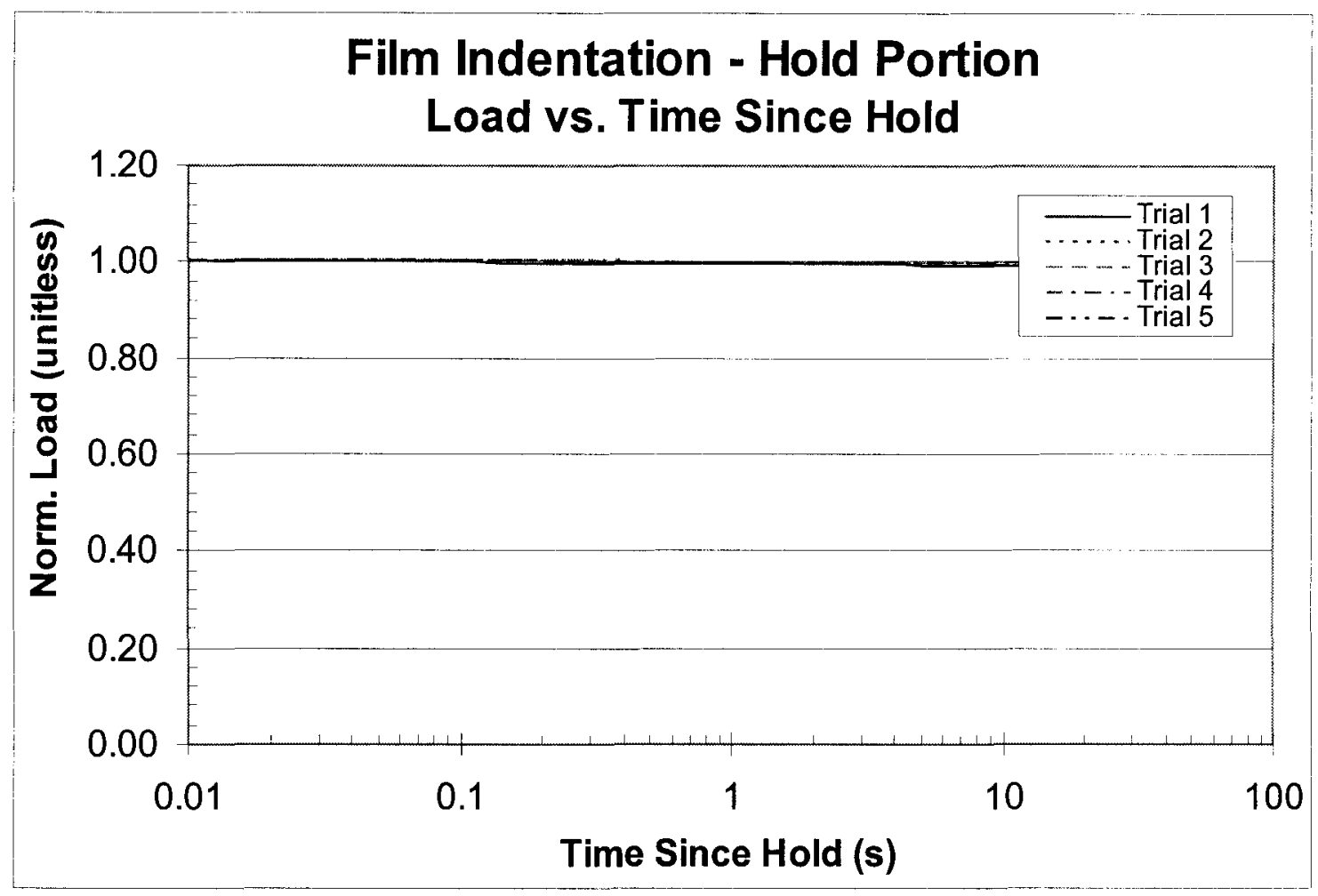

Figure 103. Normalized relaxation fits for $0.206 \mathrm{~mm}$ PVC film aged for 5 days at $125^{\circ} \mathrm{C}$

\begin{tabular}{|c|c|c|c|c|c|c|}
\hline & Trial 1 & Trial 2 & Trial 3 & Trial 4 & Trial 5 & Average \\
\hline k (lbs/in) & 960.6 & 6744.5 & 7272.1 & 2176.7 & 5428.1 & 4516.4 \\
\hline$\lambda$ (lbs) & -2.95138 & -17.56399 & -18.93898 & -8.72132 & -15.16583 & -12.66830 \\
\hline a (lbs/in) & -134.74 & -637.89 & -626.54 & -210.88 & -380.42 & -398.10 \\
\hline b (lbs/in $\left.{ }^{2}\right)$ & 93008 & 380446 & 379249 & 107224 & 260786 & 244142 \\
\hline$\alpha(\operatorname{lb} / \log (s))$ & 0.000241 & 0.000432 & 0.000202 & -0.000303 & 0.000010 & 0.000117 \\
\hline$\beta\left(\mathrm{lb} / \log (\mathrm{s})^{2}\right)$ & -0.000981 & -0.000614 & -0.000501 & -0.000118 & -0.000429 & -0.000529 \\
\hline$\gamma\left(\mathrm{lb} / \log (\mathrm{s})^{3}\right)$ & 0.0000390 & 0.0000030 & -0.0000119 & -0.0000827 & -0.0000296 & -0.0000164 \\
\hline
\end{tabular}

Table 30. Data fit coefficients for $0.008^{\prime \prime}$ PVC film aged for 5 days at $125^{\circ} \mathrm{C}$ 


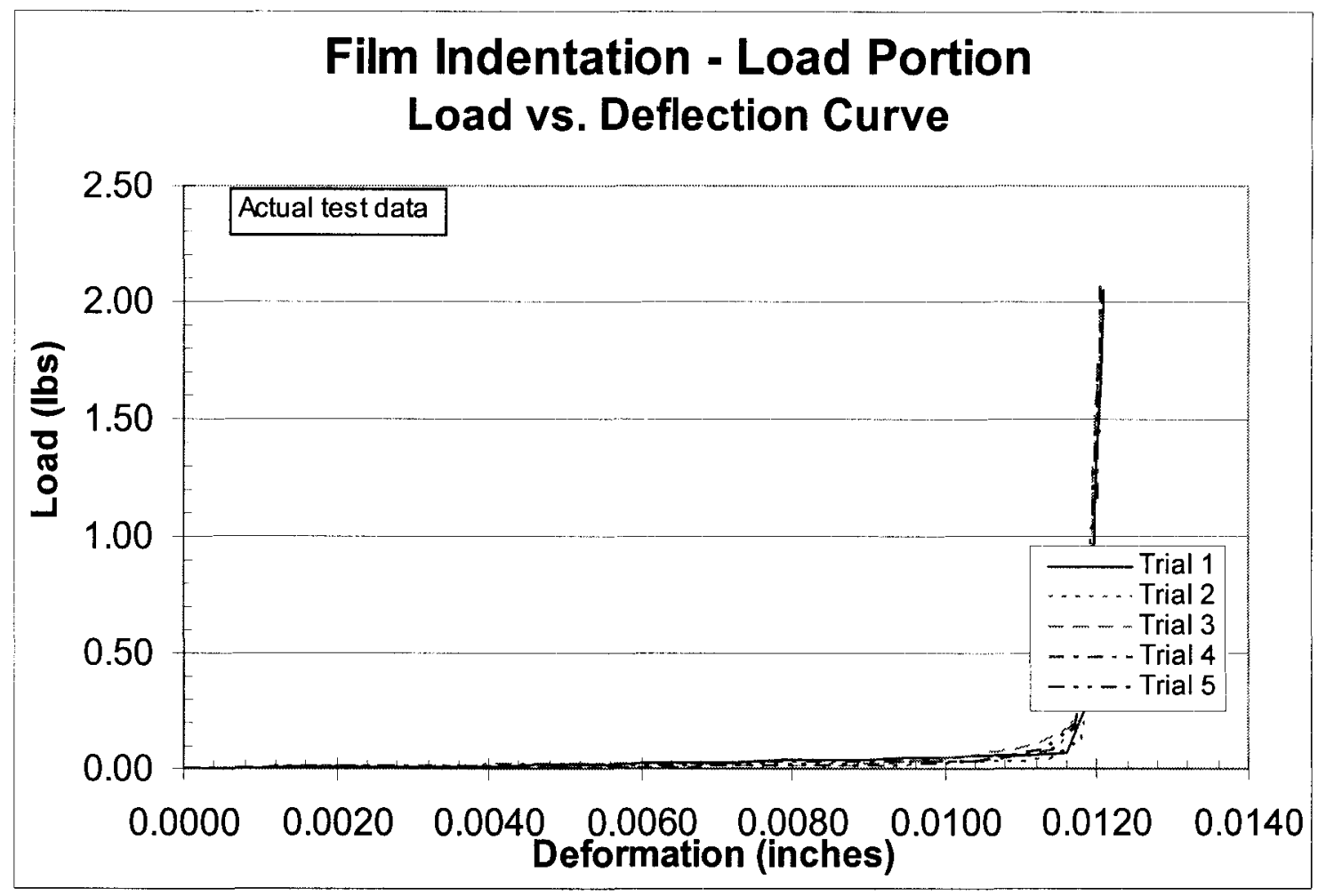

Figure 104. Load-displacement fits for $0.008^{\prime \prime} \mathrm{PVC}$ film aged for 1 week at $125^{\circ} \mathrm{C}$

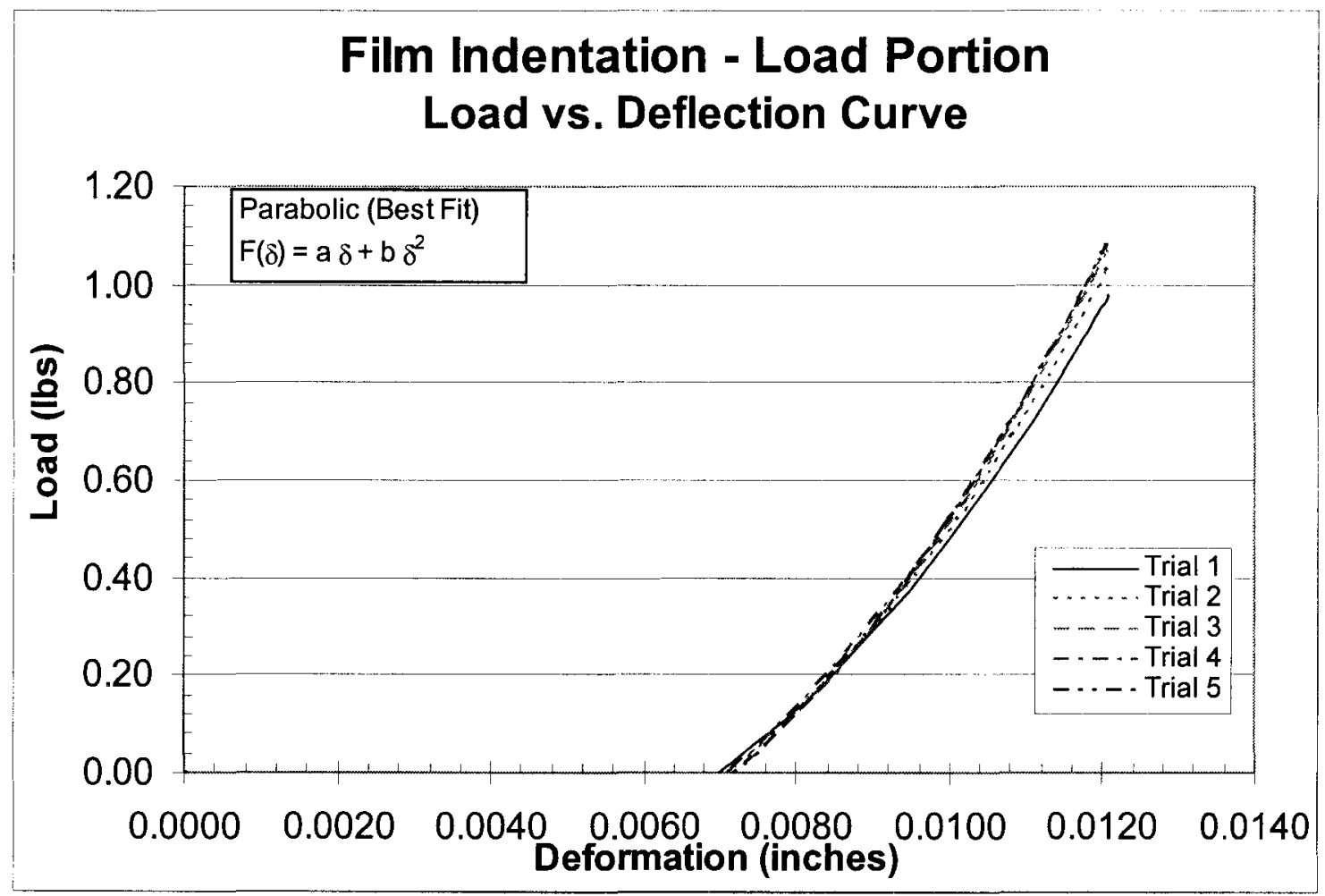

Figure 105. Load-displacement fits for $0.008^{\prime \prime} \mathrm{PVC}$ film aged for 1 week at $125^{\circ} \mathrm{C}$ 


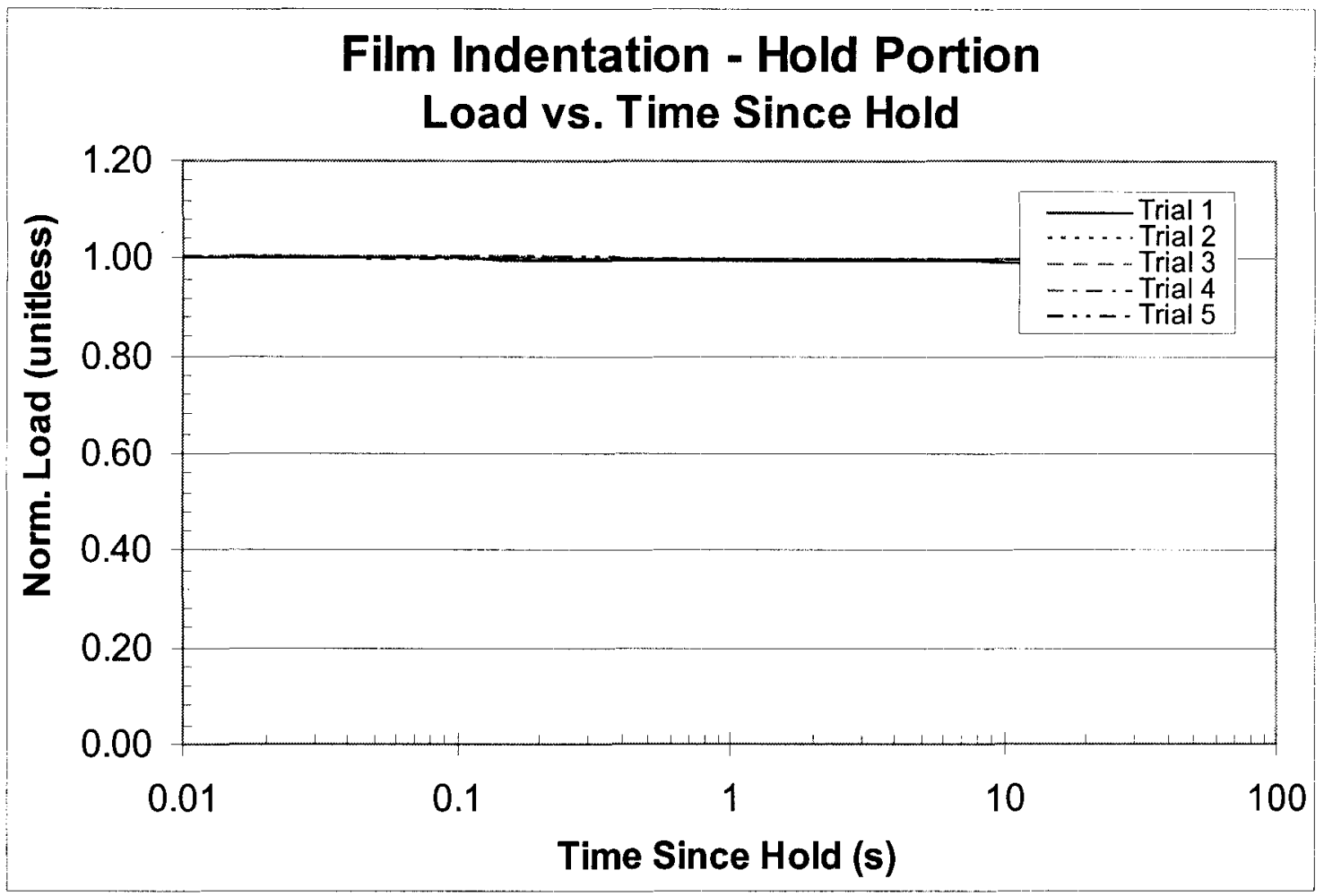

Figure 106. Normalized relaxation fits for $0.008^{\prime \prime} \mathrm{PVC}$ film aged for 1 week at $125^{\circ} \mathrm{C}$

\begin{tabular}{|c|c|c|c|c|c|c|}
\hline & Trial 1 & Trial 2 & Trial 3 & Trial 4 & Trial 5 & Average \\
\hline k (lbs/in) & 6509.0 & 8549.5 & 7509.9 & 4995.5 & 7368.3 & 6986.4 \\
\hline$\lambda$ (lbs) & -76.79870 & -101.32556 & -88.61424 & -58.70874 & -86.95911 & -82.48127 \\
\hline $\mathrm{a}(\mathrm{lbs} / \mathrm{in})$ & -111.18 & -122.34 & -130.91 & -127.96 & $\begin{array}{l}-134.33 \\
\end{array}$ & -125.34 \\
\hline$b\left(\mathrm{lbs} / \mathrm{in}^{2}\right)$ & 15904 & 17201 & 18170 & 18009 & 18599 & 17577 \\
\hline$\alpha(\mathrm{lb} / \mathrm{l}$ & -0.000121 & -0.000387 & -0.000314 & -0.001538 & -0.000278 & -0.000528 \\
\hline$\beta(\mathrm{Ib} / \mathrm{l}$ & -0.000505 & -0.000025 & -0.000054 & 0.000495 & 0.000037 & -0.000010 \\
\hline$\gamma(\mathrm{lb} / \log (\mathbf{s}$ & -0.0000281 & -0.0001084 & -0.0001060 & -0.0001883 & -0.0001159 & -0.0001094 \\
\hline
\end{tabular}

Table 31. Data fit coefficients for $0.008^{\prime \prime} \mathrm{PVC}$ film aged for 1 week at $125^{\circ} \mathrm{C}$ 


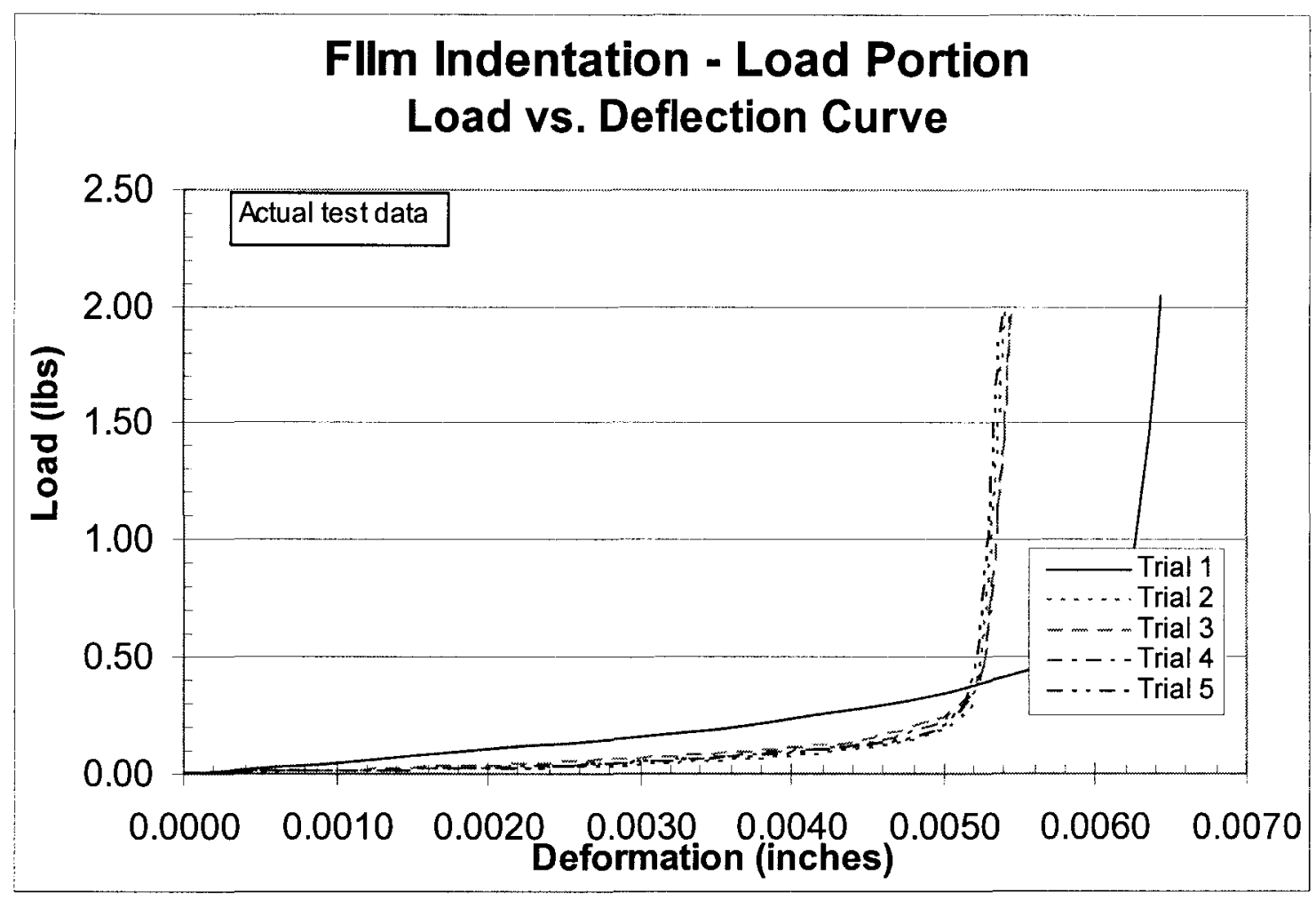

Figure 107. Load-displacement fits for $0.008^{\prime \prime} \mathrm{PVC}$ film aged for 2 weeks at $125^{\circ} \mathrm{C}$ 


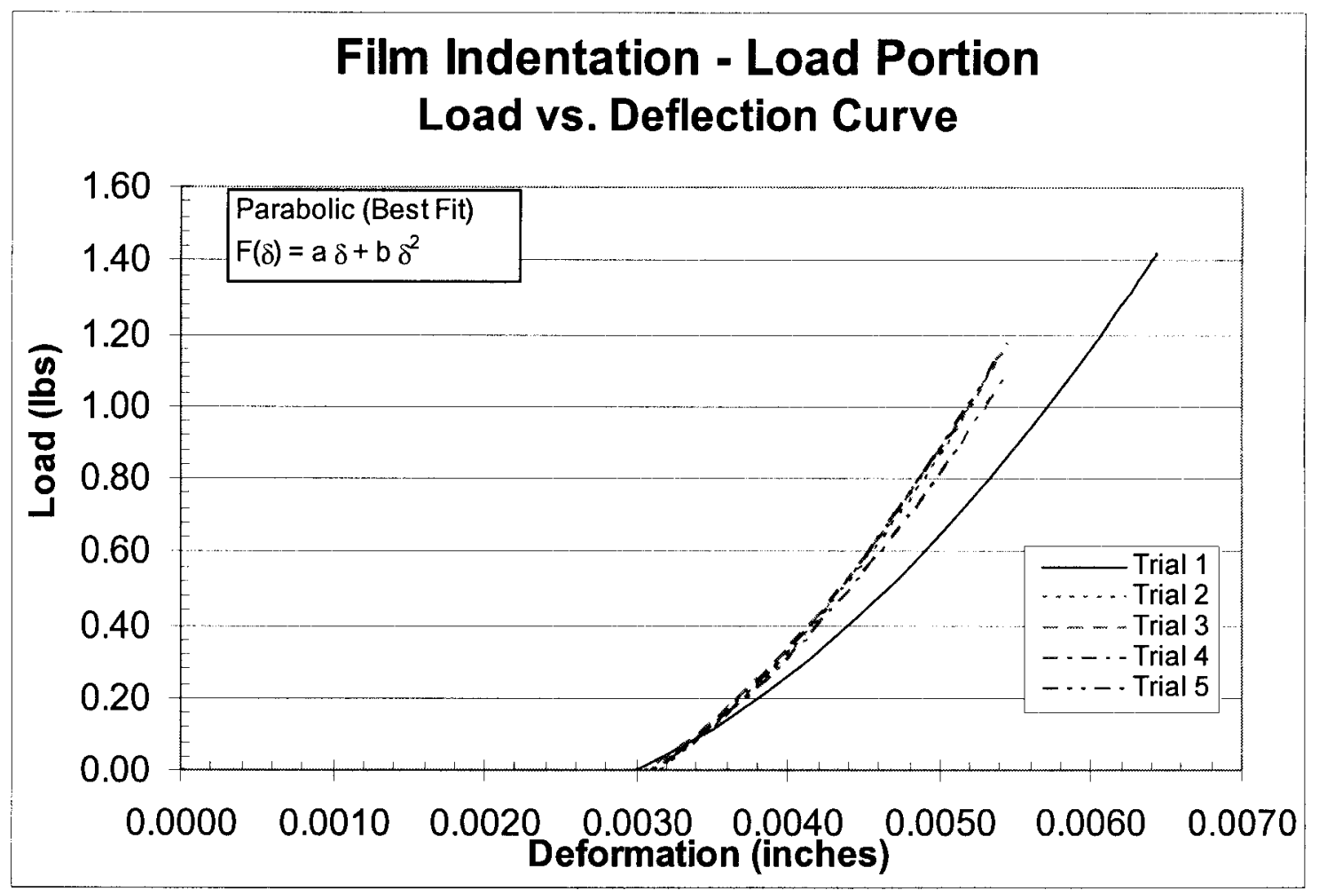

Figure 108. Load-displacement fits for 0.008 " PVC film aged for 2 weeks at $125^{\circ} \mathrm{C}$

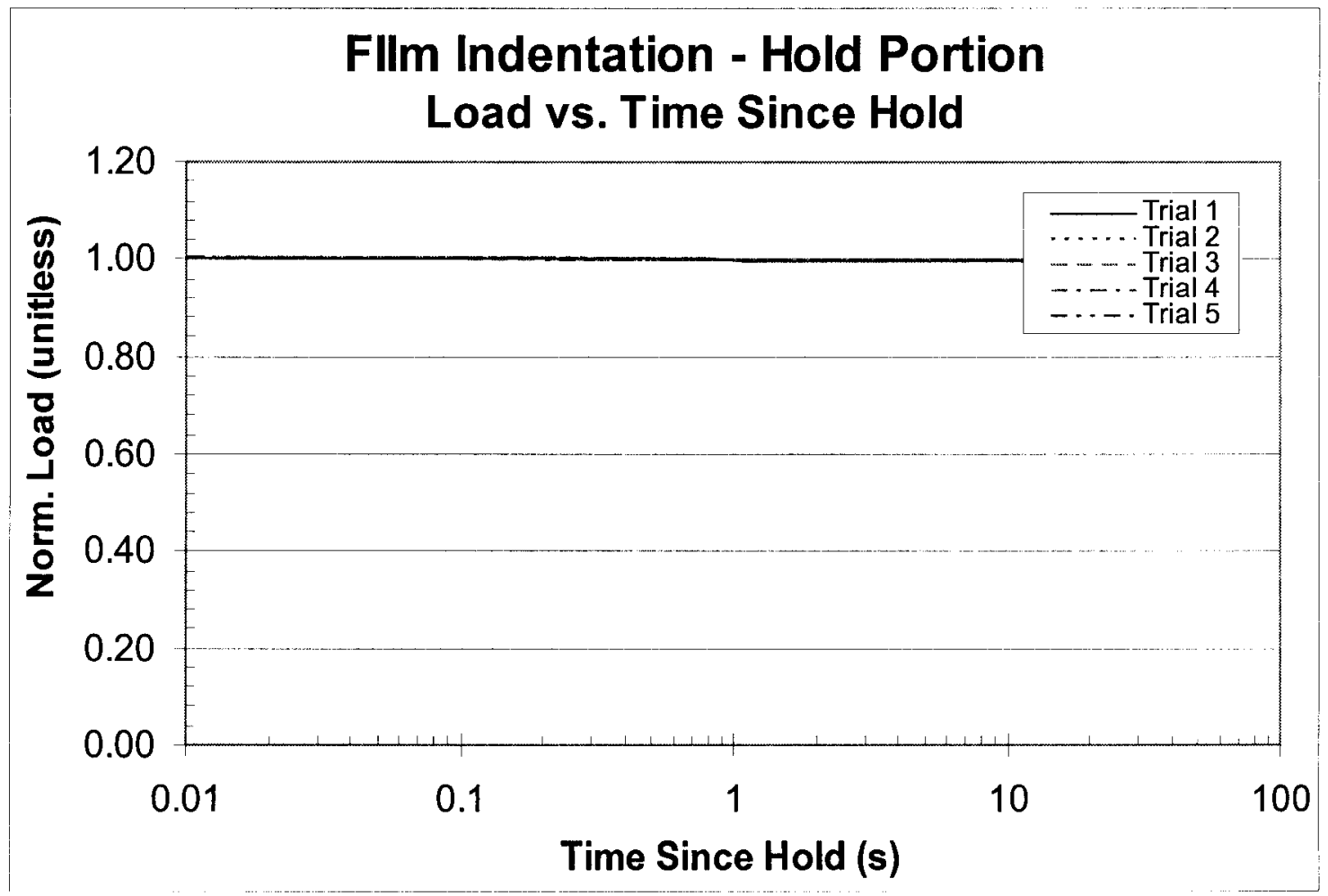

Figure 109. Normalized relaxation fits for $0.008^{\prime \prime}$ PVC film aged for 2 weeks at $125^{\circ} \mathrm{C}$ 


\begin{tabular}{|l|ccccc|c|}
\hline & Trial 1 & Trial 2 & Trial 3 & Trial 4 & Trial 5 & Average \\
\hline $\mathbf{k}(\mathbf{I b s} / \mathrm{in})$ & 1327.8 & 8186.2 & 7350.3 & 6102.6 & 7596.5 & 6112.7 \\
$\lambda(\mathbf{l b s})$ & -6.98994 & -42.47001 & -38.24843 & -31.56415 & -39.12750 & -31.68001 \\
\hline $\mathbf{a}(\mathbf{l b s} / \mathrm{in})$ & -192.17 & -295.93 & -282.54 & -266.85 & -291.96 & -265.89 \\
$\mathbf{b}\left(\mathbf{l b s} / \mathbf{i n}^{2}\right)$ & 64225 & 93664 & 91340 & 85797 & 93320 & 85669 \\
\hline$\alpha(\operatorname{lb} / \log (\mathbf{s}))$ & -0.000055 & -0.000091 & -0.000648 & 0.000123 & -0.000533 & -0.000241 \\
$\beta\left(\operatorname{lb} / \log (\mathbf{s})^{2}\right)$ & -0.000007 & -0.000389 & -0.000112 & -0.000420 & 0.000098 & -0.000166 \\
$\gamma\left(\operatorname{lb} / \log (\mathbf{s})^{3}\right)$ & -0.0000941 & -0.0000031 & -0.0000540 & -0.0000197 & -0.0001139 & -0.0000570 \\
\hline
\end{tabular}

Table 32. Data fit coefficients for $0.008^{\prime \prime}$ PVC film aged for 2 weeks at $125^{\circ} \mathrm{C}$

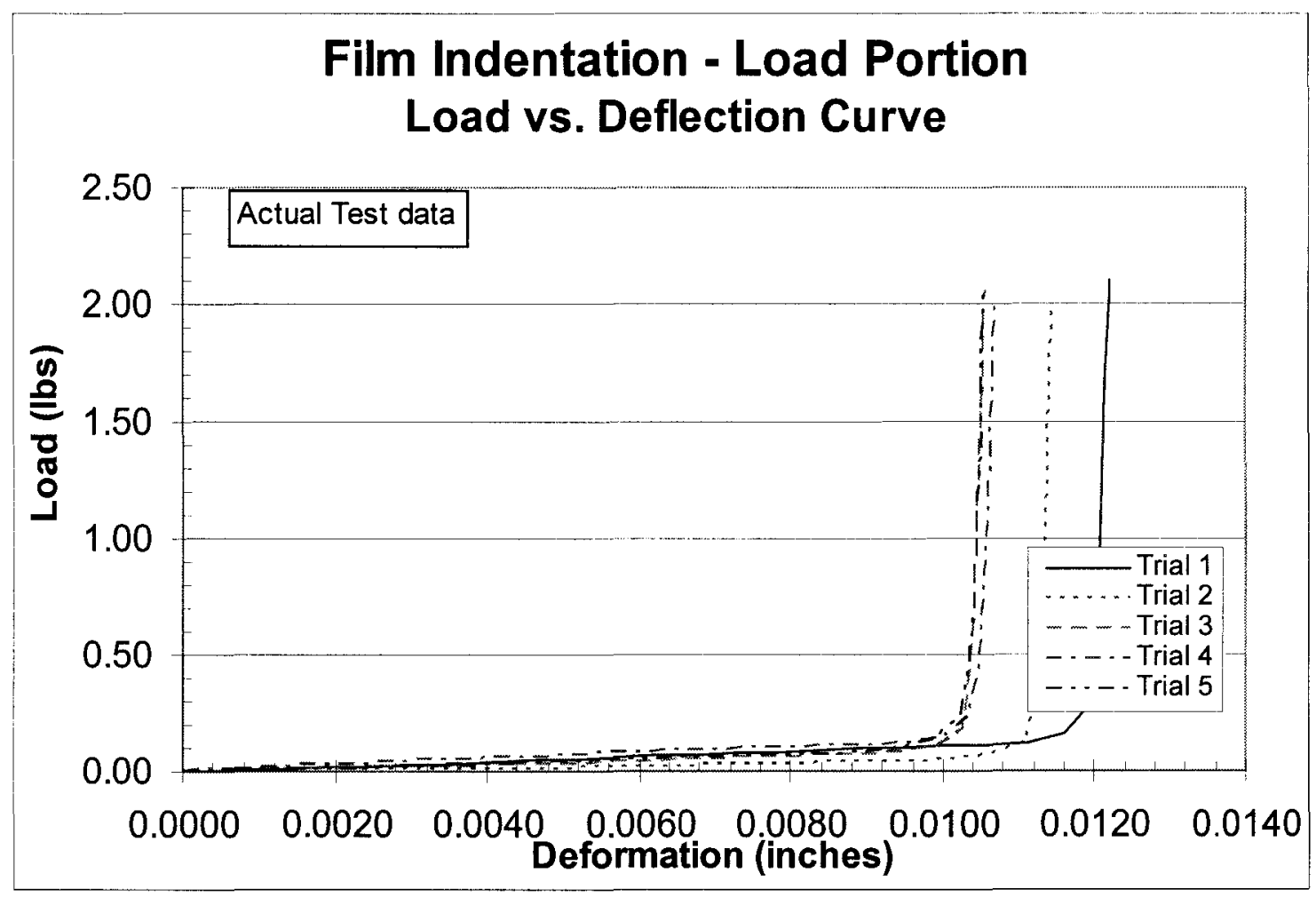

Figure 110. Load-displacement fits for $0.008^{\prime} \mathrm{PVC}$ film aged for 3 weeks at $125^{\circ} \mathrm{C}$ 


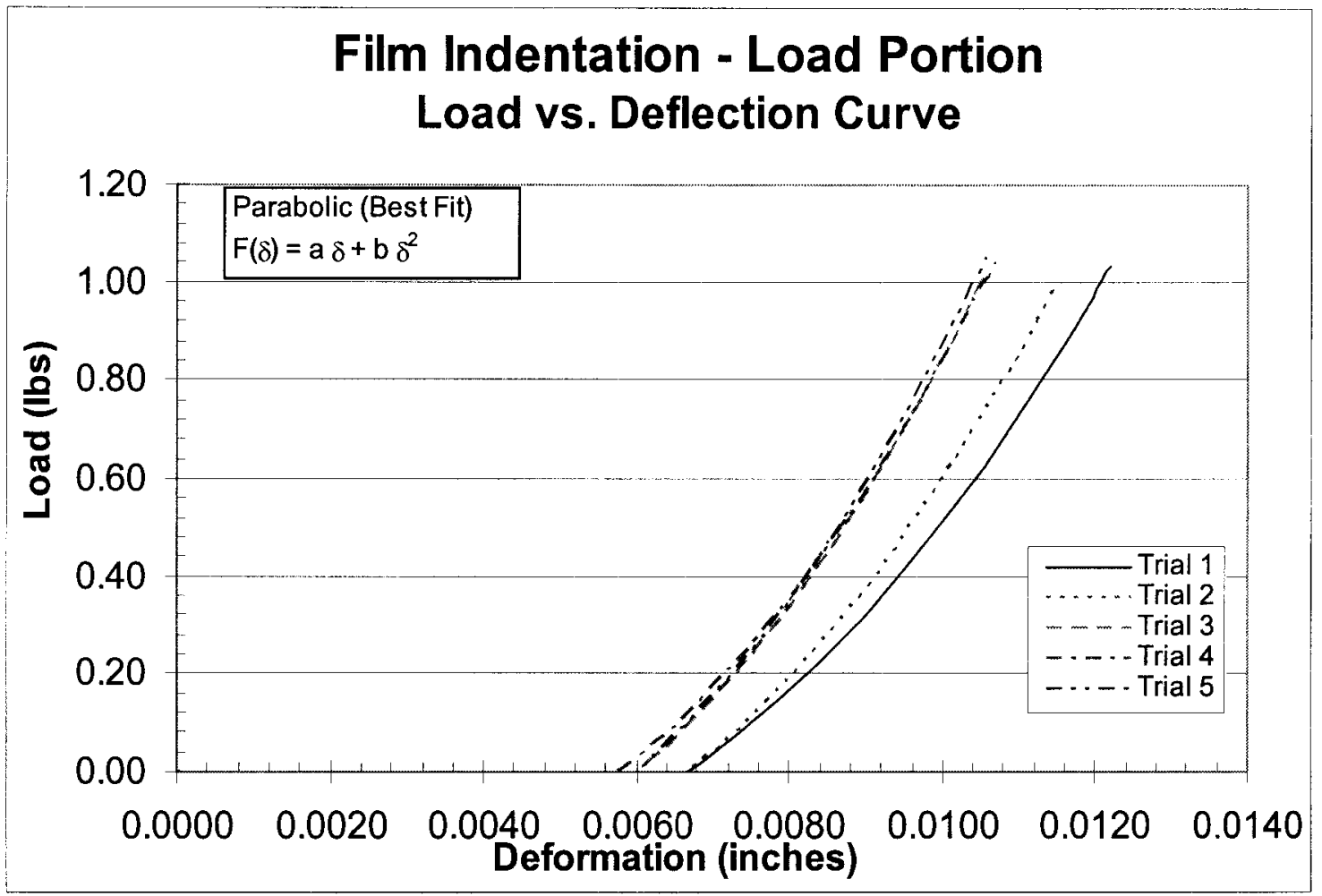

Figure 111. Load-displacement fits for $0.008^{\prime \prime} \mathrm{PVC}$ film aged for 3 weeks at $125^{\circ} \mathrm{C}$

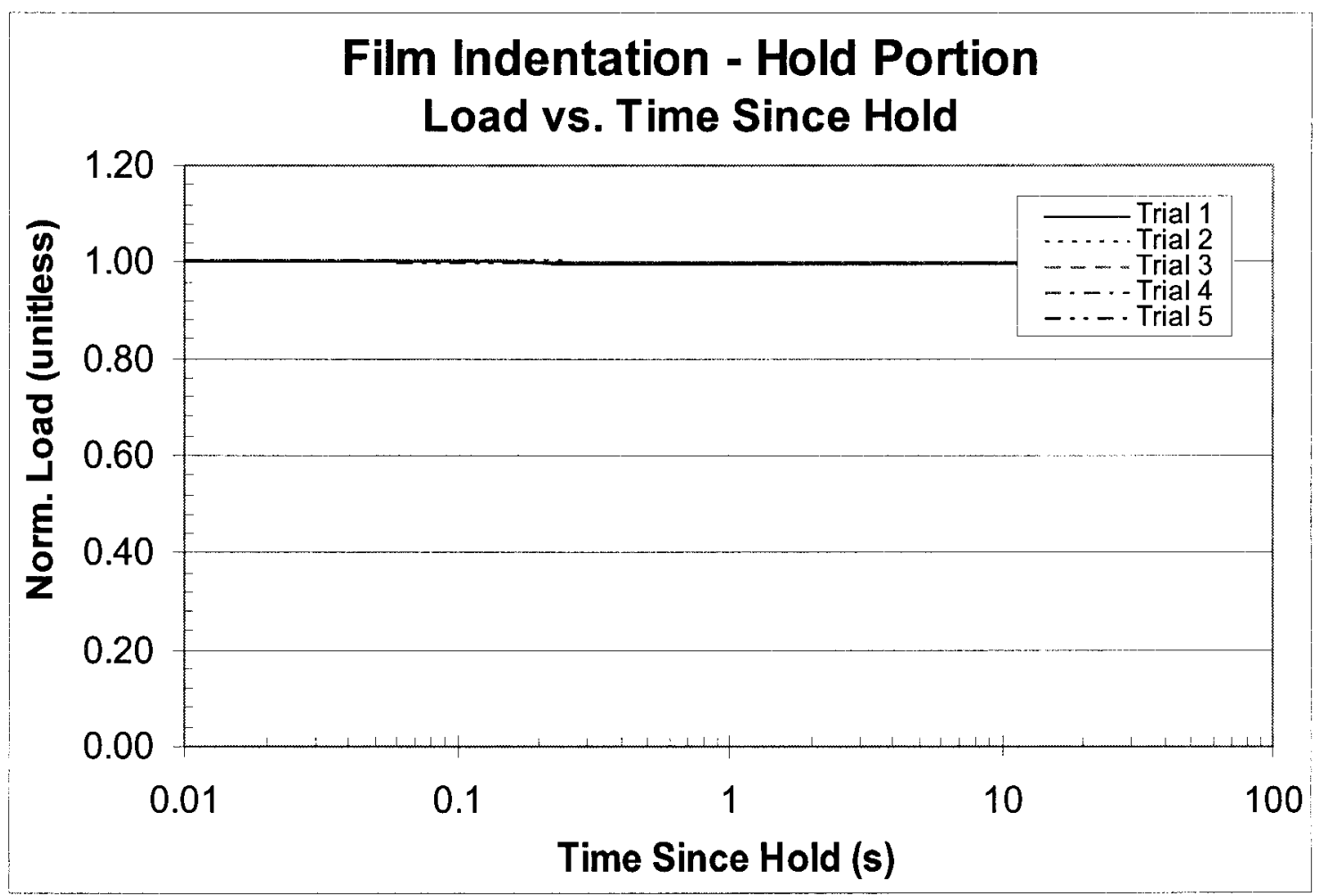

Figure 112. Normalized relaxation fits for $0.008^{\prime \prime} \mathrm{PVC}$ film aged for 3 weeks at $125^{\circ} \mathrm{C}$ 


\begin{tabular}{|c|c|c|c|c|c|c|}
\hline & Trial 1 & Trial 2 & Trial 3 & Trial 4 & Trial 5 & Average \\
\hline k (lbs/in) & 6068.4 & 7332.1 & 7888.7 & 7386.5 & 7626.6 & 7260.5 \\
\hline$\lambda$ (lbs) & -72.19677 & -82.10095 & -81.44279 & -77.10664 & -78.67250 & -78.30393 \\
\hline$a$ (Ibs/in) & -101.62 & -120.82 & -127.85 & -114.53 & -130.22 & -119.01 \\
\hline b $\left(\mathrm{lbs} / \mathrm{in}^{2}\right)$ & 15277 & 18053 & 21195 & 19812 & 21712 & 19210 \\
\hline$\alpha(\operatorname{lb} / \log (s))$ & -0.000273 & -0.000487 & -0.000590 & -0.000389 & -0.001069 & -0.000562 \\
\hline$\beta\left(\operatorname{lb} / \log (s)^{2}\right)$ & -0.000142 & 0.000116 & 0.000094 & -0.000123 & 0.000252 & 0.000039 \\
\hline$\gamma\left(\mid \mathrm{b} / \log (\mathrm{s})^{3}\right)$ & -0.0000806 & -0.0001358 & -0.0001334 & -0.0001169 & -0.0001488 & -0.0001231 \\
\hline
\end{tabular}

Table 33. Data fit coefficients for $0.008^{\prime \prime} \mathrm{PVC}$ film aged for 3 weeks at $125^{\circ} \mathrm{C}$

\section{$\underline{0.019 "}$ PVC Film Aged At $125^{\circ} \mathrm{C}$}

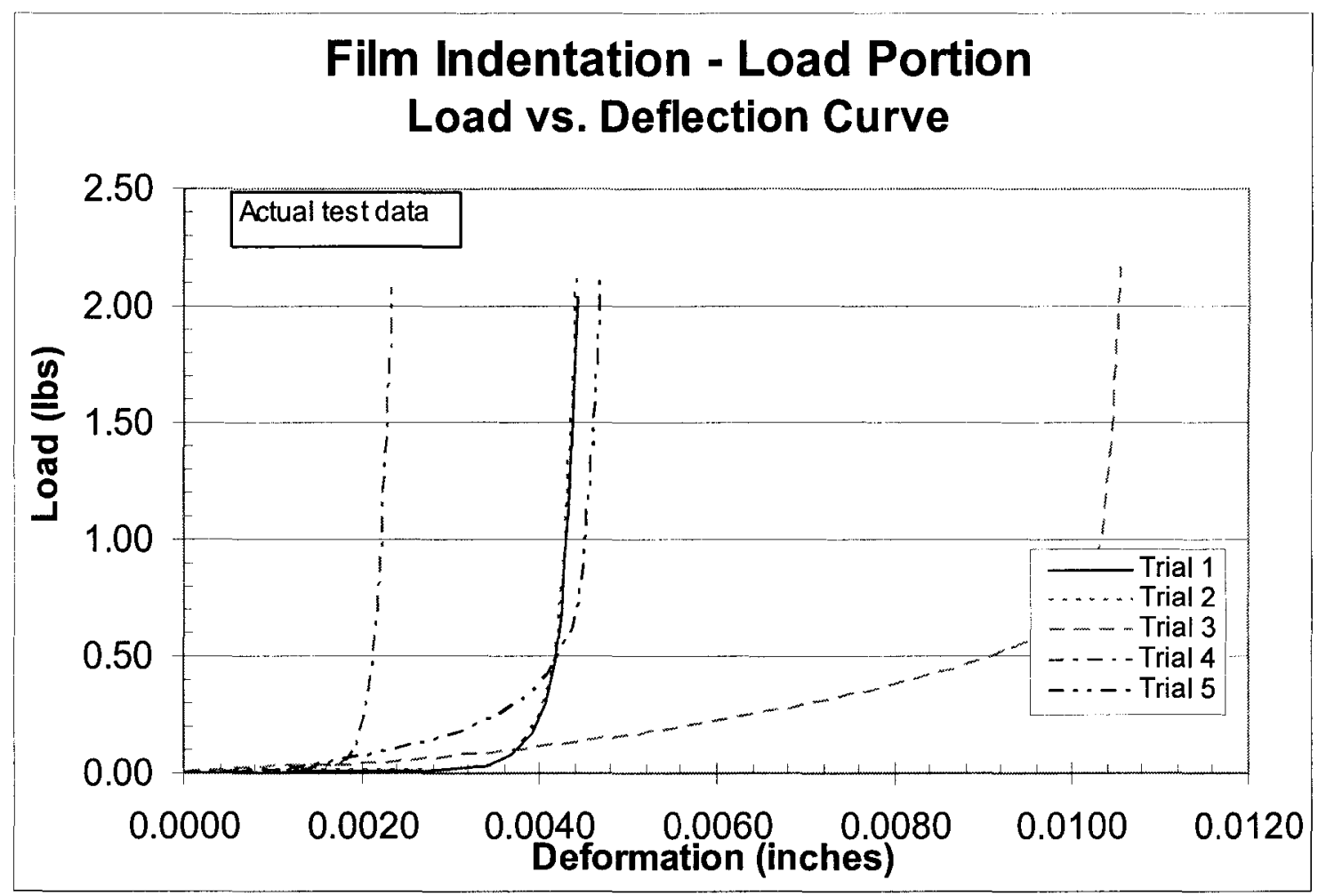

Figure 113. Load-displacement data for 0.019 " $\mathrm{PVC}$ film aged for 2 days at $125^{\circ} \mathrm{C}$ 


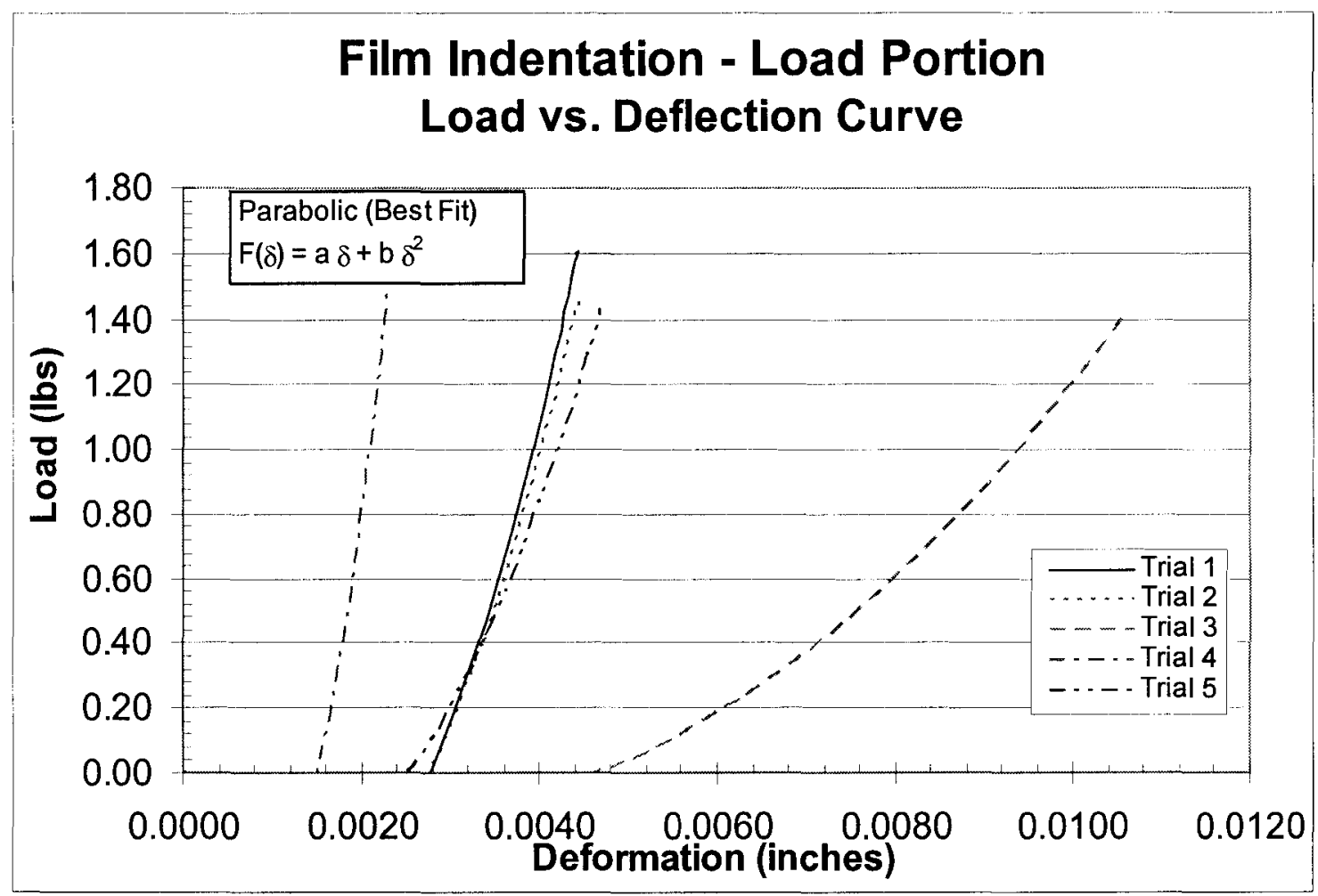

Figure 114. Load-displacement data for 0.019 " PVC film aged for 2 days at $125^{\circ} \mathrm{C}$

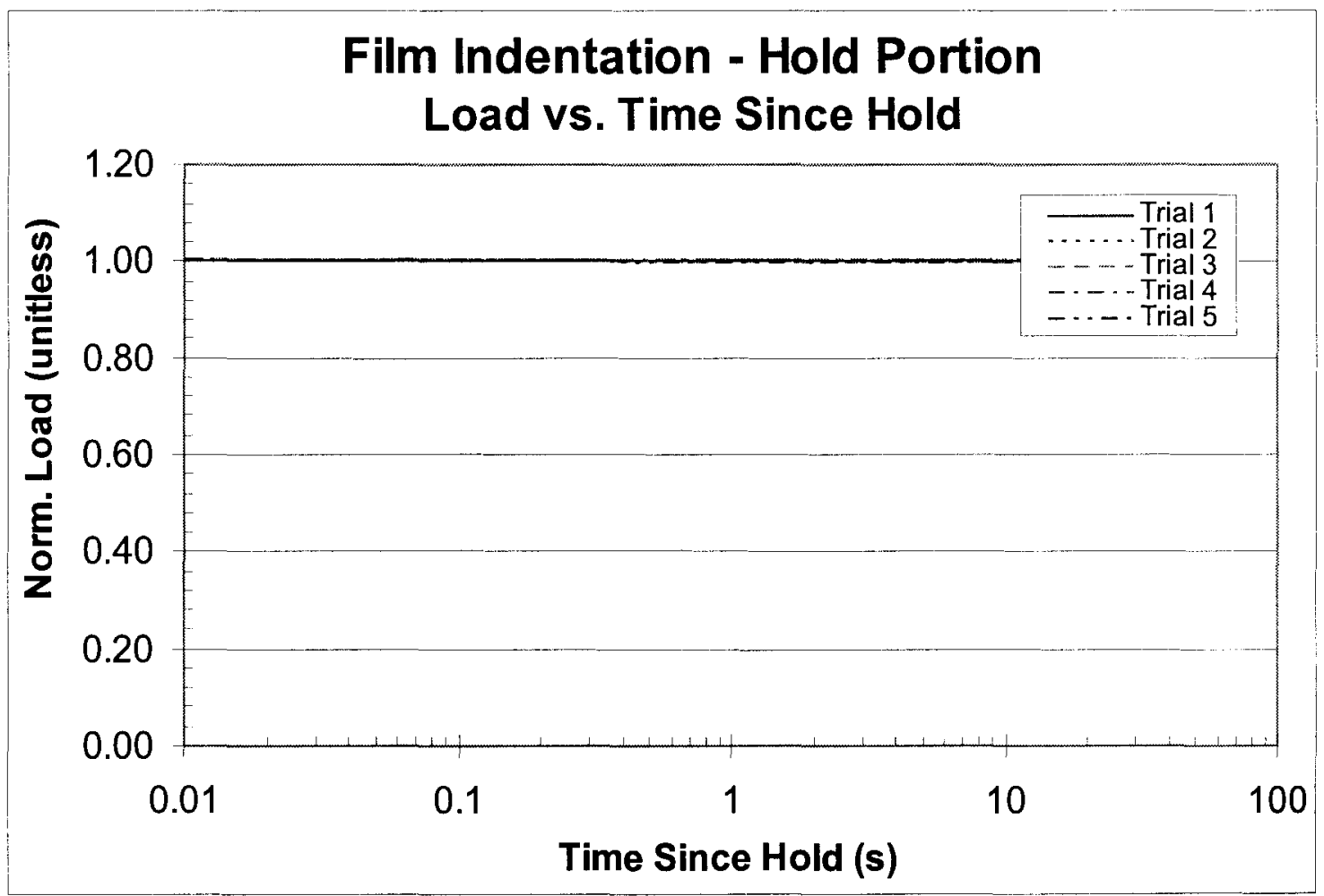

Figure 115. Normalized relaxation fits for 0.019 " PVC film aged for 2 days at $125^{\circ} \mathrm{C}$ 


\begin{tabular}{|l|ccccc|c|}
\hline & Trial 1 & Trial 2 & Trial 3 & Trial 4 & Trial 5 & Average \\
\hline $\mathbf{k}(\mathrm{Ibs} / \mathrm{in})$ & 5377.1 & 5655.0 & 779.5 & 6366.1 & 2698.5 & 4175.2 \\
$\lambda(\mathrm{lbs})$ & -22.00856 & -23.16196 & -6.56736 & -13.11336 & -10.96869 & -15.16399 \\
\hline $\mathbf{a}(\mathrm{lbs} / \mathrm{in})$ & -610.58 & -542.58 & -104.41 & -1260.53 & -353.00 & -574.22 \\
$\mathbf{b}\left(\mathrm{lbs} / \mathrm{in}^{2}\right)$ & 220375 & 196699 & 22436 & 825204 & 140175 & 280978 \\
\hline$\alpha(\mathrm{lb} / \log (\mathbf{s}))$ & -0.000417 & -0.000810 & 0.000043 & 0.001077 & -0.000604 & -0.000142 \\
$\beta\left(\mathrm{lb} / \log (\mathbf{s})^{2}\right)$ & 0.000616 & 0.000832 & -0.000262 & -0.000415 & 0.000264 & 0.000207 \\
$\gamma\left(\mathrm{lb} / \log (\mathbf{s})^{3}\right)$ & -0.0001817 & -0.0002039 & -0.0000263 & -0.0000102 & -0.0001367 & -0.0001117 \\
\hline
\end{tabular}

Table 34. Data fit coefficients for $0.019^{\prime}$ ' PVC film aged for 2 days at $125^{\circ} \mathrm{C}$

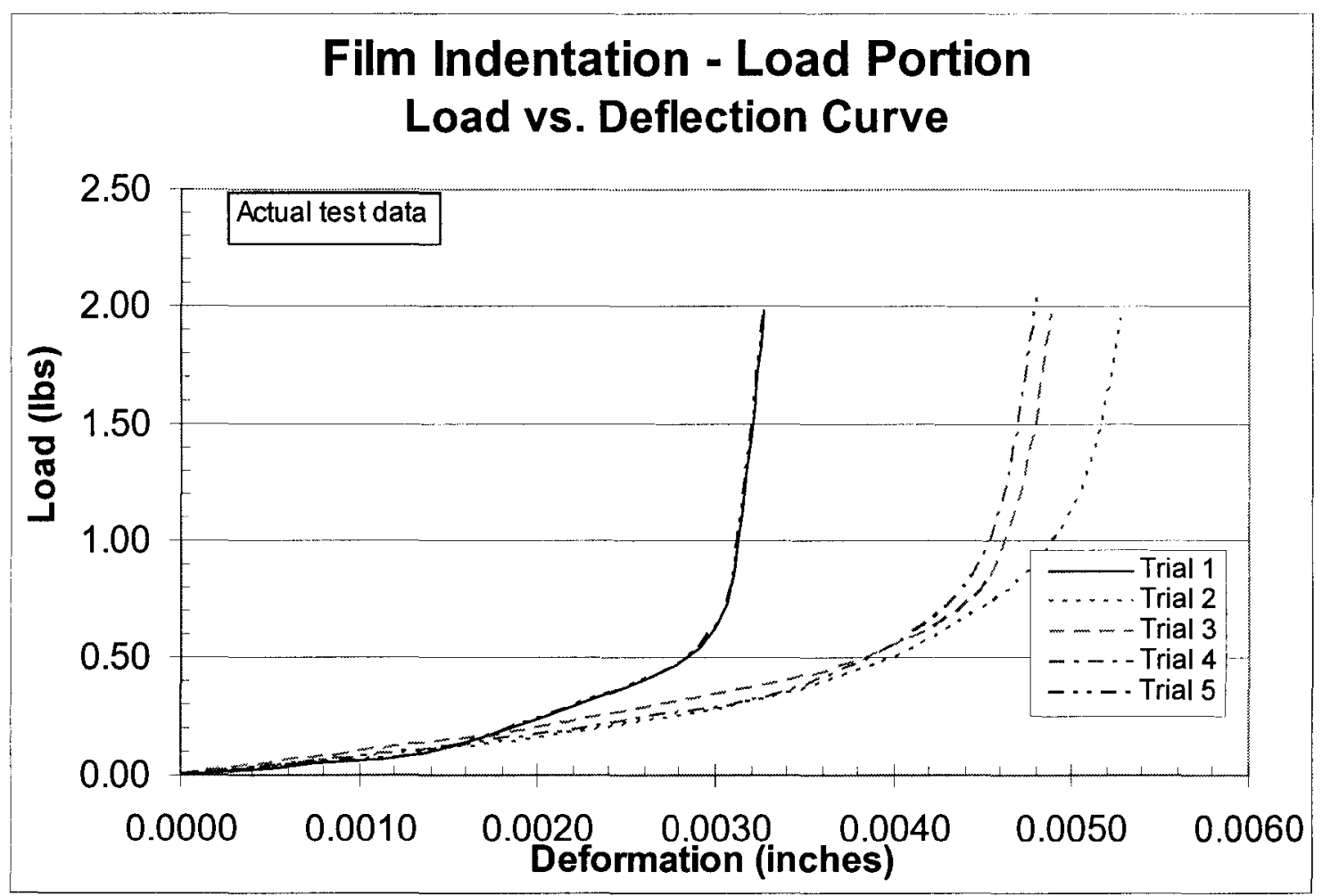

Figure 116. Load-displacement data for $0.019^{\prime \prime}$ PVC film aged for 5 days at $125^{\circ} \mathrm{C}$ 


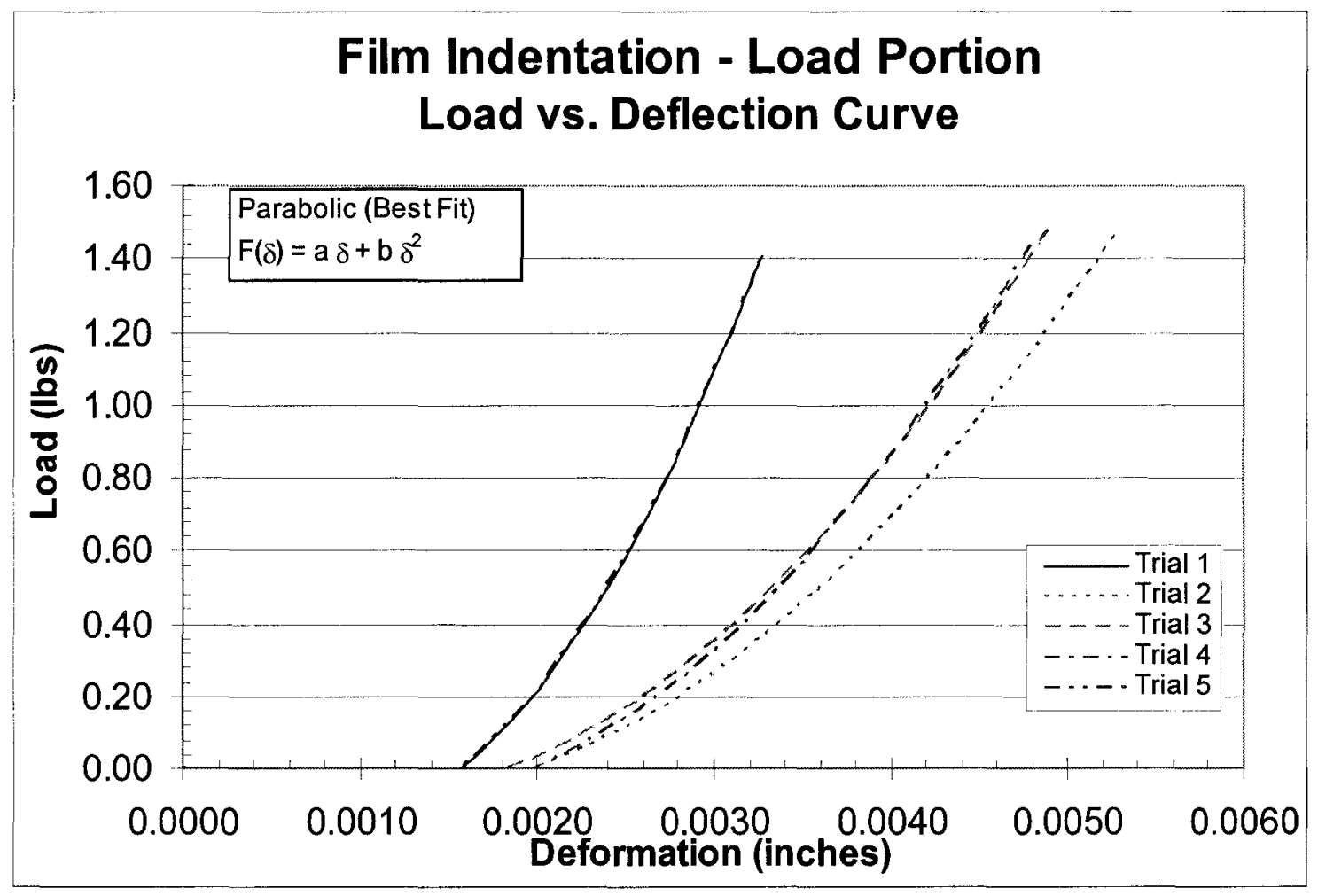

Figure 117. Load-displacement data for 0.019 " PVC film aged for 5 days at $125^{\circ} \mathrm{C}$

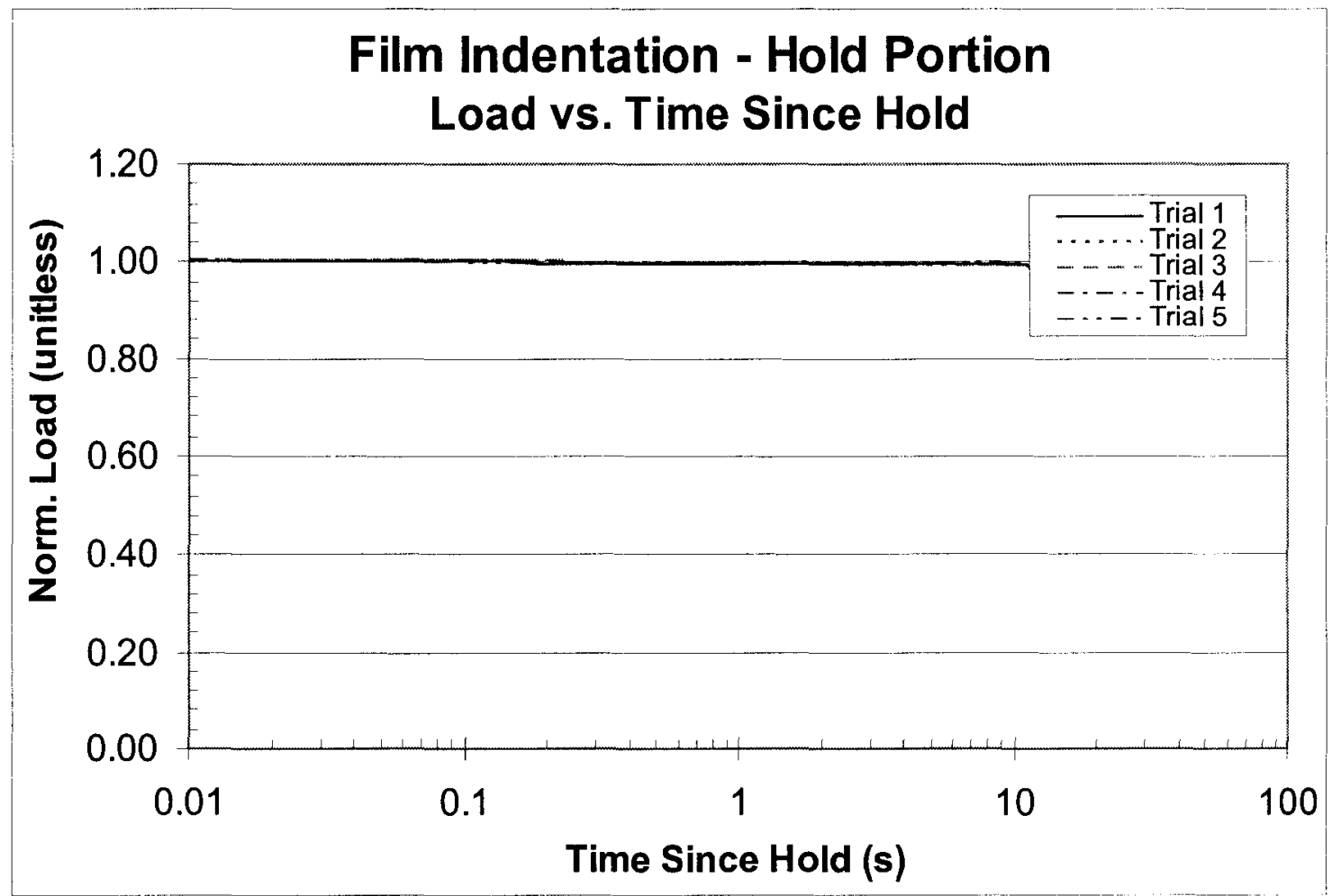

Figure 118. Normalized relaxation fits for 0.019 " PVC film aged for 5 days at $125^{\circ} \mathrm{C}$ 


\begin{tabular}{|l|ccccc|c|}
\hline & Trial 1 & Trial 2 & Trial 3 & Trial 4 & Trial 5 & Average \\
\hline $\mathbf{k}(\mathrm{lbs} / \mathrm{in})$ & 2269.0 & 716.2 & 912.1 & 1134.1 & 2269.0 & 1460.1 \\
$\lambda(\mathrm{lbs})$ & -5.83135 & -2.28632 & -2.96412 & -3.87221 & -5.83135 & -4.15707 \\
\hline $\mathbf{a}(\mathrm{Ibs} / \mathrm{in})$ & -398.36 & -163.82 & -179.47 & -212.17 & -398.36 & -270.43 \\
$\mathbf{b}\left(\mathbf{l b s} / \mathrm{in}^{2}\right)$ & 253559 & 84037 & 98634 & 106958 & 253559 & 159350 \\
\hline$\alpha(\mathrm{lb} / \log (\mathbf{s}))$ & -0.000586 & -0.000215 & -0.000053 & 0.000032 & -0.000586 & -0.000281 \\
$\beta\left(\operatorname{lb} / \log (\mathbf{s})^{2}\right)$ & 0.000160 & -0.000353 & -0.000131 & -0.000297 & 0.000160 & -0.000092 \\
$\gamma\left(\operatorname{lb} / \log (\mathbf{s})^{3}\right)$ & -0.0001876 & -0.0002403 & -0.0002026 & -0.0001407 & -0.0001876 & -0.0001918 \\
\hline
\end{tabular}

Table 35. Data fit coefficients for 0.019 " PVC film aged for 5 days at $125^{\circ} \mathrm{C}$

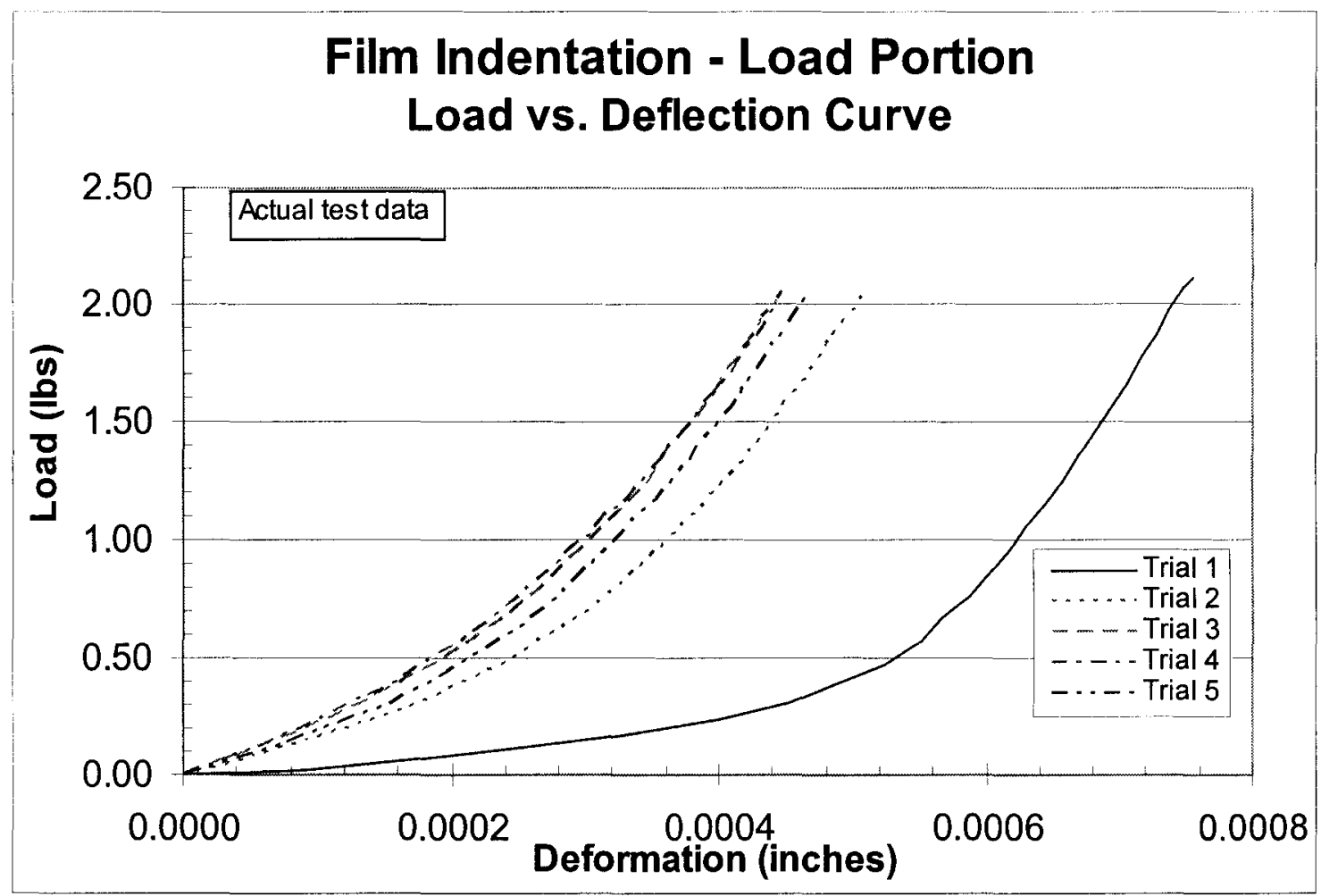

Figure 119. Load-displacement data for 0.019 ' PVC film aged for 1 week at $125^{\circ} \mathrm{C}$ 


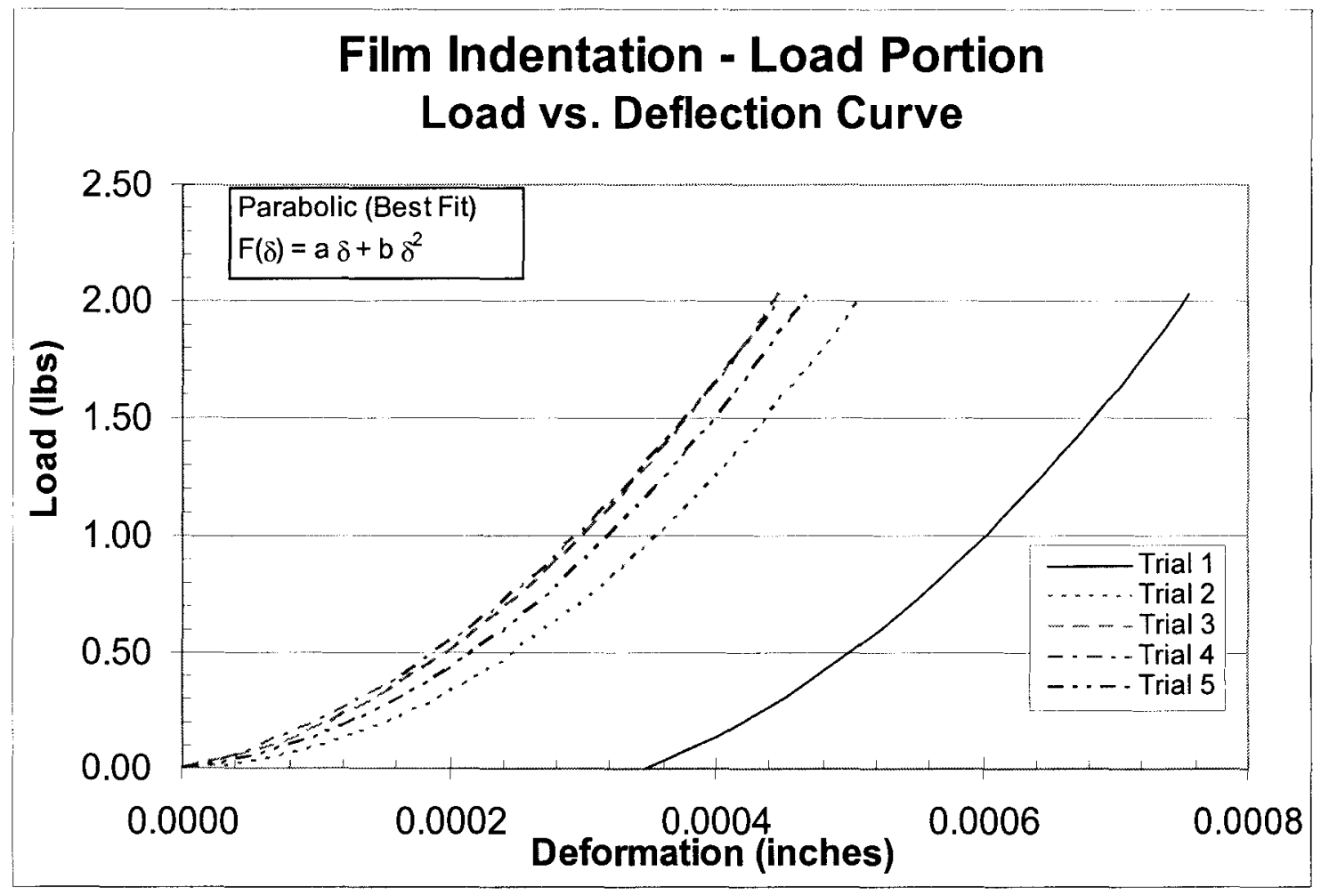

Figure 120. Load-displacement data for 0.019 " PVC film aged for 1 week at $125^{\circ} \mathrm{C}$.

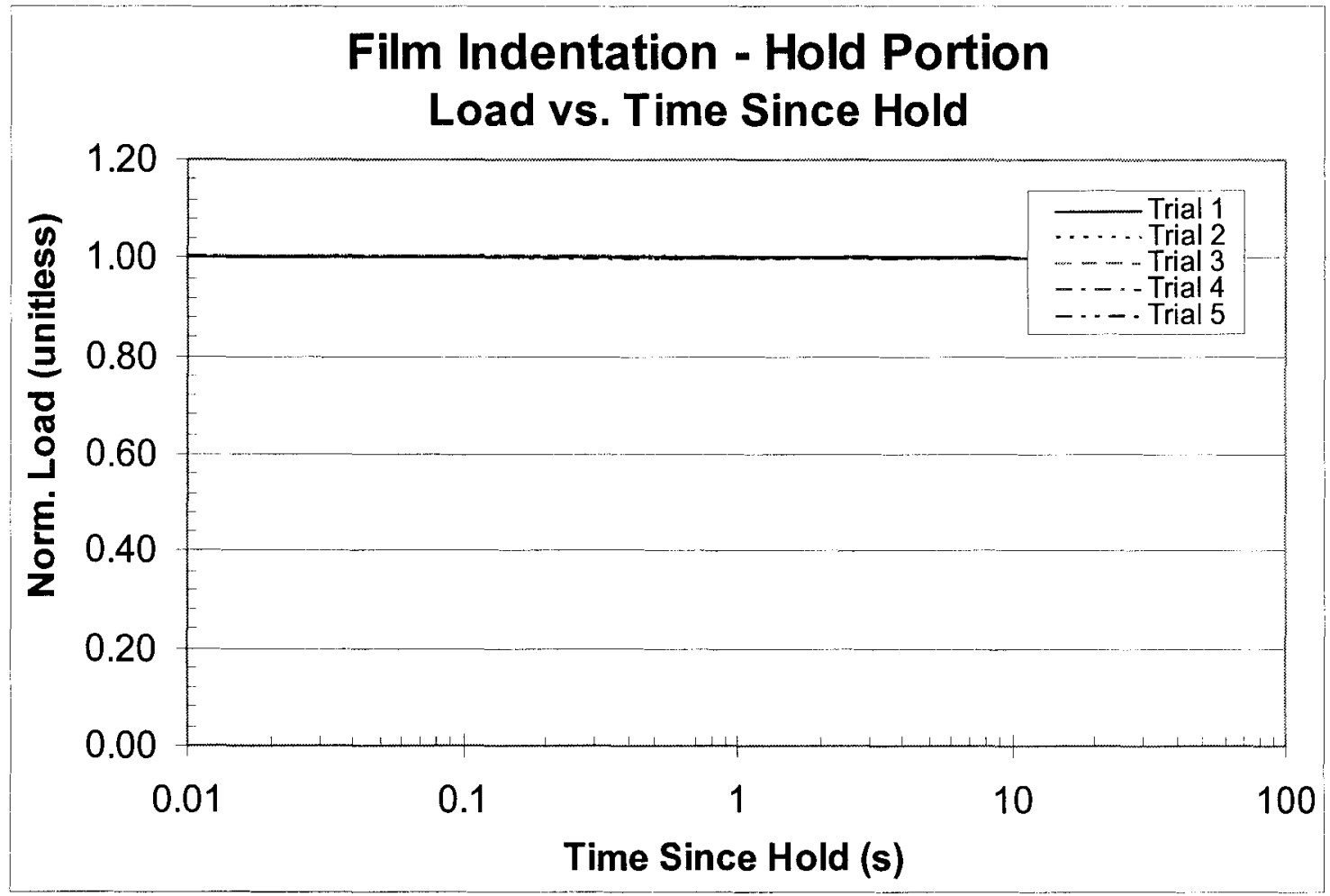

Figure 121. Normalized relaxation fits for 0.019 ” PVC film aged for 1 week at $125^{\circ} \mathrm{C}$. 


\begin{tabular}{|l|ccccc|c|}
\hline & Trial 1 & Trial 2 & Trial 3 & Trial 4 & Trial 5 & Average \\
\hline $\mathbf{k}(\mathbf{l b s} / \mathrm{in})$ & 6410.7 & 5000.9 & 5385.3 & 5140.5 & 5387.5 & 5465.0 \\
$\lambda(\mathbf{l b s})$ & -2.88374 & -0.70759 & -0.55357 & -0.45987 & -0.65948 & -1.05285 \\
\hline $\mathbf{a}(\mathbf{l b s} / \mathrm{in})$ & -2301.12 & 159.47 & 948.18 & 1280.33 & 545.88 & 126.55 \\
$\mathbf{b}\left(\mathbf{l b s} / \mathbf{i n}^{2}\right)$ & 6589893 & 7467849 & 7952408 & 7130248 & 8056756 & 7439431 \\
\hline$\alpha(\mathbf{l b} / \log (\mathbf{s}))$ & -0.000417 & 0.000320 & 0.000700 & -0.000102 & 0.001187 & 0.000338 \\
$\beta\left(\mathbf{l b} / \log (\mathbf{s})^{2}\right)$ & 0.000334 & -0.000251 & -0.000702 & -0.000421 & -0.001118 & -0.000432 \\
$\gamma\left(\operatorname{lb} / \log (\mathbf{s})^{3}\right)$ & -0.0000931 & -0.0000951 & -0.0000130 & -0.0000218 & 0.0000949 & -0.0000256 \\
\hline
\end{tabular}

Table 36. Data fit coefficients for 0.019 " PVC film aged for 1 week at $125^{\circ} \mathrm{C}$

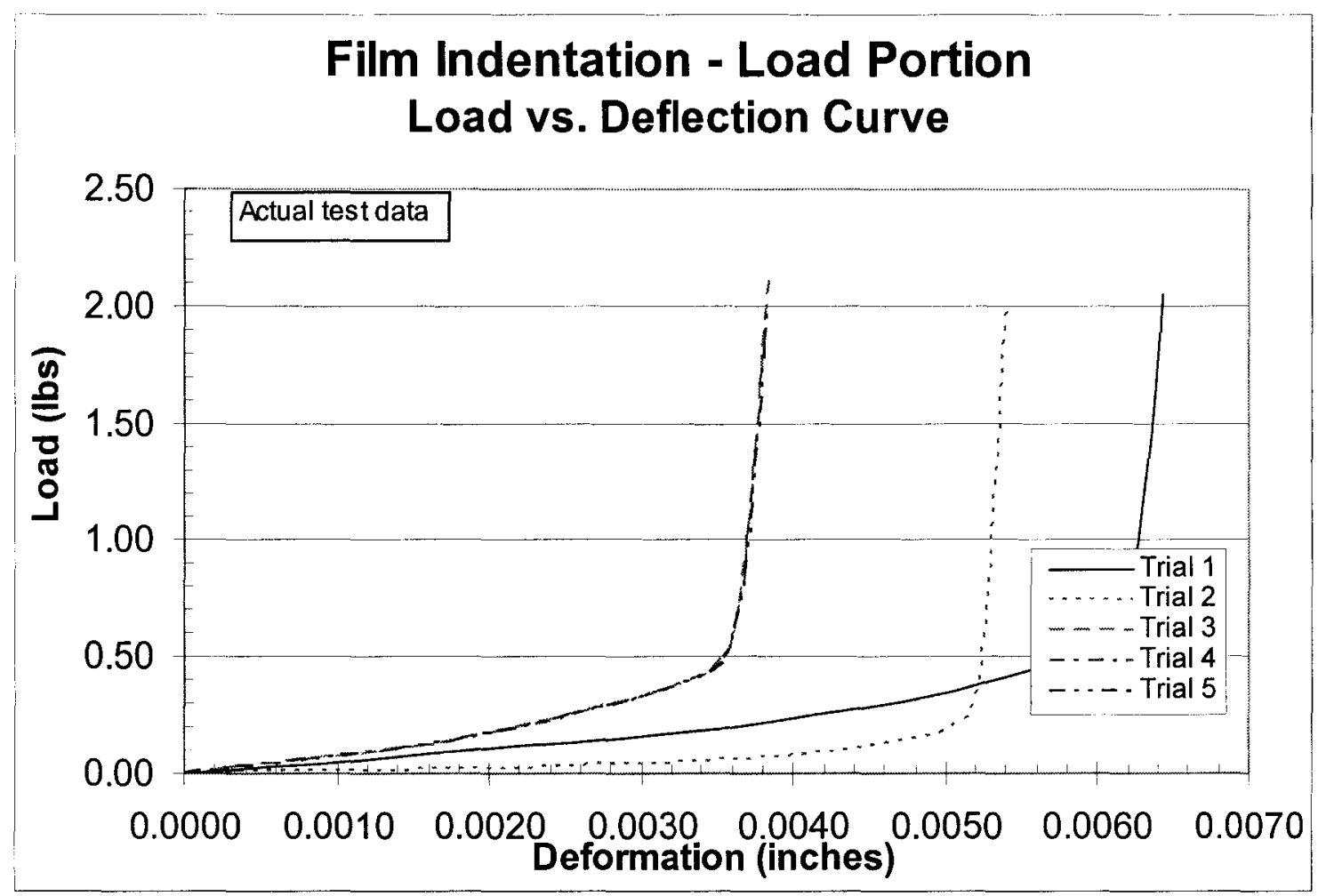

Figure 122. Load-displacement data for 0.019 " PVC film aged for 2 weeks at $125^{\circ} \mathrm{C}$. 


\section{Film Indentation - Load Portion Load vs. Deflection Curve}

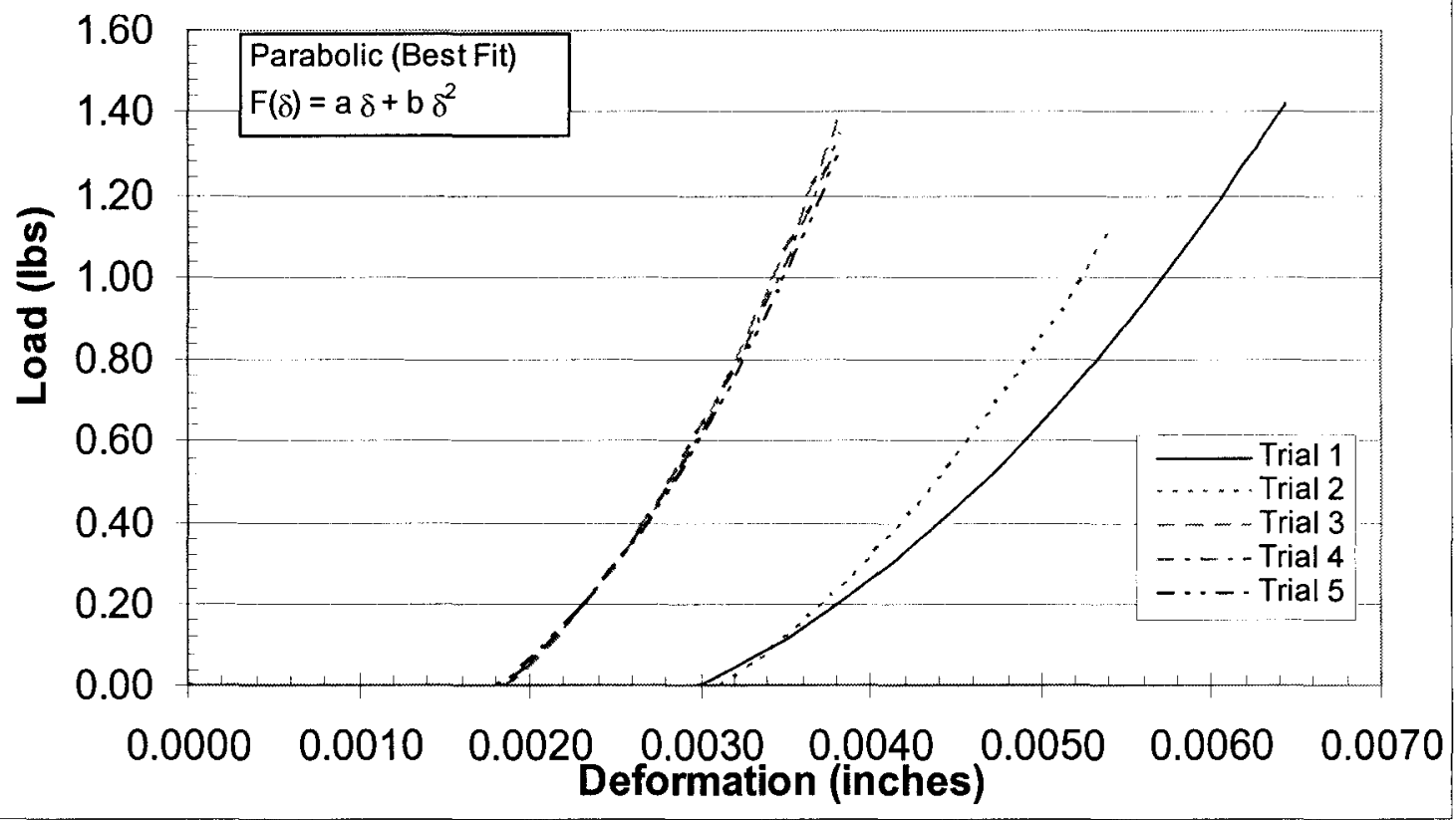

Figure 123. Load-displacement data for 0.019 " PVC film aged for 2 weeks at $125^{\circ} \mathrm{C}$

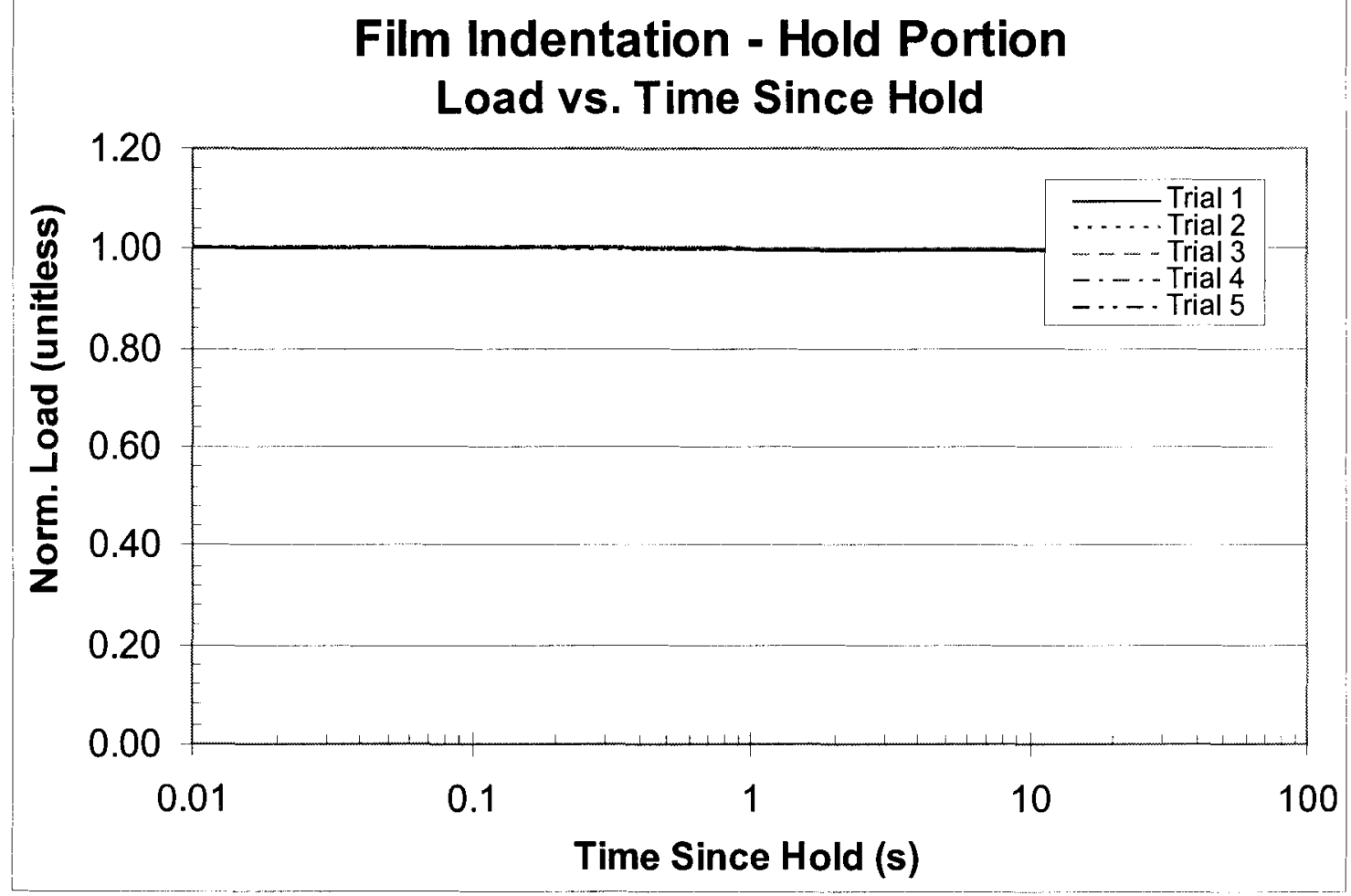

Figure 124. Normalized relaxation fits for 0.019 " PVC film aged for 2 weeks at $125^{\circ} \mathrm{C}$ 


\begin{tabular}{|l|ccccc|c|}
\hline & Trial 1 & Trial 2 & Trial 3 & Trial 4 & Trial 5 & Average \\
\hline $\mathbf{k}$ (Ibs/in) & 1327.8 & 7651.6 & 3562.4 & 3555.4 & 4503.8 & 4120.2 \\
$\lambda(\mathrm{lbs})$ & -6.98994 & -39.56422 & -11.94624 & -11.96391 & -15.56682 & -17.20622 \\
\hline $\mathbf{a}(\mathrm{lbs} / \mathrm{in})$ & -192.17 & -283.59 & -346.77 & -325.68 & -312.77 & -292.19 \\
$\mathbf{b}\left(\mathrm{lbs} / \mathrm{in}^{2}\right)$ & 64225 & 90495 & 185131 & 176687 & 171139 & 137535 \\
\hline$\alpha(\mathrm{lb} / \log (\mathbf{s}))$ & -0.000055 & -0.000192 & -0.000925 & -0.000048 & 0.000100 & -0.000224 \\
$\beta\left(\mathrm{lb} / \log (\mathbf{s})^{2}\right)$ & -0.000007 & -0.000275 & 0.000624 & -0.000293 & -0.000388 & -0.000068 \\
$\gamma\left(\mathrm{lb} / \log (\mathbf{s})^{3}\right)$ & -0.0000941 & -0.0000418 & -0.0001814 & 0.0000056 & 0.0000169 & -0.0000589 \\
\hline
\end{tabular}

Table 37. Data fit coefficients for 0.019 ' PVC film aged for 2 weeks at $125^{\circ} \mathrm{C}$

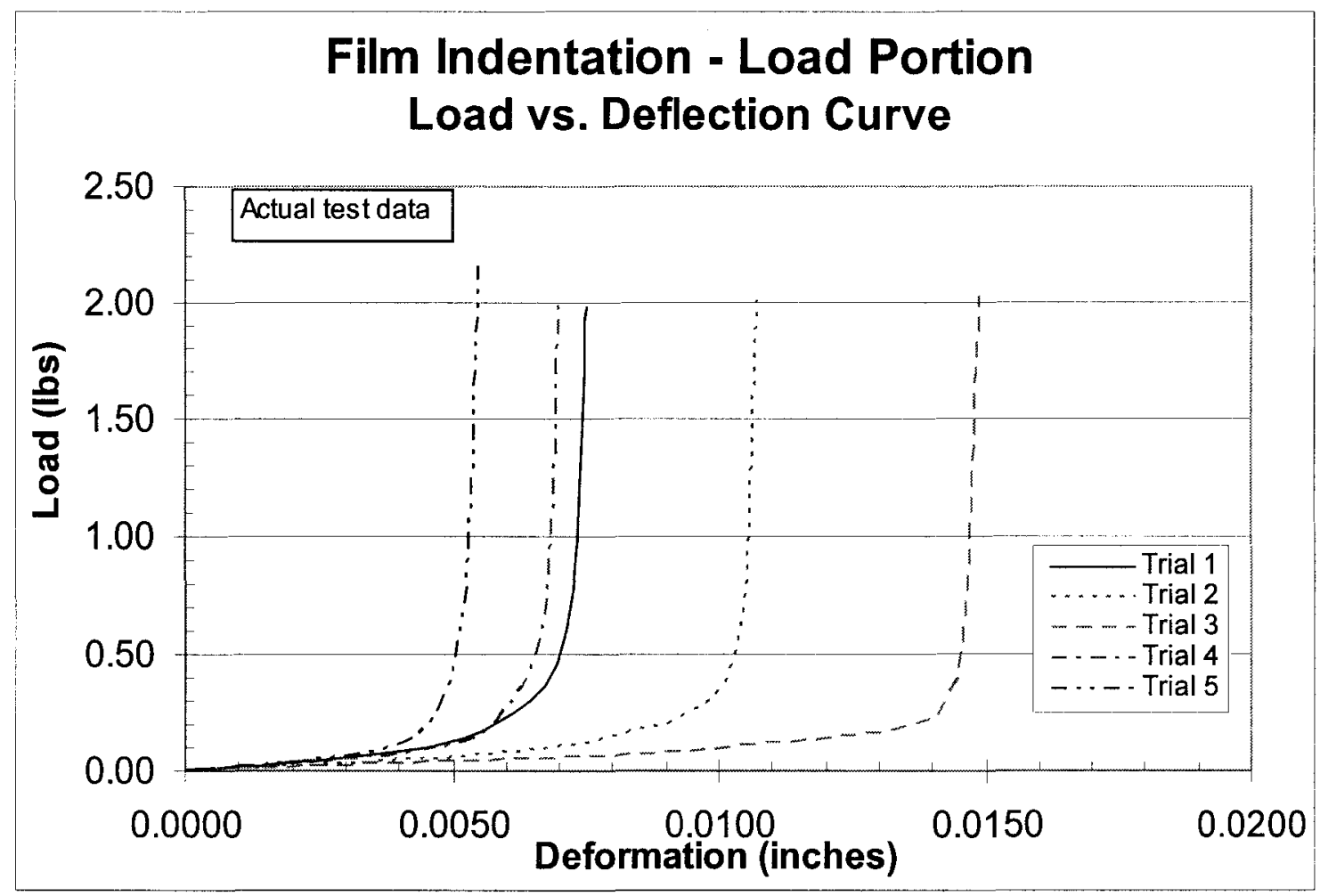

Figure 125. Load-displacement data for 0.019 " PVC film aged for 3 weeks at $125^{\circ} \mathrm{C}$ 


\section{Film Indentation - Load Portion Load vs. Deflection Curve}

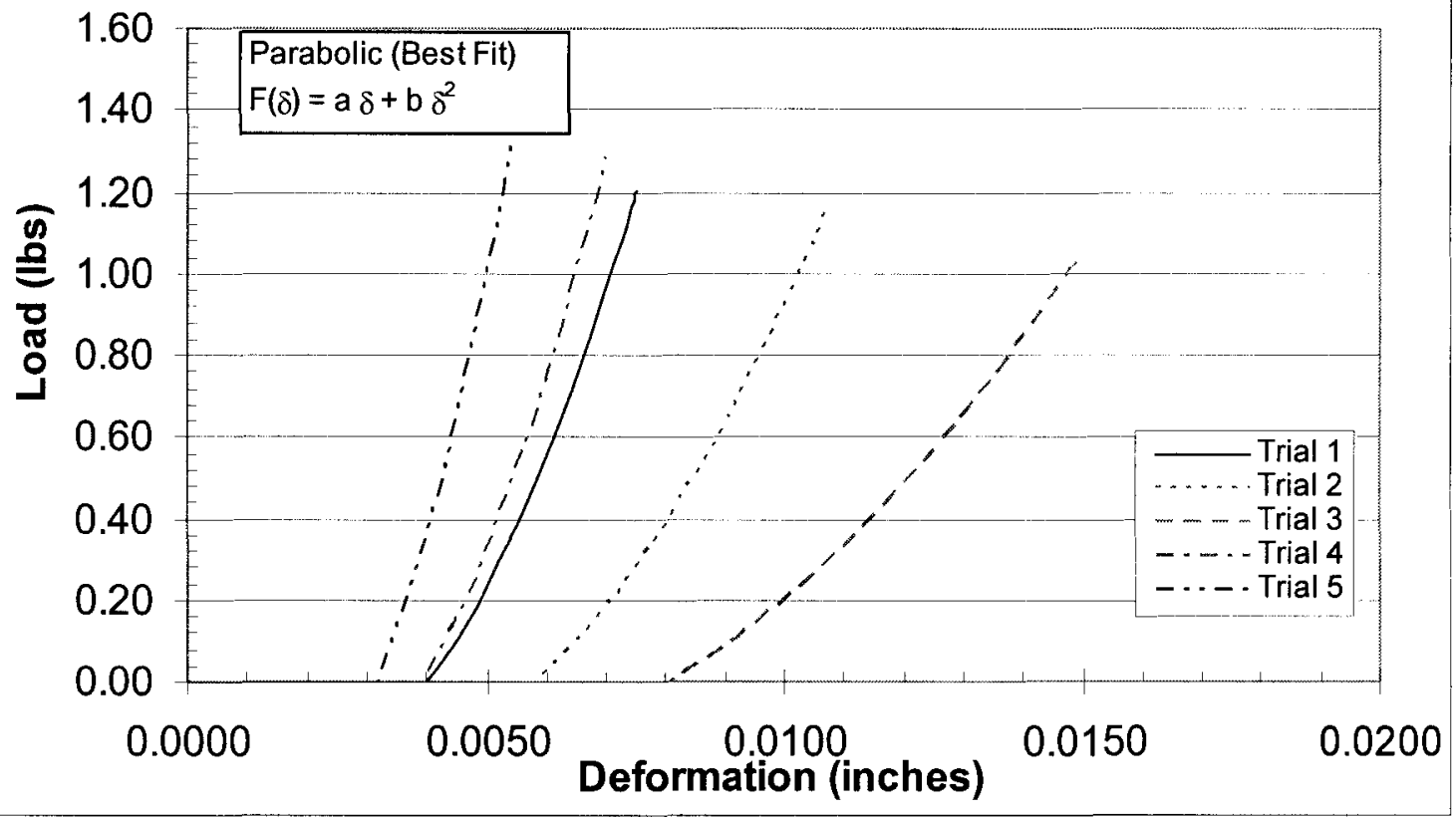

Figure 126. Load-displacement data for 0.019 " PVC film aged for 3 weeks at $125^{\circ} \mathrm{C}$

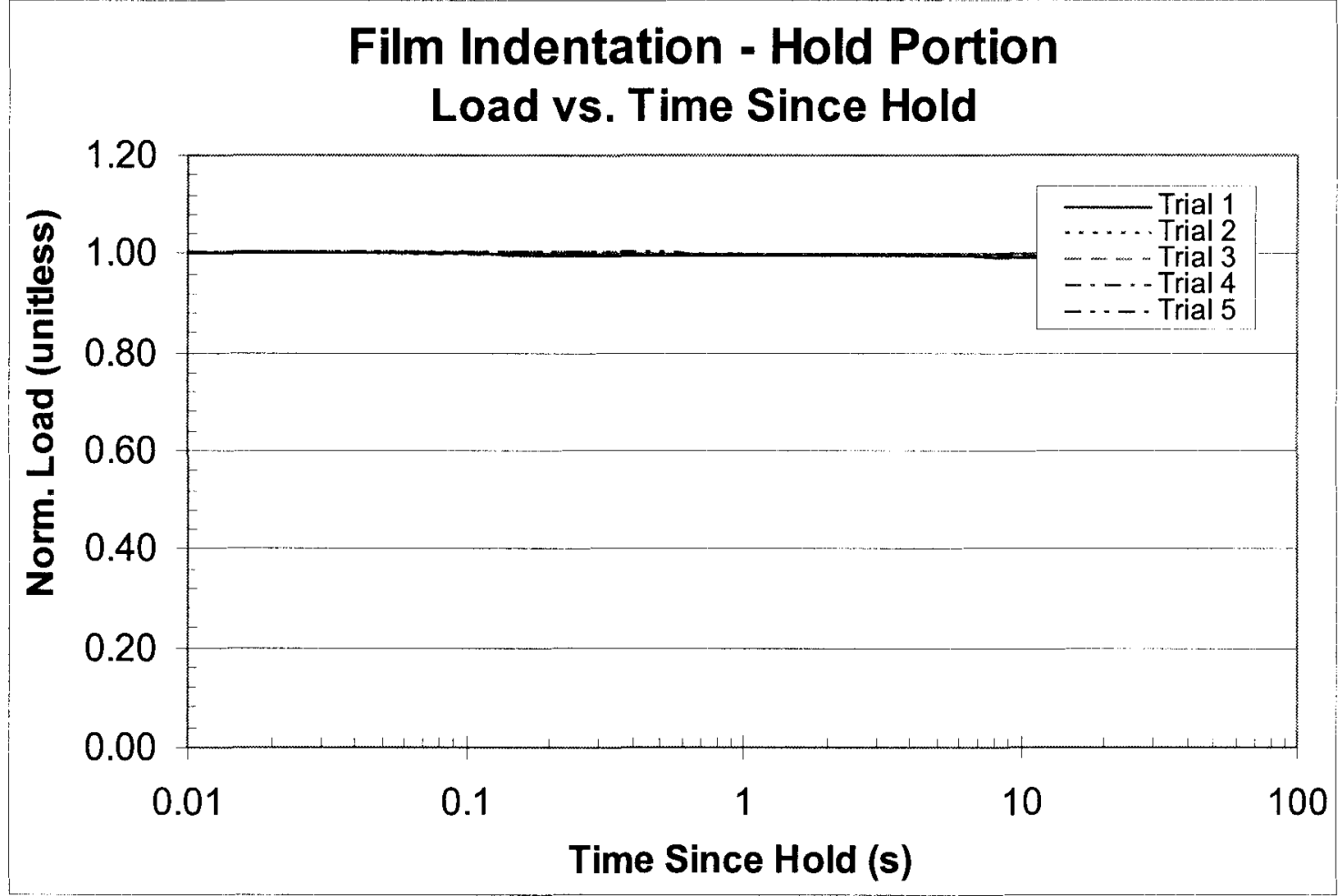

Figure 127. Normalized relaxation fits for 0.019 ” PVC film aged for 3 weeks at $125^{\circ} \mathrm{C}$ 


\begin{tabular}{|l|ccccc|c|}
\hline & Trial 1 & Trial 2 & Trial 3 & Trial 4 & Trial 5 & Average \\
\hline $\mathbf{k}(\mathbf{l b s} / \mathrm{in})$ & 2189.1 & 2094.0 & 2896.2 & 2343.6 & 3091.4 & 2522.9 \\
$\lambda(\mathbf{l b s})$ & -14.79304 & -20.88829 & -41.60248 & -14.78010 & -15.19877 & -21.45254 \\
\hline $\mathbf{a}(\mathbf{l b s} / \mathrm{in})$ & -181.37 & -127.73 & -81.23 & -234.21 & -337.14 & -192.34 \\
$\mathbf{b}\left(\mathrm{lbs} / \mathbf{i n}^{2}\right)$ & 45563 & 21981 & 10099 & 59615 & 106785 & 48809 \\
\hline$\alpha(\mathrm{lb} / \log (\mathbf{s}))$ & -0.000138 & -0.000406 & -0.000251 & -0.001143 & 0.000947 & -0.000198 \\
$\beta\left(\operatorname{lb} / \log (\mathbf{s})^{2}\right)$ & -0.000461 & -0.000061 & 0.000040 & 0.000403 & -0.000758 & -0.000167 \\
$\gamma\left(\operatorname{lb} / \log (\mathbf{s})^{3}\right)$ & -0.0000579 & -0.0001301 & -0.0001328 & -0.0002123 & 0.0000027 & -0.0001061 \\
\hline
\end{tabular}

Table 38. Data fit coefficients for 0.019 " PVC film aged for 3 weeks at $125^{\circ} \mathrm{C}$ 


\section{CURRICULUM VITA}

NAME: Kaushik Bindiganavile Nagendran

ADDRESS: Department of Mechanical Engineering

University of Louisville,

KY- 40292

DOB: $\quad$ Bangalore, India, February $22^{\text {nd }}, 1979$

EDUCATION: $\quad$ BE Mechanical Engineering

Bangalore University

1997-2001

AWARDS: $\quad$ International student of the year award for 2004

6-SIGMA Green belt 